ON INTEGRATING AUTONOMOUS ARCHITECTURE

\author{
by \\ Nathaniel Mendiola \\ B.ArchSci, Ryerson University, 2015
}

\author{
A thesis \\ presented to Ryerson University \\ in partial fulfillment of the \\ requirements for the degree of \\ Master of Architecture \\ in the Program of \\ Architecture
}

Toronto, Ontario, Canada, 2017

(C) Nathaniel Mendiola, 2017 

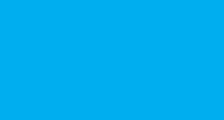

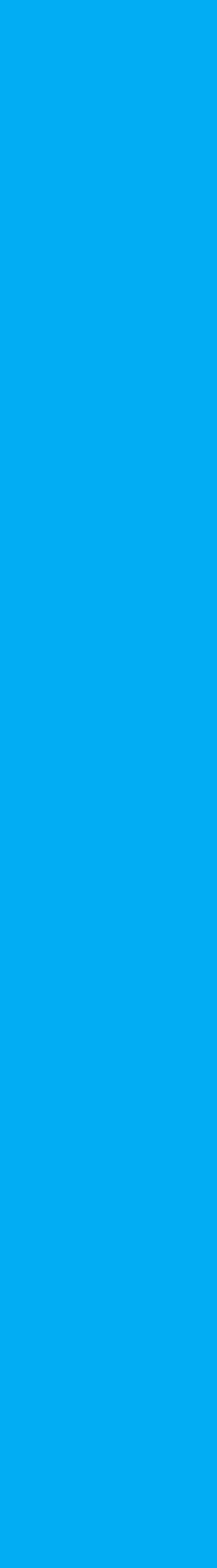


I hereby declare that I am the sole author of this thesis. This is a true copy of the thesis, including any required final revisions, as accepted by my examiners.

I authorize Ryerson University to lend this thesis to other institutions or individuals for the purpose of scholarly research.

I further authorize Ryerson University to reproduce this thesis by photocopying or by other means, in total or in part, at the request of other institutions or individuals for the purpose of scholarly research.

I understand that my thesis may be made electronically available to the public. 


\title{
On Integrating Autonomous Architecture
}

\author{
Nathaniel Mendiola \\ Master of Architecture 2017, Ryerson University
}

The Grid is the underlying construct that organizes and plots Toronto's urban fabric. While its penchant for simplicity and unification is successful at the urban level, it reinforces moments of isolation at the architectural level. But as contemporary society becomes more complex and pluralistic, our architecture should become more indicative of this condition. By exploring the creative potential of a layered and diverse society, we can establish a new framework of order to operate within, one that offers a high degree of variation and integration. We can then begin to uncover new opportunities for enhancing architectural connections and facilitating deeper social interactions. 
0.3 ACKNOWLEDGEMENTS 
I would like to thank my supervisor AI Smith for his guidance, wisdom and continued support over the past year. Your knowledge of the grid goes unmatched, and I am grateful for the foundation that you set for my thesis and for constantly challenging me to do more.

In addition, I am eternally grateful to Y.T. Leong, my secondary reader, and Kendra Schank Smith, for providing their insight and expertise. Thank you for making the time to critique my work and for continuously helping me find new approaches towards my work.

Lastly, I would like to thank my parents, my family, friends, and the rest of my graduating class for your encouragement throughout my architectural education. Thank you for cultivating an environment of support that has allowed me to succeed. 


\subsection{TABLE OF CONTENTS}

\subsection{THE CITY}

1.1 understanding cities

1.2 how cities have supported human life

1.3.1 the greek grid

1.3.2 the roman grid

1.3.3 the medieval grid

1.3.4 the renaissance grid

1.3.5 the modern grid

1.4 prioritizing the city grid

2.0 THE GRID IN ARCHITECTURE 17

2.1 arranging the grid 18

2.2 the toronto grid and its elements 19

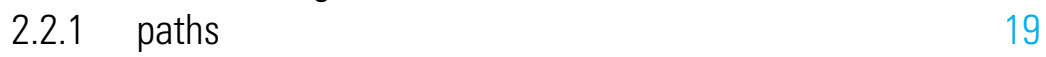

2.2 .2 edges 19

2.2 .3 districts 20

2.2 .4 nodes 20

2.3 the city block 21

2.4.1 the sidewalk 21

2.4.2 sidewalk culture and consumption 22

2.5 making a case for reframing the modern grid 23

3.0 COMPLEXITY \& THE PLURALISTIC CITY 25

3.1 shifting from simplicity and unification 26

3.2 characterizing the mature and complex 27

3.3 towards complexity and idiosyncrasy 28

\subsection{AUTONOMY v INTEGRATION 31}

4.1 a discourse for autonomy in architecture 32

4.2 approaching autonomy 33

4.3 the island within an island within an island... 34

4.4 discontinuous contiguity 35

4.5 revealing integration 35

4.6 the section: overlapping diversity 37 
5.0 THE SOCIAL DIMENSION

5.1 more meaningful connections 42

5.2 heuristic spaces: reimagining the subject-to-object 43 relationship

5.3 monochronic space vs polychronic space 45

6.0 SITE 47

6.1 site description 48

6.2 history of dundas street and its grid 48

6.3 cultural facades 49

6.4 site diagrams 51

7.0 PROGRAM: MUSEUM 53

7.1 program 54

7.2 surrounding exhibition spaces 55

7.3 programmatic spaces 62

7.4 collection: the toronto museum project 63

7.5 collection summary 64

7.6 museum as conversation 89

7.7 collection narrative $\quad 89$

8.0 DESIGN PROJECT 91

9.0 CASE STUDIES 135

9.1 wexner center for the arts 136

9.2 tres grande bibliotheque 137

9.3 jussieu library 138

9.4 roy \& diana vagelos education center 139

9.5 rosenthal center for contemporary arts $\quad 140$

9.6 the diana center at barnard college 141

9.7 markethal rotterdam 142

10.0 APPENDIX 143

11.0 REFERENCES 163 


\subsection{LIST OF FIGURES}

Figure 1.0 (Cover): Khan, Sheraz. "Toronto Laneways with Figure 1.9: Timgad Connecting Roads." Digital image. Visualizing Urban Nathaniel Mendiola Futures. November 13, 2014. Accessed September 8, 2017. https://visualizingurbanfutures.com/2014/11/13/ Figure 1.10: Ferrara toronto-laneways-portfolio-cartography-urban-planning/. Nathaniel Mendiola

Figure 1.1: The earliest depiction of the city of pure geometry

Michael Batty and Paul Longley, Fractal Cities (London: Academic Press, 1994), 19.

Figure 1.2: Piraeus

Nathaniel Mendiola

Figure 1.3: Miletus

Nathaniel Mendiola

Figure 1.4: Olynthus Nathaniel Mendiola

Figure 1.5: Rhodes Nathaniel Mendiola

Figure 1.6: Marzabotto

Nathaniel Mendiola

Figure 1.7: Pompeii

Nathaniel Mendiola

Figure 1.8: Cosa

Nathaniel Mendiola
Figure 1.11: Carcassone Expansion

Nathaniel Mendiola

Figure 1.12: Ghent

Nathaniel Mendiola

Figure 1.13: Prague (Old Town)

Nathaniel Mendiola

Figure 1.14: Palma Nova

Nathaniel Mendiola

Figure 1.15: Nove Zamky

Nathaniel Mendiola

Figure 1.16: Fort Bourtange

Nathaniel Mendiola

Figure 1.17: The Radiant City

Nathaniel Mendiola

Figure 1.18: Manhattan

Nathaniel Mendiola 
Figure 1.19: Salt Lake City

Nathaniel Mendiola

\section{Figure 1.20: Toronto}

Nathaniel Mendiola

Figure 2.1: New York City Block

Nathaniel Mendiola

Figure 2.2: Toronto City Block

Nathaniel Mendiola

Figure 3.1: Binnenrotte Theatre Square

Digital image. West 8 Urban Design \& Landscape Architecture. Accessed August 4, 2017. http://www. west8.nl/images/dbase/2276.jpg.

Figure 3.2: An example of a personal indulgence at Binenerotte Theatre Square

Digital image. West 8 Urban Design \& Landscape Architecture. Accessed August 4, 2017. http://www. west8.nl/images/dbase/42.jpg.

\section{Figure 4.1: Delirious New York}

Rem Koolhaas, Delirious New York: A Retroactive Manifesto for Manhattan (New York: Monacelli Press, 1994), 295.

Figure 4.2: New York Athletic Club

Rem Koolhaas, Delirious New York: A Retroactive Manifesto for Manhattan (New York: Monacelli Press, 1994), 154.

Figure 4.3: Jussieu Library Circulation Diagram Rem Koolhaas, Bruce Mau, and Jennifer Sigler, S, M, L, XL (New York: Monacelli Press, 1995).
Figure 4.4: 1111 Lincoln Road

1111 Lincoln Road. Digital image. ArchDaily. May 7, 10. Accessed August 4, 2017. http://images.adsttc.com/ media/images/5009/0175/28ba/0d27/a700/1225/large_ jpg/stringio.jpg?1375395637.

Figure 4.5: Eyebeam Museum

The Eyebeam, New York, by Diller Scofidio Renfro. Digital image. Arcspace. April 8, 2002. Accessed August 4, 2017. http://www.arcspace.com/features/diller-scofidio--renfro/ eyebeam/.

Figure 5.1: Palais de Congres Strasbourg

Palais de Congres Strasbourg. Digital image. Quondam. October 9, 2016. Accessed August 4, 2017. http://www. quondam.com/37/3749i01.gif.

Figure 5.2: Agadir Convention Center Lisnovsky, Martín. Agadir Convention Center. Digital image. Arq His. January 10, 2012. Accessed August 4, 2017. http://1.bp.blogspot.com/-LHSEMZvvOMo/ TwzPF9qv5jl/AAAAAAAABNw/fHBCIfQX46o/s1600/0MAAGADIR-010.jpg.

Figure 5.3: Agadir Convention Center Sections Lisnovsky, Martín. Agadir Convention Center Sections. Digital image. Arq His. January 10, 2012. Accessed August 4, 2017. http://4.bp.blogspot.com/Nf3wC9y01mY/TwzPkxsiUXI/AAAAAAABBOU/gd8_ RomrHTs/s1600/0MA-AGADIR-014.jpg.

Figure 5.4: Harvard Carpenter Center Kroll, Andrew. Harvard Carpenter Center. Digital image. ArchDaily. March 13, 2011. Accessed August 4, 2017. http://images.adsttc.com/media/images/5038/0579/28b a/0d59/9b00/097e/large_.jpg/stringio.jpg?1414197746. 
Figure 6.1: Site Plan

Nathaniel Mendiola

Figure 6.2: Cultural Facades

Nathaniel Mendiola

Figure 6.3: Typical City Grid

Nathaniel Mendiola

Figure 6.4: Dundas Street Grid

Nathaniel Mendiola

Figure 6.5: Dundas Street Grid Uses

Nathaniel Mendiola

Figure 6.6: TTC Access

Nathaniel Mendiola

Figure 6.7: Cultural Zones around Little Portugal Nathaniel Mendiola

Figure 6.8: Urban Open Spaces around Little Portugal Nathaniel Mendiola

Figure 7.1: Zoning

Nathaniel Mendiola

Figure 7.2: Nearby Galleries

Nathaniel Mendiola

Figure 7.3: Nearby Museums

Nathaniel Mendiola

Figure 7.4: Program Spatial Requirements

Nathaniel Mendiola
Figure 7.5: Select Artefact's Taxonomy Relationships Nathaniel Mendiola

Figure 8.1: Dundas Street West, west approach Nathaniel Mendiola

Figure 8.2: Design Approach Diagrams

Nathaniel Mendiola

Figure 8.3: Grid Concept

Nathaniel Mendiola

Figure 8.4: Conceptual Section

Nathaniel Mendiola

Figure 8.5: Dundas Street Grid and City Grid Intersection Nathaniel Mendiola

Figure 8.6: Dundas Street Grid

Nathaniel Mendiola

Figure 8.7: City Grid

Nathaniel Mendiola

Figure 8.8: Rotated Grid in Section

Nathaniel Mendiola

Figure 8.9: Tertiary Rotated Grid

Nathaniel Mendiola

Figure 8.10: Grid Intersection Around Central Atrium Nathaniel Mendiola

Figure 8.11: Ground Floor

Nathaniel Mendiola 
Figure 8.12: Second Floor

Nathaniel Mendiola

Figure 8.13: Aboriginal Heritage Gallery

Nathaniel Mendiola

Figure 8.14: Cultural Diversity Gallery

Nathaniel Mendiola

Figure 8.15: Third Floor

Nathaniel Mendiola

Figure 8.16: Immigration Gallery

Nathaniel Mendiola

Figure 8.17: Women's History Gallery

Nathaniel Mendiola

Figure 8.18: Fourth Floor

Nathaniel Mendiola

Figure 8.19: Industry and Transportation Gallery

Nathaniel Mendiola

Figure 8.20: Architectural Heritage Gallery

Nathaniel Mendiola

Figure 8.21: Atrium

Nathaniel Mendiola

Figure 8.22: Western Material Elevation

Nathaniel Mendiola

Figure 8.23: Dundas Street West Elevation

Nathaniel Mendiola
Figure 8.24: Section A-A

Nathaniel Mendiola

Figure 8.25: Section B-B

Nathaniel Mendiola

Figure 8.26: Structural Diagram

Nathaniel Mendiola

Figure 8.27: Dynamic Exhibition Wall Nathaniel Mendiola

Figure 8.28: Northern Galleries Section

Nathaniel Mendiola

Figure 8.29: Women's History Gallery Section Nathaniel Mendiola 


\subsection{LIST OF APPENDICES}

Figure A.1: Ambidextrous Reality 1 Nathaniel Mendiola

Figure A.2: Ambidextrous Reality 2 Nathaniel Mendiola

Figure A.3: Neighbourhood Mural 1 Nathaniel Mendiola

Figure A.4: Neighbourhood Mural 2 Nathaniel Mendiola

Figure A.5: Lula Facade \& Alley Nathaniel Mendiola

Figure A.6: Lula Alley Mural

Nathaniel Mendiola

Figure A.7: Neighbourhood Mural 3 Nathaniel Mendiola

Figure A.8: Neighbourhood Mural 4 Nathaniel Mendiola

Figure A.9: Building Grid Condition 1 Nathaniel Mendiola

Figure A.10: Building Grid Condition 2 Nathaniel Mendiola
Figure A.11: Little Portugal Institution: St. Helen's Church 1

Nathaniel Mendiola

Figure A.12: Little Portugal Institution: St. Helen's Church 2

Nathaniel Mendiola

Figure A.13: Current Site Condtion 1

Nathaniel Mendiola

Figure A.14: Current Site Condtion 2

Nathaniel Mendiola

Figure A.15: Parking

Nathaniel Mendiola

Figure A.16: Building Block Orientation Nathaniel Mendiola

Figure A. 17: Ground Floor Circulation Hierarchy Nathaniel Mendiola

Figure A.18: Second Floor Circulation Hierarchy Nathaniel Mendiola

Figure A.19: Third Floor Circulation Hierarchy Nathaniel Mendiola

Figure A.20: Fourth Floor Circulation Hierarchy Nathaniel Mendiola 
Figure A.21: Concept Model 1

Nathaniel Mendiola

Figure A.22: Concept Model 2

Nathaniel Mendiola

Figure A.23: Concept Model 3

Nathaniel Mendiola

Figure A.24: Concept Model 4

Nathaniel Mendiola

Figure A.25: Building Section Model

Nathaniel Mendiola

Figure A.26: Context Model

Nathaniel Mendiola 


\subsection{THE CITY}

"Why have cities not, long since, been identified, understood and treated as problems
of organized complexity? If the people concerned with the life sciences were able to
identify their difficult problems as problems of organized complexity, why have people
professionally concerned with cities not identified the kind of problems they had?"
Jane Jacobs

"Why have cities not, long since, been identified, understood and treated as problems
of organized complexity? If the people concerned with the life sciences were able to
identify their difficult problems as problems of organized complexity, why have people
professionally concerned with cities not identified the kind of problems they had?"
Jane Jacobs

"Why have cities not, long since, been identified, understood and treated as problems
of organized complexity? If the people concerned with the life sciences were able to
identify their difficult problems as problems of organized complexity, why have people
professionally concerned with cities not identified the kind of problems they had?"
Jane Jacobs

"Why have cities not, long since, been identified, understood and treated as problems
of organized complexity? If the people concerned with the life sciences were able to
identify their difficult problems as problems of organized complexity, why have people
professionally concerned with cities not identified the kind of problems they had?"
Jane Jacobs

"Why have cities not, long since, been identified, understood and treated as problems
of organized complexity? If the people concerned with the life sciences were able to
identify their difficult problems as problems of organized complexity, why have people
professionally concerned with cities not identified the kind of problems they had?"
Jane Jacobs
\end{abstract}

(1)

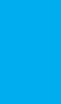

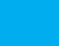

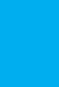
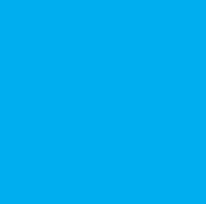

(1)




\section{1 understanding cities}

Over the last century, a large focus has been placed on attributing order to our cities to better understand them. Typically urban planners and architects have tried to articulate this order visually whether it is through an analysis of its many legible, organized patterns or a dissection of its parts.

Yet throughout history, there have been two prominent approaches to city building that have gone on to reflect man's socio-cultural concerns at the time. The two major categorizations that we can ascribe to city developments include those that are grown naturally or organically, and those that are planned.

When comparing organic cities to planned cities, there are some major distinctions that can be made, aside from their obvious visual aesthetic, which include the rate at which these cities change and the scale of development. For the most part, organic cities develop on a smaller scale which serve individual, local use. The unpredictability of this organic growth also opens the potential to a decline as well, which isn't typically found in planned cities. Inherently, planned cities grow more rapidly and systemically, usually outlined by a governing enterprise whether it is by a political or religious power, and in the recent century has occurred on a much larger scale.

Visually, there is a stark contrast to these two city developments when viewed in plan. Organic plans tend to reflect the topographical behaviour of their surroundings as they follow the natural landscape. This is a result of the many tracings made by transportation technology of the time along the most efficient, comfortable routes. In contrast, planned cities are designed from a literal top-down perspective which man infringes upon his natural landscape through a carefully articulated geometry of straight lines and smooth curves. 


\section{2 how cities have supported human life}

Historically, urban planning and development has had a fundamental impact on the ways cities function and how people interact on a daily basis. It is during the Greek and Roman colonial times in which the first distinctions between organic cities and planned cities were made. While organic cities grew through a multitude of small local expansion, the Greek and Romans laid out large planned settlements using an gridiron geometry to establish garrison towns efficiently.

Hippodamian towns such as Piraeus, Miletus and Priene are just some examples of early rigid town plans. ${ }^{1}$ The Romans utilized a similar approach to the Hippodamian grid, centered around a regimen of two main street axes, forums, and public buildings to reinforce their military and political functions. Later Medieval towns were also organized according to social, economic and political factors. While typically smaller than some of the Greek and Roman colonies, Medieval towns were compact in their organization, to minimize walking distances towards the inner marketplaces. This supported a Medieval centre for trade and craftsmanship. ${ }^{2}$

These practices would be rediscovered during the European Renaissance by figures such as Leon Battista Alberti. His architectural treatise $D e R e$ Aedificatoria, advanced urban planning ideologies on creating cities after the Roman Empire's collapse. ${ }^{3}$ Alberti outlined an urban planning approach in which the archetypal Renaissance city could be designed much like an architectural object based on pure geometry. The radial arrangement and fortifications would exhibit a pleasant aesthetic that glorified the city, and it's military and spiritual powers. The European Renaissance would serve as a precursor the modern age.

Towards the latter half of the 18th century, especially in western society, urban development had shifted towards commerce and enterprising prosperity. Similarly, the simple idea of a neutral grid was imposed upon untouched available land. While religious and military powers no 
longer dictated urban growth, the commercial market would become the determining factor in patterning the city. Cities such as New York, Philadelphia and Toronto are examples characteristic of such commercial cities, in which an endless grid was used as a mechanic to divide and parcel land for enterprising use.

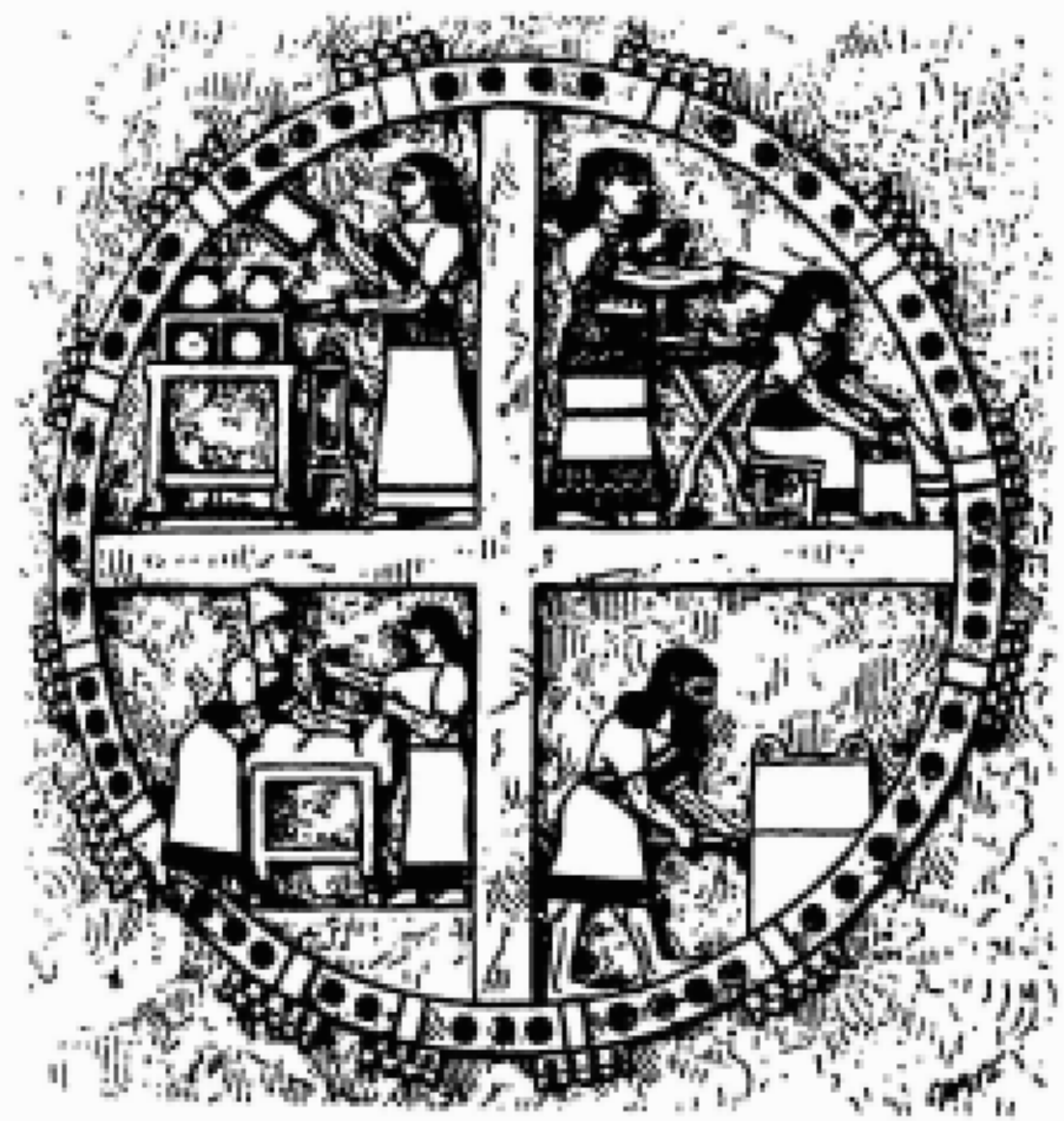

Figure 1.1: The earliest depiction of the city of pure geometry 


\subsection{1 greek grid}

There are many factors that determine where and how cities grow. Natural advantages, along with strategic, economic and political forces are some of the main influences that have incited the growth of ancient cities.

Historically, the nucleus of old Greek cities has been the acropolis. The site of the acropolis has always been determined by a spiritual entity, such as a priest, who defines a holy site. Tactfully, the acropolis sits elevated from invaders, but remains easily accessible by the population. It watches over the town and its cultivatable land, while housing the seat of the king during times of monarchy. ${ }^{4}$

This centralized model is true for Greek colonial towns as well. But to accelerate the growth of these satellite towns, a gridiron geometry is utilized. While the gridiron has been used before in other parts of the world, Hippodamus was the first to theorize a gridiron development plan under the commission of Aristotle. Hippodamus was largely influential in the rebuilding of Piraeus and Miletus after Persian attacks in 494 B.C. ${ }^{5}$

Following the establishment of a centralized acropolis public space was allotted near the acropolis. The agora, shrines, theatres, government buildings and marketplaces were defined by the intersection of an ascribed Decumanus Maximus and Cardo Maximus axes. Other sites for public space were also designated in advance, while the rest of the gridiron was to be used for housing.

This newfound sense of order, credited to Hippodamus, theorized a division of public, sacred, and private land, the earliest known form of zoning. The traverse Cardo Maximus is one of the ordering elements that reinforced a city orientation that allowed for optimization of wind flow through the city for comfort and hygienic purposes. The centralized intersection of the predominant axes also allowed for an accessible exchange of public activity within the agora. In turn, this provided the opportunity for outward growth and the further development of the city. 


$$
\begin{aligned}
& \equiv+ \\
& F=4
\end{aligned}
$$




\subsection{2 the roman grid}

While the Romans borrowed standardized principles from the Greek expansion, their merit was in correlating military and civil elements as part of the city development. Many cities were established during the Roman colonial expansion under military intent through Etruscan ritual. This ritual was initiated by a priest who would choose a sacred site. A surveyor would then use a tool called a groma to determine east and inscribe the decumanus maximus axis. On special occasion, the decumanus would point to the sunrise on particular dates of significance, such as the birthday of founding Emperors. The cardo maximus would then be inscribed perpendicular to the decumanus maximus and would reach the extents of the settlement, terminating at entrance gates, so that the intersection of the axes would meet at a central location of the town. A series of square blocks measuring 2400 by 2400 Roman feet, the theoretical equivalent of 100 small holdings know as "centuries" were then laid out. ${ }^{6}$ This would eventually become the castrae model used by the Roman military in the rest of their military expansion due to its fast and efficient growth.

Once the castrae model established the forum as the centre for city growth, there were many other concerns for the Romans to address to sustain healthy human activity. These public works included a system of defensive walls and gates, a water supply, and a drainage system. Like Rome, these colonies need to establish a sense of infrastructure that was indicative of their past prosperity. Some of the Roman's main concerns dealt with communications, agricultural wealth, the control of river crossings and natural harbour facilities. 
Figure 1.6: Marzabotto

Figure 1.7: Pompeii

Figure 1.8: Cosa

Figure 1.9: Timgad
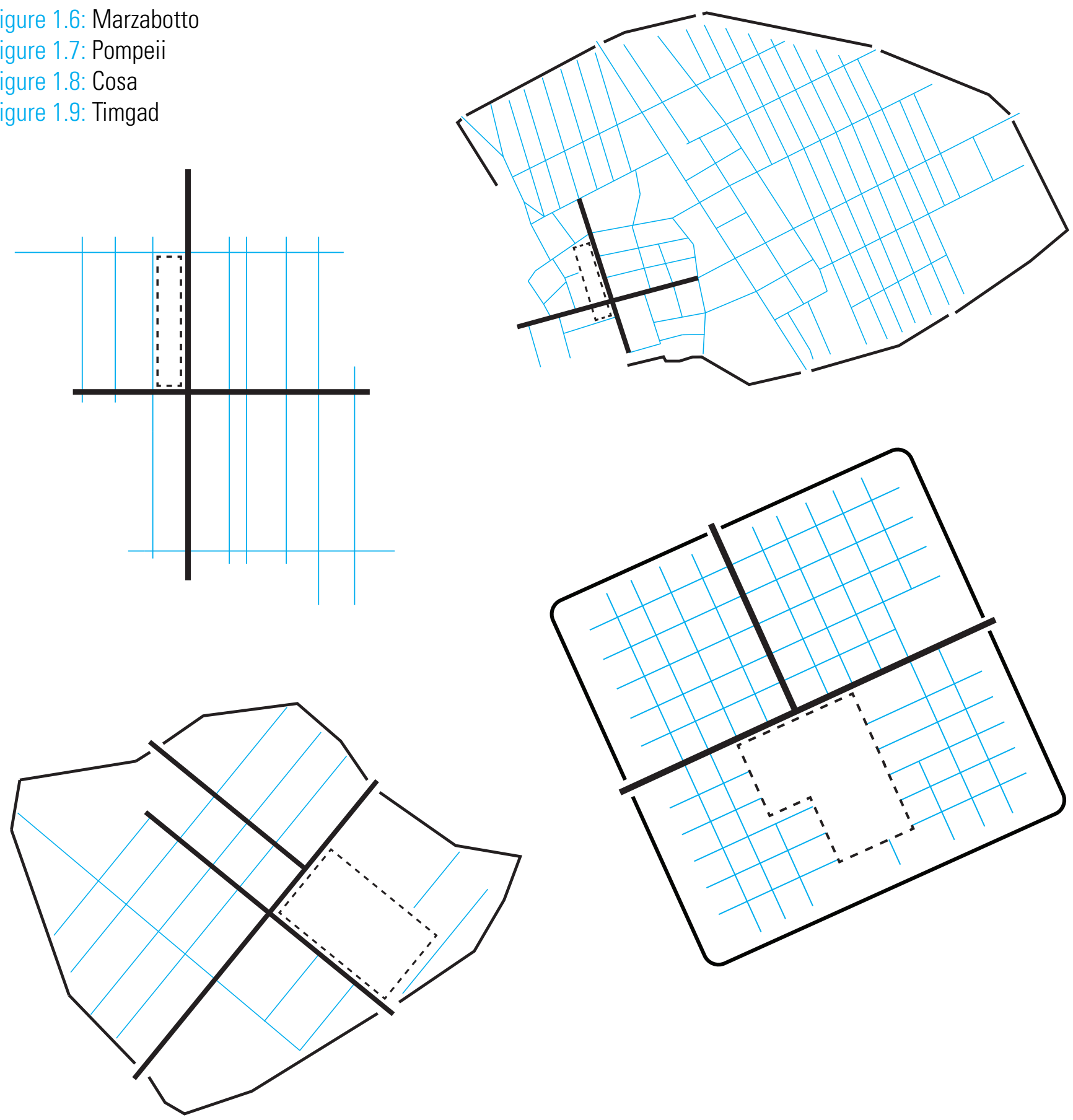


\subsection{3 the medieval grid}

The period following the fall of the Roman Empire is defined as the Middle Ages. At the end of the Classical world, historians lost track of the grid for several centuries, until its definitive resurgence in Europe sometime around the year 1100.? The grid would return, and be employed under its two principle functions, of establishing new cities and extending those of earlier existing cities, the latter of the two being more prominent. ${ }^{8}$ This can be seen in cities such as Massa Marittima, Carcassone, Fano, Gubbio and Ferrara.

A typical Medieval city borrows many ideas from the Roman Empire that made them so prosperous. These cities largely accommodated for defense, agriculture and trade. Organized processes for production and distribution of goods and services became an underlying means of order.

This order governed pedestrian circulation and city structure. It was reflective of an interwoven pattern or constant exchange of commercial and public activities. This resulted in an integrated social climate in which various social groups would live and work side by side. Merchants next to craftsmen, rich next to the poor, and the young next to the old. An integrated model was further reinforced by a series of centralized spaces. ${ }^{9}$

While the medieval city closely resembles the Roman colonies, they were more compact in their organization, to minimize walking distances towards the inner marketplaces. The close proximity of these marketplaces would support an era centred around the exchange of agricultural goods, the trades and craftsmanship with greater efficiency.

The establishment of cities during the Middle Ages slowly revived Classical precedents and had a large influence in the formal theorization of Renaissance city planning. 
Figure 1.10: Ferrara

Figure 1.11: Carcassone Expansion

Figure 1.12: Ghent

Figure 1.13: Prague (Old Town)
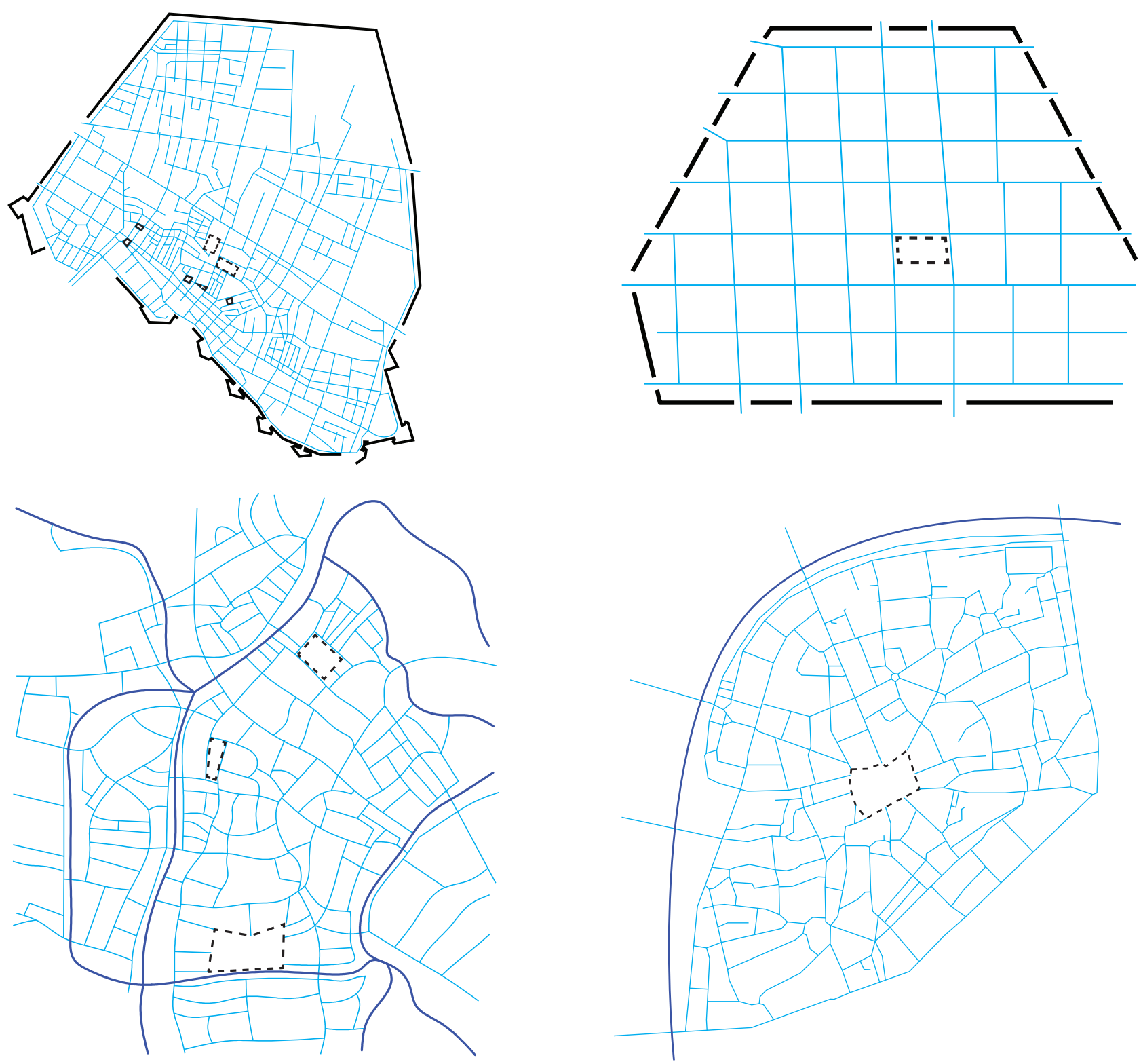


\subsection{4 the renaissance grid}

The Renaissance was a time of high theory during the 15th century with regards to city planning based on pure geometry. Much of this theory was disseminated in the form of a written treatise. Speculation on the ideal city form was being theorized based on the rediscovery of Greece and Rome through written books from key figures such as Vitruvius and Leon Battista Alberti.

Their work outlined that the ancient city building was always conceived as an element in the urban context, as part of a larger composition that is governed by symmetry, perspective and proportion. This led to a building model in which the ideal city was designed and planned as an architectural object in itself. Combined with the work of Serlio, Scamozzi, Palladio and Vignola, a particular grammar of city development began to form, which incorporated Greek and Roman ideas of centralized space, zoning, fortification, and monumental unity.

What defines city building of the Renaissance era, is the shift from a socioeconomic centre to one of political-military power based on high doctrinal theory. ${ }^{10}$ Many Renaissance towns were built and situated tactfully in areas surrounding larger cities as a means of protection. The all-encompassing fortification walls of the ideal Renaissance city lend itself perfectly for this purpose. Much like a garrison town, these cities were outfitted with military camps and general equipment for war.

A more political and civic-minded town serves as another means of the ideal city. Much like churches and palaces are indicative of divine and political power, Renaissance cities were designed holistically to represent these values. By starting with a geometrical unitary space at the centre, buildings for worship, economic exchange, social and political exchanges were laid out in equal proportion to each other. The notion of space in high Renaissance theory laid claim to the fact that perspective was no longer considered as the law of our vision but as the constructive rule of space itself. 
Figure 1.14: Palma Nova

Figure 1.15: Nove Zamky

Figure 1.16: Fort Bourtange
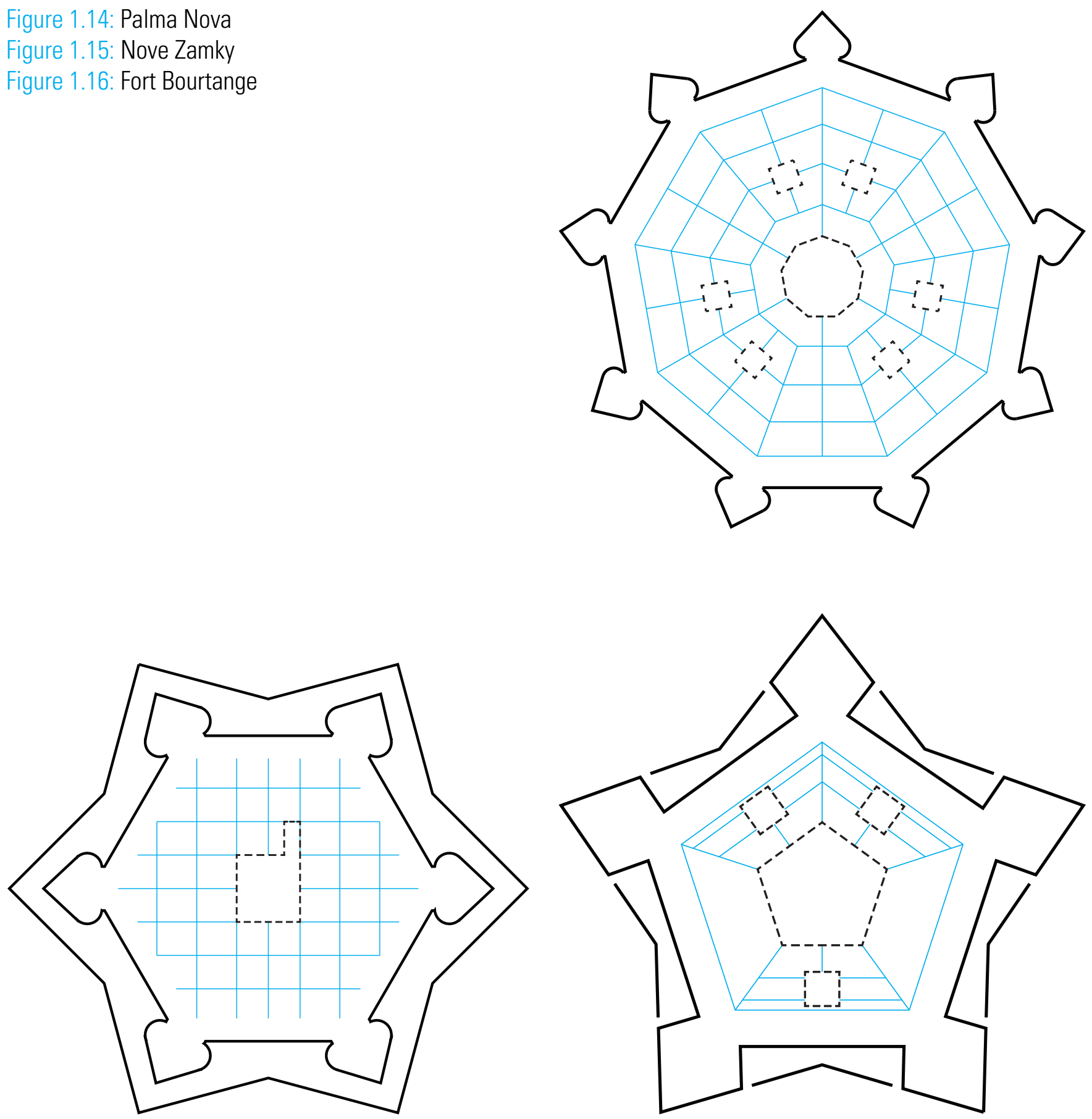


\subsection{5 the modern grid}

Towards the second half of the 18th century, urban developmental control shifted away from religious and political power towards an economic commercial prosperity. The city grid became a neutral construct that invited enterprising entities and equal opportunity to dictate the growth of the city. This model was popular in western society in places such as Manhattan, San Francisco, Chicago and Toronto.

The open grid, as opposed to the closed grid of pre-modern cities, is founded on the idea of a capitalist society. In this sense, it is unrestricted and only bounded by economic profitability. As a result, public spaces such as parks and plazas were subordinated in favour of profitable real estate when determining city form. This diminished sense of public space is evident in Toronto, and was even solidified in legislative ordinances such as the Commissioners' Plan of 1811.

This system of urban planning had large implications on public life that contrasts that of ancient centralized gridiron cities. Subsequently this is during the Industrial Revolution in which building technology has allowed man to build high and traverse through the city in vehicular traffic. Without much contingency for public space, the grid confines human activity to the city block while discouraging it on the street. This forces builders and property owners to develop a new system of formal values to provide distinction or replace previous occupancy at the expense of others. In the end, the city becomes a mosaic of episodes, each with its own particular life space, that contest each other through the medium of the grid. ${ }^{11}$ 
Figure 1.17: The Radiant City

Figure 1.18: Manhattan

Figure 1.19: Salt Lake City

Figure 1.20: Toronto
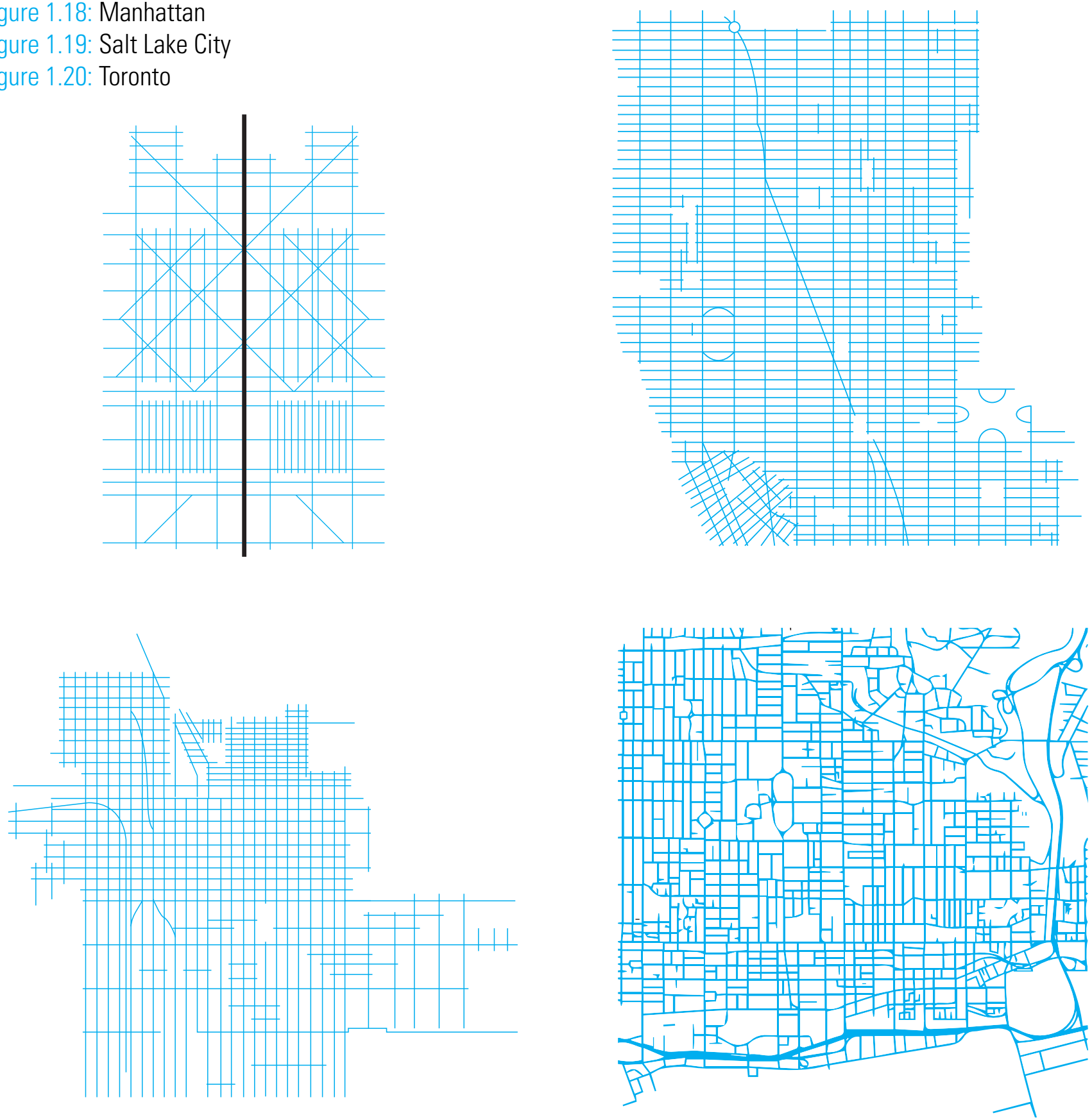


\section{4 prioritizing the city grid}

Since the beginning of the 20th century, the modern city grid has decentralized human activity and displaced many public activities relative to the aforementioned historical grids. The prioritization of commercial growth along with an increased interest in rapid vehicular travel has subordinated sidewalk culture and relegated sidewalks for pure foot traffic as opposed to public activity. Where cities like Paris have successfully attracted activity to the streets and away from the building, cities like New York and Toronto have brought activity off of the street and into the building. With major developments in modern construction, the higher we construct, the more human activities can be isolated within a single building. Activity then becomes transcribed to the vertical plane, and far from greater access at the public horizontal plane at grade. Architecture has the potential to challenge these isolating barriers and return them to the street. 
1 Batty, Michael, and Paul Longley. Fractal Cities: A Geometry of Form and Function. London: Academic Press, 1994.

2 Gehl, Jan. Cities for People. Washington, DC: Island Press, 2010.

3 Evers, Bernd, and Christof Thoenes. Architecture Theory: From the Renaissance to the Present: 89 Essays on 117 Treatises. Köln: Taschen, 2011.

4 R. E. Wycherley, How the Greeks Built Cities (London: Macmillan, 1962), 5.

5 R. E. Wycherley, How the Greeks Built Cities (London: Macmillan, 1962), 17.

6 John B. Ward-Perkins, Cities of Ancient Greece and Italy: Planning in Classical Antiquity (New York: Braziller, 1975), 28.

7 Spiro Kostof, The City Shaped: Urban Patterns and Meanings Through History (Boston: Little, Brown, 1991), 108.

8 Ibid.

9 Jan Gehl, Life Between Buildings: Using Public Space (Copenhagen: Danish Architectural Press, 2006), 101.

10 Bernd Evers and Christof Thoenes, Architecture Theory: From the Renaissance to the Present: 89 Essays on 117 Treatises (Köln: Taschen, 2011).

11 Rem Koolhaas, Delirious New York: A Retroactive Manifesto for Manhattan (New York: Monacelli Press, 1994), 21. 
2.0 THE GRID

$\frac{\pi=}{m=}= \pm=$ 


\section{1 arranging the grid}

Within the preceding quote, Le Corbusier uncovers the organic scheme that has shaped civilization's many unplanned cities. The donkey takes the path of least resistance, which is inhibited by its natural environment and shows no concern for the distance it travels. In this case, the donkey is reflective of the tools of preceding eras and the values centered on agriculture and small settlement cultivation. Le Corbusier proposes an alternative configuration of the city, one that service man and his values surrounding modernization and the concern for infrastructure development when he suggests, "Man walks in a straight line, because he has a goal and knows where he is going." ${ }^{1}$ His solution is the Grid.

The Grid or Gridiron is the most common patterned configuration of cities since the establishment of civilization. Historically, the Gridiron organization has been used to serve two contrasting functions: the facilitation of an orderly settlement or colony, and to serve as a vehicle for modernization. ${ }^{2}$ As previously established, settlements such as Piraeus, Miletus, and Timgad are some of the Greek and Roman colonies that took advantage of an orderly, efficient deployment system. The Grid as a modernizing apparatus was used in various cities that were not developed as orderly cities from their inception, such as the Renaissance extensions of medieval towns. Many of today's prominent metropolis' fall under this second category as well, with cities like London, Paris, or Manhattan. 


\section{2 the toronto city grid and its ordering elements}

Identifying and structuring our environment is intrinsically tied to the coherence of organized parts that make up our city Grid. In Toronto, a number of structural elements can be identified within the Grid that creates a sense of order. These parts can also be attributed to most of the elements from Kevin Lynch's analysis of cityscape legibility, namely paths, edges, districts and nodes. ${ }^{3}$

\subsection{1 paths}

Paths are the most common element that people identify with as they navigate the city. Within Toronto, it is hard not to navigate along a path on the city Grid regardless of your method of transport or frequency in which you move. Streets, walkways, transit corridors, canals, and railroads are all examples of path. ${ }^{4}$ Other elements are arranged and related to our city Grid paths to serve various functions. Toronto exhibits a very regular Grid, but is also layered with various intermediate paths that create another sense of depth and order. Some of them adhere to the Grid, as with most laneways and back alleys, while others may diverge from the Grid drastically like, Dundas Street West and Front Street East; or very subtly like Carlton Street, and Richmond Street East and Adelaide Street East at Jarvis Street. All of these various may occur for various reasons.

\subsection{2 edges}

Lynch defines edges as linear elements that we do not traditionally use or consider as paths. They can manifest as breaks in continuity or as boundaries and barriers with various levels of penetrability. For most people, edges would be described as the second most important organizing feature of the city. ${ }^{5}$ While Lynch distinctly path from edge, some paths can be defined as edges, and vice versa, depending on perspective. Spadina Avenue, especially towards the south end near Wellington or Front Street may be considered a pedestrian barrier, as it inhibits the throughput of foot 
traffic due to poorly located crosswalks. This same edge condition can also be thought of as an efficient path as it allows the rapid vehicular transit, whether you traverse by automobile or on the central streetcar tracks. This fluctuation makes it difficult to discern the nature of an edge as it can be seen as both an inhibiting and connective tissue within the Grid. The relative nature of edges will play a vital role in the further discourse of autonomy within the Grid at an urban level, and how it operates at the level of the individual building.

\subsection{3 districts}

Lynch describes the city district as having a two-dimensional extent, which users can mentally enter "inside of" and use as exterior reference when on the outside. Districts are differentiated and recognized as having some sort of identifying character. ${ }^{6}$ Toronto is fortunate to have a plethora of districts that exhibit different qualities and values that fulfill a variety of uses. The boundary of these districts can simply be traced along Toronto's city Grid, and may overlap with paths and edges.

\subsection{4 nodes}

Similarly to the district, nodes are identified relative to other organizational elements found in the Grid. It can manifest in some sort of physical nature, such as the intersection of Yonge and Dundas Street, or symbolically as the characteristic center of a neighbourhood. Thus, it can be defined as the convergence of multiple paths or as the intensive foci of a district. ${ }^{7}$ This variable notion of nodes as defined by their physical or symbolic attributes will be further elaborated on as we develop a discourse for autonomy at the urban level and how it translates to the architectural building, all of which is afforded by the concept of the Grid. 


\section{3 the city block}

Overall, the Grid's ubiquity has serves as a successful arrangement for allotting and distributing land democratically. Within the context of the modern urban city, the Grid offers two-dimensional neutrality for human activity as it relentlessly conquers the open topography. But of all the elements of the city Grid that Kevin Lynch identifies, he does not address the component that architects concerns themselves with the most - the city block and the building site.

At the expense of open public space, the Grid affords a mosaic-like fragmentation of uses on each city block or individual site. In return, the Grid permits the three-dimensional extrusion of the site, unlocking an infinite densification of identical floor plates for autonomous use. While all of the other Grid elements are interrelated to one another, the segregated condition of the building site exists independently. As an architect, the Grid seems to have backfired by reinforcing the separation of human activity through proximity and juxtaposition.

\subsection{1 the sidewalk}

Prior to the 17th century, the implementation of sidewalks was nearly nonexistent. It was not until the mid-17th century until sidewalks became common practice, and were being established in public spaces in European cities. In Jane Jacob's The Death and Life of Great American Cities, she asserts the sidewalk as another vital component of the city grid. She describes the sidewalk as the main public spaces of the city as they are freely accessible and are a clearly demarcated pedestrianized part of the street.

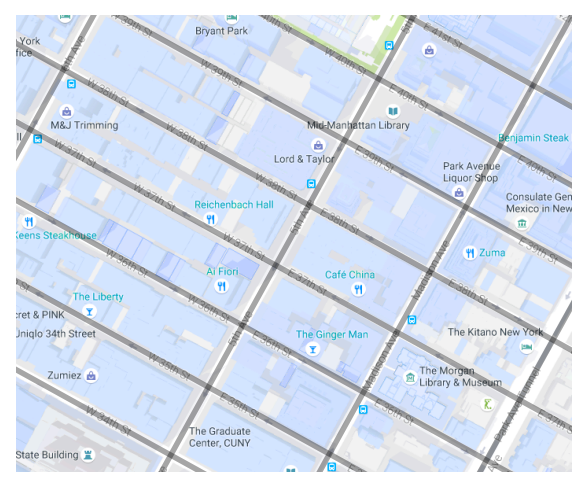

Figure 2.1: New York City Block

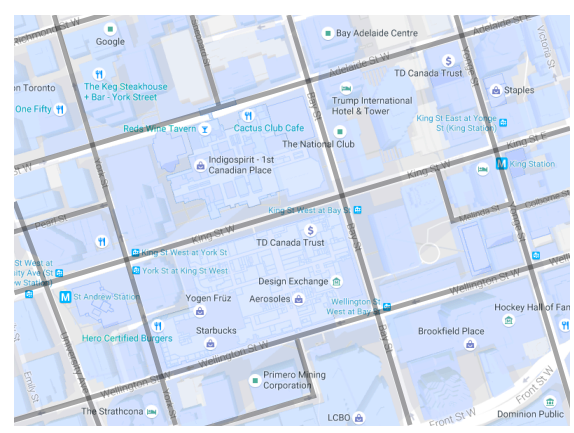

Figure 2.2: Toronto City Block 


\subsection{2 sidewalk culture and consumption}

Paris served as a site for innovation in terms of the sidewalk and sidewalk culture. It was the first city to incorporate broad tree-lined boulevards that separated vehicles from pedestrians, encouraging walking as a public activity. This led to a revolutionary increase of individuals who could observe and participate in the life on the street. The regularization of sidewalks in the late 18th century to early 19th century unsurprisingly coincided with the development of sidewalk culture and rise of consumer culture.

The experience of modern sidewalks and modern shopping are both glamourous and sexual in nature. French author and journalist Emile Zola describes both as "driven by an essentially erotic desire produced by, and directed toward, a visually promiscuous commodity spectacle surging from the shops into the streets and back again". ${ }^{8}$ Following his observations, we can say that the sidewalk and consumerism together can be a reflection of each individual consumer and their social identity.

Architecture has the opportunity to operate on a similar level, in which the commodity being consumed can be replaced with something that we innately find more interesting - people and activities. Today in architectural design, there are a variety of barriers that limit the degree of consumption on viewing human activity, which will be discussed later in Section 4.2: Approaching Autonomy. As it has been concluded earlier, western cities are inclined to bring people and activities off the street into the building. At the very least, by identifying and limiting these barriers, architects have the ability to return these activities back to the street for visual consumption. By projecting these activities onto the street, and enhancing sidewalk culture, we can start to develop a more complex architecture that is reflective of a pluralistic, contemporary society. 


\section{5 making a case for reframing the modern grid}

During the inaugural era of the skyscraper, there was acclaim surrounding the exploitation of the vertical reproduction of the site and its newly unlocked potential. While this is indicative of a modern penchant for unification and simplification, there is a growing concern for individuality and complexity that must be addressed in contemporary urban life. While the modernist notion of the Grid has limited public centralized space, there is a desire for an enhanced social interaction that challenges the autonomy of our architecture.

A new approach towards architectural design should be reflective of this shift from modern simplicity towards one that accommodates for complexity and the idiosyncrasies found in the maturing individual. In what ways can architects begin to humanize the grid? Can a new order be established using the medium of the grid to allow for more integrated experiences, whether they are architectural, sensorial, or social? 
1 Spiro Kostof, The City Shaped: Urban Patterns and Meanings Through History (Boston: Little, Brown, 1991), 95.

2 Ibid., 102.

3 Kevin Lynch, The Image of the City (Cambridge, MA: MIT Press, 1960), 47.

4 Ibid., 47.

5 Ibid.

6 Ibid.

$7 \quad$ Ibid., 48 .

8 Christoph Lindner, Imagining New York City: Literature, Urbanism, and the Visual Arts, 1890-1940 (New York: Oxford University Press, 2015), 113. 
3.0 THE COMPLEX CITY

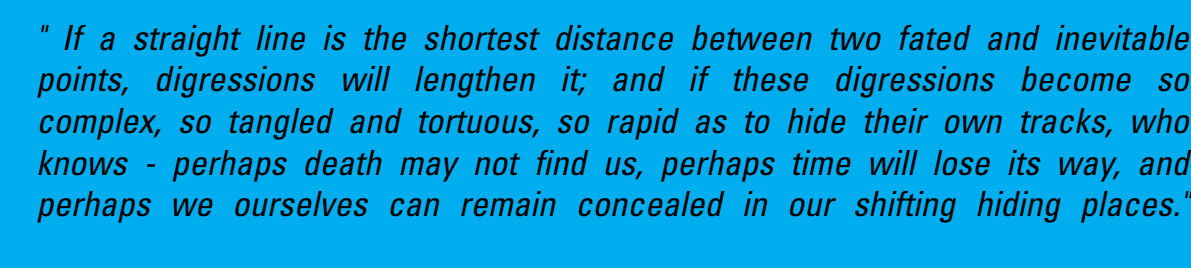




\section{1 shifting from simplicity and unification}

In recent centuries, the Grid has substantiated a modernist proclivity for simplification and unification. But within a burgeoning metropolis such as Toronto, the recognition of diversity and individuality is critical. The essence of development as a human being is developing the capacity for more complex experiences. ${ }^{1}$ Moving from a simple orderly way of life to one that is complex is essential in order to embrace the layering of experiences and differences that are embedded in our social lives.

Manifested within the urban and social fabric of Toronto lie two of the most important facets of complexity: diversity and idiosyncrasy. As a city that embraces variety and difference, Toronto has exhibited success at organizing its many neighbourhoods and districts that are distinct in character. It is hard to distinguish another major metropolis that is as diverse in culture and vibrant in character as that found in Toronto.

But within the context of architecture, architects have struggled with integrating this complexity. Most buildings are subservient to the modern city grid, which would rather segment, as opposed to overlay, diversity and idiosyncrasy. While the city is pluralistic in nature, the ordering Grid presents and reinforces this diversity in isolation.

If architecture were to facilitate our innate transition from an orderly, simple life to one that is complex and mature, we must develop strategies that expand on the capacity for diversity and idiosyncrasy. While this ability may be limited at the urban scale, architecture has the capacity to do so while still preserving and operating within a framework of order and continuity. By presenting an architecture that orders and enhances a mixing of diverse activities, it makes it possible for users to extrapolate and understand the operational systems of their pluralistic environments. 


\section{2 characterizing the mature \& complex}

As we expand our capacities to absorb more complex experiences, it is important to define what constitutes both a simple and a mature individual. In the previous chapter, the idea of simplicity has been attributed towards a penchant for modernism and the idea of complexity with our contemporary society. We can look towards Georg Simmel's dissection of the modern cynic versus the blasé attitude as comparison of the two ideologies.

Simmel states that the modern cynic's "awareness of life is adequately expressed only when he has theoretically and practically exemplified the baseness of the highest values and the illusion of any differences in values." 2 By this reasoning, Simmel claims that the modern cynic is only concerned with reducing all experiences to a monetary value. The cynic is only comfortable and satiated by the reassurance that all personal values and emotions can be acquired or consumed. All values, even in the highest forms such as knowledge, love and respect can all by purchased, and no human bond can surmount this principle.

On the other hand, the concept of the blasé type is rarely ever fully realized, but also loses the feeling fro value differences. Manfredo Tafuri's interpretation of the blasé type is defined as "a neurasthenic who survives increase in nervous life by becoming totally intellectualized and indifferent." ${ }^{3}$ In this case, the blasé type does not deliberately care about value. Rather they are in constant search of exciting activity. To maintain a level of satisfaction, exciting activity must be found in the rapid succession of strong, impressionable experiences. Such experiences include the idiosyncrasies of social life, the simultaneity of communications, accelerated rhythms of use, and a rapidity of change and organization. ${ }^{4}$

While Simmel provides two character types on polar ends of the spectrum, a shift from a simple way of life towards a complex maturation oscillates between these ideologies. The value of money and experience is inversely related to the modern cynic and the blasé type, but it is the tendency towards the blasé's search for variable experiences that architecture 
is predominantly concerned with. An architecture that embodies this philosophy of consuming experiences will present the opportunity for various architectural experiences and spontaneous social encounters.

\section{3 towards complexity and idiosyncrasy}

Designing for the contemporary city means to design for a mixture of uses, to accommodate diversity and to be sufficiently complex. It's success hinges on the fact that so many people are densely situated in close proximity and offer various tastes, skills, needs and supplies. ${ }^{5}$ These are the primary ingredients for generating the diversity that is required to sustain the complex and idiosyncratic nature of contemporary society.

As more and more people move into big cities, the added diversity permits and stimulates more diversity. It becomes an incubator of new enterprises and ideas of all kinds. With this, a contradictory definition of diversity presents itself. Jane Jacobs presents an order in The Death and Life of Great American Cities that is complex and highly developed. But as diversity invites diversity, the various interactions of different city uses can be perceived as chaotic. It invites an esthetic 'ugliness', conflicting uses, and congestion. In the midst of this complexity, Adriaan Geuze outlines that the contemporary urbanite is self-assured, well-informed, and finds his freedom and chooses his own sub-cultures. The city is his domain, exciting and seductive. He was proved himself capable of finding his way around

Figure 3.1: Binnenrotte Theatre Square

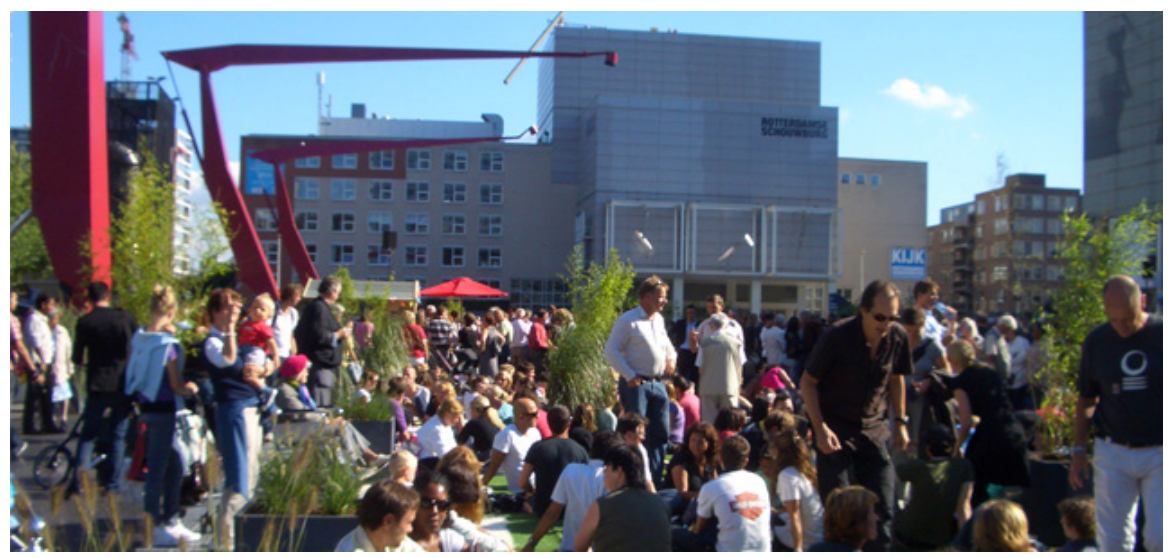


the new landscape and of making places his own. ${ }^{6}$ His definition coincides with Tafuri's definition of the blasé type.

Geuze's work is exemplified in West8's Binnenrotte Theatre Square in Rotterdam. He describes it as an 'emptiness' in which urban dwellers are more than capable to create, adapt to or imagine whatever they way. The interstice of the square becomes a flexible space that accommodates a variety of uses without the disadvantages of over-programming. The simple and spare nature of the squares surface, and the alterability of the whimsical lighting fixtures lends itself to Peter Cook's concept of architecture's ability to absorb the idiosyncratic.

As the contemporary city and its architecture has been established as a perpetuator of diversity, it requires complexity and the ability to absorb the idiosyncratic. Cook describes this as the ability to celebrate some particular commonplace activity, whether it is collecting books, keeping cats, having a view of the sea, or doing aerobics and etc ${ }^{7}$ As architects, the ability to overlay idiosyncrasies stems from the obsession with the client/clients and their diverse backgrounds, their individual needs, small nuances, and especially their indulgences.

Moving forward, for architecture to accommodate the level of diversity offered by contemporary society, the ability to address complexity and idiosyncrasy becomes necessary. From Jacob's ideas of a complex order,

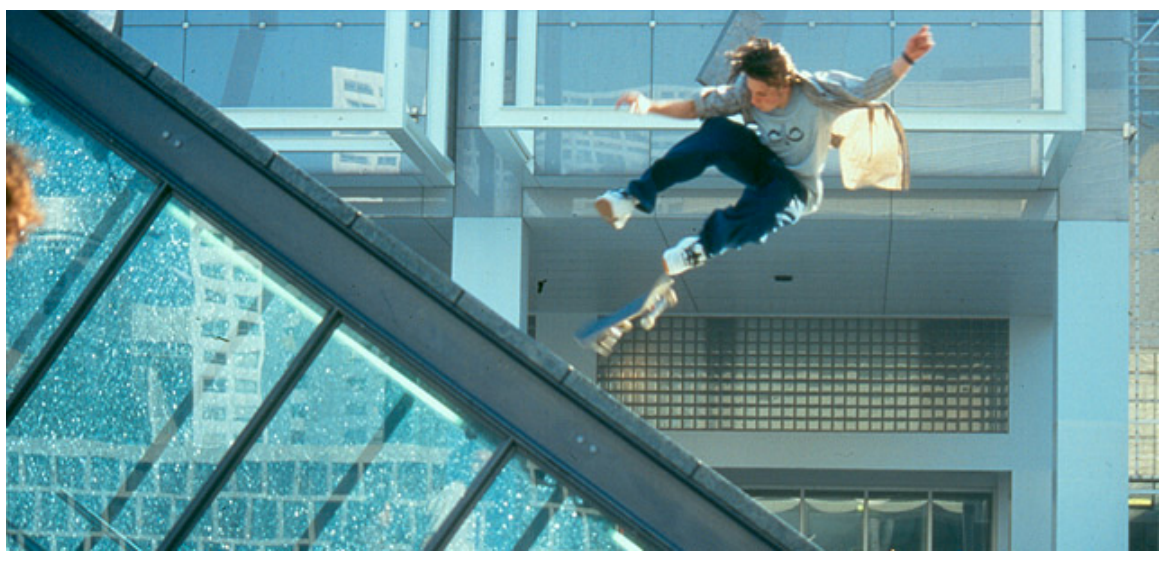

Figure 3.2: An example of a personal indulgence at Binnenrotte Theatre Square 
we can attribute its disadvantages to those typically stemming from urban planning, and in turn those related to the city grid. To counter those drawbacks at an architectural level, there must be innovation at the building grid. This innovation must be able to offer a high degree of flexibility while absorbing layers of the idiosyncratic.

1 Thom Mayne, "Connected Isolation," in Theories and Manifestoes of Contemporary Architecture, ed. Charles Jencks and Karl Kropf (Chicester: Academy Editions, 1997), 302.

2 Georg Simmel, The Philosophy of Money (London: Routledge \& Kegan Paul, 1978), 256.

3 Manfredo Tafuri, "Toward a Critique of Architectural Ideology," in Architecture Theory Since 1968, trans. Stephen Sartarelli, ed. K. M. Hays (Cambridge, MA: MIT Press, 1998), 197.

4 Ibid.

5 Jane Jacobs, The Death and Life of Great American Cities (New York: Vintage Books, 1992), 147.

6 Alex Wall, "Programming the Urban Surface," in Recovering Landscape: Essays in Contemporary Landscape Architecture, ed. James Corner (New York: Princeton Architectural Press, 1999).

7 Peter Cook and George Rand, Morphosis: Buildings and Projects (New York: Rizzoli, 1989), 15. 


\subsection{AUTONOMY v INTEGRATION}

$=-5= \pm=$

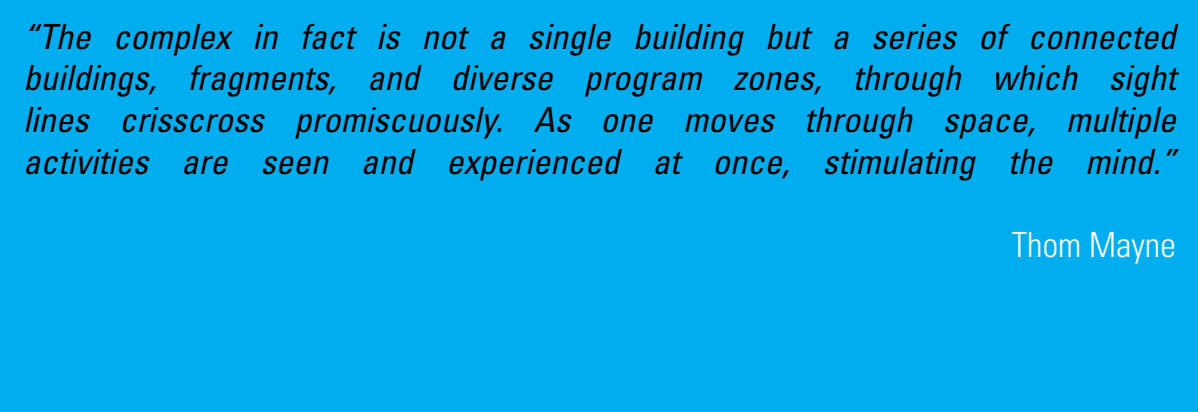

$=-5=5=$

$=-5=5=$

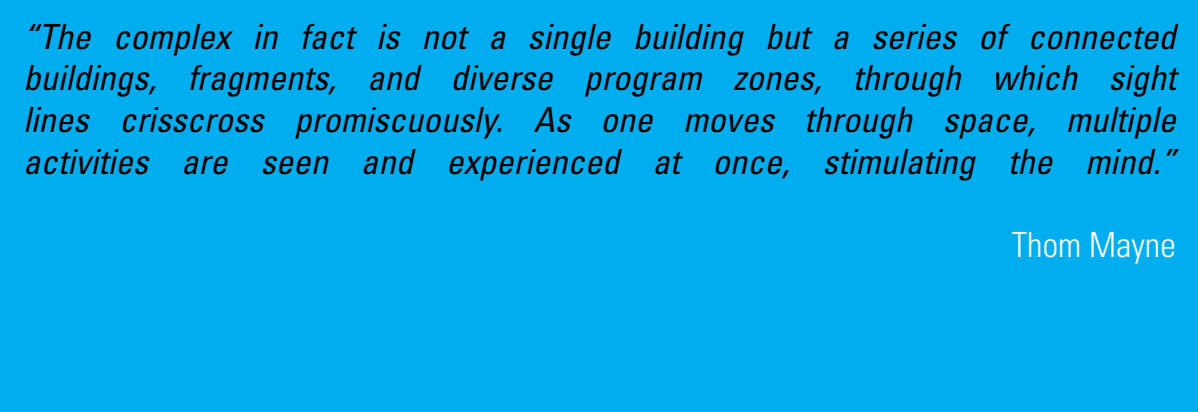

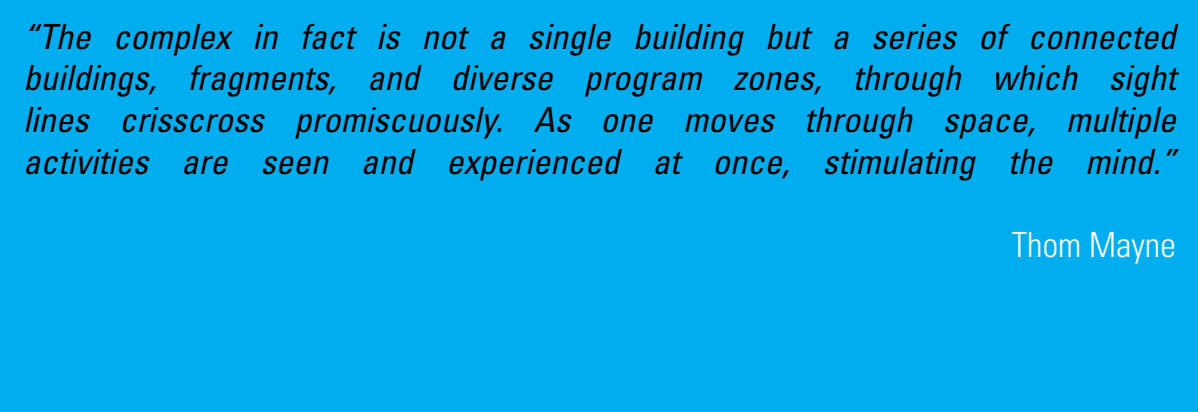

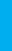

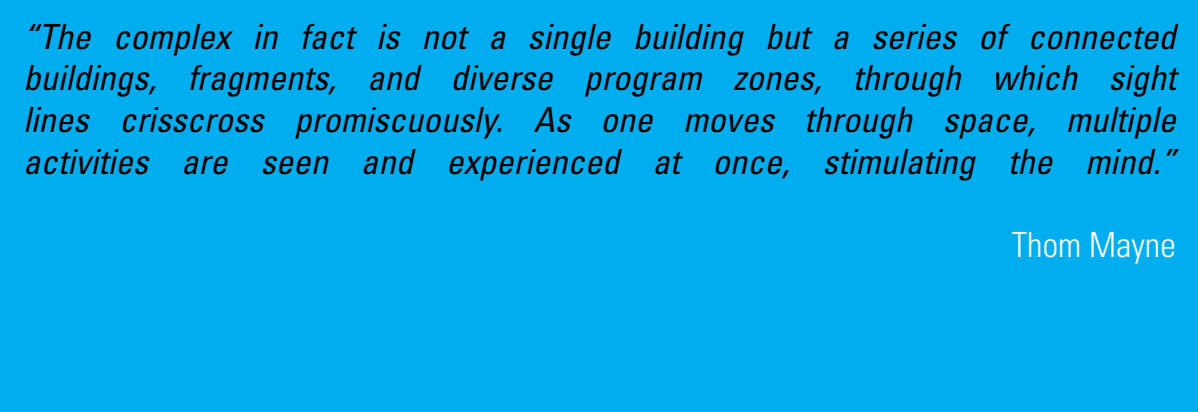

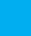




\section{1 the island within an island within an island...}

The city of Toronto can be described as a metropolitan island within a sprawling landscape of surrounding suburbs. Since the implementation of the modern city Grid and the rapid growth of the city, the idea of an autonomous island can be further translated down to the urban scale. As the downtown area becomes more and more developed, the urban fabric becomes less homogenous. What once was a centralized city has now become a mosaic of complementary fragments of a human activity. Within each singular fragment, or the city block/building site, various activities and ideologies are consolidated. The city Grid corroborates the contention between each building in their arrangement and juxtaposition.

Since the implementation of the Gridiron, a discourse for autonomy in architecture has become more and more relevant. The combination of the elevator with the development of steel construction technology has negated the need to accumulate land in order to accommodate for a variety of activities. The seemingly infinite reproduction of identical floor slabs allows for the autonomous control over individual environments and programming.

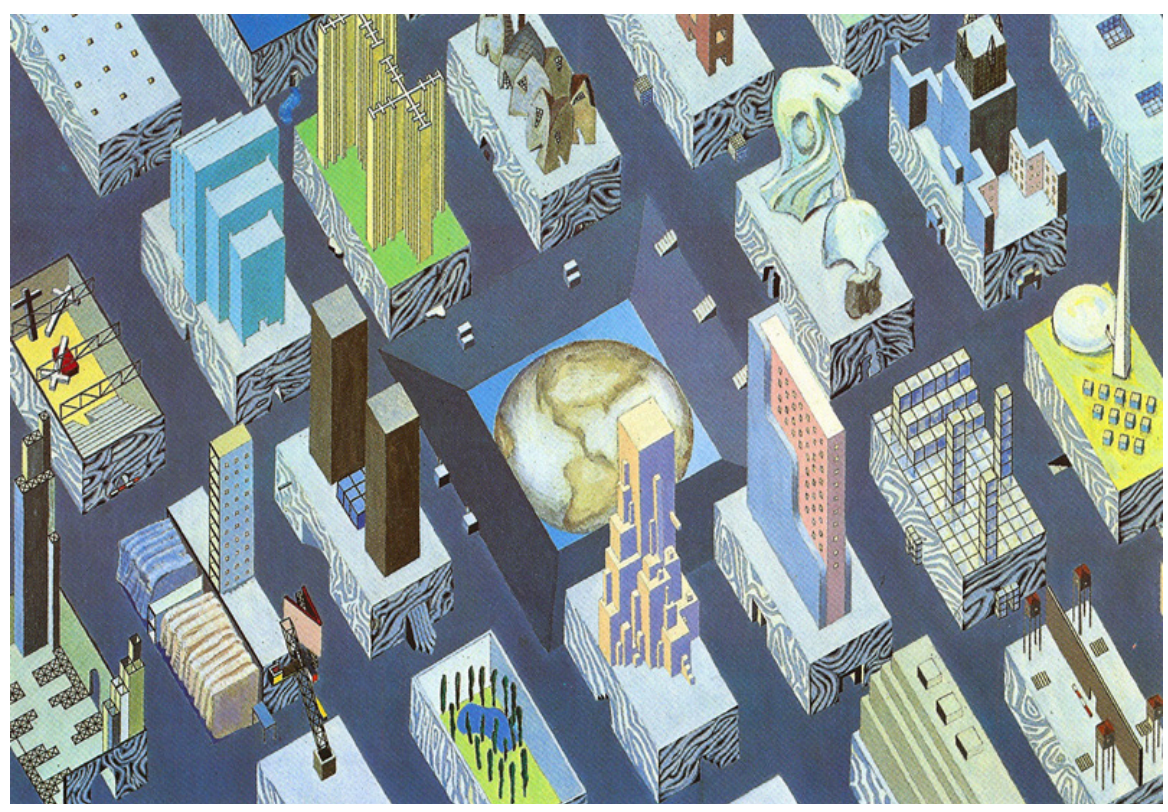




\section{2 a discourse for autonomy in architecture}

In Rem Koolhaas' essay Bigness: or the Problem of Large, he defines architecture that goes beyond a certain scale will acquire "... properties of Bigness. Bigness is the ultimate architecture. It seems incredible that the size of a building alone embodies an ideological program, independent of the will of its architects." Due to technological breakthroughs in the past century including: manufacturing interior environments, longer spans, rapid construction, the elevator, electricity, water pumps, HVAC, and steel, has lead to an insurgence of Big buildings. This becomes a particular topic of concern following the analysis of the New York Athletic Club and its relation to autonomy in mixed-used architecture.

Koolhaas credits the concept of Bigness as a response to disarray, disassembly, dissociation and disclamation as a vehicle for modernization to reclaim the collective. But through the past century society's values and ideas have constantly evolved, thus making it imperative represent this reinvention of the collective in architecture, especially within the complex cultural landscape of Toronto.

As part of Koolhaas' five postulates on his Theory of Bigness, the ever expanding distance between a building's core and façade becomes the point of entry in the discourse of autonomy in architecture. He argues that as buildings become larger, the façade no longer becomes indicative of the activities inside, resulting in a monotonous appearance. This has predominantly remained true over the past century, while society's values have been reinvented. As a result, we begin to question architecture's honesty based on this dishonest proxemic relationship. This approach can be seen in New York's Waldorf Astoria (1893), and locally in the TorontoDominion Centre (1969) and the Shangri La Hotel (2012). While each project boasts a plethora of spaces including: ballrooms, galleries, clubs, bars, lounges, restaurants, cafes, shops, banks, suites, and residences, they all project an autonomous appearance separate from the surrounding city.

Moving forward as architects we are confronted with several questions. 


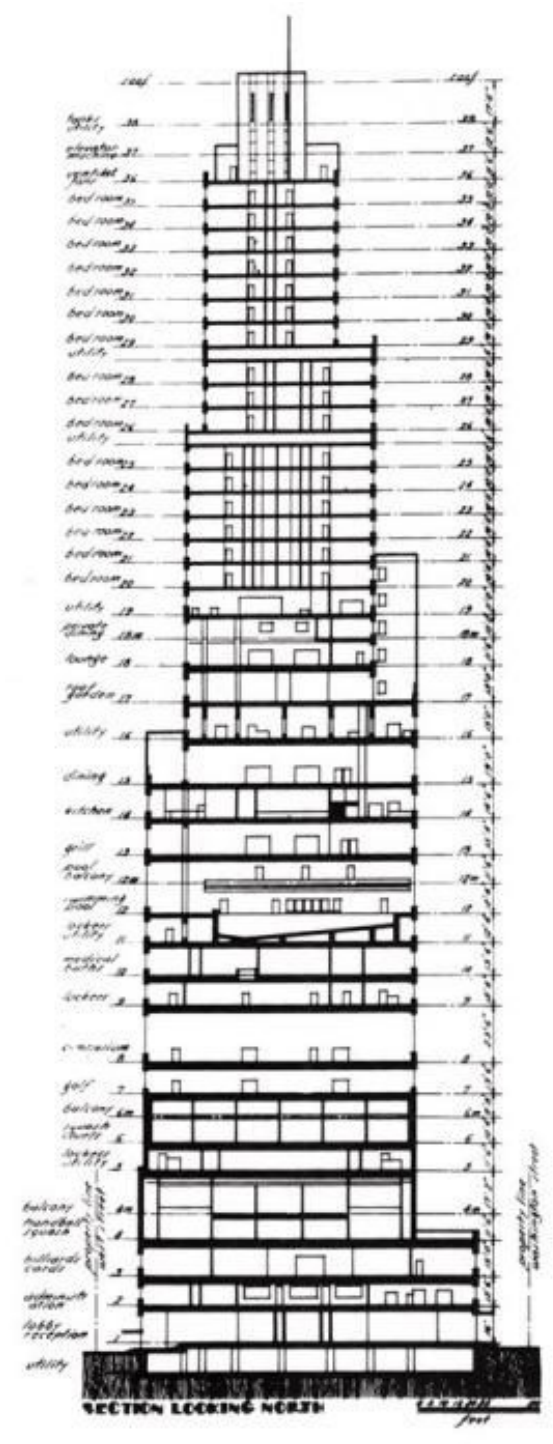

Figure 4.2: New York Athletic Club
Can programmatic functions still maintain an honest relationship with its surrounding programs and users from an interior perspective as well? How can we open up the core of these monolithic buildings to allow a transparency of function that exhibits an understanding of user and user activity from both the exterior and interior - from both its exterior facades and interior elevations?

This leads into the last of Koolhaas' postulates, where Bigness is no longer part of any urban tissue, in which its subtext is "fuck context". As these self-referential buildings steadily overcome the metropolitan grid, they reinforce a decentralized city of autonomous moments. As these buildings struggle with creating a relationship with the city, they further isolate themselves through sheer quantity and complexity, becoming an icon of the urban condition. They begin to compete with the city by offering all the possibilities of the city within itself. The streets become the residual organization device that fragments the city predicated on the grid.

\section{3 the plan: approaching autonomy}

In Rem Koolhaas' retroactive manifesto of Manhattan, Delirious New York, he dissects a very common model of architecture, exemplified in the New York Athletic Club. The building is described as a "machine to generate and intensify desirable forms of human intercourse". ' A series of leisurely activities are stacked within the Club's 38 floor plates which are approximately the exact size of the site. Koolhaas proposes an idea of discontinuity in which the only connective tissue that binds each activity is the 13-elevator core. He suggests that the development of this technology absolves any need for any functional or meaningful contiguous relationship between floors. Koolhaas would later explore this idea further in the future with his proposal for Parc de la Villette. Peter Eisenman would term this diagrammatic model as "contiguous discontinuity".

In his entry for Parc de la Villette, Koolhaas would later explore the idea of contiguous discontinuity at the urban scale. The concept of a stacked functional layers were translated in plan, creating a series of programmatic 
strips that were host to over 40 unique activities. The diagrammatic metaphor for the elevator in this case was a bisecting band that linked all the strips and acted as the main social gathering space. It is through this proposal that brings attention to ideas of autonomy in architecture. The New York Athletic Club serves as the archetypal example of contiguous discontinuity between programmatic activities, which are directly afforded by the distribution of the modern city grid.

\section{4 discontiguous continuity}

While the elevator serves as a mechanical connector of autonomous functions, it is the contiguous relationship of activities between each floor slab that perpetuates the idea of rigid autonomy in architecture. The elevator undermines and eliminates a users spatial perceptibility and cognizance. It also undermines architects and their knowledge of creating a meaningful threshold in which an architectural connection can simply be replaced by a mechanical connection. ${ }^{3}$

While elevators serve a practical function on our contemporary environment, regardless the scale of a building, we can return the experiential threshold back to architecture. By confronting and critically examining the contiguous relationship of thresholds and barriers we can enhance not only the architectural experience, but the social experience between users as well. Instead of isolating such experiences, architecture should be able to present these experiences at once and in rapid succession. By liberating architecture from its simplification inducing constraints and approach one that is more complex and reflective of our diverse contemporary society.

\section{5 the facade: revealing integration}

As described in 4.2: A Discourse for Autonomy in Architecture, the building façade becomes the point of entry when experiencing architecture, and perpetuates autonomous relationships in Big buildings. Based on this principle, it would imply the vertical plane's subordination to the horizontal plane, as architects find it most feasible to begin with the site, and allocate

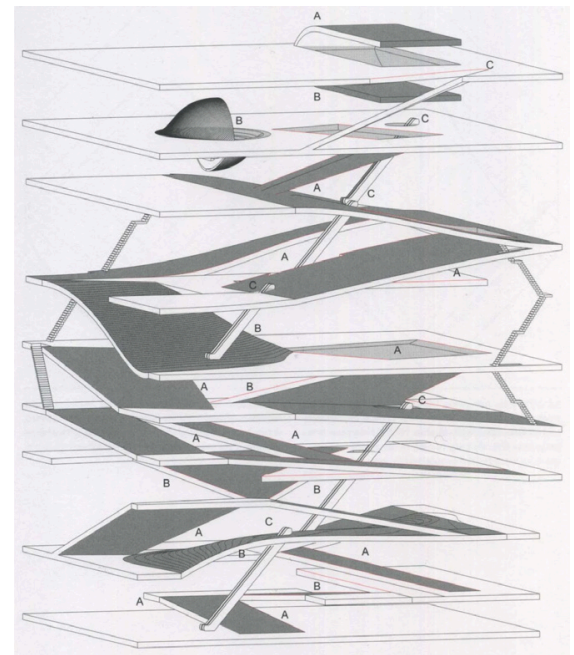

Figure 4.3: Jussieu Library Circulation Diagram 
space through the medium of a grid. This design approach privileges the plan as the primary design generator, allowing the simulation and segregation of autonomous environments within buildings. This thesis challenges this normative approach of design by exploring the possibilities of section or façade treatment as a basis of design, in which its value is considered greater than or equal to that of the plan.

In recent years, the work of Herzog and de Meuron have shifted away from façade design and ornamentation, as prominent building generators, to the diversion of the façade. This is done in favour of the floor plate - the plan. Of their recent projects, 1111 Lincoln Road serves an example of this design approach, whose program is comprised of over 300 parking spots, 11 retail store, 3 restaurants a restaurant and luxury residences. The expression of the building is defined by the nature of the parking lot in which the floor plates becoming the generator of both form and façade. Concrete floor slabs are detailed to taper towards the edges, creating a reductive form of ornament in which the floor plates become a visual element of the voided façade. The ramping nature and shift in scale of spaces are fully exposed, revealing the voyeuristic nature of the activities within. What is considered a product of the horizontal plane, the floor plate, becomes a subverted element of the building's façade. Traditionally the vertical

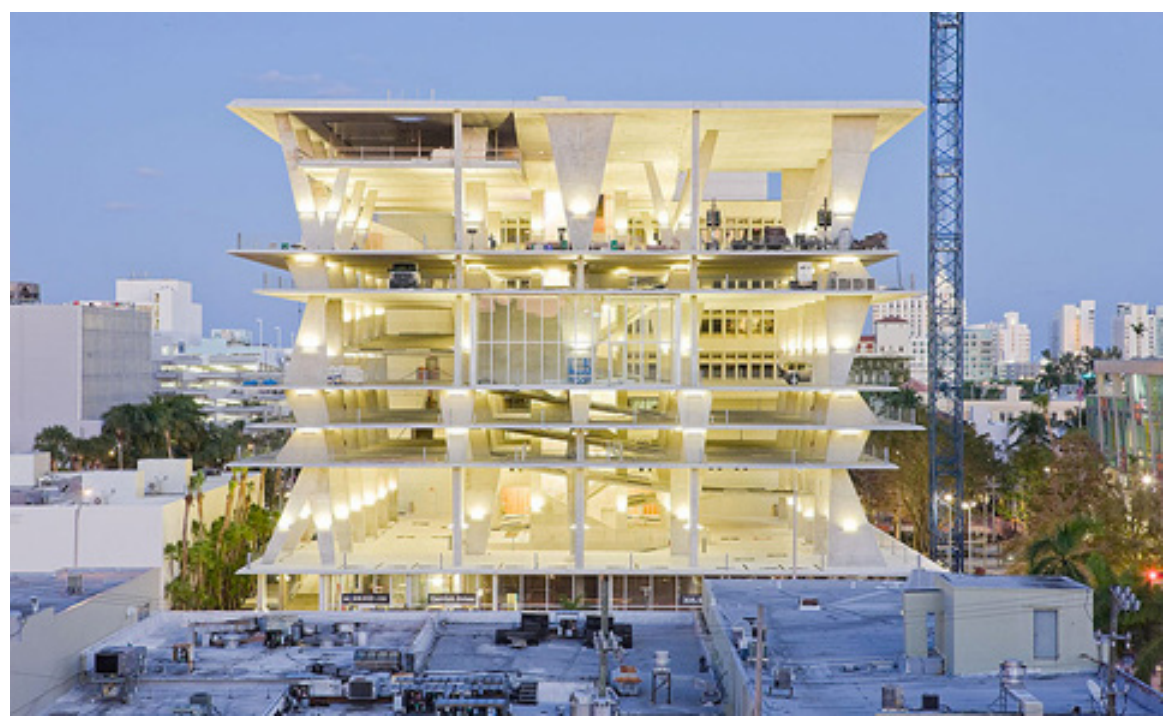


plane of a building, for example a curtain wall façade, tends to hides the horizontal elements of the building - the floor plates. In the case of Herzog and de Meuron, they deliberately reveal the floor plate as a prominent visual element of the façade. This technique is similarly employed in their luxury Tribeca condominiums, 56 Leonard Street in New York City.

Early works by Diller+Scofidio and Renfro also explore the idea of the floor plate revealing the facade. D+SR's winning proposal for the Eyebeam Museum reveals the symbiotic relationship between the horizontal plane and the vertical plane. Their proposal takes a literal approach to manipulating the horizontal plane, in which the floor plates conceptually fold over each other, becoming a continuous fabric that augments space. As the ribbon-like floor plate stretches and bends to create a variety of experiences, its vertical consequence is transcribed onto the façade of the building. A strong sense of continuity, both visually and programmatically facilitates the understanding of the mechanics, activities and the relationships of the interior spaces onto the street façade.

In both of these two cases by Herzog and de Meuron and Diller+Scofio and Renfro, the floor plan, an architectural medium typically used to allocate activity, is translated to the exterior of the building. The façade becomes an informative description of the activity within. This technique will prove vital to the development of the thesis project in translating the complex relationship of integrated spaces to the facade and ultimately the street.

\section{6 the section: overlapping diversity}

When delving deeper into understanding the various architectural conditions that generate autonomous environments, the building section becomes a critical point of interest in the design process. Ideas pertaining to the city grid, the horizontal plane, and the building façade have been previously discussed and can be simultaneously discussed within the context of the building section's role in architectural design and practice. As the typical approach to architectural design begins with the city grid, the plan and horizontal plane become the primary design driver and means of exploration - whereas this thesis will explore the section as the source of architectural 
innovation.

In Manual of Section by Paul Lewis, Marc Tsurumaki, and David J. Lewis, they outline 7 spatial hierarchies as they pertain to the building section. The various types and definition include:

Extrusion: the direction extrusion of a plan to a height sufficient for the intended use

Stack: the laying of floors directly on top of one another - an extruded section, repeated with or without variation

Shape: the deformation of one or more of the primary horizontal surfaces of a building to sculpt space

Shear: the use of a rift or cut along either the horizontal or vertical axis of a building to generate sectional difference

Hole: the deployment of any number or scale of penetrations through a slab, exchanging lost floor area for benefits in section

Incline: the manipulation of the angle of an occupiable horizontal plane, which tilts the plan into section

Nest: the creation of sectional consequences through an interplay or overlap of legible volumes. ${ }^{4}$

When challenging autonomy in architecture, the last category of nesting becomes the primary technique of exploration and innovation. With Koolhaas' critique of the New York Athletic Club in mind, nesting becomes the perfect vehicle to challenge the typical architectural model of autonomy as it deals with the interplay of 3 dimensional figures of volumes of space, whereas the 6 other sectional categories deal with the horizontal plane. Traditionally, nesting requires the intricate understanding of the building's various programs and functions to create complex spatial relationships and sequences. 
As the importance of the city grid and building façade have already been proven critical to the discourse of autonomy in architecture, the section drawing harmonizes these factors into one critical exploration. The section simultaneously demonstrates the strong relationship of space to the exterior skin and other internal spaces. Thus the design of the interstitial spaces and contiguous barriers between programmatic spaces becomes critical in optimizing function. Through the combination of shape, shear, hole, with an emphasis on nesting ordered along a quaternary axis in a flexible framework, a new type of architecture can emerge that embraces diversity, complexity and idiosyncrasy. A sectional approach towards architecture as a primary design driver subverts the traditional subordination of the section to the plan. The sectional drawing is no longer a reductive drawing at the end of the design process as a means of construction contract, but takes on an early role that is above or equal to the plan in the design process. The diverse and idiosyncratic spaces that result from this design approach can create complex interactions that dynamically enhance the sensorial experience. This approach creates the potential to result in the rapid succession and change in lighting conditions, acoustics, visual transparency, and circulation than that found in flat-stacked extrusion construction that is typical in Toronto. The resulting complex architectural diversity becomes an approach to architecture that is reflective of Toronto's diverse socio-cultural needs. 
1 Rem Koolhaas, Delirious New York: A Retroactive Manifesto for Manhattan (New York: Monacelli Press, 1994), 1.

2 Peter Eisenman, Ten Canonical Buildings: 1950-2000 (New York: Rizzoli, 2008).

3 Rem Koolhaas, Delirious New York: A Retroactive Manifesto for Manhattan (New York: Monacelli Press, 1994), 82.

4 Paul Lewis, Marc Tsurumaki, and David J. Lewis, Manual of Section (New York: Princeton Architectural Press, 2016), 9. 
5.0 THE SOCIAL DIMENSION

列

\footnotetext{
"Man is man's greatest joy. Nothing is more important or more compelling."
Hávamál

"Man is man's greatest joy. Nothing is more important or more compelling."
Hávamál

"Man is man's greatest joy. Nothing is more important or more compelling."
Hávamál
}

更
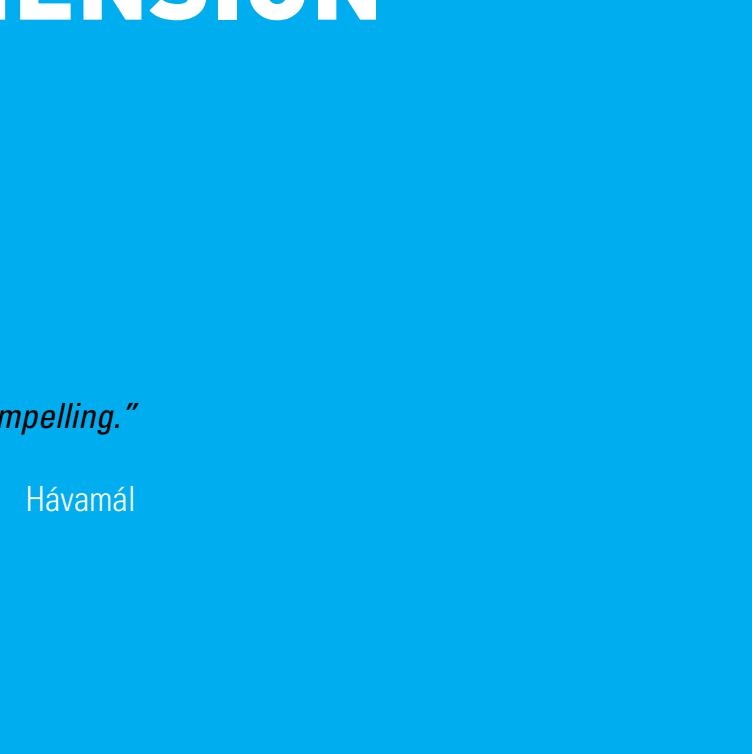

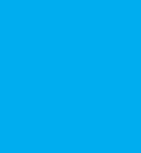

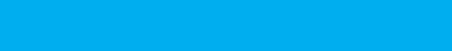

- 


\section{1 more meaningful connections}

In a city as multifaceted as Toronto, the cityscape has constantly served a variety of versatile and complex daily activities. At almost every corner there is an unpredictable opportunity for social activity. We are continuously being observed and observing events and other people interacting with their environment. It is this spontaneity that invites us to stay or move into the city.

Architecture provides an inescapable backdrop for opportunities for a broad spectrum of social activities. Jan Gehl claims that the most modest, and unpretentious form of social activity is the passive act of watching people and what is happening. 'This can also be called a "see and hear contact". More active social contacts can potentially stem from these see and hear moments and could lead to initial greetings and casual conversation, opening the door to much deeper encounters. It is through these activities that create a basis for establishing personal connections with our surroundings and the people we encounter.

See and hear activities make up the largest category of social contact, which is largely influenced by our built environment, and more directly, urban planning. It is through the arrangement of the modern city grid that can render buildings in a state of isolation within their neighbourhoods and city blocks. This state of autonomy has also translated into some forms of architecture, as previously established in the New York Athletic Club, as a diverse set of human occupancy and activities are cordoned off to their own introspective floor plates.

While there are various strategies that are successful at creating a certain degree of continuity at the urban scale, a new model can be extrapolated and applied to the scale of a building. One that is as complex as our personal relationships. One that is a reflection of our overlapping lifestyles that blend a variety of activity regarding how we live, work, play and move. By creating a model that maximizes see and hear activities in many directions, we can start to approach a deeper level of meaningful connections, that enhance our social encounters and personal well-being. 


\section{2 heuristic spaces: reimagining the subject-to-object relationship}

In response to the idea of autonomy in architecture, Le Corbusier's Palais de Congres Strasbourg and Rem Koolhaas' explorations within the Agadir Convention Center challenge the notion of discontinuous contiguity. Peter Eisenman's critique of the works in Ten Canonical Building's establish a reimagined subject-to-object relationship in which the ground, floor and roof are no longer treated as unique datums. Rather, each figure or spatial edge is treated as a continuous malleable fabric. ${ }^{2}$

In Palais de Congres Strasbourg, Le Corbusier begins to break away from the traditional planar organization of figured parts. While most of the spaces, circulation and windows maintain the figuration of parts along a strict grid, the northern ramp begins to diverge from his modernist principles. The ramping condition along the north of the building breaks the notion of a datum as it simultaneously registers a continuity in plan and section without respect to any privileged plane. This condition created a unique consideration for acoustical insulation between the floors and halls to accommodate the program's conference rooms and auditorium.

At the same time, Le Corbusier was working on the new Carpenter Center for the Visual Arts at Harvard University. While the Carpenter Center experimented more with the subversion of his Five Points of Architecture, it incorporated a centralized ramp that slowly revealed the user to the surrounding studio spaces introducing an inquisitive gaze. The idea of an inquisitive gaze will figure largely into conception of the thesis project, while extending its interaction beyond the separation of a building's floor plates and programmed spaces.

Although the Palais de Congres at Strasbourg was never completed due to Le Corbusier's death, it served as a critical precedent for Koolhaas' Agadir Convention Center. Founded on these investigations, Koolhaas continued his research on discontinuous continuity which he explored with the Jussieu Library. In keeping with their central themes, the ground, floor and roof do

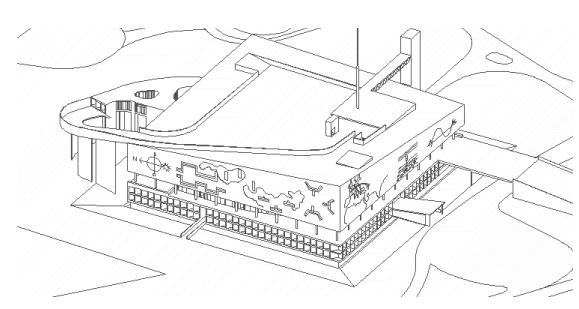

Figure 5.1: Palais de Congres Strasbourg

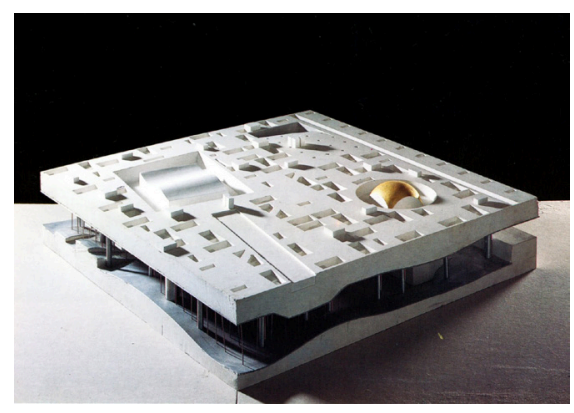

Figure 5.2: Agadir Convention Center

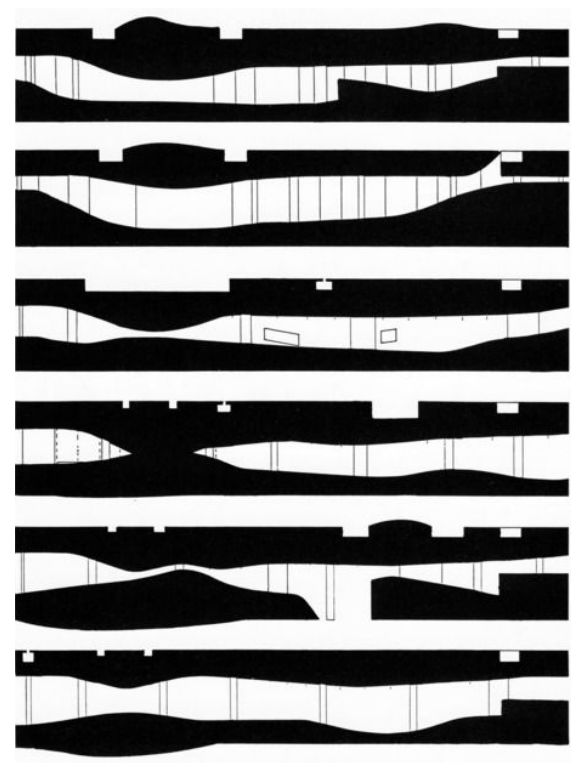

Figure 5.3: Agadir Convention Center Sections 


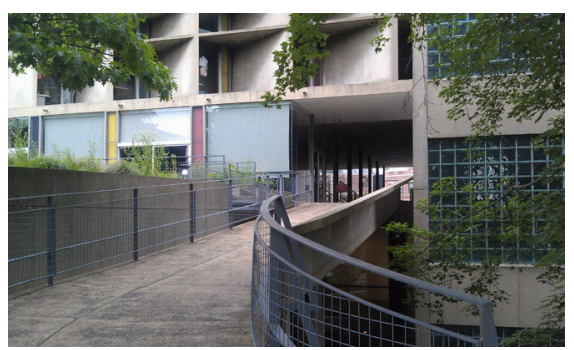

Figure 5.4: Harvard Carpenter Center

not resemble the concept of a datum.

The Agadir Convention Center was founded the inversion of a figure-ground model, where the void becomes the predominant generator of space. The central void figures as a grand plaza sandwiched between the hotel mass on top and convention center on the bottom. In contrast to the vertical extrusion of postwar architecture, a horizontal avulsion occurs where the interior facing surfaces of the hotel and convention center carve and shape the plaza. The resulting space consists of undulating surfaces that both blocks direct vision and reveals elements and activity. This reintroduces the concept of heuristic interaction or an heuristic space in which users contribute to a collective performance of human activities and interactions. As the user traverses through the building, they encounter unique moments where they can engage in various activities at once, where other users or subjects are viewed as objects. This relationship is expressed along all four facades of the building, constantly reflecting new experiences to the exterior. In this precedent, Koolhaas' manipulation of the interior surfaces seem arbitrary and are superficially justified by the surrounding desert landscape of Agadir, Morocco. With regards to the thesis project, creating a sense of inquisition in human activity and its observation from the interior and exterior of the building are an important goal.

In Peter Eisenman's critique of the Agadir Convention Center, he employs the term "voyeuristic gaze" to describe the sensation afforded by the concealment and reveal of human activity. ${ }^{3}$ Within the context of this thesis, the term "voyeuristic gaze" is removed of it's sexual and pleasurable inclinations and have been reframed and re-appropriated as "heuristic interaction". This new term aligns with Jan Gehl's observation that we as humans have a constant need to gather new information - especially information about the people and environments around us. "Man is man's greatest joy. Nothing is more important or more compelling". ${ }^{4}$

There are many valuable concepts brought forth by these precedents that can be explored further and applied to this thesis project. The malleable ramp surface in the Palais de Congres Strasbourg introduces many acoustical implications that can be embraced in the inevitable thesis 
project, as opposed to being subdued. Any acoustical activity that may occur in adjacent galleries will reinforce see-hear contact, while creating a sense of intrigue and inquisition.

The manipulation and careful choreography of contiguous surfaces can also serve as way to enhance other sensorial experiences that are not limited sound. This dynamic, if under careful design and control, can create various light conditions that will prove to be useful in the exhibition of a gallery and design of art exhibits and installations. From a social perspective, the introduction of visual transparency coupled with the concealing and reveal of human activity can open up various degrees of heuristic engagements.

By articulating these engagements along the backdrop of design research, the aforementioned experiences can be related back into the context of architecture. The integration of various architectural grids can be used as a device to establish rational ordering system for organizing and overlaying new spatial relationships. Using various grids that are unique to the site, these new relationships can be related back into the surrounding context in more ways than were superficially explored in works by Koolhaas and Eisenman.

\section{3 monochronic space vs polychronic space}

In The Hidden Dimension, Edward T. Hall defines the terms 'monochronic' and 'polychronic' within a temporal context. But the same terms can be used to describe a sensorial experience or an organizational strategy within an architectural context. He describes monochronic as being "characteristic of low-involvement peoples, who compartmentalize time; they schedule one thing at a time and become disoriented if they have to deal with too many thing at once". ${ }^{5}$ Within an architectural context, this definition can come to describe a traditional modernist organization method. Again, this notion is prevalent in the New York Athletic Club, in which each floor is treated as it's own single, artificialized environment. As users enter arrive at each floor through the elevator, they are encountered with a single environment designed for one particular program or use. Within Hall's context, this can 
be described as a monochronic space, or the New York Athletic Club can be described as being monochronically organized.

Consequently, Hall's definition of the polychronic can be applied to an architectural organization method as well. Hall states "polychronic people tend to keep several operations going at once. The monochronic person often finds it easier to function if he can separate activities in space, whereas the polychronic person tends to collect activities" ${ }^{6}$ This definition of depicting multiple activities can be attributed to centralized space, whether it be a public plaza, a city square or even building atria. Similarly to the concept of monochronic space, polychronic space can be described as a centralized space in which a multiplicity activities can be consumed or experienced at once. The overwhelming experience of a rapid succession of activities is akin to the blasé type. A polychronic approach to architectural design could open the possibilities for addressing the complexities and idiosyncrasies of contemporary society, especially amongst the backdrop of Toronto's urban life.

1 Gehl, Jan. Cities for People. Washington, DC: Island Press, 2010.

2 Peter Eisenman, Ten Canonical Buildings: 1950-2000 (New York: Rizzoli, 2008), 204.

3 Ibid., 202.

4 Jan Gehl, Cities for People (Washington, DC: Island Press, 2010), 23.

5 Edward T. Hall, The Hidden Dimension (Garden City, NY: Doubleday, 1966), 173. 
ATKINS AVE

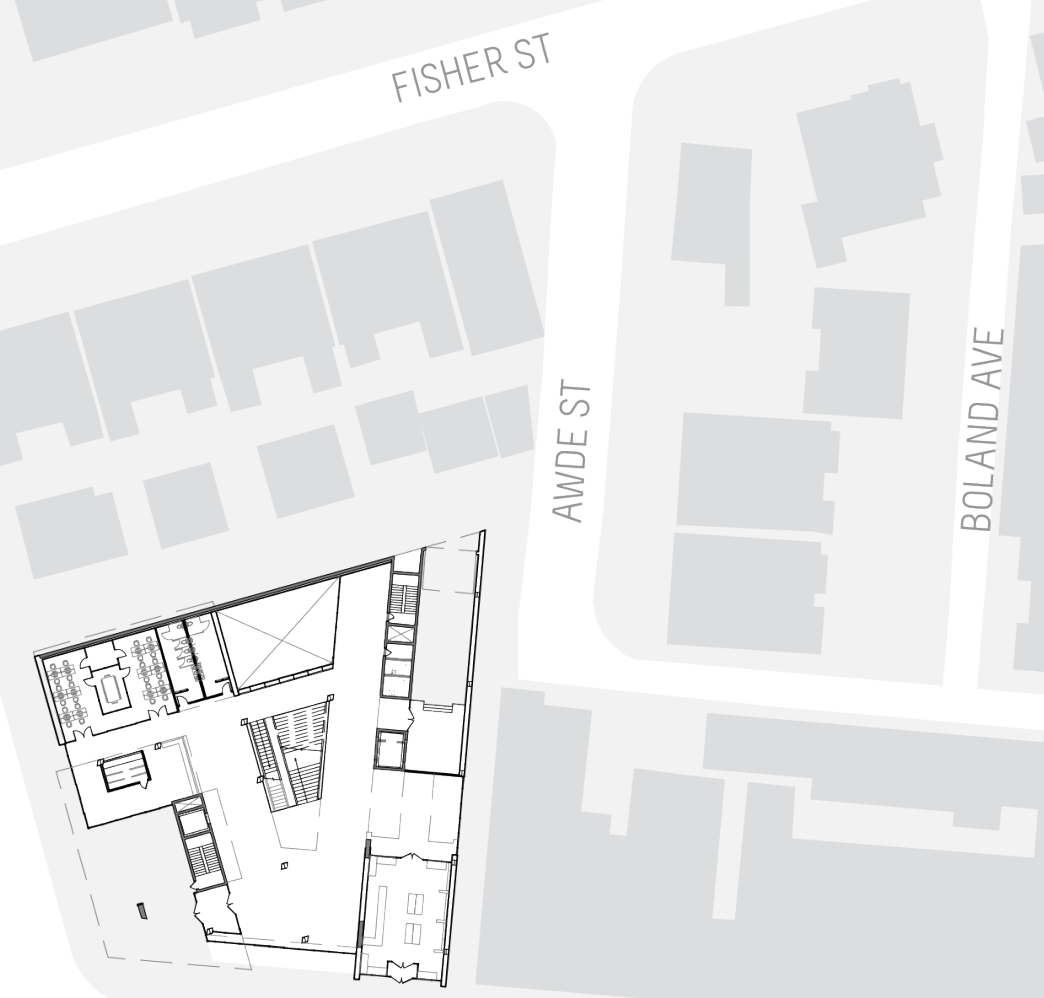

DUNDAS STREET W

Figure 6.1: Site Plan 


\section{1 site description}

\section{$43.6500644,-79.4355115$ \\ 1544 Dundas Street West}

Little Portugal has remained a vibrant, colourful and well-preserved neighbourhood over the past several decades, in spite of the residential and commercial gentrification in recent years. In the past decade, most of the first and second generation Portuguese population are retiring and/ or moving into the suburbs to raise their children. ${ }^{1}$ The number of urban professionals living in the area has increased dramatically, as they seek to buy older homes close to the downtown core and within close proximity to their work.

While the Portuguese demographic is slowing decreasing, the neighbourhood maintains a strong identity due to its well-preserved social, cultural, commercial and religious institutions. Of the cultural institutions, small local art galleries have become more prominent, whose exhibited works range from traditional mediums to contemporary arts. As the community becomes increasingly diverse, the artist demographic will continue to grow as many of their public programs extend their social relations with one another.

\section{2 history of dundas street and its grid}

Prior to any European contact, First Nation's people residing near the Niagara Escarpment would travel to areas currently occupied by modern day Toronto. They created a vast trail network, many of which have since been paved over and have transformed into the modern highways and roads that we still use today.

Dundas Street West was part of one of the most prominent trails known as the "Upper Road to Niagara" under the territory of the Haudenosaunee, the Métis and the Mississaugas of the New Credit First Nation. In 1787, the British purchased a large swath of land, stretching as far back as 45 
kilometres from the north shore of Lake Ontario. This newly acquired land would go on to develop into the City of Toronto.

During the year 1791, General John Graves Simcoe would be appointed the first Lieutenant Governor of Upper Canada. He was commissioned to settle and develop the land and prepare defensive measures against the possibility of an American invasion from the south. In order to easily transport soldiers and goods, Simcoe's first commissioned road was Yonge Street, to connect Lake Ontario to Lake Simcoe. His second road was Dundas Street, named after the British Colonial Secretary, Henry Dundas. Dundas Street would serve as the main road.

\section{3 cultural facades}

Figure 6.2 identifies several of the cultural facades along Dundas Street West between Brock Avenue and Dufferin Street. Various artists take advantage of the unique condition in the neighbourhood of forced perspectives along the street. Buildings facing onto Dundas Street have their side elevations become coloufully exaggerated to contribute to the vibrancy of the neighbourhood. As people walk along the streets, a completely different experience can be had when walking in the opposite direction. The museum aims to take advantage of this condition on a more architectural level, especially on it's interior experience as well. 


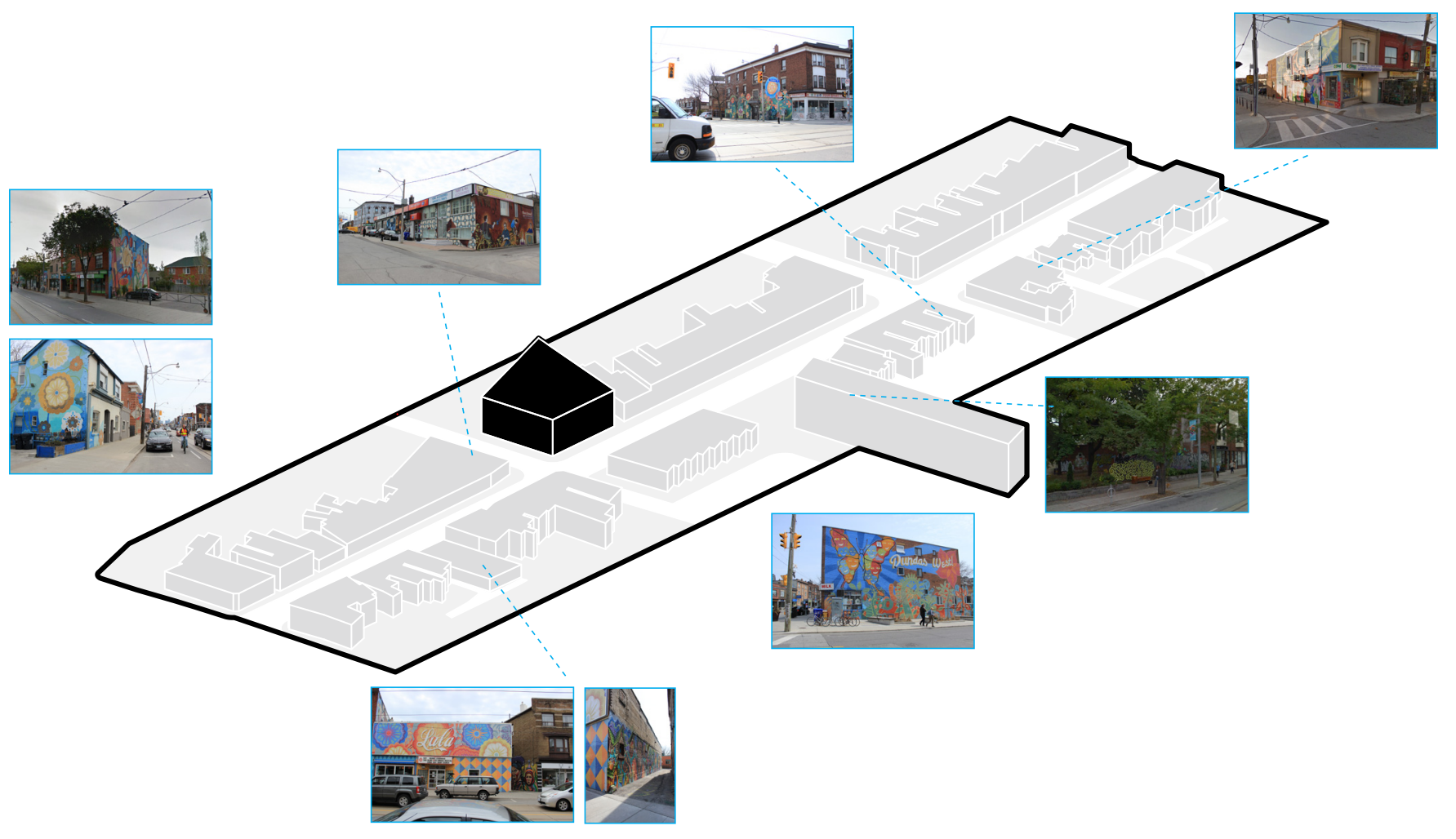

Figure 6.2: Cultural Facades 
6.4 site diagrams

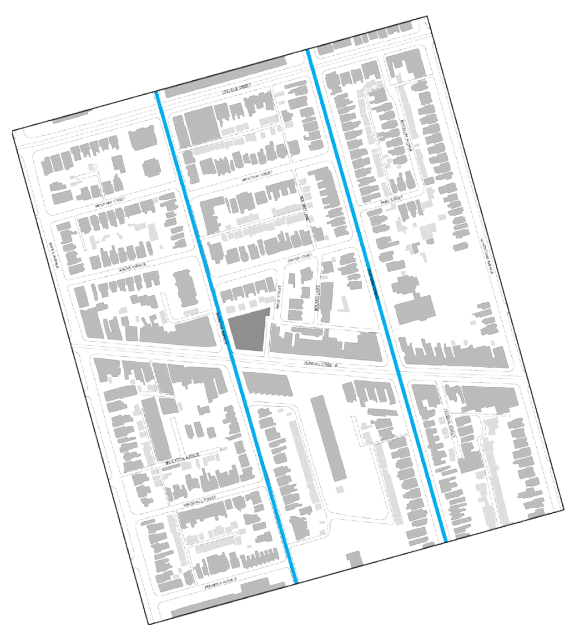

Figure 6.3: Typical City Grid

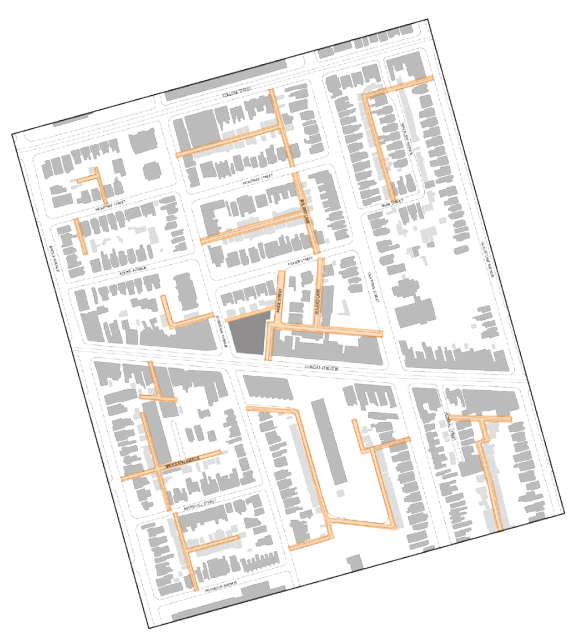

Figure 6.5: Dundas Street Grid Uses

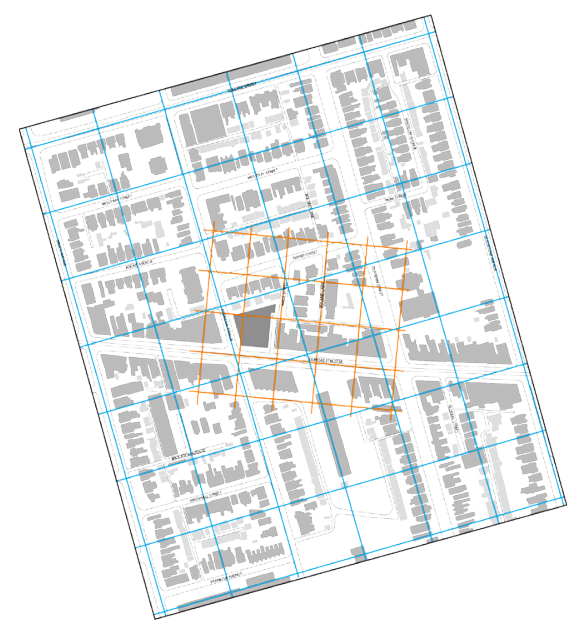

Figure 6.4: Dundas Street Grid

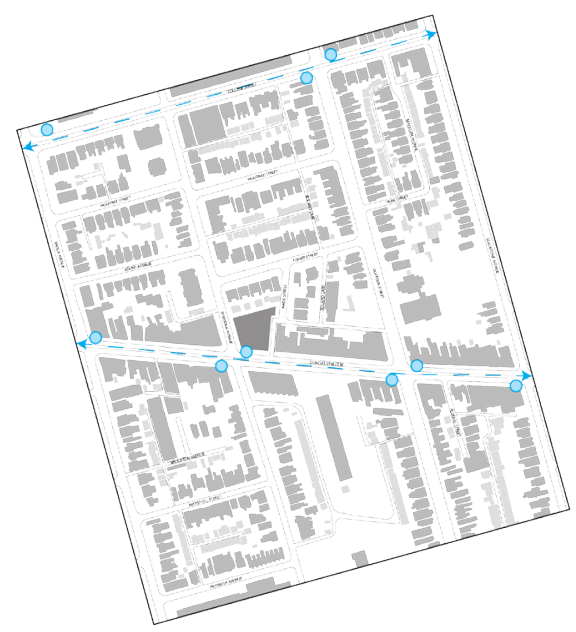

Figure 6.6: TTC Access 
Figure 6.7: Cultural Zones around Little Portugal

Figure 6.8: Urban Open Spaces around Little Portugal
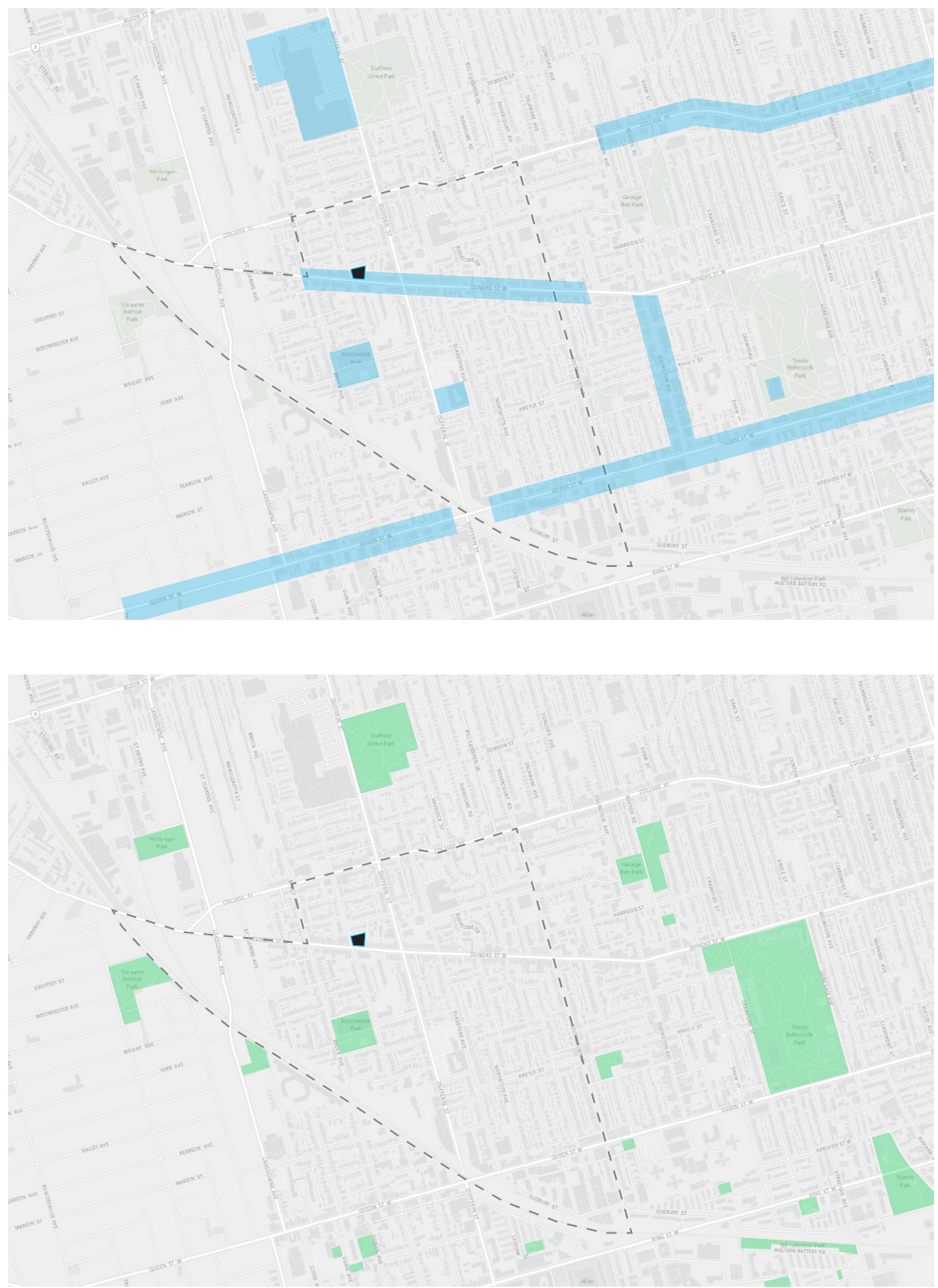

1 Carlos Teixeira, Toronto's Little Portugal: A Neighbourhood in Transition, publication no. 35, Centre for Urban \& Community Studies, University of Toronto, March 2007, 1, accessed November 2016, http://www.urbancentre. utoronto.ca/pdfs/researchbulletins/CUCSRB35Teixeira.pdf. 


\subsection{PROGRAM: \\ MUSEUM

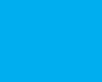 \\ MUSEUM

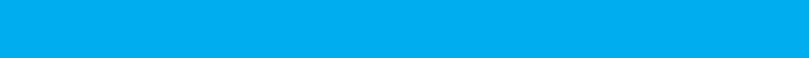

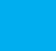

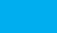

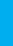

$\sqrt{2}+x^{2}$ . .

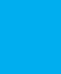

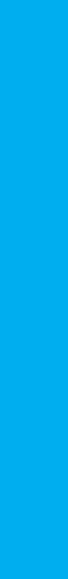

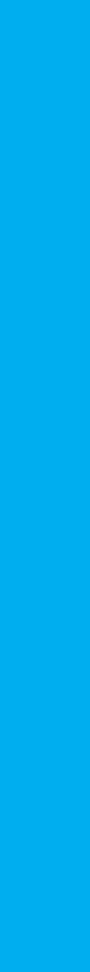




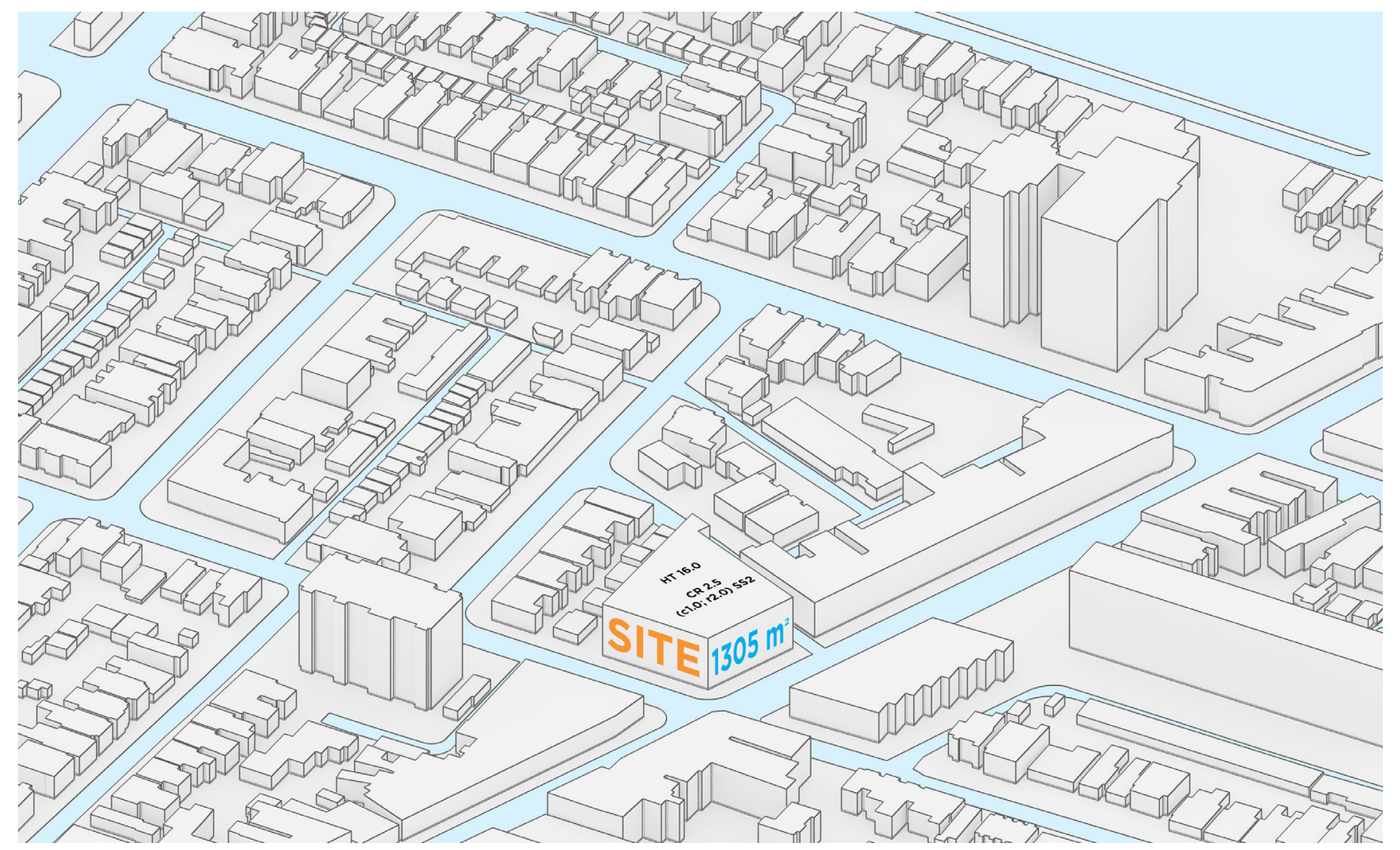

Figure 7.1: Zoning

\section{1 program}

Toronto is Canada's largest city and sixth largest government, and home to a population of approximately 2.6 million people. It is the economic engine of Canada and one of the most creative and diverse cities in North America. To showcase our unique diversity and various diverse histories, Toronto has various established museums addressing many of these various facets including Fort York, Spadina House, Todmorden Mills, and the Mackenzie House. These small scale museums successfully communicate with particular demographics but none of which consider the entire history of the city and its people. The larger museums such as The Bata Shoe Museum and the Royal Ontario Museum both house large impressive collections, but exist in isolation and neglect to address the city at large. A City of Toronto Museum could serve as an overarching hub that would serve as a physical dialogue of Toronto's history, and equal the city museum's of other prominent North American cities like Vancouver, New York and San Francisco. 
Figure 7.2: Nearby Galleries

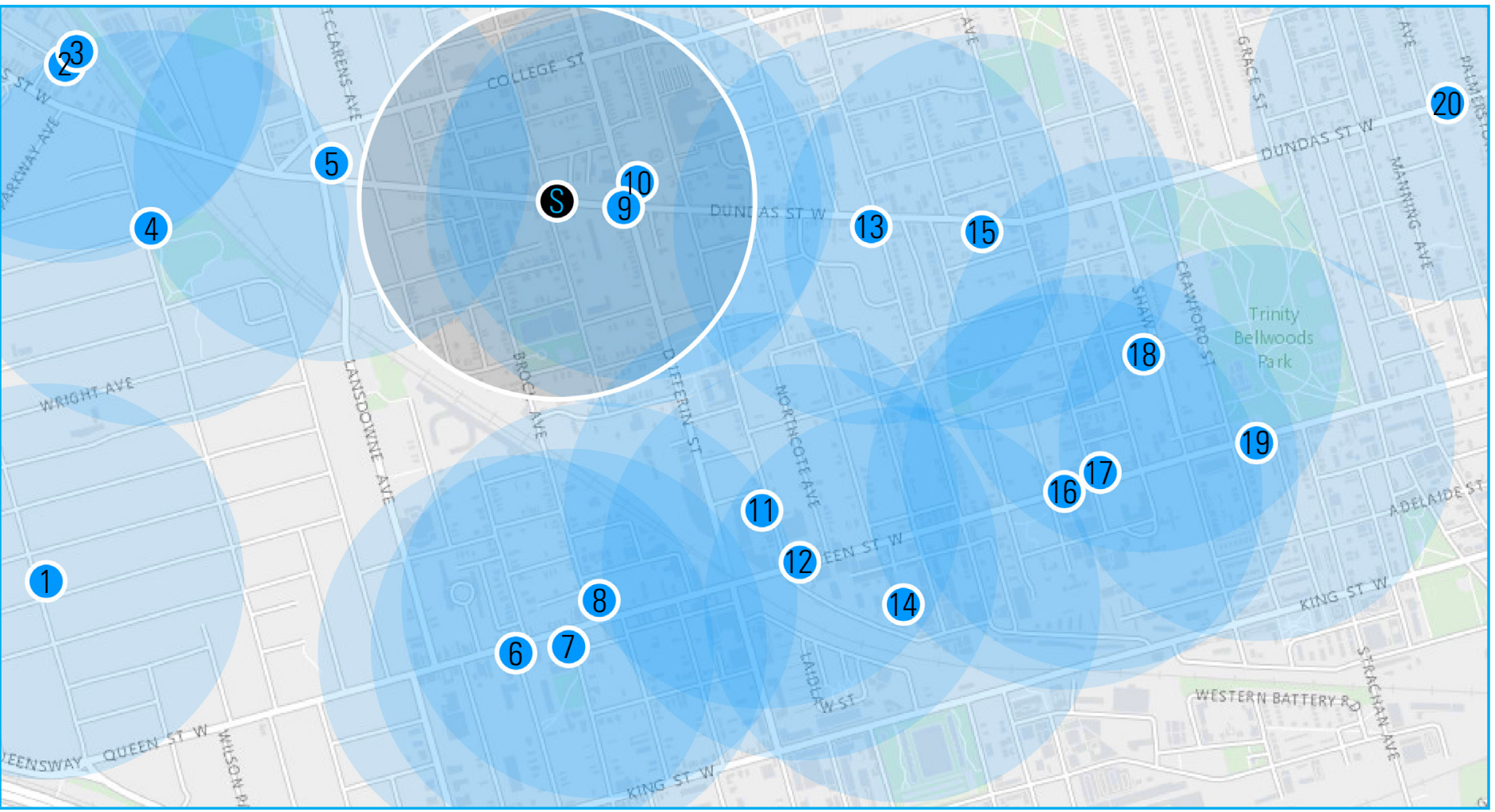

7.2 surrounding exhibition spaces

$1 \quad$ NORMAN FELIX GALLERY

2 OLGA KORPER GALLERY

3 CHRISTOPHER CUTTS GALLERY

$4 \quad$ GALLERY 345

5 XSPACE CULTURAL CENTRE

6 ELAINE FLECK GALLERY

7 GALLERY THIRTEEN THIRTEEN

8 ONLY ONE GALLERY

9 ART METROPOLE

10 WORKMAN ARTS

11 GALLERY 50

12 RYERSON ARTSPACE

13 LOOP GALLERY

14 PROPELLER

15 WIL KUCEY GALLERY
16 STEPHEN BULGER GALLERY

17 INTERACCESS

18 KOFFLER GALLERY

19 STUART JACKSON GALLERY

20 \#HASHTAG GALLERY

21 MUSEUM OF CONTEMPORARY CANADIAN ART

22 SPADINA HOUSE MUSEUM

23 FORT YORK NATIONAL HISTORIC SITE

24 BATA SHOE MUSEUM

25 ROYAL ONTARIO MUSEUM

26 GARDINER MUSEUM

27 ART GALLERY OF ONTARIO

28 TEXTILE MUSEUM OF CANADA

29 CAMPBELL HOUSE

30 CBC MUSEUM 
Figure 7.3: Nearby Museums

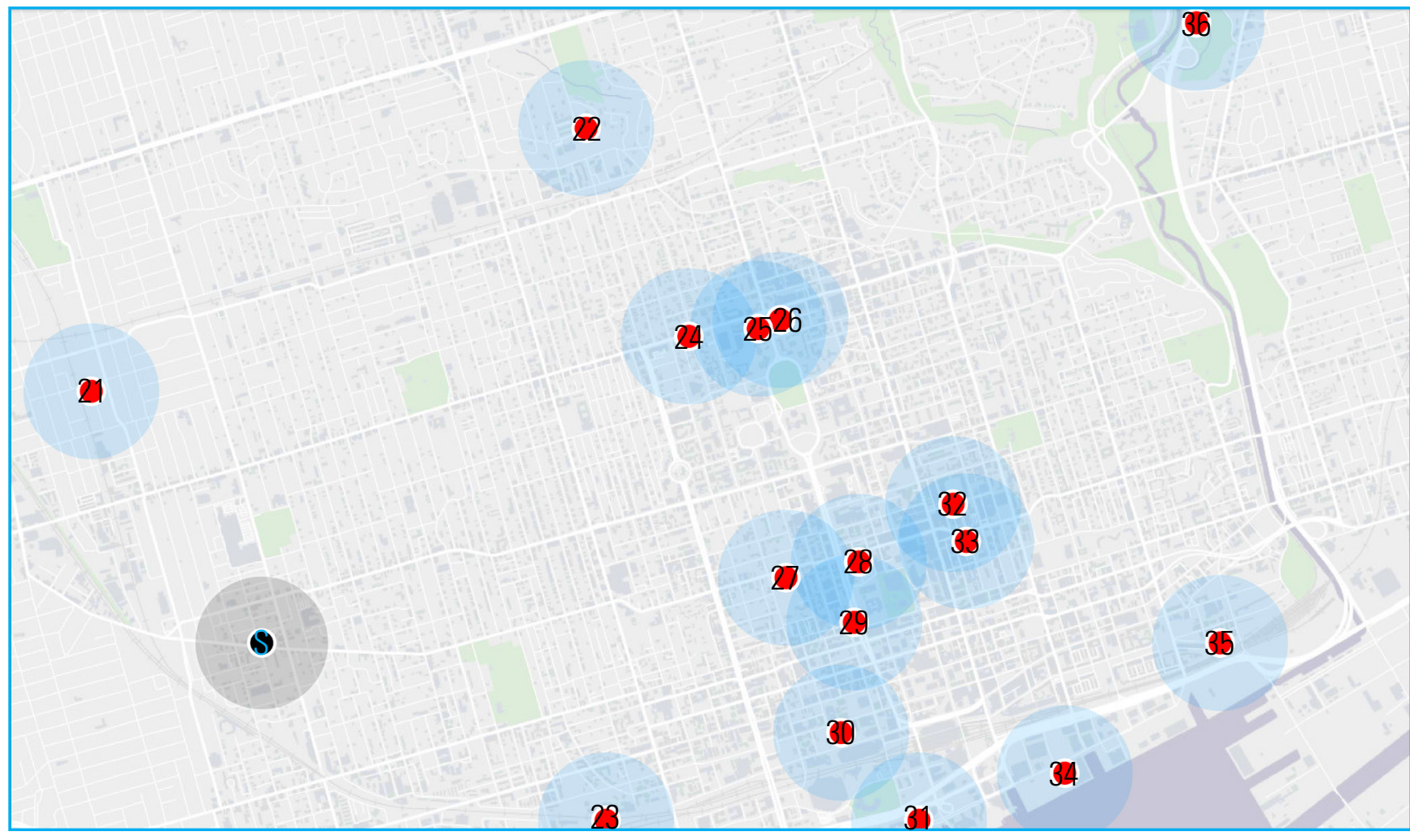

31 THE POWER PLANT CONTEMPORARY ART GALLERY

32 RYERSON IMAGE CENTRE

33 MACKENZIE HOUSE

34 REDPATH SUGAR REFINERY

35 THEATRE MUSEUM CANADA

36 TODMORDEN MILLS HERITAGE SITE

S SITE: 1544 DUNDAS STREET WEST 


\section{NORMAN FELIX GALLERY}

Represents over 100 Canadian artists. Houses an array of contemporary painting, photos, illustrations and sculptures by emerging and established artists, focusing on Canadian artists.

Program includes an art gallery and cafe venue including virtual offices, weekend arts and crafts market, retail and pop up space.

\section{GALLERY 345}

Created in 2005 by Edward Epstein who has been involved with contemporary music in the city. Known as one of the great piano salons in Toronto. The gallery is a listening room for chamber music including classical, jazz, improvisation and contemporary composition. The gallery can be rented for concerts, fundraisers, $C D$ releases, private parties, weddings, book launches

\section{OLGA KORPER GALLERY}

Since 1973, the gallery has been committed to the promotion and exhibition of Canadian and international contemporary art, both local and internationally Strong commitment to painting and sculpture. Their scope has been increasing to accommodate installation and photography.

\section{XSPACE CULTURAL CENTRE}

Artist-run centre dedicated to providing emerging artists and student artists and designers to exhibit work in a professional setting. Program and contemporary practices respond to interests and needs of membership. Supported by OCAD Student Union

Multiple spaces: main space, project space, window space, external space, library. The main space hosts group curatorial exhibitions. The project space is intended for installation based practices. The external space is located in OCAD University Learning Zone and offers opportunities for media-based works with emphasis on video and animation.

\section{CHRISTOPHER CUTTS GALLERY}

A commercial fine art gallery dealing with acclaimed works of modern and contemporary art. Collects works of historically significant Canadian artists, notably of the Painters 11 group during the 1950s era of modern abstraction. Represent established artists from Canada and Europe.

\section{ELAINE FLECK GALLERY}

-founded in 2005, representing contemporary Canadian and American artists -monthly exhibitions -curated fine art of painting, photography and mixed media -weekly portfolio reviews for emerging and mid career artists -routine meetings with media, art collectors, art consultants and museum curators' 


\section{GALLERY THIRTEEN THIRTEEN}

Not for profit charitable artist-run centre. Exhibits local, national and international contemporary art. Houses over 70 exhibitions and many cultural events each year. Supports emerging artists with professional development and career building opportunities. Specializes in gaining exposure for emerging artists looking for exhibition experience with mentorship programs and promotional and installation support. Programming coincides with major local art events like Contact, Nuit Blanche, and BFA and MFA thesis shows.

\section{GALLERY 50}

Ideal location for exhibition, workshop and launch parties. Walking distance to Gladstone Hotel, Drake Hotel, The Theatre Centre and a number of art galleries. Professionally run rental gallery Two 1000sqft gallery spaces are available for rent.

\section{ONLY ONE GALLERY}

$\mathrm{N} / \mathrm{A}$

\section{WORKMAN ARTS}

Mandate includes empowering aspiring, emerging and established artists with mental illness and addiction issues to develop and refine their art practice through training programs. Deal with music, theatre, visual and literary and media arts. Excellence in programming, research, and partnering with other arts organizations. Mission is to promote a greater public understanding of mental illness and addiction through creation, presentation and discussion of the artistic media. Hosts communication and education workshops, lectures, seminars and public events on mental health.

\section{ART METROPOLE}

Not for profit organization focusing on production, dissemination and contextualisation of artist-initiated publication in any media. Accepts books, edition and multiples in any media. Founded in 1974 by artist's collective General Idea as an artist-run centre. Early commitment to collecting, cataloguing and preserving artistic production and documentary evidence of the conceptual art movement unique in alternative gallery communities developed in Canada in the 1970s Collection donated in 1999 to the National Gallery of Canada.

\section{RYERSON ARTSPACE}

N/A 


\section{LOOP GALLERY}

Conceived in response to the scarcity of permanent exhibition venues in 2000. Self sustaining, collectively run space for professional member artists. Operating with $30+$ members as two simultaneous solo shows at a time. Follows an artist led curatorial model.

\section{KOFFLER GALLERY}

Emerged out of program of the Koffler Centre of the Arts in 1977 as part of Bathurst Jewish Community Centre. Exhibitions were to enlighten and inspire Jewish community. The gallery was established in 1980 and shifted its mandate to collect exclusively contemporary Canadian art. Offers a dynamic forum for presentation of art, with year round program of exhibitions, publications, public programs and educational initiatives to foster the production of new works by Canadian and international artists. Program highlights the contemporary Jewish experience in a framework that invites a comparative examination of narratives among people of varied heritages within a larger discussion of identity, memory and place.

\section{PROPELLER}

Propeller Centre for the Visual Arts is a member-run gallery supporting innovative, sustainable programming and provides networking and partnership opportunities. An independently funded space since 1996 funded by community memberships, fundraising and gallery rentals. Its diverse range of experimental programming, include video game exploration, comedy, story-telling evenings, local theatre production

\section{INTERACCESS}

Gallery, education facility and production studio dedicated to creative use of technology, electronic art and new media culture. Program support with tech integration from conception and development to exhibition. Programs include exhibition, live music and performance, hands on workshops, professional develop and teacher training, free drop in studio weekly, artist talks and panel discussion. Annual support for InterAccess Media Arts Award with OCAD. Collaboration with MaRS, Google, Eyebeam, Design Exchange, The Power Plant, OCAD TDSB, Google, South Asian Visual Arts Centre.

\section{WIL KUCEY GALLERY}

Dealers of contemporary and historical fine art. Collect works of art by important artists that were influential of their time. Promotes purchase of original works and the awareness of significant works, exhibitions, and accomplishments in the careers of artists that the gallery works with. Artists are unique in their approach to representing the conversations of contemporary culture. Provide consulting services to building an important and valuable collection of art

\section{STEPHEN BULGER GALLERY}

Focused on the sale and exhibition of international contemporary and historical photographs since 1994. Houses an inventory of 15000 photos with emphasis on documentary tradition and historical photographs from Canada. Maintains over 3000 books on photography. The gallery specializes in first time buyers, but open to all levels of collecting for individuals and institutions. Hosts Saturday afternoon film screenings. 


\section{STUART JACKSON GALLERY}

The oldest gallery dealing in antique Japanese woodblock prints in Canada. Ukiyo-e depict the fleeting pleasures of life.

\section{\#HASTAG GALLERY}

Their mandate is to bring together established artists from a variety of backgrounds to showcase a carefully curated roster of talent on both the critical and commercial contemporary arts stage, fostering who they believe to be the next generation of successful Canadian artists across a range of media and disciplines, giving online communities a touchstone in the Toronto contemporary art world. They host workshops on various crafts ie. watercolour, calligraphy, painting, embroidery, planting, origami, corre collage. Provides services in custom framing, art installation, art consultation, commissioned artwork, art rentals, event planning. 

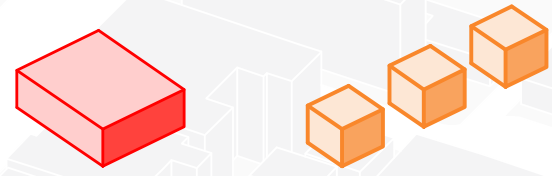

LOADING WASHROOMS

GIFT \& BOOK SHOP
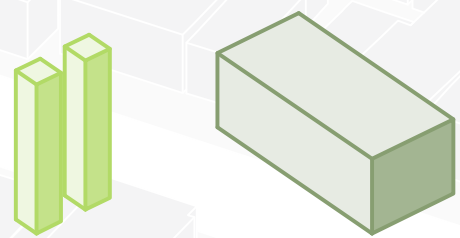

ELEVATORS AUDITORIUM

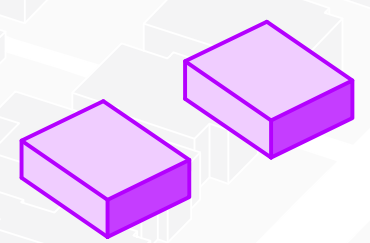

OFFICES
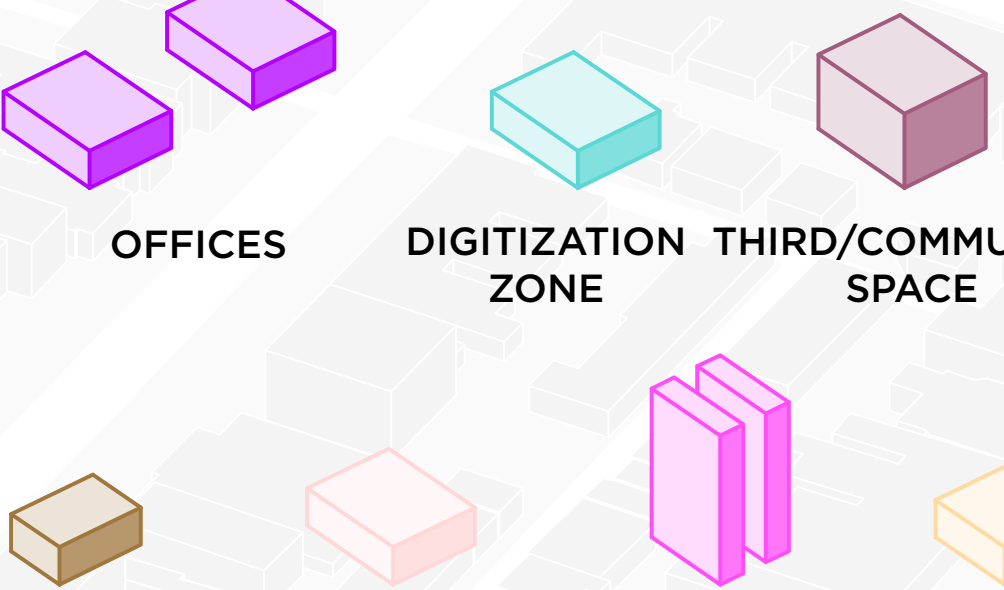

DIGITIZATION THIRD/COMMUNITY ZONE SPACE

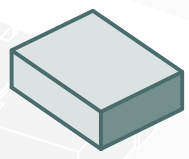

TEMPORARY

EXHIBITIONS
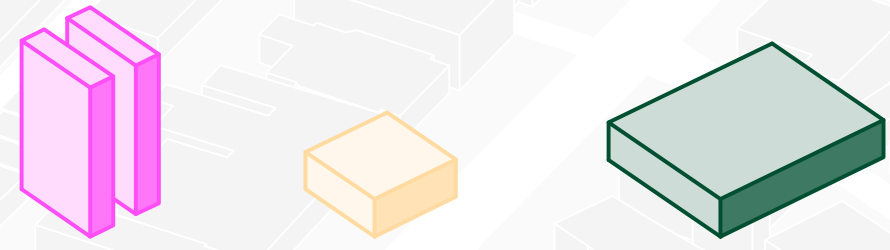

TICKETS \& ARCHIVE ROOM

LOBBY ROOM

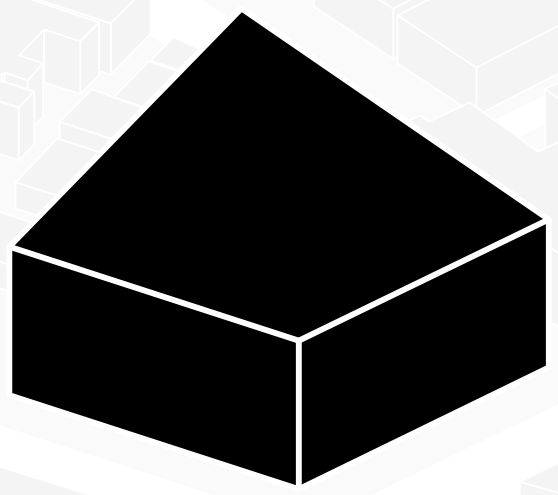


LOADING

125 SOM

WASHROOMS

25 SOM X 3

\section{GIFT \& BOOK SHOP}

100 SQM

\section{ATRIUM}

80 SQM

\section{ELEVATORS}

9 SOM X 2

\section{AUDITORIUM}

225 SOM

\section{SMALL GALLERIES}

100 SQM X 8 (AVG.)

\section{LARGE GALLERIES}

175 SOM X 2 (AVG.)

\section{OFFICES}

125 SQM X 2

\section{DIGITIZATION ZONE}

125 SOM

THIRD/COMMUNITY SPACE

125 SOM

\section{TEMPORARY EXHIBITIONS}

130 SOM

\section{TICKETS \& COAT ROOM}

70 SOM

\section{ARCHIVE ROOM}

125 SQM

\section{SERVICE CORES}

25 SOM X 2

MULTIPURPOSE ROOM

100 SQM

\section{LOBBY}

325 SQM

\section{3 programmatic spaces}

The proposed City of Toronto Museum is designed around the appropriate exhibition of the Toronto Museum Project's collection of 100 items, 100 stories, and the ideas surrounding the identity of the city at large. It will serve as the preeminent institution dedicated to furthering Toronto's past, present and future socio-cultural identity. The open contribution nature of the museum will reinforce an intimate central precinct largely influenced by Torontonians themselves.

Based on the taxonomies of the different artifacts, a variety of gallery sizes are required to exhibit the collection in their appropriate contexts within the 14,000 sqf facility. In order to support a contemporary gallery of this size typically requires supplementary programming for a workshop or prep room, an archive room, and storage. Classrooms/multipurpose rooms and a 125-seat auditorium will serve as a backdrop to facilitating the ongoing discussion of Toronto's values and identity. They will serve as a space to hold various open lectures, guest lectures, intimate social events or public civil events to contribute to the museum's daily operations.

On a more frequent daily scale of operation, various outlets for exhibition offer unique opportunities to exhibit Torontonian curated installations or other visiting artists. At the ground level, street frontage is allocated to temporary exhibition space, offering a commercial presence solely for local artists. A more formal exhibition space, will be offered for extended visiting exhibitions that will contribute to the museum's operation. This extended temporary exhibition space differs from the local temporary exhibition space as it affords more a flexible spatial experience, compared to the limited local gallery.

Aside from exhibition, a public domain dedicated to generating operation costs for the museum will be offered at ground level. A dedicated bookstore complimenting the City of Toronto Museum's themes and values will be situated at ground level along Dundas Street West to take advantage of the commercial sidewalk culture already present in Little Portugal. The 
continual circulation of literature between various institutions, local and abroad, ensures the opportunity to curate a collection of similar themed books.

\section{4 collection: the toronto museum project}

Unlike many other major metropolitan cities, Toronto seems to lack a city museum of the same caliber as the Museum of Vancouver, the Museum of the City of New York, or the Museum of the City of San Francisco for example. But over 15 years ago, Mayor David Miller commissioned the curation of a small collection to begin the efforts to bringing such an ambitious project to reality. The Toronto Museum Project was formed in 2002 in hopes of securing $\$ 100 \mathrm{M}$ in funding to realize the project, $\$ 40 \mathrm{M}$ of which was to be secured by private funding. The project has since been looking for a site to house the museum ranging from the Old City Hall courtyard and eventually to the old malting silos at the foot of Bathurst Street. But in 2009, a debate between Toronto's Heritage Preservation Services and several city council executives arose over restoring the silos and demolishing the buildings, substantially increasing the project funds.

The confluence of many other factors, such as the lack of a cohesive curation and unclear avenues to sustain operational costs, would eventually put the project on an indefinite hold. But in 2010, a federal grant of $\$ 200 \mathrm{k}$ was put towards the digitization of the 100 donated artefacts. An event was held at Fort York in which 100 Torontonians were invited to share a story pertaining the memory or values of each item. Various members of the community, including politicians, architects, artists, professors and young children contributed their stories to the project. The event was a success with regards to initiating a discourse on understanding how we define and interact with Toronto's past, present and future. Following the event, the 100 artefacts and 100 stories were made available online at http://www.torontomuseumproject.ca/ . This collection and project was made possible through the support and sponsorship of the City of Toronto, Exentricarts Inc, The Toronto Star, York University, and the Department of Canadian Heritage through the Canadian Culture Online Strategy. 


\section{5 collection summary}

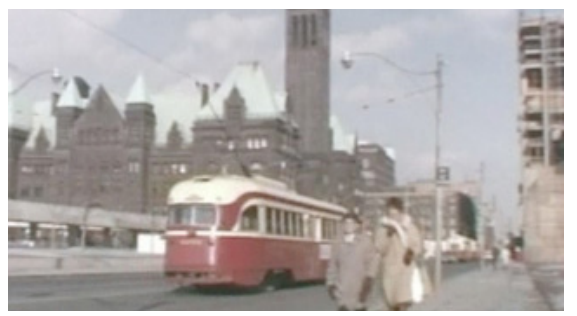

\section{CITY HALL DOCUMENTARY}

A DVD documentary centered around the construction and inauguration of the New City Hall and Nathan Phillips Square.

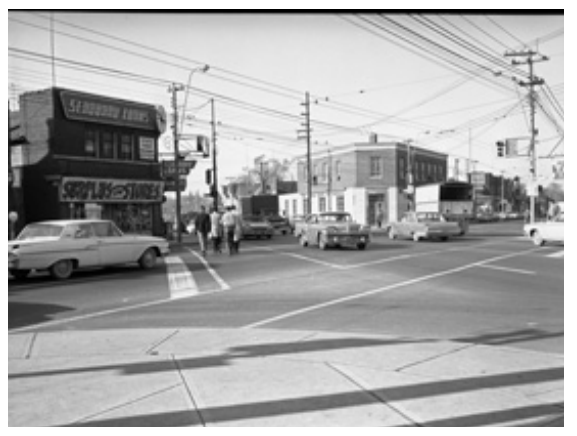

\section{PHOTO OF WESTON ROAD AND LAWRENCE AVENUE WEST}

This intersection was know as the gateway to the Weston Village. The neighbourhood was adapted due to the area's history of manufacturing bicycles at the old CCM factory on Lawrence Avenue just east of Weston Road.

\section{PHOTO OF WESTON ROAD AND LAWRENCE AVENUE WEST}

This advertisement is made from an enamel steel panel and has been severely damaged by rust. The advertisement is for a jeweller who operated on King Street in the 1880s. Little is know about the family other than they relocated theri watchmaking and jewelry business from Hagersville, $\mathrm{ON}$ in the late 1870 s.

\section{CHUM RADIO "SUPER STAR" ADVERTISING PIN}

CHUM has a long standing history in Toronto since its founding in 1945. For a long time, it was the number one station in its market. The station was acquired by CTVGlobalMedia in 2007 for $\$ 1.7 \mathrm{~B}$. The new owners vacated the building at 1331 Yonge Street to be sold for condo development. 


\section{PHOTO OF JANE STREET AND FINCH AVENUE WEST (1960)}

This photograph depicts the crossroads before the construction of housing complexes for low-income families. The development was intended to be a model for meeting the needs of a growing urban population but led to areas of poverty and isolation of immigrants. In recent years, community organizations have been working towards development and representation of neglected communities.

\section{LOUIS RIEL LETTER (1885)}

This letter was written by Louis Riel, the leader of the Metis people in Canadian West who led two rebellions against the Canadian government. This particular letter was written three days before the Battle of Batoche that resulted in his surrender to the Canadian Forces on May 15th 1885.

\section{CELLO}

A rare surviving piece from the mid-19th century of Toronto's musical history. The cello dates back to the same period that the city established their music scene with a growing number of performing groups, small auditoriums and the first Philharmonic Society. It is made of mahogany, maple and ebony. The label on the interior reads"K. Emery, Maker, Toronto, March 2nd, 1841, Pearson."

\section{INDUSTRIAL EXHIBITION ASSOCIATION OF TORONTO MANAGEMENT BADGE}

This badges dates back to before the exhibition was renamed to the Canadian National Exhibition. It was renamed to reflection the national importance of the fair.
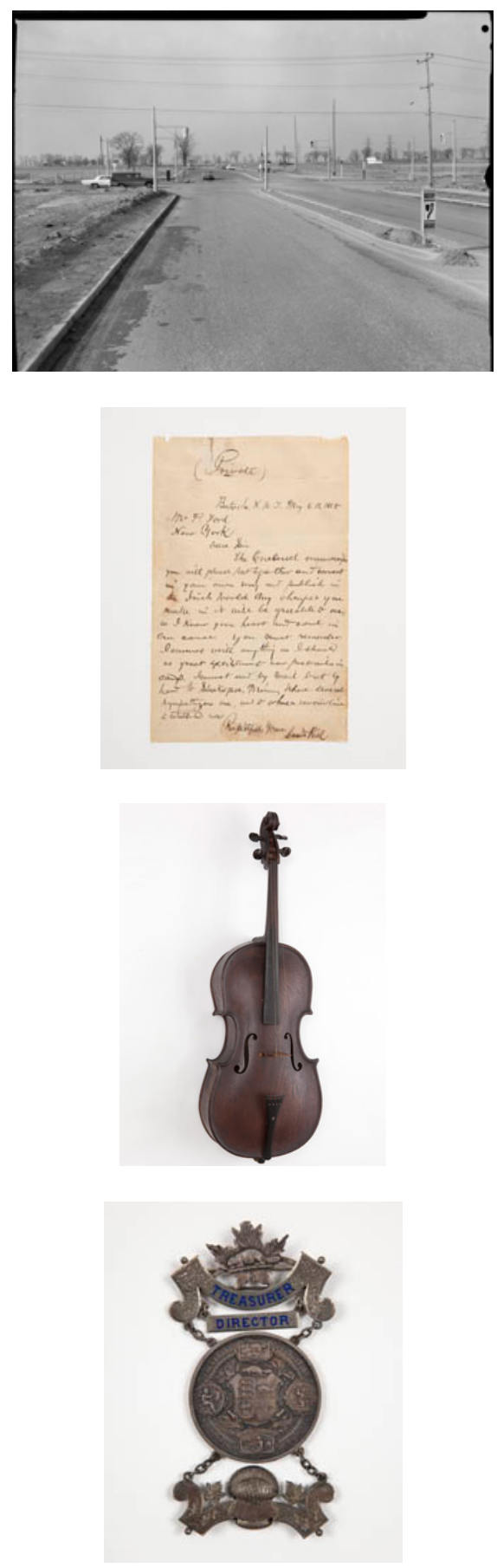


\section{1992 BLUE JAYS WORLD SERIES SOUVENIR COCA-COLA CAN}

Unopened, but empty, can from the 1992 World Series outlining the results of each game.

\section{BANARAS SAREE}

A traditional wedding garb for a bride in India, worn by the donor's mother in 1932. Most Saris are red as a symbol for fertility. Made of silk imported from China.

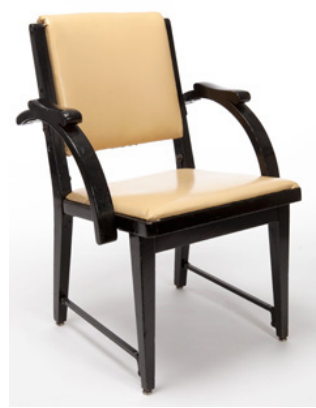

\section{EATON AUDITORIUM FOLDING CHAIR}

From the Eaton's Auditorium that opened on the 7th floor of the Eaton College building in 1931. It was designed in the Art Deco style by Jacques Carlu with a seating capacity of 1275. The auditorium closed in 1976 for commercial development but the Supreme Court of Canada prohibited demolotion in 1986 after a decade long debate. It was renamed the Carlu after a major restoration project in 2001.

\section{PROGRAM FOR CONCERT MAHILA JACKSON}

Programe for Mahalia Jackson concert at Massey Hall to benefit the Grant African Methodist Episopal Church. Mahalia Jackson was considered the Queen of Gospel music with 35 albums and six Grammy Awards. 


\section{DON VALLEY TORONTO VIADUCT CONSTRUCTION VIDEO}

The Don Valley Viaduct was a major achievement of its time as the main artery between East and West Toronto. The DVD recording of the Don Valley Toronto Viaduct construction was produced by James and Sons.

\section{PHOTOGRAPH OF NEGRO CHORAL SOCIETY (1950)}

Photo of donor, Betty C., and her sister at a performance of Gilbert and Sullivan's "Trial by Jury" as part of the Toronto Negro Choral Society's music repertoire. The Negro Choral Choir Society was founded in the 1940s at the British Methodist Episcopal Church on Shaw Street. It was founded by a small group of people of African descent that did not feel welcome in other churches. Photo taken by Ray McFadden of the Toronto Telegram.

\section{DAVID DUNLOP OBSERVATORY SOUVENIR LAPEL PIN}

David Dunlop Observatory opened as a research and teaching centre in 1935. Its $1.88 \mathrm{~m}$ telescope was the second largest in the world at the time. The site in Richmond Hill was eventually sold off in 2008 and the funds were used to create an endowment to establish the Dunlop Institute for Astronomy and Astrophysics in the Faculty of Arts and Science on the University of Toronto St. George Campus.

\section{HOLY BIBLE}

The family bible of William Lyon Mackenzie. The family bible was traditionally a place to record milestone events in the life of a family. It contains hand-written accounts of births, marriages and deaths in the Mackenzie family. It was published the same year as Mackenzie's illegitimate son, whose birth is not recorded, but there are signs of an erased entry by his mother, Elizabeth. Printed and bound in Edinburgh in 1814.
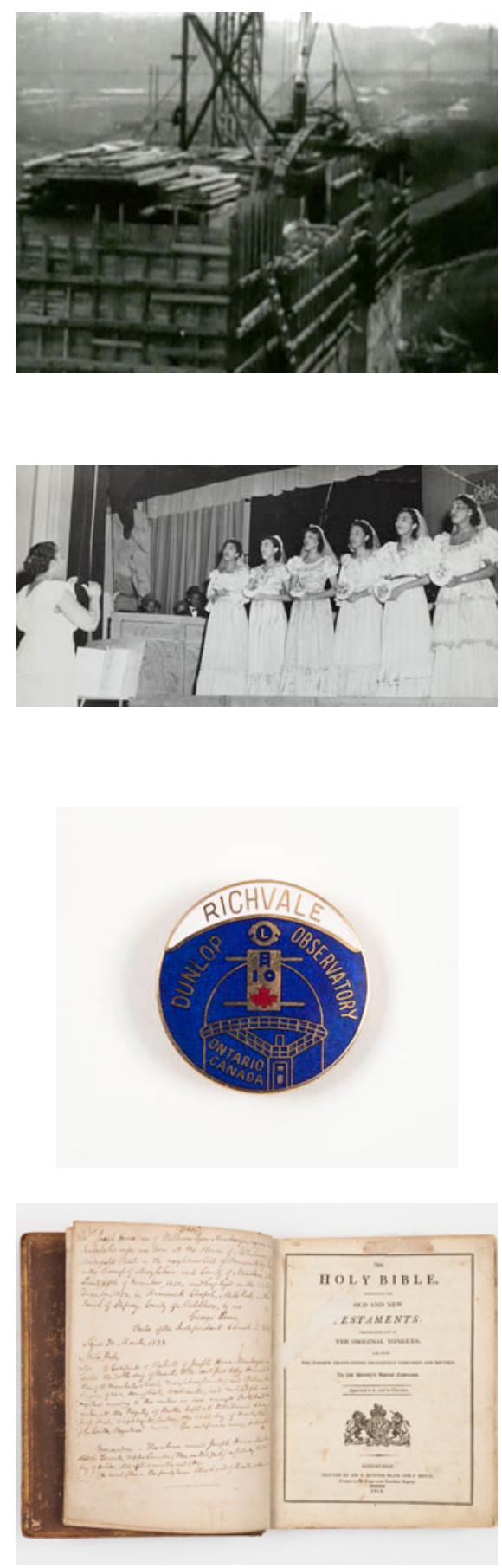

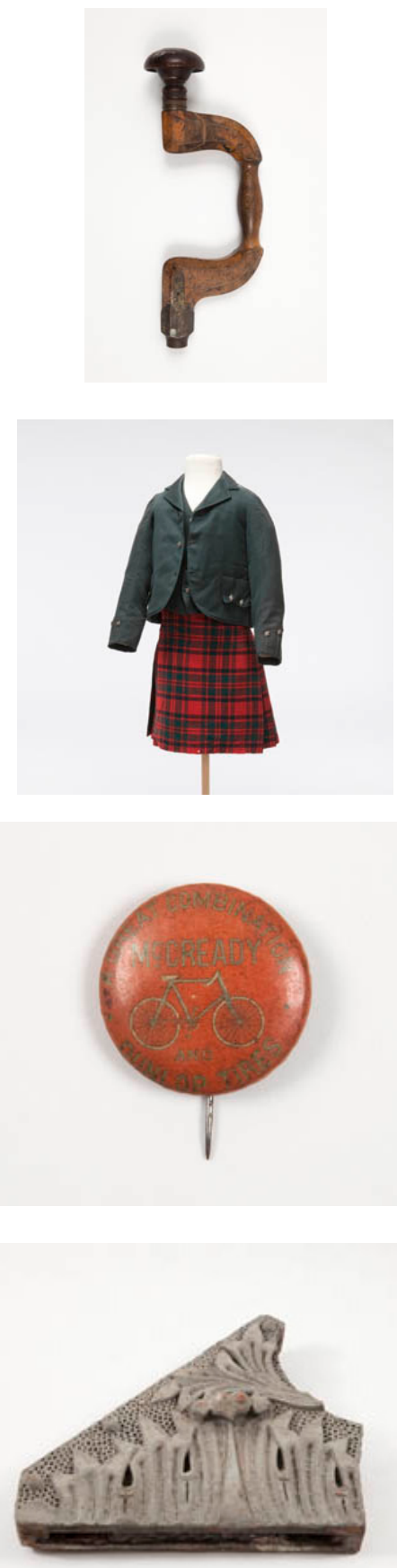

\section{CABINET MAKER'S BRACE}

Crankshaft made of beech and walnut wood with a spring loaded brass chuck. Belonged to William Burke who patterned to create Smith, Burke and Company, a company operating from 1822-1899. The company operated a planing mill and chassis factory but moved into other services, and were part of the construction of the Crystal Palace and steam mill and distillery of Gooderham and Worts. Burke sold construction materials and was father to Edmund Burke, a notorious Toronto architect

\section{HIGHLAND DRESS}

Product of John Catto who emigrated form Fraserburgh, Scotland in 1883 to St. Johns, Newfoundland. He settled in Toronto in 1854 and worked in the shop of Peter Paterson, who was the leading merchant of dry goods at the time. He opened his shop on King Street East in 1864 and introduced Canadian consumers to Scottish garb, imported directly from Scotland. He remained in his shop for 46 years until he was forcibly vacated to Yonge and Shuter after the King Edward Hotel expansion.

\section{GREAT COMBINATION MCCREADY \& DUNLOP TIRES}

In 1887, Scottish veterinarian inverted the pneumatic bicycle tire. The patent was sold to Harvey Cross Jr who stated Dunlop Pneumatic Tyre Co. Ltd. and contributed to the explosion of interest in bicycling beginning in the 1890s. The advertising button is made of celluloid.

\section{ARCHITECTURAL BAS-RELIEF TERRACOTTA PANEL}

Molded and laminated terracotta fragment as part of a frieze with traces of green-grey paint. Part of the City of Toronto's private collection. It originated from a house designed by EJ Lennox near Church and Gerrard. Lennox also designed Casa Loma, King Edward Hotel and Old City Hall. 


\section{ARPILLERA, EXILE \& SOLIDARITY}

Made in reference to the Welcome House in Toronto which facilitated the settlement needs of new immigrants to Toronto. In Chile, arpilleras are used as a form of social and political protest. Women used any materials that were left of deceased family members to remember them. Arpilleras came to symbolize women's quiet protest and activism against Augusto Pinochet's dictatorship.

\section{PHOTOGRAPH OF BANK OF MONTREAL}

Black and white photo of the Bank of Montreal Building at Front and Yonge Street in the early 1900s. The ornate beaux-arts building held most powerful Canadian bank of the 19th century and served as downtown branch when it opened in 1847 until 1983. The buildign became part of the Hockey Hall of Fame at BCE Place in 1993. Taken by Alexander W. Galbraith.

\section{COPY BOOK OF DEEDS, INDIAN TREATIES}

Copy of deeds and provisional agreements for the cession of lands in Upper Canada signed by chiefs of the Chippewa and Mississauga tribes and representatives of Great Britain. When the British purchased the Toronto region from the Mississaugas in 1787, they acquired inland territory stretching back 45 kilometres from the north shore of Lake Ontario.

\section{BEADED DRESS TRAIN}

A pink velvet dress decorated in floral and swag pattern with rhinestones, sequins and several types of beads. Part of a formal outfit worn by Flora McCrea Eaton when her retail merchant husband John Craig Eaton was knight in 1915. The collection features a matching feather fan and headdress.
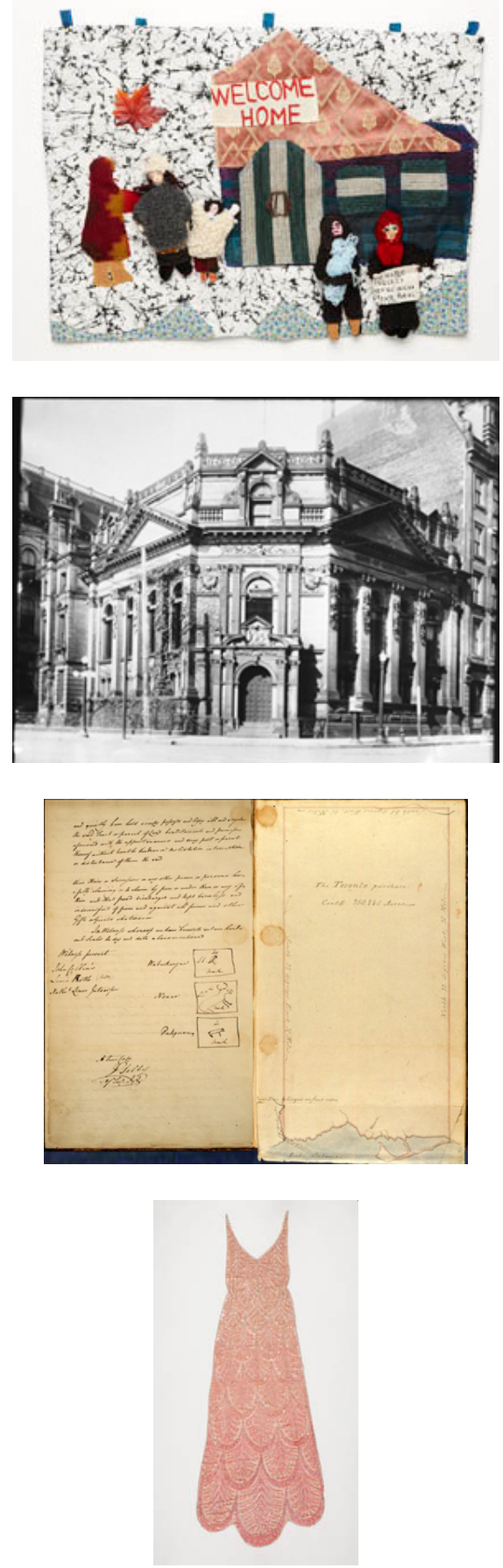


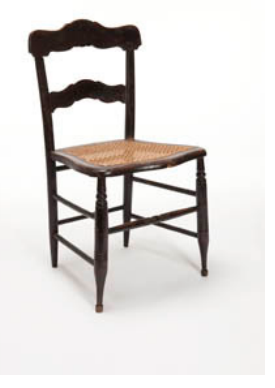

\section{C. HATCH \& CO. PAINTED SIDE CHAIR}

Chester Hatch began the successful chair-making business in Kingston, ON in 1815 and operated a showroom in Toronto in 1821. American competition forced him to declare bankruptcy in 1847. Began making chairs with his son from imported prefabricated parts to undercut imported furniture. This is one in a pair of black painted pine chairs decoratd in gold outlining, caned seat and box stretchers.

\section{WILLIAM JARVIS' QUEEN'S RANGERS UNIFORM JACKET}

Captain's uniform of Queen's Rangers made of green wool with black velvet collar, cuffs, and lapels with embroidered silver lace epaulettes and buttons. William Jarvis was a cavalry officer in Queen's Rangers under John Graves Simcoe during the American Revolution. The uniform dates back to the reinstatement of regiment following Simcoe being appointed Lieutenant Governor of Upper Canada in 1791 when Jarvis became Provincial Secretary. Donated to the City of Toronto collection by Jarvis' descendants in 1964.

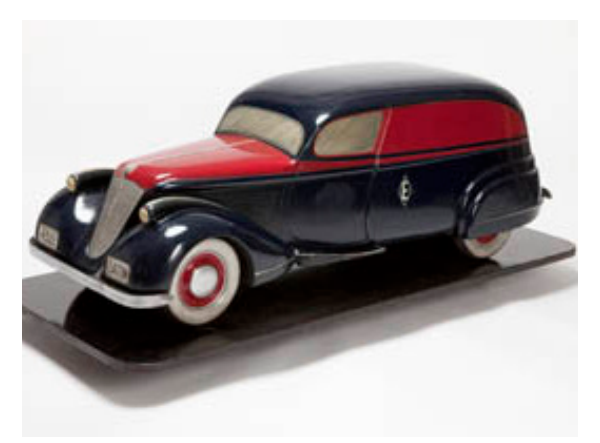

\section{EATON DELIVERY VAN MODEL}

Model of a delivery van, painted blue, red with a chrome bumper. T. Eaton Compant was the first to employ motorized vehicles in 1911 and by 1919 had a fleet of 66 vehicles to carry out the delivery of goods and furniture to the suburbs.

\section{BLACK BALLET SLIPPERS}

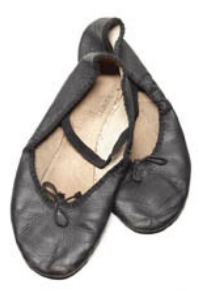

Black ballet slippers made of leather with suede soles, elastic strap and drawstrings. In 1976, the Markowitz family opened the first Capezio store in Toronto, carrying the most appropriate shoes and attire for dance. In 1978, a second store was opened on Bloor Street near Bay Street. 


\section{JESUITS ESTATES CRISIS MEDAL}

Silver plated medal depicts The Mail motto "Equal Rights for All". The reverse has the names of 13 Members of Parliament, and date March 28th 1889, who voted to disallow Quebec's 1888 Jesuits' Estates Act. The act would have compensated the Jesuit Order for estates confiscated in the 18th century. MPs were supported as part of a Protestant, anti-Quebec nationalist campaign undertaken by The Mail newspaper.

\section{LEE LUNG SAI ASSOCIATION LOAN AGREEMENT}

A rare surviving document from Toronto's Chinese community in the early 20th century. The Chinese community was firmly established on Bay between Queen and Dundas by the 1920s but was forced to move westward to Spadina Avenue due to construction of New City Hall. The Agreement for the loan is in the amount of $\$ 300$ and is signed and dated December 19th 1923, 55 Elizabeth Street Toronto.

\section{VICTORIAN SILVER BABY RATTLE}

English silver baby rattle with whistle, bells, and coral pacifier. Made in the same year Timothy Eaton started his famous catalogue in 1884. Engraved monogram "WGE/1886" and maker's mark "H\&T". The date implies its intention as a Christening gift for a member of the Eaton family.

\section{DABQAAD, SOMALI INCENSE BURNER}

Traditional Somali pots are made of clay or soapstone and used to burn incense, such as olive oil, in houses in Somalia. This particular pot is made of clay, and was crafted in Elbur, Somalia. They are lit after meals and on special occasions and believed to remove evil spirits.
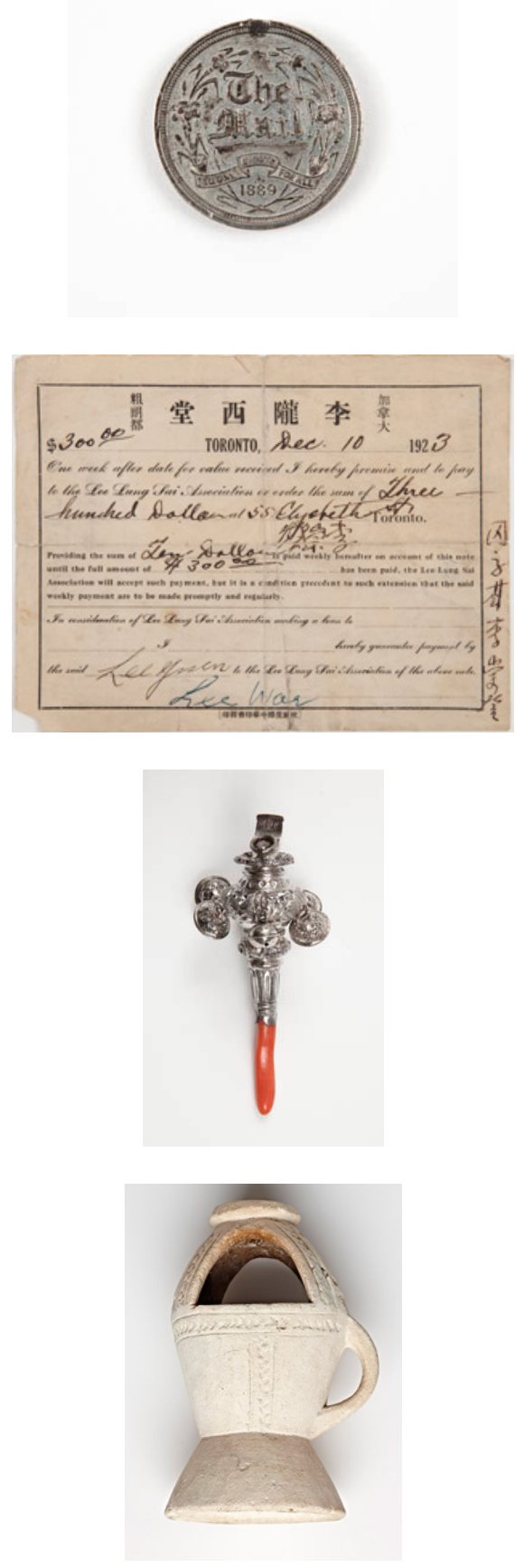


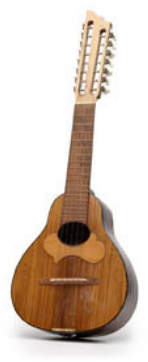

\section{MANDOLIN}

Constructed in the 1950s in Ecuador by prominent builder Don Vicente Baculima who believed instruments should only be crafted from tree trunks that are a minimum of 100 years old. This mandolin is made of walnut and cedar. Once its form was crafted, it was left to dry for several years before being hand finished.

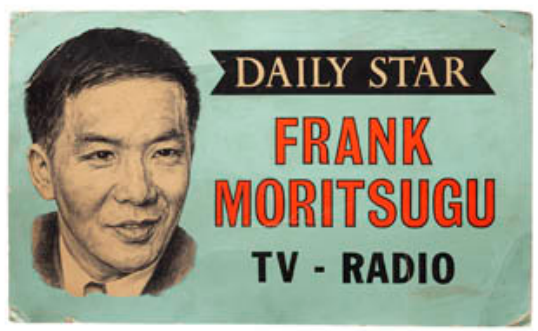

\section{TTC POSTER PROMOTING TORONTO STAR COLUMNIST}

Cardboard poster depicting the portrait of the first Japanese Canadian columnist hired by the Toronto Star, Frank Moritsugu. The poster was shown in 1964 on delivery trucks and streetcars.

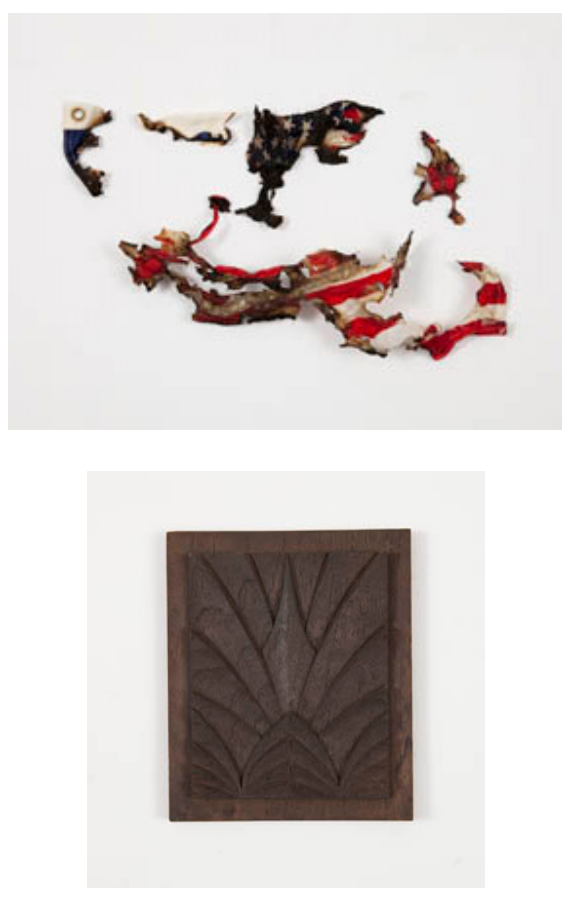

\section{FLAG OF THE UNITED STATES OF AMERICA}

Charred and melted remains of a nylon flag burned on August 27th, 1971 by Anti-Vietnam War protestors outside the Officer's Mess at Fort York National Historic Site.

\section{ART DECO ARCHITECTURAL PATTERN BLOCK}

Hand carved oak architectural mould pattern block depicting an art deco geometry. Created and used by McCormack and Carroll, woodcarvers and interior artisans. Their company's work can be found on many Toronto homes and buildings. Their works can still be seen on the Ontario Legistlative Building, University College and Osgoode Hall. 


\section{SMITH FAMILY MOVIES: SPADINA GARDEN}

Amateur 16mm film taken by the family of Nathan Smith in 1931-32.

Depicts family footage in 5 sets at their home or in parkland around the city. Nathan Smith was a prominent merchant and philanthropist who founded the N. Smith Belting Works.

\section{AVRO AIRCRAFT UNVEILING PROGRAMME}

Programme for the Avro Arrow unveiling in Malton, ON on October 4, 1957. The Avro Canada CF-105 Arrow was a supersonic fighter plane as part of Canada's contribution to the North American defence system. It suffered from rising manufacturing costs and the lack of foreign sales from the Allies. All technical data was destroyed and over 15000 of Toronto's manufacturing jobs were lost in the process.

\section{HEAD TAX CERTIFICATE TO HARVEY LOW'S GRANDFATHER}

A head tax was required of all people of Chinese descent to prove that they paid to enter Canada. The tax was introduced in 1885 to dissuade Chinese immigrants from coming to Canada. The government did not keep copies and very few were publicly donated. Despite the tax, an increased number of immigrants resulted in the Chinese Immigration Act or Exclusionary Act in 1924 which limited entry of Chinese immigrants between 1923 and 1947.

\section{DUNSMORE PIPE}

A ceramic pipe of a human-wolf effigy that belonged to ancestral HuronWendat that occupied a site northeast of Toronto. The woodpecker pipe is made of limestone. Part of over 100,000 other artifacts that were recovered

from the site.
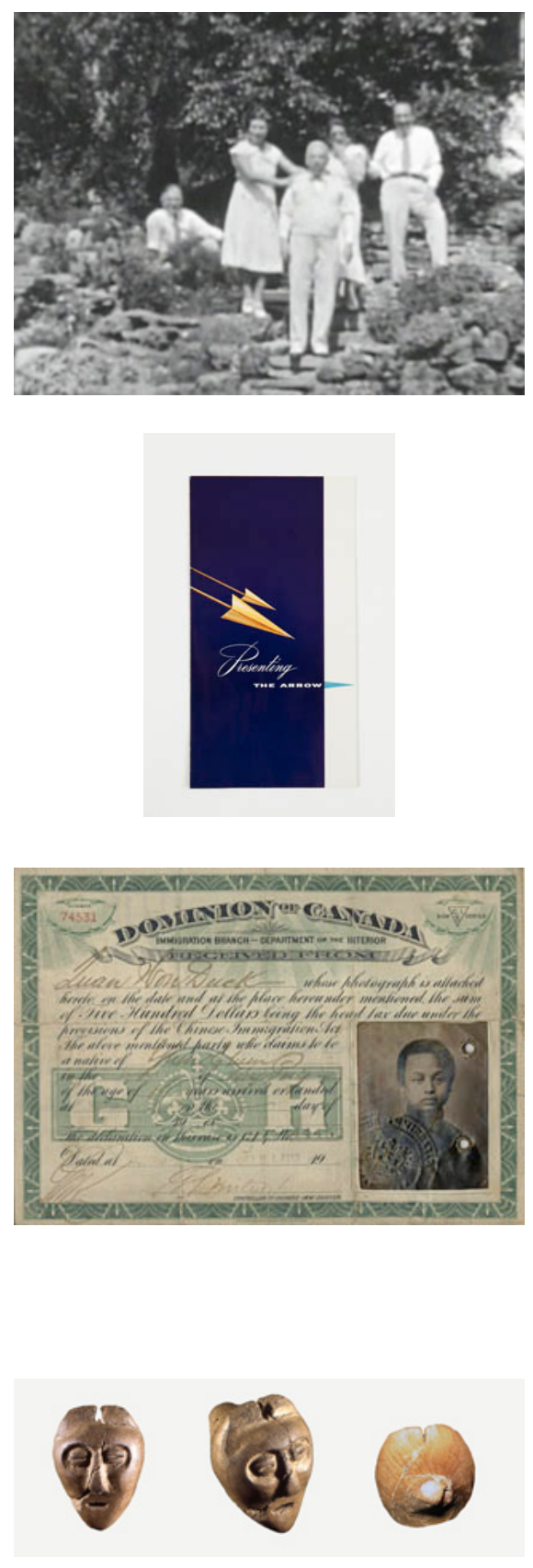


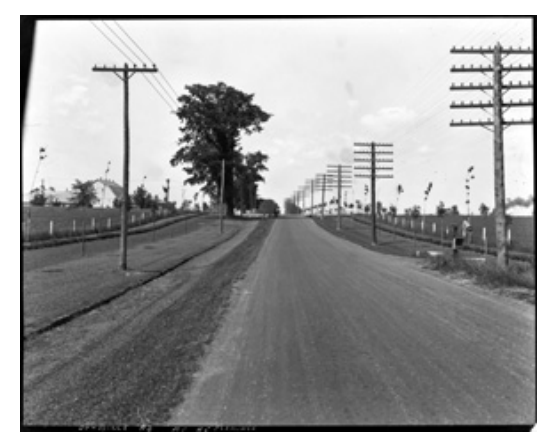

\section{PHOTOGRAPH OF DON MILLS ROAD (1925)}

Photograph depicts the area now known as Flemingdon and Flemingdon Park, named after RJ Fleming whose farm was bought in 1958 to create the high-density development. The planned apartment city was to accommodate for the immigrants coming to Canada after World War II. Fleming was a former mayor of Toronto in the late 1800s.

\section{COFFEE POT}

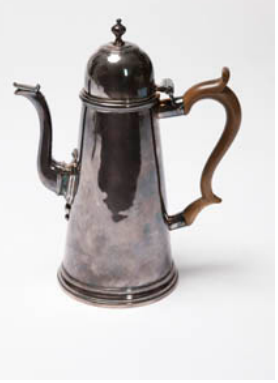

A silver coffee pot of Queen Anne design. Made to Britannia standard in London.

\section{CANADIAN KODAK COMPANY LTD. GRADUATED CYLINDER}

Canadian Kodak Company Ltd was founded in 1899 and held production facilities manufacturing photographic films, papers and equipment for over a century in Toronto. The rise of digital photography made these tools obsolete, forcing the closure of these manufacturing facilities in 2004.

\section{CANADA AND LIQUOR CONTROL PAMPHLET}

Ontario passed prohibition law in 1916. This was largely abandoned in 1927 when the LCBO began regulating the sale of alcohol. 


\section{PHOTOGRAPH OF BANK OF COMMERCE AND DOWNTOWN (1930)}

Photo taken from the Royal York Hotel in 1930. It depicts one of the tallest buildings in Toronto's financial and central business district in the British Commonwealth in 1962. Captured at the height of the Great Depression.

\section{AGRICULTURAL ASSOCIATION OF UPPER CANADA MEDAL}

Earliest known example of a silver medal for this Exhibiton that took place in Toronto in 1846. It was awarded in recognition for encouraging domestic manufacturing and promoting useful inventions to improve all aspects of the rural and domestic economy. Run by the Provincial Agricultural Association and Board of Agriculture for Canada West. The Exhibition would rotate annually through Ontario towns. In 1879, Toronto would organize its own show based on this model, and developed into the CNE.

\section{FOLK ART CHAIR OF MEL EASTMAN}

A whimsical folk art chair with the image of Mel Eastman, mayor of Toronto from 1997-2003 painted onto it. It was presented to him by Kingsboro Taxi on behalf of the taxi industry in 2000 .

\section{PLAN OF HIGH PARK MAP}

In 1873 architect, engineer and artist John Howard and wife donated his estate, High Park, to the city including the agreement that the park remain free, free of alcohol, and reserved for the use and benefit to the enjoyment of the citizens of Toronto. In 1876 and 1930, City purchased more land bringing land total to 37 hectares. Howard and his wife are buried under monument overlooking Grenadier Park. Artist is John George Howard, in ink and watercolour of a cartographic plan of High Park and surrounding area.
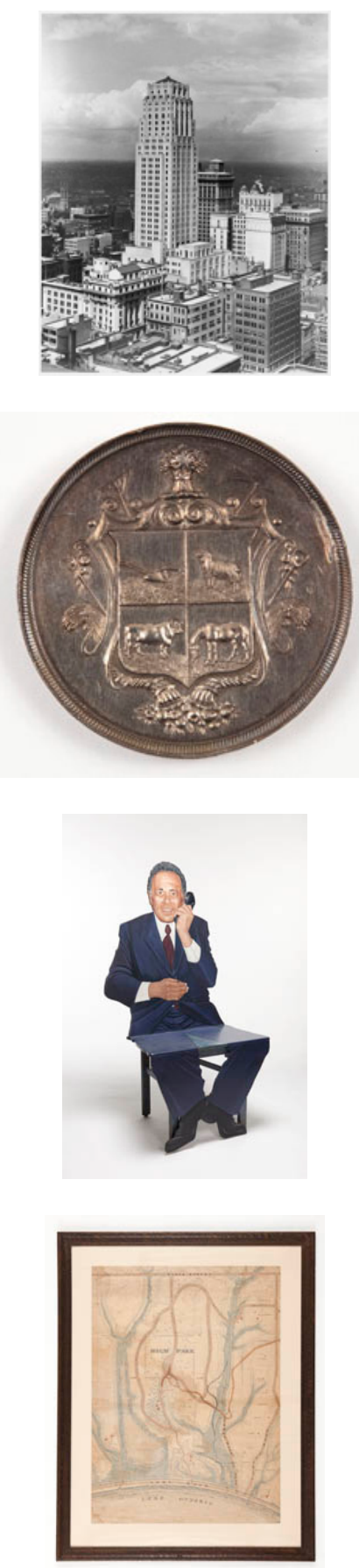


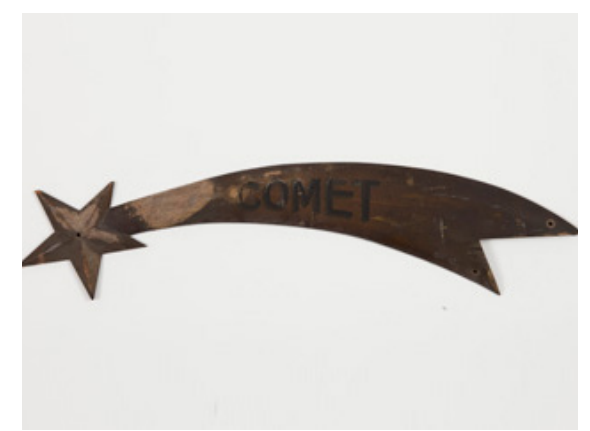

\section{ICEBOAT COMET NAME PLATE}

Name plate for the Toronto Harbour sailing Iceboat Comet. Comet was one of the many iceboats that sailed the frozen surface of the Toronto Bay in the 19th and early 20th century. It served as a ferry to Toronto Island, ice patrol and rescue by the Toronto Lifesaving and Police Patrol and Toronto Harbour Police. Was one of the bigger iceboats used in Toronto and could carry a dozen passengers traveling up to $100 \mathrm{~km} / \mathrm{h}$.

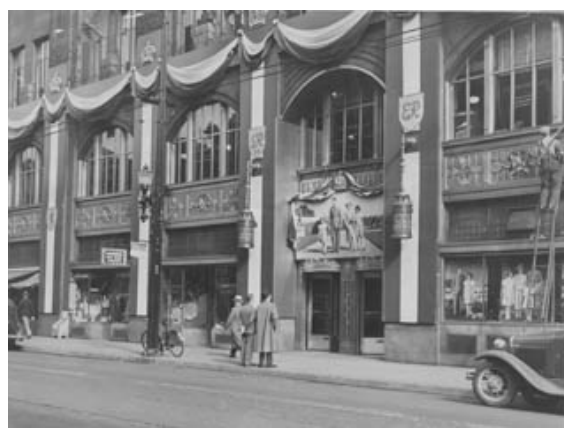

\section{BRONZE SCONCES}

Two bronze sconces decorating the exterior facade of 80 King Street West, the Toronto Star building. Demolished in 1972 to make way for First Canadian Place.

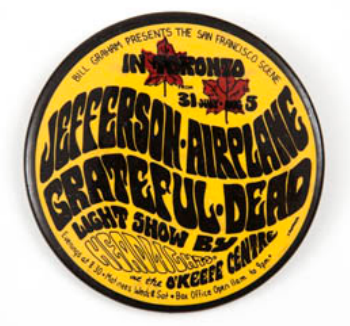

\section{JEFFERSON AIRPLANE AND GRATEFUL DEAD CONCERT BUTTON}

The original concerts took place July 31 to August 5 at OKeefe Centre for the Performing Arts at Yonge and Front. Also the long time home to the National Ballet of Canada and Canadian Opera Company until 2006. Renamed in 1996 to Hummingbird Communications after Canadian software Company. Renamed again in 2007 to Sony Centre for the Performing Arts when it was bought again.

\section{S. PRICE \& SONS MILK TOKEN}

Circular stamped aluminum token with scalloped edge. Empty milk bottles and milk tokens were left outside to be collected. The tokens were used as they were less likely to be stolen than by money. In the 1960s, cars were uncommon and stores were far away, so milk delivery was very convenient. Milkmen would also bring cheese and eggs. 


\section{METRO SANTA CLAUS PARADE BUTTON}

White plastic circular button printed in red and black with a stem on the back. Front depicts Santa on the left with an outstretched arm toward the city on the horizon. In 1982, the parade was almost cancelled due to financial constraints of T. Eaton Co since its first show in 1905. Two companies offered to sponsor the event to continue the tradition that marks the first day of winter in Toronto.

\section{PHOTOGRAPH OF BATHERS AND CARS IN HUMBER RIVER}

Depicts bathers in the Humber River. Also captues people washing their cars in the river. Photo taken in 1922 by William James.

\section{PAPER SHOPPING BAG}

Festa Italiana was a T. Eaton Company sales promotion that ran from October 7-17, 9164. It was done in recognition of the Italian community as part of the growing multicultural nature of Toronto since World War II.

\section{BEAVER'S 204th SHAM BATTLE IN HIGH PARK VIDEO}

DVD footage of a re-enactment in 1915 when World War I had begun and men of the 204th infantry Battalion (the Beavers) Canadian Expeditionary Force went into battle.
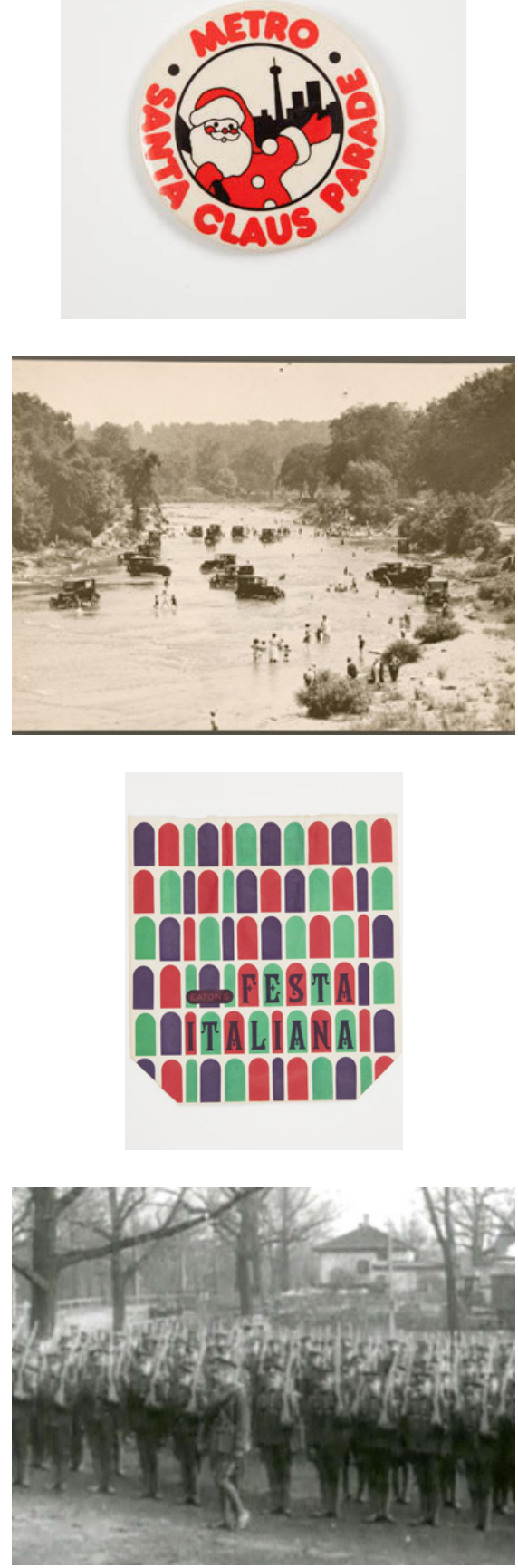

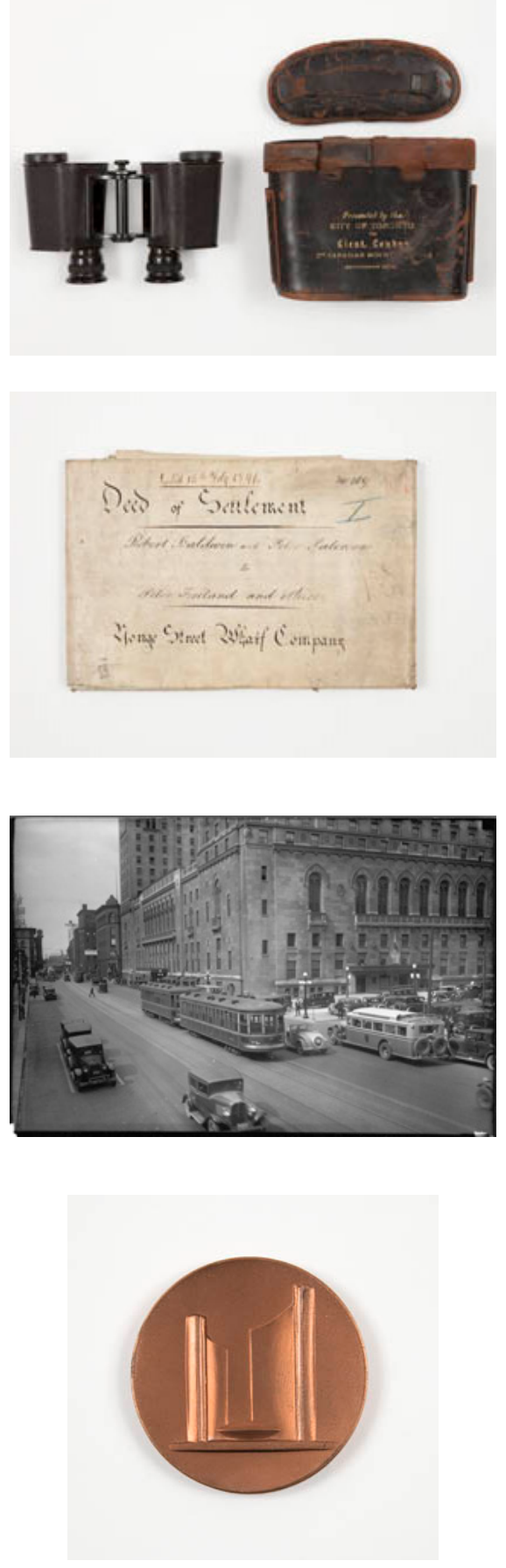

\section{BOER WAR PRESENTATION BINOCULARS}

Lieutenant Walter John Loudon (1880-1921) served in both the Second Boer War and First World War. He joined the 2nd Regiment, Canadian Mounted Rifles and departed Canada for South Africa as part of the 5th Contingent in January, 1902 and was presented with these binoculars by the City of Toronto on his return. Zeiss-Stereo Day Marine Class 12 power binoculars made by Bausch and Lomb Optical Company.

\section{DEED OF SETTLEMENT, ROBERT BALDWIN AND PETER PATERSON TO PETER FREELAND AND OTHERS}

In the 1830s, Peter Freeland began assembling water lots and water front property to expand his trade that would go onto create the Yonge Street Wharf Company in 1841. This document sets out rules governing construction of wharf and buildings, operations of joint-stock, number of stock of each investor, and the appointment of Baldwin and Paterson as trustees.

\section{PHOTOGRAPH OF ROYAL YORK HOTEL (1930)}

The Royal York was designed by Montreal architecture firm Ross and Macdonald and assisted by Toronto office, Sproatt and Rolph. The art deco hotel opened in 1929 and hosted celebrities and members of the royal family. The photo, taken in 1930, captures the spirit of a moment captivated by all things modern: machines and concrete.

\section{TORONTO CITY HALL OPENING COMMEMORATIVE MEDAL}

Circular copper medal commemorating the opening of the new City Hall. 


\section{DUGOUT CANOE}

Long-nose Ojibway-style canoe, distinctive of its profile. It was made by Chippewa members near Bear Island circa 1850. Bark canoes provided Native people with a lightweight vessel that was easily repairable.

\section{PHOTOGRAPH OF REPLICA MURAL PAINTING DEPICTING THE HISTORY OF THE SCRAP METAL INDUSTRY IN TORONTO}

Depicts the history of the scrap metal industry in Toronto since the early 20th century. A photo of a duplicate mural that was commissioned by Leon Kaminsky to commemorate the Jewish community's contribution to the industry. Uldis Gallis and Harry Pavelson were two local artists commissioned for the mural. The original was painted on the sides of the scrap metal business building on Eastern Avenue.

\section{VICTORIAN CHILD'S ROCKING CHAIR}

Believed to have belonged to Laura Secord, known for her famous walk to warn British General James FitzGibbon on an impending American attack at the Beaver Dams during the War of 1812. Laura was in her 60s when the chair was made, and likely used by her grandchildren. Made of a dark walnut stained butternut frame with drop seat and tall back and curved arms. Reupholstered in striped floral.

\section{THE CHAMPION SCULLER'S RETURN FROM ENGLAND, 1879}

Depicts Toronto harbour and triumphal return of Edward Hanlan to Toronto following his defeat of the English rowing champion W. Elliot in 1879. Hanlan would go onto become the world sculling champion for 5 consecutive years. Watercolour on paper by William Armstrong of Hanlan's Point.
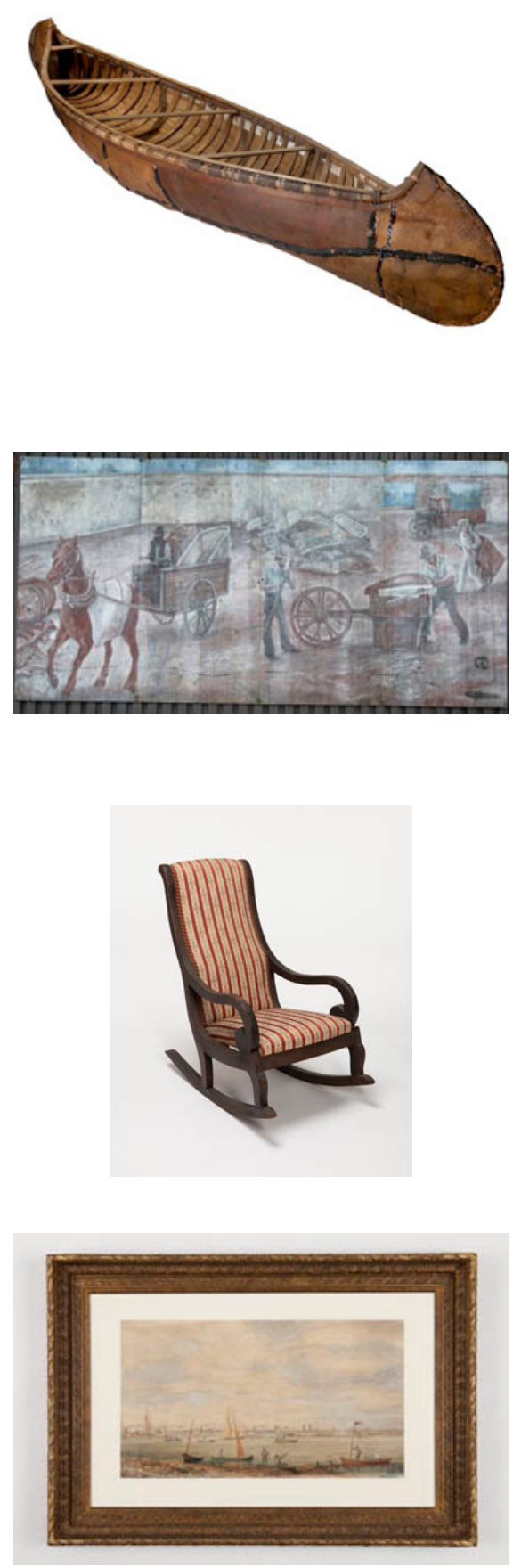

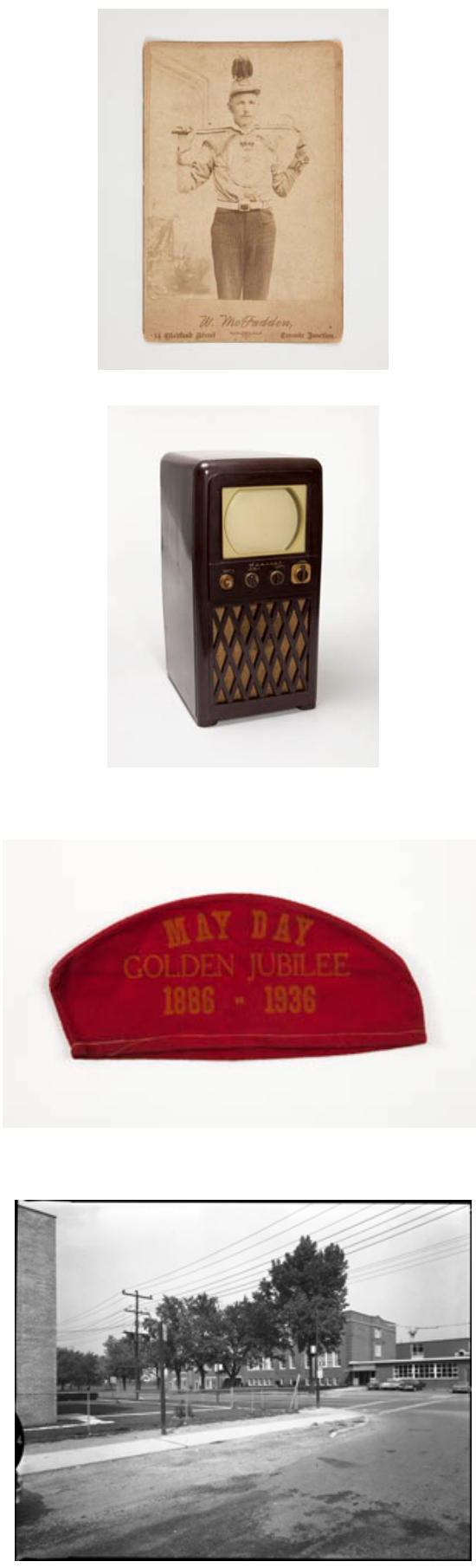

\section{PHOTOGRAPH OF WEST TORONTO JUNCTION VOLUNTEER FIREMAN}

The Village of West Toronto Junction was founded in 1884 and annexed by the City of Toronto in 1909. The area had a manufacturing boom in the late 1800s including Canadian Cycle and Moto and Heintzman Piano because of the low cost of land, labour and taxes than in Toronto. At the same time the area became more ethnically diverse first attracting Irish Catholics, then Italians, Croatian, Poland, Malta and Macedonia. WM McFadden listed as the photographer between 1891-93.

\section{10-INCH SCREEN TELEVISION WITH BAKELITE CASE}

By the end of 1951, around 70000 televisions sold in Canada, but there were no Canadian broadcasters until Sept 1952 when CBC and RadioCanada TV, CBLT-Toronto and CBFT-Montreal were launched. The launch was initially delayed a year due to lack of equipment resulting from Korean War.

\section{MAY DAY SOUVENIR CAP}

Formed in1921, the Communist Part of Canada pushed for labour issues following WWI. They supported and organized rallies such as the May Day Parade, which this hat was produced for. Supporters were banned from gathering publicly until 1924 and often were successful at mobilizing unemployed Torontonians affected by the Depression. Wedge-type red felt wool hat with yellow stencilling.

\section{PHOTOGRAPH OF MIDLAND AVENUE \& AYLESWORTH DRIVE (1960s)}

Toronto based photo studio, Alexandra Studio, was commissioned by the government to document various schools in the Toronto area. Taken in the 1960s. 


\section{GREAT TORONTO FIRE VIDEO}

DVD footage of Toronto firefighters racing to put out a fire at Bay and Wellington Street on April 19th, 1904 at 8:09PM. The earliest known footage on Toronto streets. The fire began in E. \& S. Currie's neckwear factory on Welling St, and destroyed the commercial and warehouse district between Bay, Wellington, Yonge and Front and land currently occupied by Union Station. The fire lasted 9 hours across 20 acres, in which 5000 jobs were temporarily lost, with one casualty.

\section{THIRTY-SEVEN WELFARE ORGANIZATIONS ASK YOUR HELP! BROADSIDE}

A breakdown of how money donated is divided among members of the Federation for Community Service. Signed by 5 religious leaders from Toronto churches. This plea of assistance is dated some time in the Great Depression in the 1930s. In 1933, 27\% of Canadian population was unemployed and $20 \%$ was dependant on government assistance.

\section{PASTEURIZED MILK BOTTLE, HOSPITAL FOR SICK CHILDREN}

The Hospital for Sick Children is recognized as one of the world's leading paediatric hospitals, originally founded in 1875 and established a series of downtown homes. Under the patronage of newspaper publisher, John Ross Robertson, the city's first milk pasteurization plant was financed. Cylindrical glass bottle with a chipped edge, with graduation and stamped "Hostpital/ For Sick Children".

\section{PHOTOGRAPH OF LINEMEN OF HYDRO POWER SYSTEM (1910)}

Depicts linemen of hydroelectric system erecting a post on Mutual Street on July 25th, 1910. Taken 3 years after Toronto City Council approved development and public ownership of a hydroelectric system. In 1910 a Toronto engineering section adopted the name Toronto Hydro-Electric System.
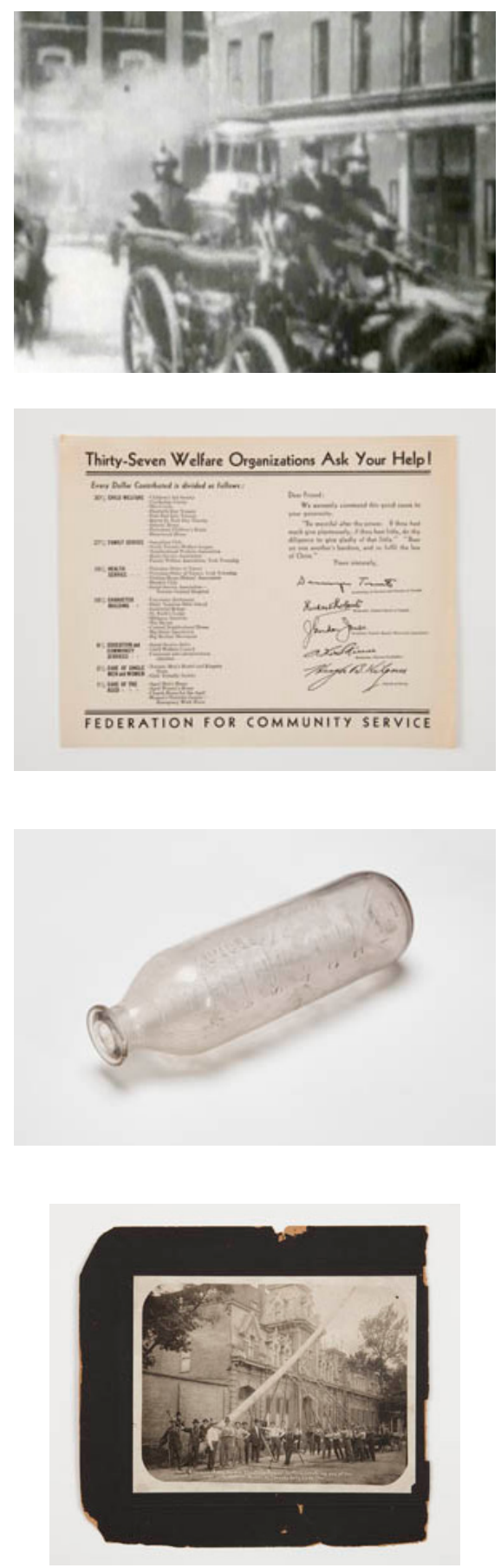


\section{ALGONQUIN-STYLE BIRCH BARK CANOE}

Model of Algonquin-style birch bark canoe made with traditional materials and techniques. One in a set of three traditionally construction model canoes created for the Marine Museum of Upper Canada by Chief Matt Bernard of the Pikwakanagan Indian Reserve, Golden Lake, Ontario.

\section{SYLLABUS OF PHYSICAL EXERCISE FOR SCHOOLS}

Until 1950, cadet corps were common features of secondary schools in Toronto. The Canadian High Commissioner of Britain created an endowment of $\$ 500,000$ to introduce physical training in the public school curriculum. Published by the Executive Council, Strathcona Trust, 1911.

\section{1962 ST. MICHAELS COLLEGE HOCKEY JERSEY}

St. Michaels College has had a hockey team since 1906, and the same jersey style has been worn by their various other sports teams with very minimal design changes. Blue and white wool hockey jersey with cottoned monogram M, worn by the school's hockey team since the 1950s.

\section{SAVE ISLAND HOMES BUTTON}

In 1931, the City of Toronto agreed to allow permanent homes to be built on Toronto Islands. By 1960, communities on Centre and Hanlan's Island were demolished and in 1963 plans to remove the remaining homes to create a giant park were met with resistance. After 30 years, in 1993, Toronto Islands Residential Community Trust was established allowing 99 year land leases for residents. 


\section{LUNCH MENU FROM THE SS NORONIC}

Built in 1913, the SS Nordic was one of the most popular passenger vessels that traveled across the Great Lakes. A fire on September 17 1949, during a stop over from Detroit, a fire broke out and destroyed the ship killing over 100 passengers, ending all passenger transportation on the Great Lakes. Lunch menu containing 4 pages and 3 resort drawings with a cooler portrait of Etienne Brule and a map. Mentions respect for rationing in time of war.

\section{RIFLE COMPANY MILITARY UNIFORM}

Uniform for a lieutenant in the 2nd Leeds Militia, Rifle Company, Upper Canada and rare surviving artifact from War of 1812. Accompanying note saying it was worn by Lt. Levi Soper and donated on the 100th anniversary of the war. The style suggests it was of American origin, from New York militia unit and retailed for a new owner in Canada. Olive green wool tunic with black velvet collar, cuffs and lapels

\section{WOODPECKER EFFIGY PIPE BOWL}

A 500 year old effigy pipe bowl made of limestone and recovered from Mantle site, located northeast of Toronto. The ancestral Huron-Wendat, early 16th century Mantle site was occupied by approximately 2000 people. The site is the largest and most complex Huron site to be excavated. Over 100000 artifacts were recovered.

\section{IMMIGRATION IDENTIFICATION CARD}

From 1928-1971, Pier 21 was the gateway to Canada and counterpart to Ellis Island in New York. The port welcomed over one million immigrants over a period of 40 years. In the late 1940s and 1950s, many displaced persons and refugees arrived in Halifax due to WWII. Official immigration document for immigrants admitted to Pier 21 in Halifax. Contains stamp dating from 1953 and mentions Saturnia, a vessel that transported new immigrants from the Mediterranean countries, in this case Naples, Italy to Canada.
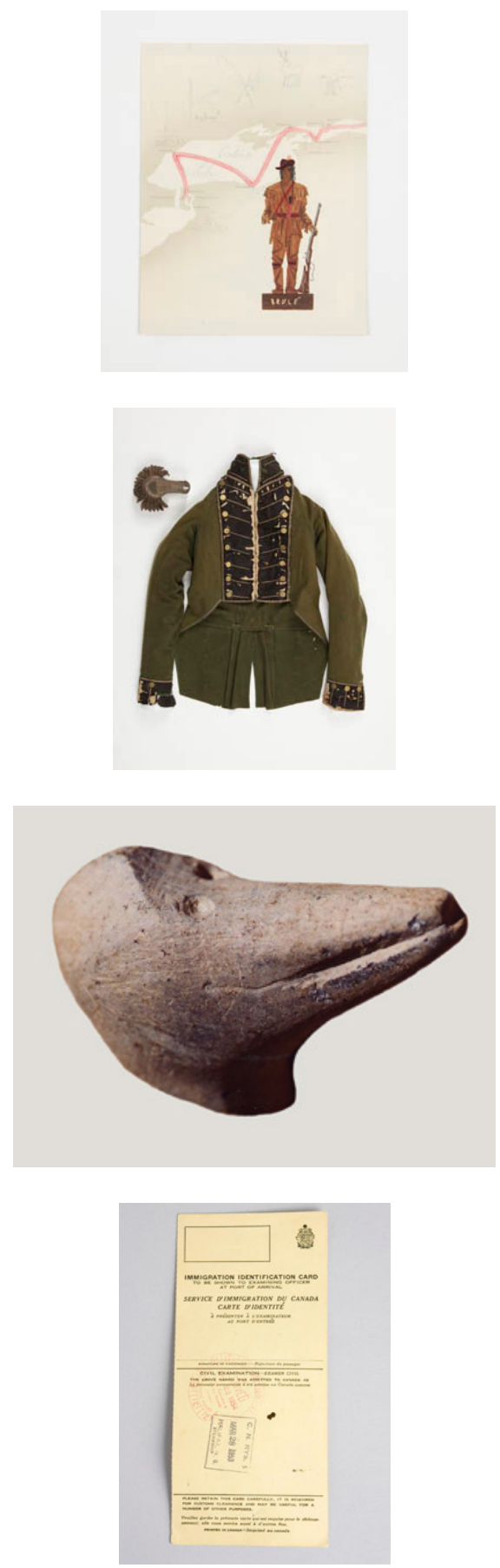

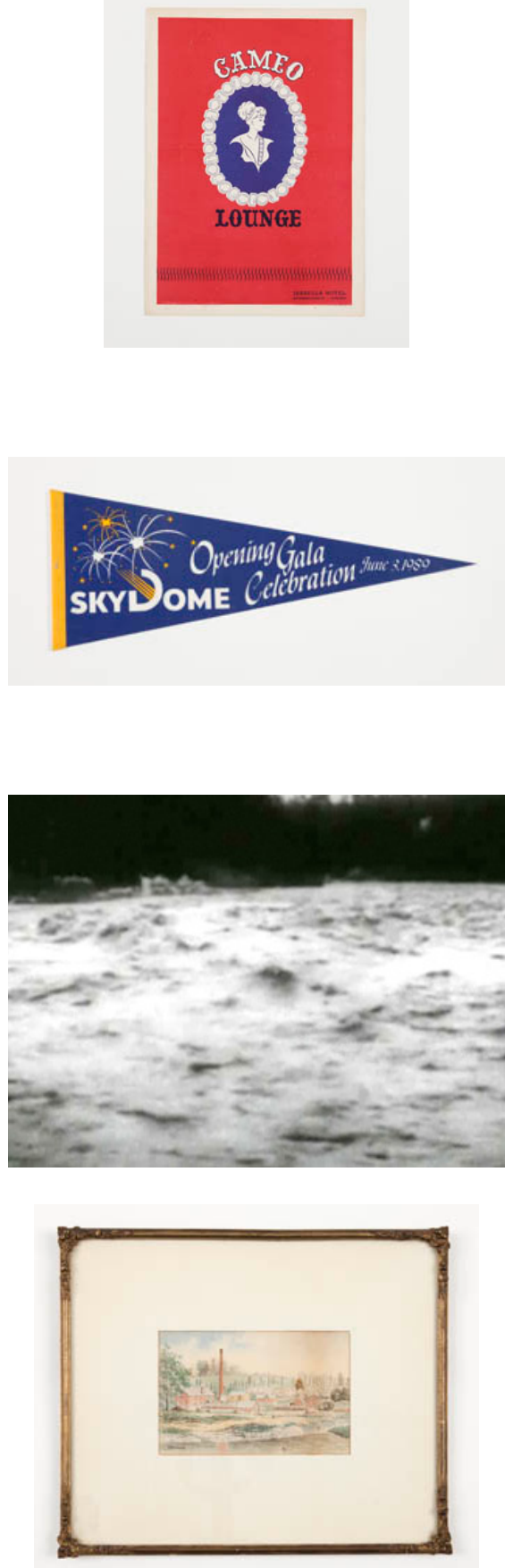

\section{CAMEO LOUNGE DRINKS MENU}

A drink menu from the Cameo Lounge at Hotel Isabella, Toronto. In the 70s and 80s, Cameo Lounge was the centre of the Toronto Blues scene. The original manor built on Sherbourne Street in 1891 expereince difficult times along with the neighbourhood, and the monument has since become a hotel. Menu includes colour illustrations of drinks and price list.

\section{SKYDOME OPENING GALA CELEBRATIONS SOUVENIR PENNANT}

The Skydome opened on June 3, 1989 to the public and two days later the Blue Jays played their first home opener. The stadium ran into financial difficulty in 1988 and was forced into bankruptcy protection before being purchased by Rogers Communications in 2005 and renamed the Rogers Centre.

\section{HUMBER RIVER FLOODS VIDEO}

Depicts the weather effocts on the Humber River Bridge in 1916 where ice flow carries parts of the bridge away. The Humber Bridge had just been completed during the time of footage.

\section{VIEW OF TODMORDEN MILLS WATERCOLOUR (1900)}

Todmorden Mills Heritage Museum and Arts Centre is a complex of historic buildings, once part of a small industrial community of Todmorden located in the Don River Valley. Visible in the artwork are the recently renovated Papermill with its distinct smokestack, distillery, brewery, and William Helliwell's house. Watercolour on paper by George Robert Bruenech from about 1900. 


\section{LEARNER'S FLIGHT OVER TORONTO BAY VIDEO}

Depicts a student at the flight school at The Centre Island Aviation School during a training flight of a Curtiss Pusher. The frame of the planes were often built of wood and bamboo covered in cotton, linen or canvas. Footage shot by Pupil G. Hervey.

\section{SHIP'S FIGUREHEAD DEPICTING NIKE}

A carved and painted wood figurehead depicting the winged femle figure Nike holding a wreath. Possibly from a small schooner or yacht, based on its size. It was discovered on Copperhead Island, Georgian Bay following a storm. Carving of figureheads as folk art tradition has become lost in the evolution of ship construction from wood to iron the late 19th century. Carvers found alternate employment creating advertising figures for tobacconists and carousel animals.

\section{PRAYER RUG}

Characterized by a Mosque's niche, arch-shaped design at the front end of the carpet. The design uses direction to direct the worshipper towards Mecca. Many muslims believe the mat serves as a connection between God and man. Bought in 1993, and 1 metre long to fit an adult comfortably when kneeling or prostrating. Modern rugs are usually made of cotton or silk.

\section{PORTRAIT OF IRIS BURNSIDE}

Iris Burnside was the daughter of Josephine Burnside, a daughter of Timothy Eaton. Iris resided in London, but her mother returned to Canada after she had separated form her marriage in which Iris would frequently visit her mother and family. The painting is believed to have come to Toronto with Josephine. Oil painting on canvas by M.E. Grey.
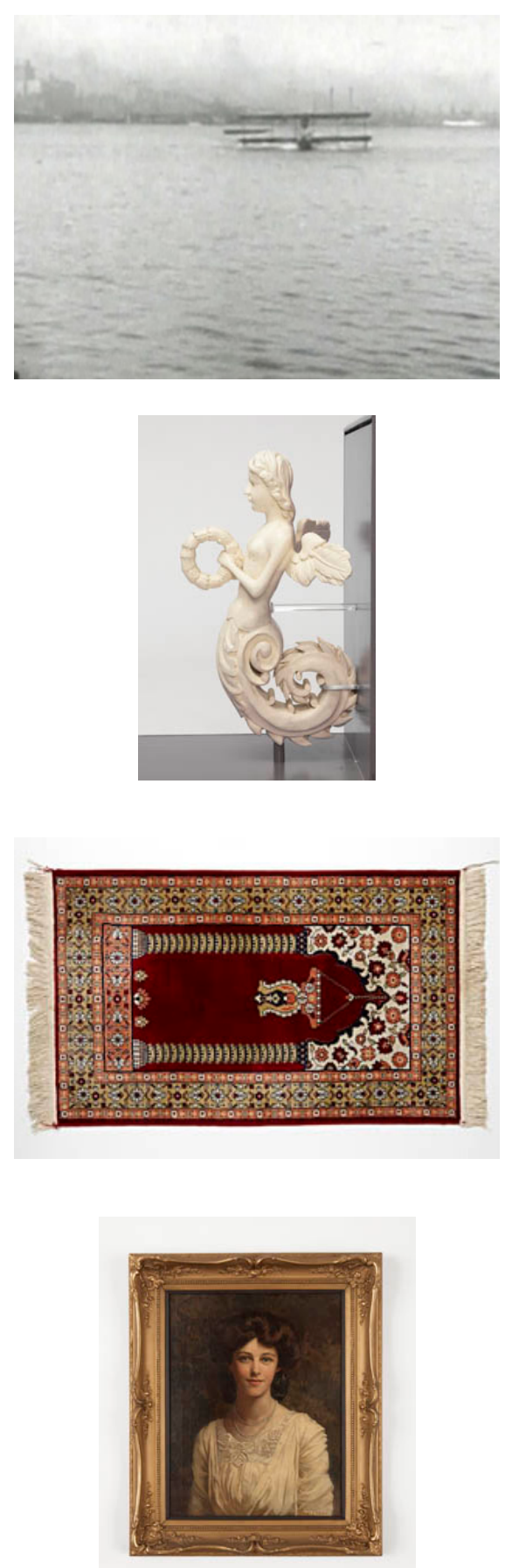

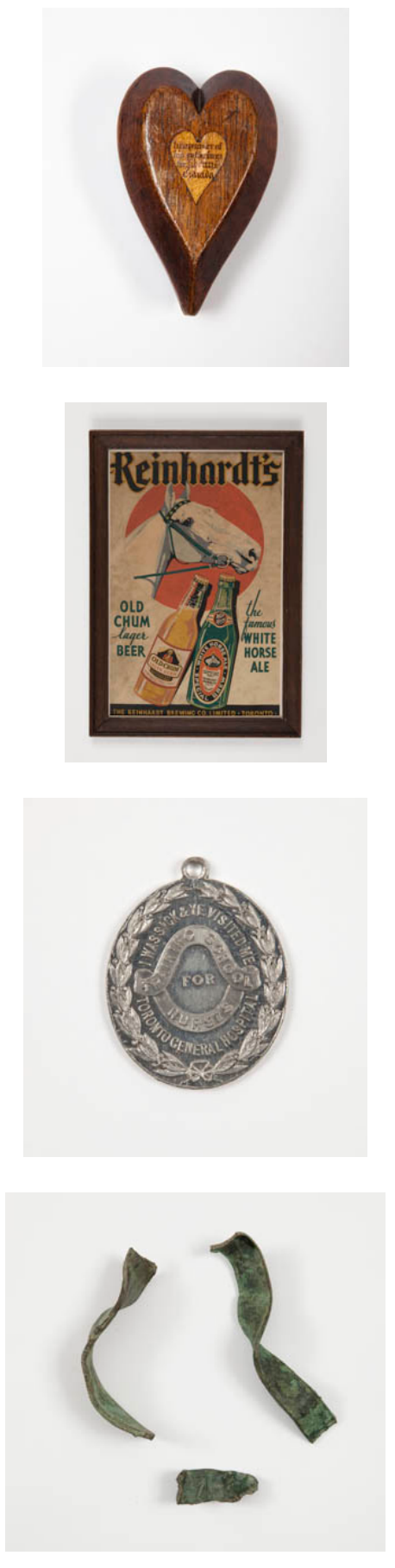

\section{REBELLION OF 1837 PRISONER'S BOX}

In December 1837, an armed mob led by former mayor William Lyon Mackenzie tried to overthrow provincial government but was crushed by local citizens, and some were taken prisoner. There is a long tradition of prisoners carving decorative boxes as gifts or supplement imcome during time in jail. This box was carved by Daniel Sheppard. Heart shaped, hand carved oak box with lid and pine plaques with ink insciption inlay.

\section{REINHARDT \& COMPANY BREWERS ADVERTISING POSTER}

Reinhardt Bewing Company Limited was founded in 1881 on Duchess Street in Cabbagetown. The brewery was considered to be the first to produce lager in Toronto. Rectangular cardboard poster in its original oak wood frame.

\section{TORONTO GENERAL HOSPITAL TRAINING SCHOOL FOR NURSES BADGE}

The Toronto General Hospital Training School for Nurses was founded in 1881 and in 1884 the appointment of Mary Agnes Snively to Lady Superintendent was significant as she held position for 25 years. She establised the first nursing student residenceies and proper curriculum in which this artefact is modelled on the fist bade issued in 1884 created for the 100th anniversary of the school. Oval aluminum badge.

\section{COPPER BARREL HOOPS}

This artefact dates back to the War of 1812. The Battle of Fort York with the Americans forced the British to retreat and blew up the Fort's gunpowder magazine to prevent it from falling into American hands. These barrel hoop fragements coe from the magazine explosion and speak to the deveastation of the event. Fragments of copper strapping used on gunpowder barrels. 


\section{TORONTO PUBLIC SCHOOL BOARD ATTENDANCE MEDAL}

Bronze medal depicting the crest of the school board. In 1857 the City of Toronot Board of Education instituted a program that certifies and encourages attendance The first attendance medals were issued in 1889. Bronze medals were issued for 4 years, silver for 8 years, and later awards were given out for 9 to 12 years as it became more common for students to attend school beyond grade 8. The last medals were issued in 1973.

\section{INTERNATIONAL ORDER OF ALLIED MOTHERS IN SACRIFICE MEDAL}

On September 17, 1917, Private Thomas Reeve Gill, 15th Infantry Battalion, died in combat during World War I. This medal was awarded to his mother Maria Gill in recognition of his sacrifice. Medal in red copper.

\section{QUEEN'S WHARF LIGHTHOUSE PAINTING}

An oil painting on canvas by Harry Neil Grunsten that depicts the Queen's Wharf Lighthouse that played an important role in safeguarding ships entering the Toronot Harbour. It was built in 1861 but decomissioned in 1912. It escaped demolition and was moved to Fleet Street. In 1988, it was restored to its original working conditions.

\section{1961 MAPLE LEAF GARDENS PROGRAMME}

Official programme and sports magazine for Toronto vs Detroit on Saturday November 11, 1961. Depicts Eddie Shack and signed by him, Red Kelly, Tim Horton and Johnny Bower. The Maple Leaf Gardens was built in 1931 and in only 155 days. It was financed by Toronto Maple Leafs Managing Director and could seat 13,000 fans. During the team's time at the Gardens, they won 11 Stanley Cup trophies. The program dates from a championship year. The team has been playing at the ACC since 1999. 80 pages and card wrap.
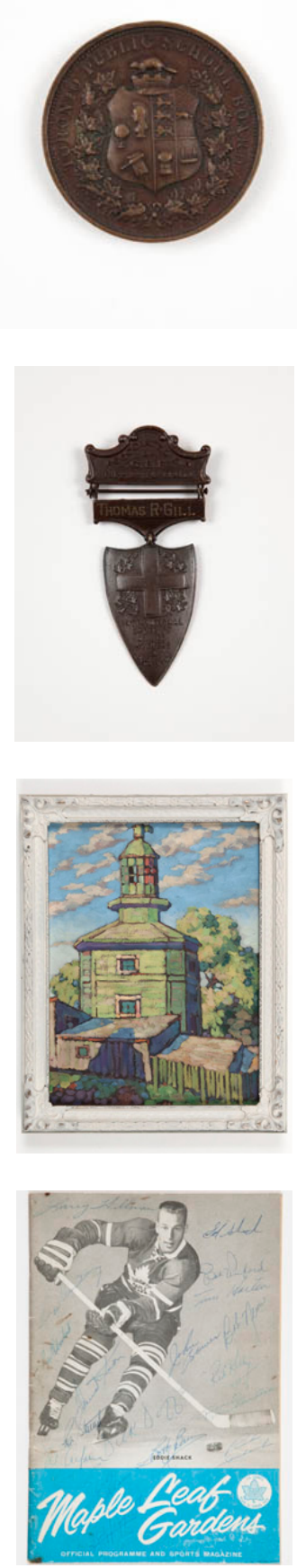

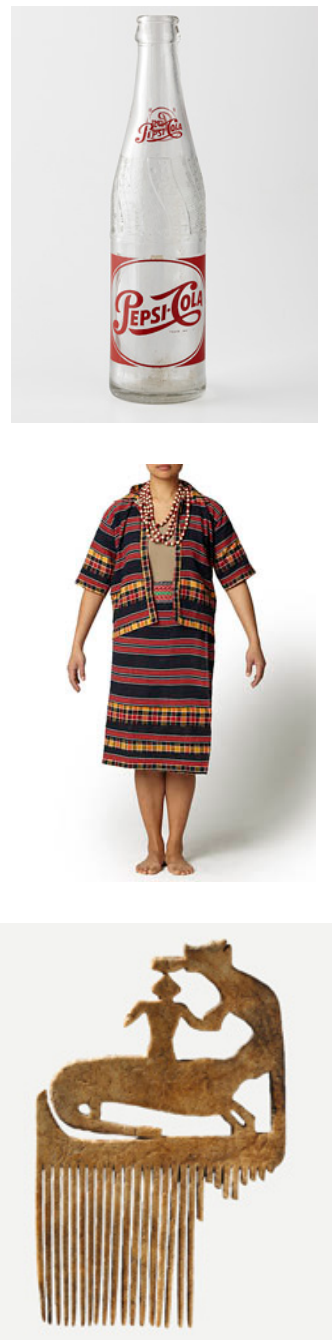

I'MAN

UNCLE BOBBY

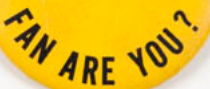

\section{PEPSI-COLA BOTTLE}

12 ounce clear glass soda pop bottle manufactured by Pepsi-Cola Company of Canada. Embossed 1952 on bottom. "Brad's Drink" a carbonated drink with pepsin and kola nuts first made in a North Carolina pharmacy in the 1890s. Pepsi-Cola brand appeared in 1898, and trademarked in the US in 1903 and Canada in 1907. Pepsi introduced the 12 oz bottle priced the same as 6 oz bottle from competiting colas. The bottle depicts the company's fifth logo introduced in 1950 until 1962.

\section{BENDAYAN DRESS}

Woven costume imported from the Philippines in the early 1980s for a performance by the Folklorico Filipino Dance Company at Vancouver's 1986 Expo. This type of dress was found in rural areas of the Philippines and worn for a specific repertoire of dances in the Filipino folk dance tradition. The performances enabled new immigrants to showcase their cultural dance traditions to eager audiences in Canada.

\section{SENECA EFFIGY COMB}

Carved comb to depict Michipescheu, Bear and Human. The development of antler combs reached a peak in the mid to late 17 th century. Seneca produced more combs than any other loquoian-speaking group. Comb development seems to have coincided with the introduction of iron tools and growth of political and military strenth in post 1650 period. Moose antler comb found at the site of Teiaigon (Baby Point) buried with a Seneca woman.

\section{UNCLE BOBBY SOUVENIR PIN BACK BUTTON}

The Uncle Bobby Show was a children's television program starring Bobby Ash that ran from 1964 to 1979 on Toronto's CFTO television station. The show featured guest performers form ventriloquists to singers and musicians. The highlight of the show was the birthday greetings accompanied by Bimbo the Birthday Clown. 


\section{6 museum as conversation}

The Toronto Museum Project can be described not as a collection of objects, but as a collection of ideas. These ideas reflect on Toronto's past, present and future and seem to suggest on going dialogue regarding Toronto's ever-changing values. The museum and its artefacts perpetuate a dialogue regarding Toronto's diverse population, but also questions who's history, and who's future are we referring. In addition to the existing collection of 100 objects, the museum serves as a starting point of this conversation in which visitors are welcome to share their own stories with those they encounter. Visitors will also be encouraged to bring their own 'artefacts' that they wish to be digitized and disseminated physically or online with the rest of the collection. As the collection grows, the ideas about Toronto's history and future will be more clearly defined, increasing the ways we interact with Toronto's narrative and ultimately increasing the avenues of discussion.

\section{7 collection narrative}

\section{PEOPLE}

Aboriginal Heritage …......... Cultural Diversity $\quad \cdots \ldots \ldots \ldots . . . . \quad$ Immigration

\section{ACTIVITY}

Entertainment $\cdots$ Women's History $\cdots$ Transportation $\cdots$ Education \& Industry

\section{CITY}

Architectural Heritage

Civic Military

The City of Toronto abandoned plans to build the original proposal for a city museum at the Canada Malting Silos at the foot of Bathurst Street for various reasons. Thematically, curators struggled to create a cohesive narrative around the Toronto Museum Project's 100 items and 100 stories. This proposed narrative follows this thesis' proposed design approach that begins with the human experience, then extends to the scope of the city. 


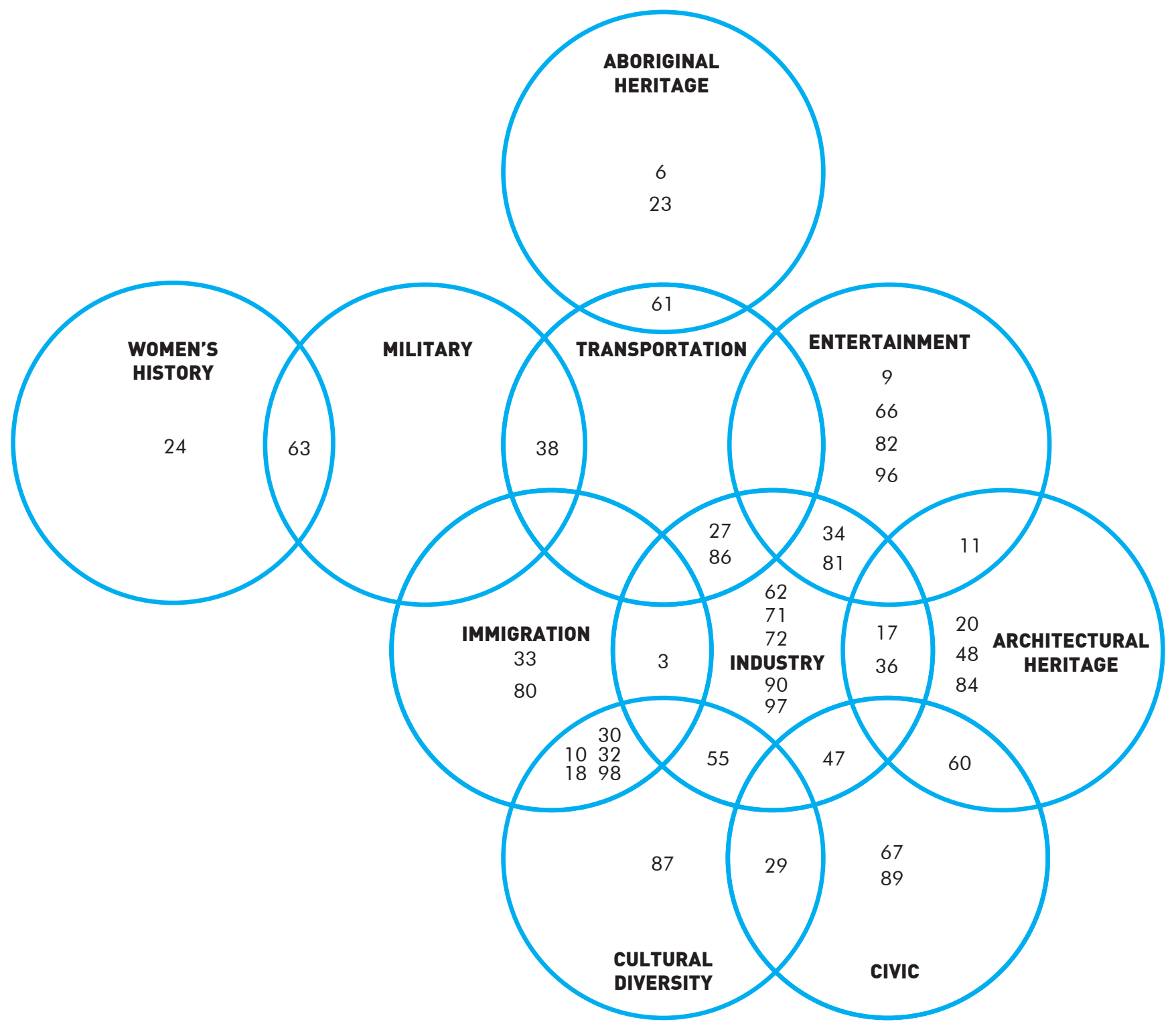

Figure 7.5: Select Artefact's Taxonomy Relationships 



\section{1 design approach}

\section{Typical Design Approach}

\section{BUILDINGS $\rightarrow$ SPACE $\longrightarrow$ LIFE}

\section{Proposed Design Approach}

\section{LIFE $\longrightarrow$ SPACE $\rightarrow$ BUILDINGS \\ ENGAGE \\ CENTRALIZED SPACE \\ CONNECTIONS}

maximize see-hear activities

intersecting visual sightlines

have variety and choice of human activity

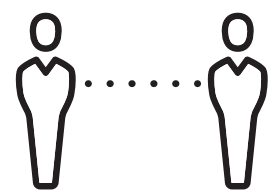

centralized meeting spaces

flow of circulation as continuity

opportunity for serendipitious social encounters

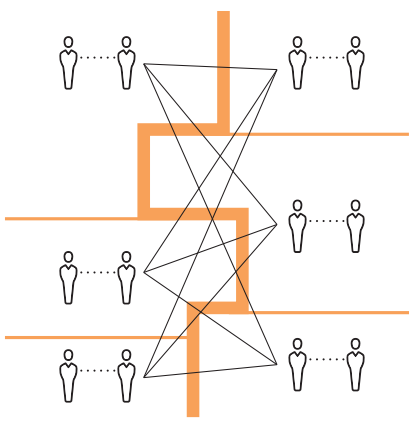

create meaningful connections between spaces and programs

maintain a level of privacy, semi-autonomy enhance the architectural qualities of contiguous spaces

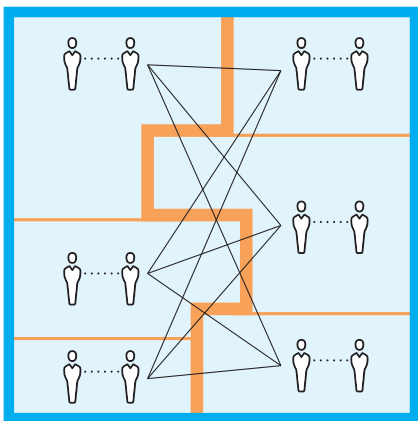




\section{2 key definitions}

\section{ORDER}

A coherency of place as it pertains to a defined perception of an edge or boundary.

- Thom Mayne in Connected Isolation

\section{ENGAGE}

Social activities include all types of communication between people in city space and require the presence of other people. If there is life and activity in city space, there are also many social exchanges. If city space is desolate and empty, nothing happens.

See and hear activities are the largest category of social contact. These passive see and hear contacts provide the background and springboard for the other forms of contact. By watching, listening and experiencing others, we gather information about people and the society around us.

Experiencing life in the city is also diverting and stimulating entertainment. The scene changes by the minute. There is much to see: behaviour, faces, colours and feelings. And these experiences are related to one of the most important themes in human life: people.

- Jan Gehl in Cities for People

\section{CENTRALIZED SPACE}

A condition in which heterogeneous elements no longer exist in isolation. As a place of encounter, communication and information, the city (central space) is also a place in which constraints and normality are dissolved and joined by the elements of the playful and unpredictable.

The urban is defined as the place where people walk around, find themselves standing before and inside piles of objects, experience the intertwining of the threads of their activities until they become 
unrecognizable, entangle situations in such a way that they engender unexpected situations.

- Henri Lefebvre in Cities for People Not for Profit

\section{CONNECTION}

[Connection] is the broader concept, exchange the narrower concept. In human relations, interactions generally appears in forms which lend themselves to being viewed as exchange.

The sum of values is greater afterward than it was before, and this implies that each party gives the other more than he had himself possessed.

- Georg Simmel from Individuality \& Social Forms

\section{EXCHANGE}

The sum of values is greater afterward than it was before, and this implies that each party gives the other more than he had himself possessed.

Interaction is the broader concept, exchange the narrower concept. In human relations, interaction generally appears in forms which lend themselves to being viewed as exchange.

- Georg Simmel from Individuality \& Social Forms 


\section{3 concept}

The initial concept for the museum begin with the identification of two architectural grids. These were derived from the rigid city grid identified by College Street and Sheridan Avenue, with the other deriving from the bisecting Dundas Street West and the surrounding laneways. Initially, each grid would be associated with a particular ordering system, where one would be primarily concerned with exhibition, the architectural grid, and the other concerned with circulation, the social grid. Instead of integrating a superimposed relationship, the removal of hierarchy in a superposition of the grids would avoid a figure-void relationship while increasing the degree of variation and integration between the two. To enhance the opportunities for a greater socio-architectural relationship, this superposition of the grid would be translated in the vertical plane as well.

\subsection{1 engage}

As Torontonians approach the Museum of the City of Toronto, visitors are immediately confronted with multiple visual and spatial experiences that define a sense of awareness and understanding. If you were to approach from the north, south or west of the Dundas St West and Sheridan Avenue intersection, a visitor's first encounter will be with the buildings façade. The facades are a direct translation of the building's internal activity and arrangement, and an initial understanding of the organization can be derived. The forced perspective allowed by the shifting of Dundas Street from the city grid allows more west exposure onto the street which helps to suggest an entrance under the lifted auditorium space. As visitors enter the museum under the ramped seating space, the convergence of the two city grids are immediately understood. The relationships between the various galleries and programmatic spaces through the 4 floors of the building create a cross pollination of engaging sightlines within the building and also onto the street.

Figure 8.3: Grid Concept

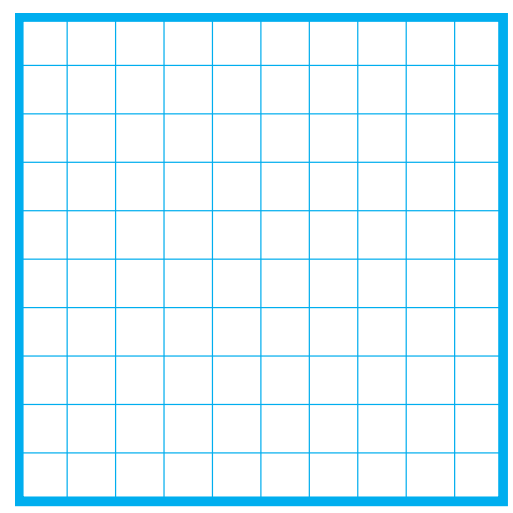

Gallery \& Art Exhibition - Architectural Grid

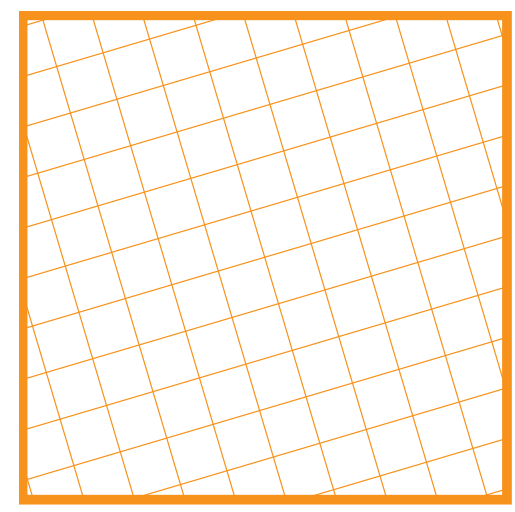

Circulation - Social Grid

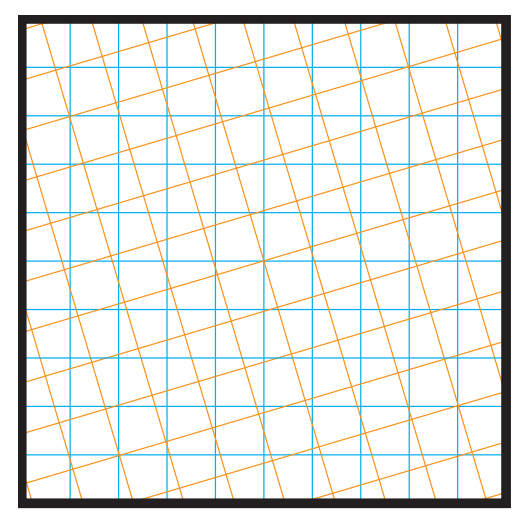

Superposed Grids 


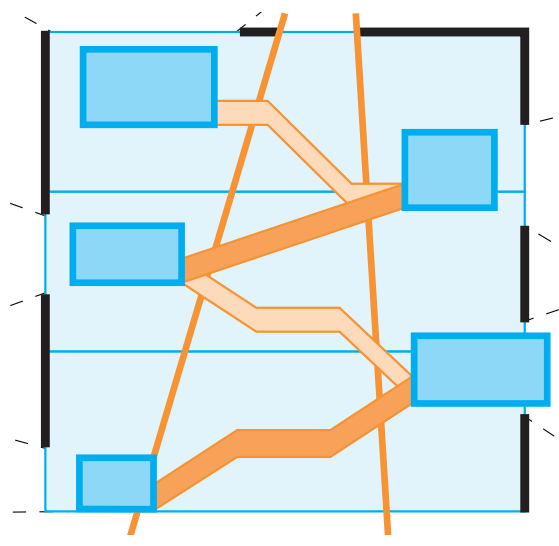

Figure 8.4: Conceptual Section

\subsection{2 centralized space}

Located in the center of the museum is the four-storey atrium space, which acts as the main circulation and social spine. Visually, the atrium reinforces the prescribed route that weaves and navigates through the building and its surrounding gallery spaces. The flow of visitors reflect a continuity of space and the museum collection's overarching narrative, while increasing the opportunity for serendipitous social encounters. Along the route, the arrangement of gallery spaces and the building's structure begin to hide and reveal various spaces and activity creating moments of inquisition and anticipation for the experiences ahead. The maximization of see-hear contacts throughout the atrium reinforces a cross pollination of human activity across the entire building. As visitors reach the end of the exhibits, they are free to go back along the prescribed route or take the elevator back down to the main lobby. While the main atrium acts as the centralized architectural space, the central flow of visitors stimulates a centralized social engagement with the museums artefacts and with other users.

\subsection{3 connections}

From the moment visitors enter the museum, all the way up to the last gallery, they engage with various thresholds and architectural exchanges with the building. The nesting of various galleries and supplementary spaces within the museum's ordered framework begin to challenge the traditional grid to offer more meaningful architectural experiences. As the various spaces seem to expand on the intersection of various grids, an overlapping or 'rubbing' of contiguous spaces create a broader spatial experience. The perceived forms of the galleries or supplementary spaces can alter the sense of transparency, acoustics, light and sense of scale, to appropriate the museum's various needs. Traditionally, within a typical museum or 'big' building, these contrasting environments are experienced horizontally or are connected via elevator. But with this proposed museum, the arrangement of the spaces, supported by the narrative of the museum's collection, create an enhanced sense of architectural connections created by the intersection of various contextual grids. 
8.6 axes of order
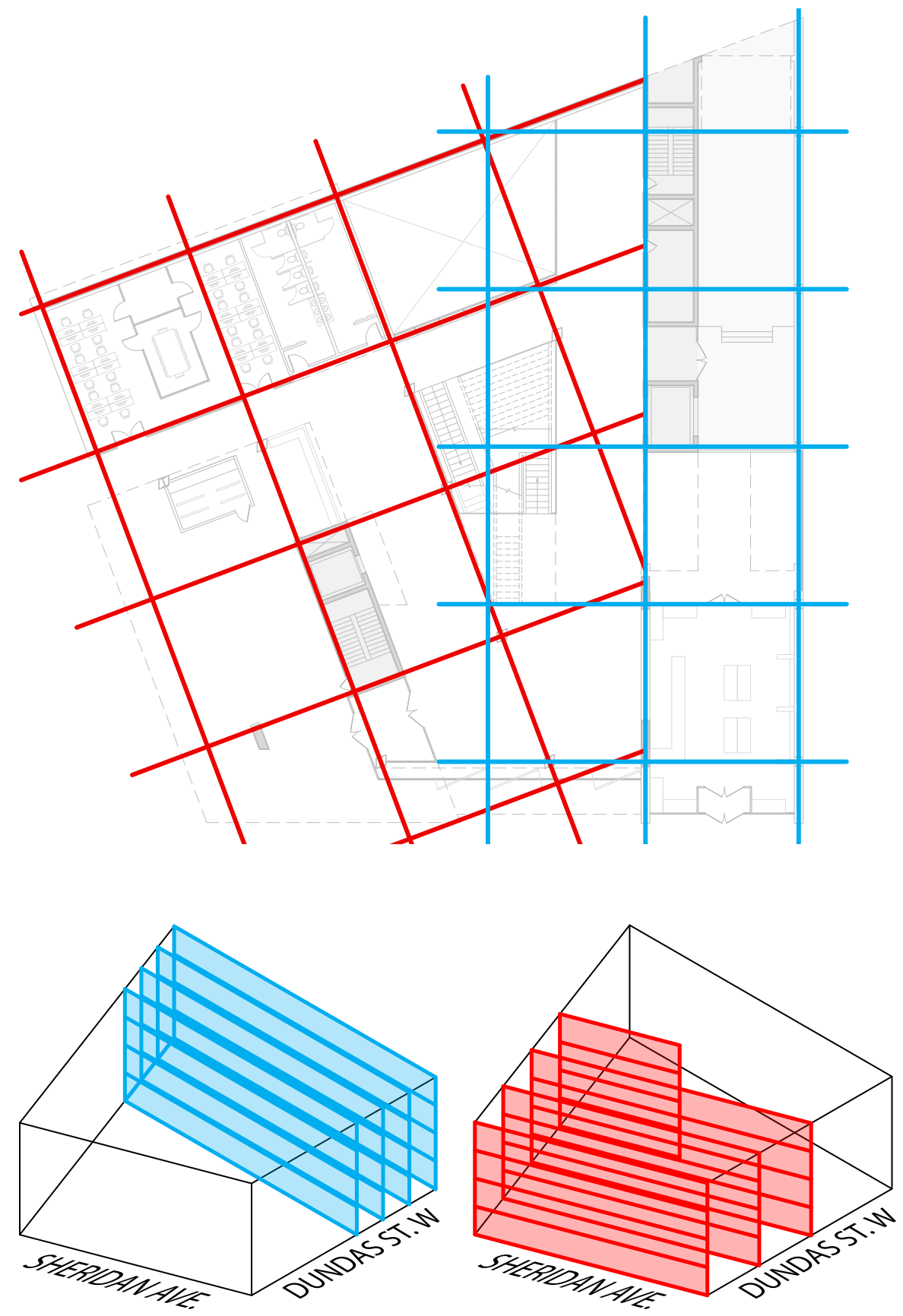

Figure 8.5: Dundas Street Grid and City Grid Intersection
Figure 8.6: Dundas Street Grid Figure 8.7: City Grid 
Figure 8.8: Rotated Grid in Section

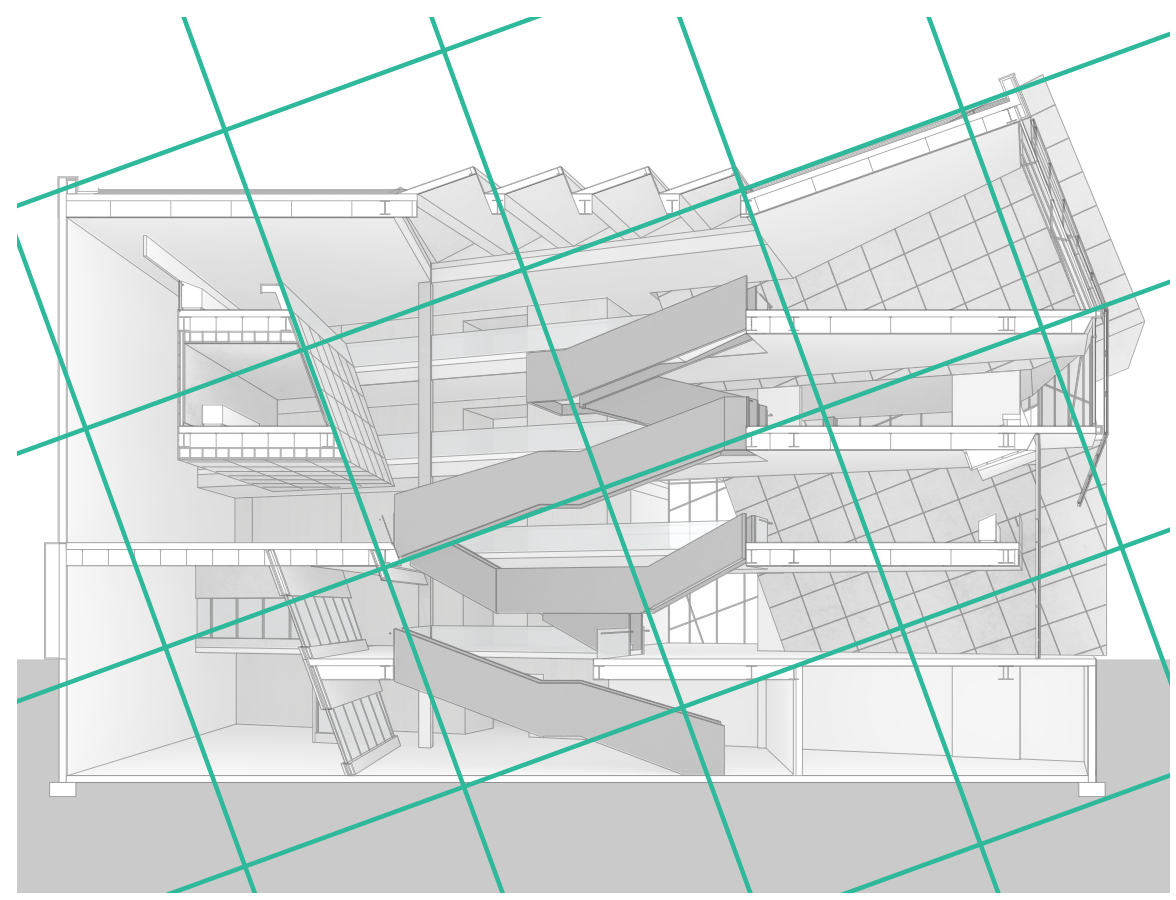

Figure 8.9: Tertiary Rotated Grid

Figure 8.10: Grid Intersection Around Central Atrium
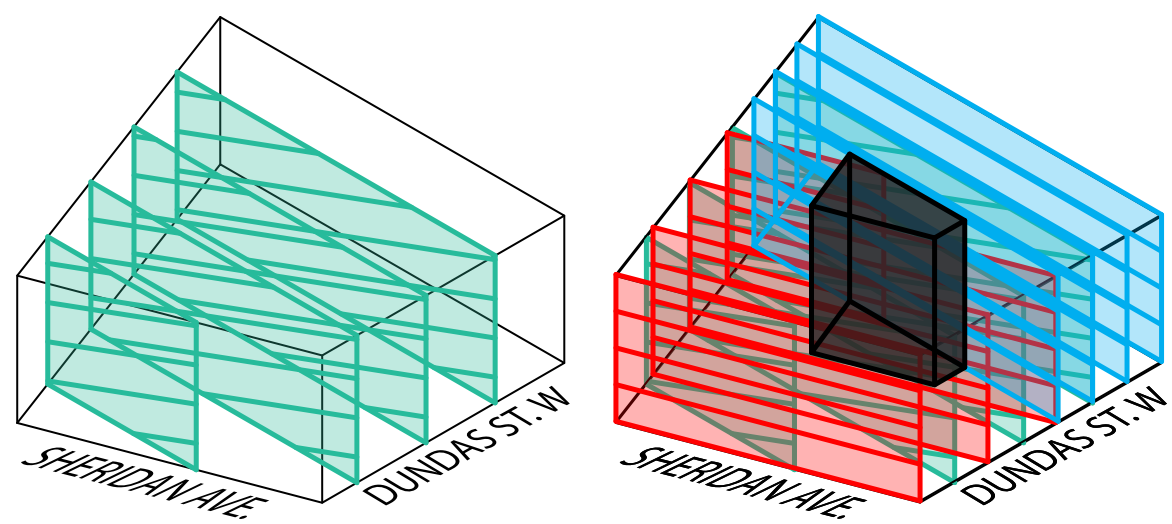


\section{7 entrance and lobby}

When initially approaching the museum, visitors are intuitively pulled off the street and into the building under the overhang of the museum's auditorium facing onto Dundas Street. As visitors enter through the off-axis vestibule, they experience of the convergence of the two city grids that are present. This is emphasized by the canted structural column that is diagrammatic of the shifting from the Sheridan Avenue grid to the Dundas Street grid.

\section{8 bookstore and giftshop}

At grade the museum preserves the architectural rhythm while maintaining a consumer presence to passerbys. By breaking up the western volume of the museum at approximately 8 meters, the giftshop and bookstore seemlessly blends in with the surrounding context along Dundas Street West. The giftshop will sell products created by various local makers while circulating a carefully curated collection of books pertaining to city's identity.

\section{9 temporary exhibition gallery}

Similarly to the bookstore and giftshop, the temporary exhibition space maintains a strong commerical presence along Dundas Street West. The temporary nature of the space invites visitors come into the museum while enticing a serendipitous visit into the museum to visit without worrying about the cost of admission. The space would host various local exhibitions that can benefit from the retail presence of the bookstore and giftshop.

\subsection{0 artefact digitization space}

As the museum is designed to be experienced along a prescribed route of the following thematic galleries of local artefacts, a digitization space can be found on the fourth floor concluding the exhibition spaces. The space serves as a continuation of the dialogue initiated by the museum by extending the opportunity for visitors have their personal items be donated, loaned or digitized to contribute to the growth of the TMP's collection. 
1 entrance

2 lobby

3 temporary exhibition gallery

4 book store \& gift shop

5 ticket desk

6 coat check

0125

7 offices

8 washrooms

9 archive room below

10 storage

11 loading

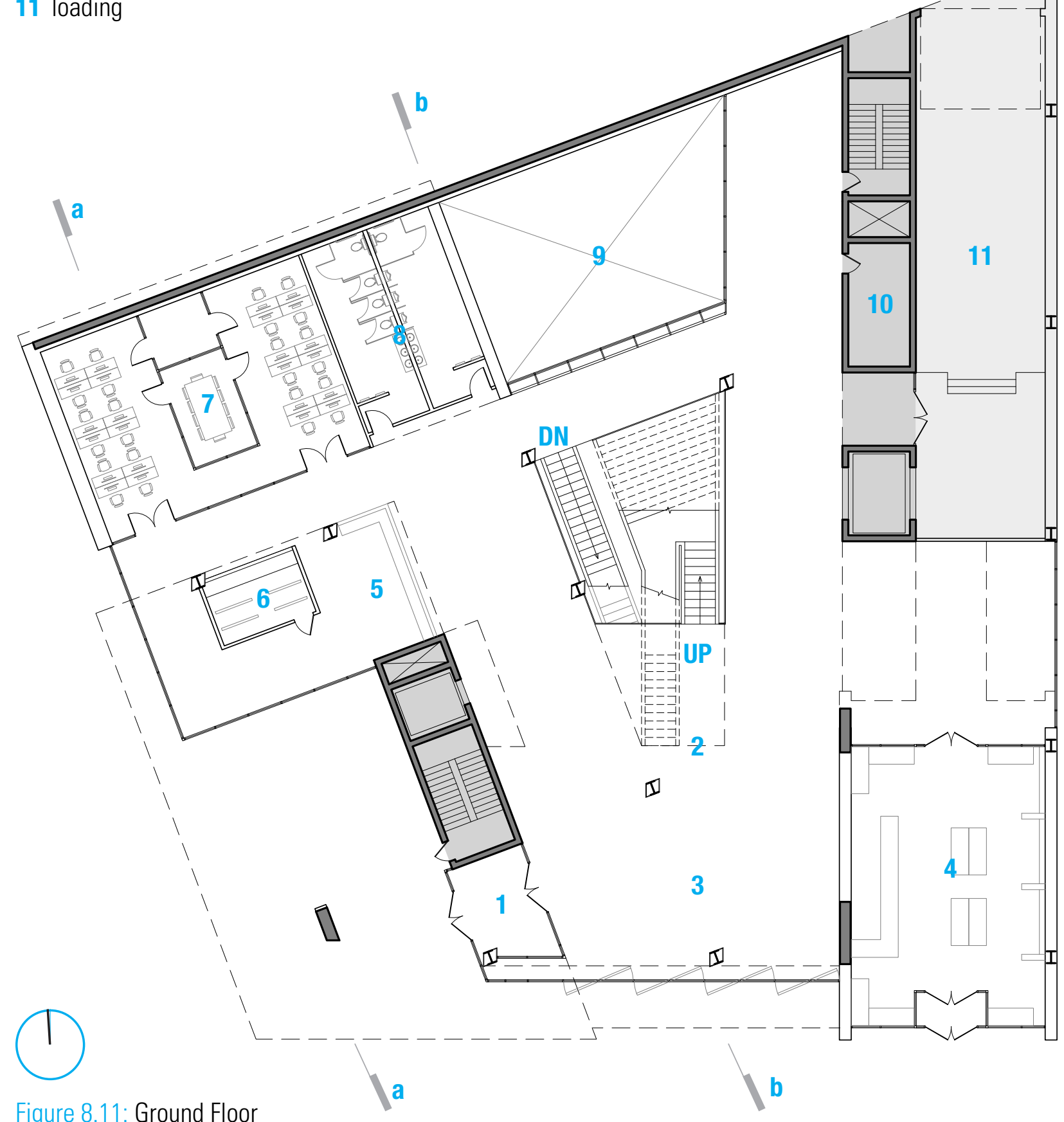

Figure 8.11: Ground Floor 


\subsection{1 extended temporary exhibition gallery}

This space differs from the temporary space at grade by serving as an exhibition space not part of the musueums collection on a long term basis. It would be ideal for travelling exhibits or for large scale installations that can take advantage of the increased height of atrium, the change in scale created by the floating gallery above, and the resulting light conditions. Access to this is exhibition space is included in the price of admission.

\subsection{2 aboriginal heritage gallery}

As visitors enter up the lobby stairs, the prescribed route recommends the Aboriginal Heritage gallery on the southern facade of the building as the first to be experienced. The exhibition is designed in a linear orientation along the Dundas Street grid to chronicle the history of the various artefacts. To supplement the artefacts, a curated exhibition will be designed in reference to the Upper Road to Niagara, in which the museum site is formerly located on.

\subsection{3 cultural diversity gallery}

As visitors make their way back to the rear of the building, they encounter the Cultural Diversity Gallery before making their way up the central stairs to the third floor. The gallery houses various artefacts of a personal scale that demonstrate Toronto's diverse historical foundation. The items are ordered along simple grid derived form the museum's own order to allow for all the objects to be experienced from all angles. Coupled with the compressed scale created by the gallery above, the fluid circulation through the gallery extends an opportunity for a short intimate conversation with other visitors. Much like the city grid, this arrangement of the artefacts allows for an isolated experience of differing artefacts, devoid of any context but the stories of the TMP, without privileging any particular culture. 
1 extended temporary exhibition gallery

2 aboriginal heritage gallery

3 cultural diversity gallery

4 125-seat auditorium

5 offices

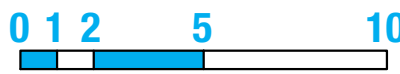

6 multipurpose room

7 washrooms

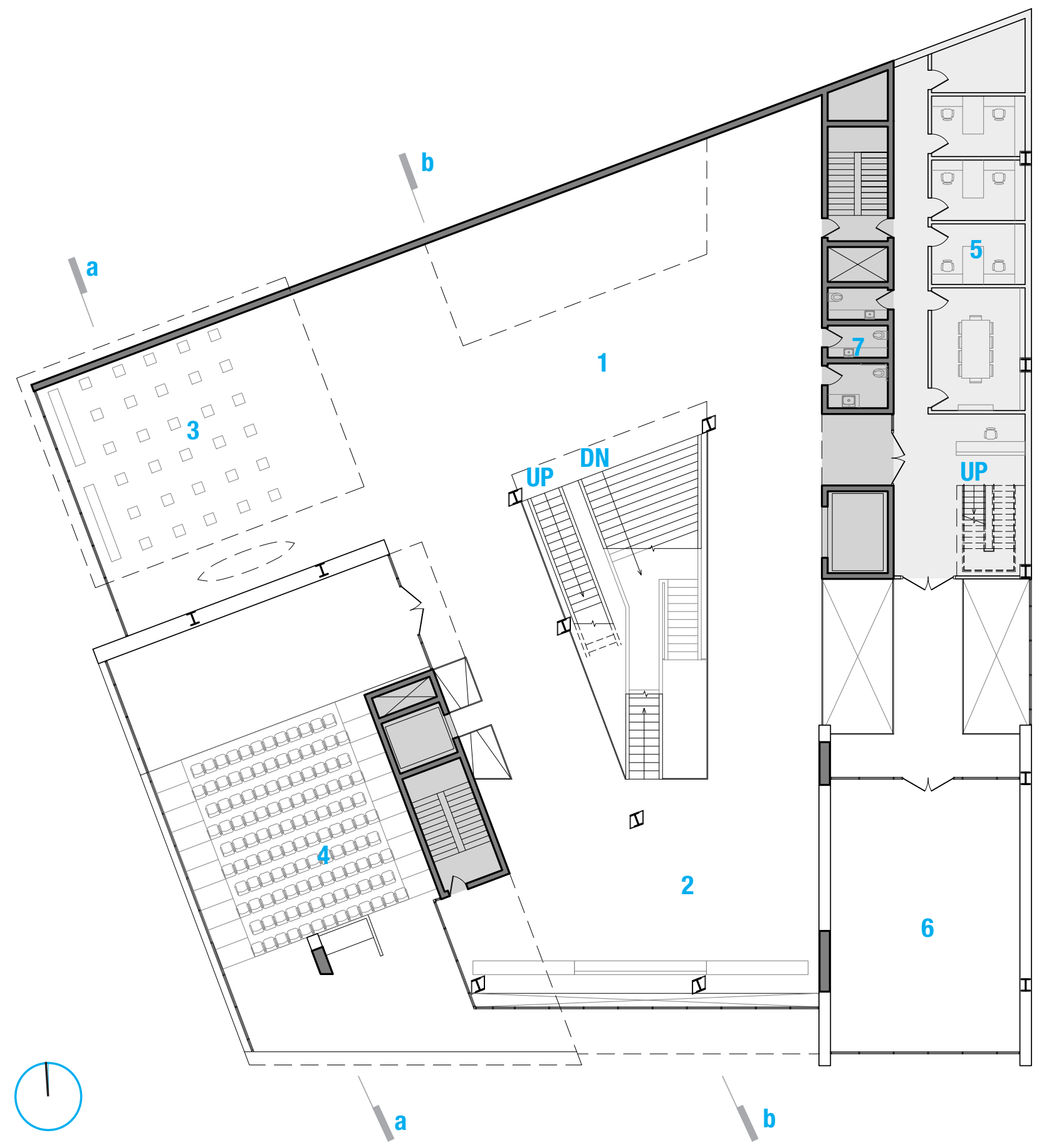

Figure 8.12: Second Floor 


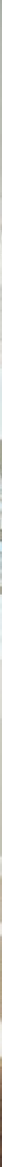




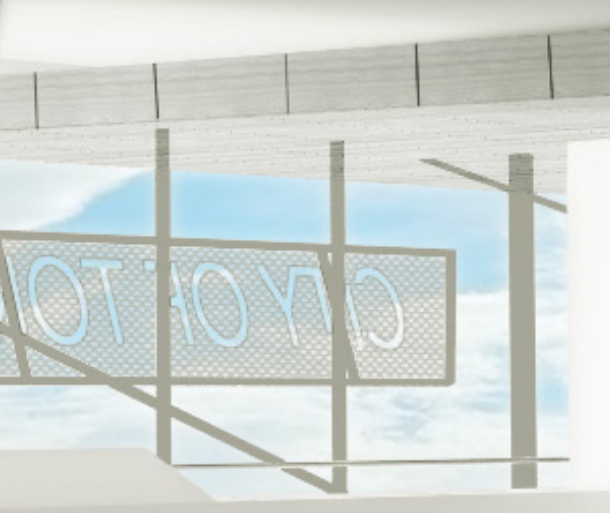

Figure 8.13: Aboriginal Heritage Gallery 


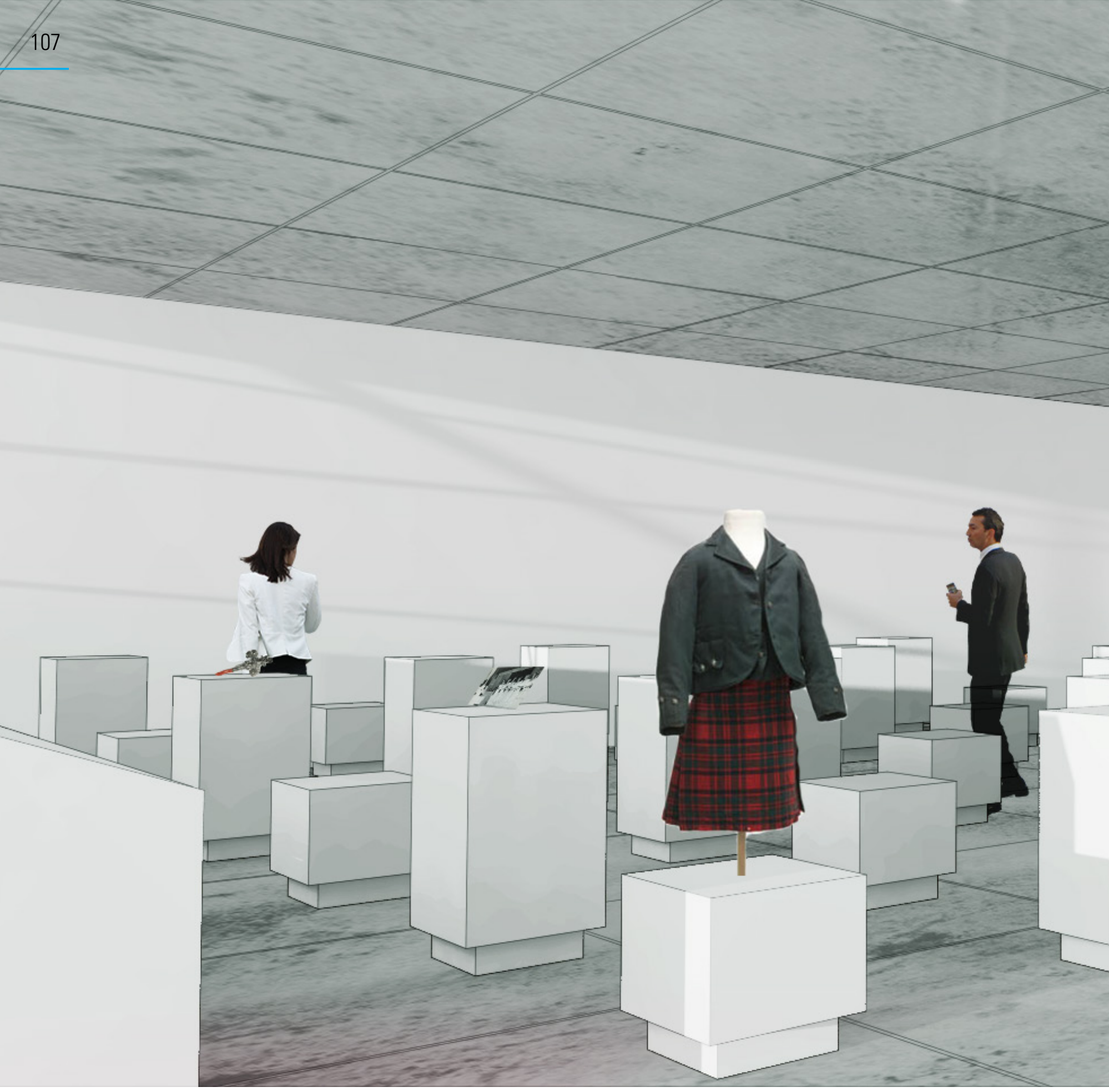




\subsection{4 immigration gallery}

Similarly to the Cultural Diversity gallery, the Immigration gallery exhibits various artefacts that highlight Toronto's various cultures, with an emphasis on immigration which ranges from new immigrants to early immigrants from the 19th century. Currently, there is a larger quantity of items in the Cultural Diversity gallery than in the Immigration gallery, allowing for social associations to be easily established. These narratives can be told in a linearly and are established as such. Again, a shift in height occurs created by the space above, creating a more intimate experience, architecturally with the artefacts, and socially with other visitors. As visitors navigate the rowed exhibition, they are put into a position in which they could seredipitously encounter others and potentially share their ideas or values pertaining to their own culture or personal immigration stories.

\subsection{5 women's history and entertainment galleries}

As visitors make their way to the northern end of the building, they progress through the hovering gallery space housing various small scale objects that are significant to Toronto Women's History. The gallery is designed to control certain lighting conditions in which it can be sufficiently lit naturally, so that every detail can be seen, while providing indirect light for other particular objects to be safeguarded from deterioration. The Women's History Gallery flows into the enclosed gallery to the west in which the central exhibition space would hold the bigger artefacts that are largely prone to UV deterioration. The Entertainment gallery and it's artefacts would be arranged around the Women's History items, much like a showroom of various paraphernalia. As visitors circle around this gallery they loop back to the central stairs to proceed to the fourth floor. 
1 immigration gallery

2 women's history gallery

3 entertainment gallery

4 125-seat auditorium

5 auditorium crush space

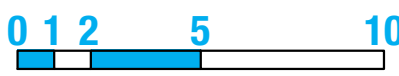

6 offices

7 washrooms

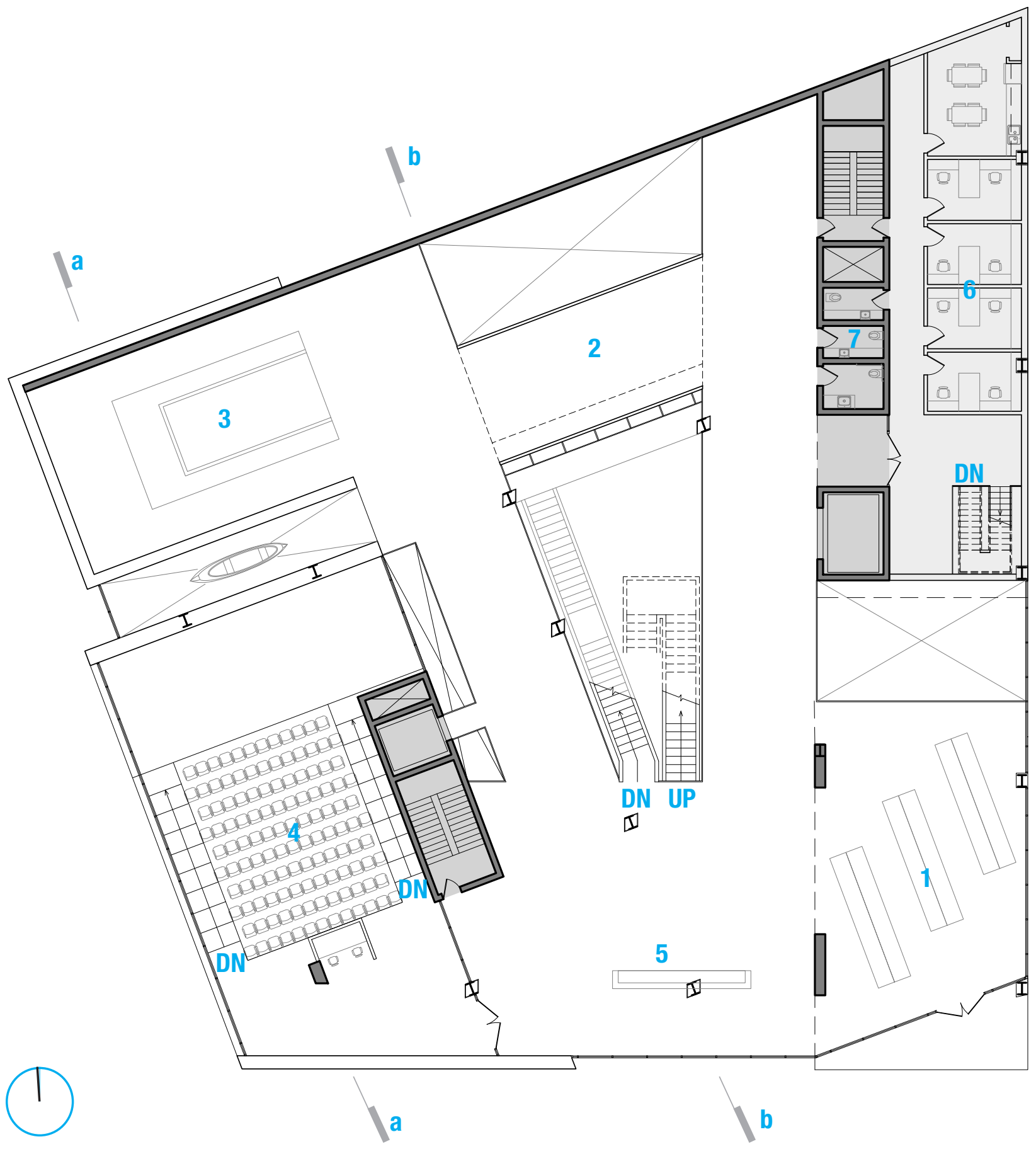

Figure 8.15: Third Floor 


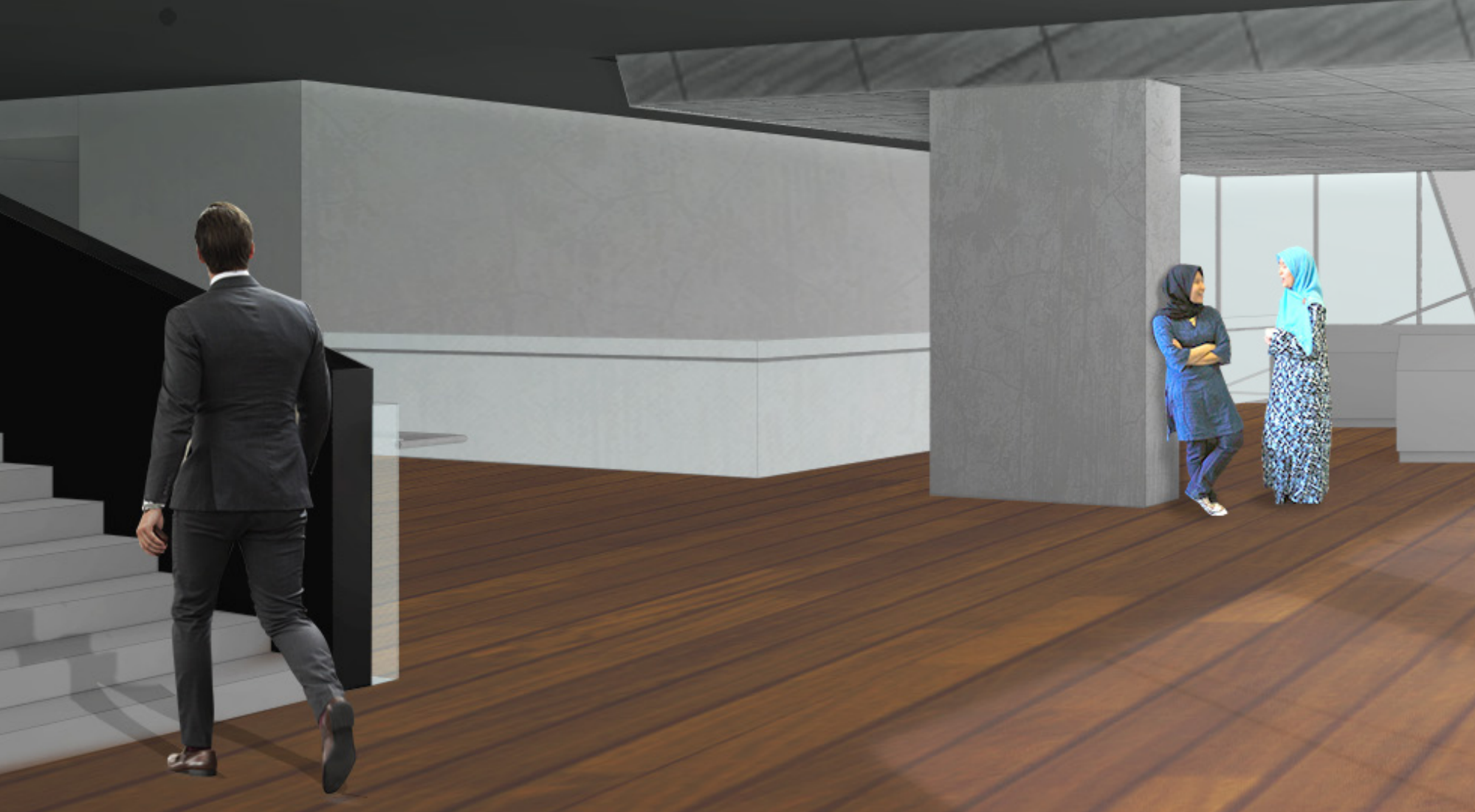




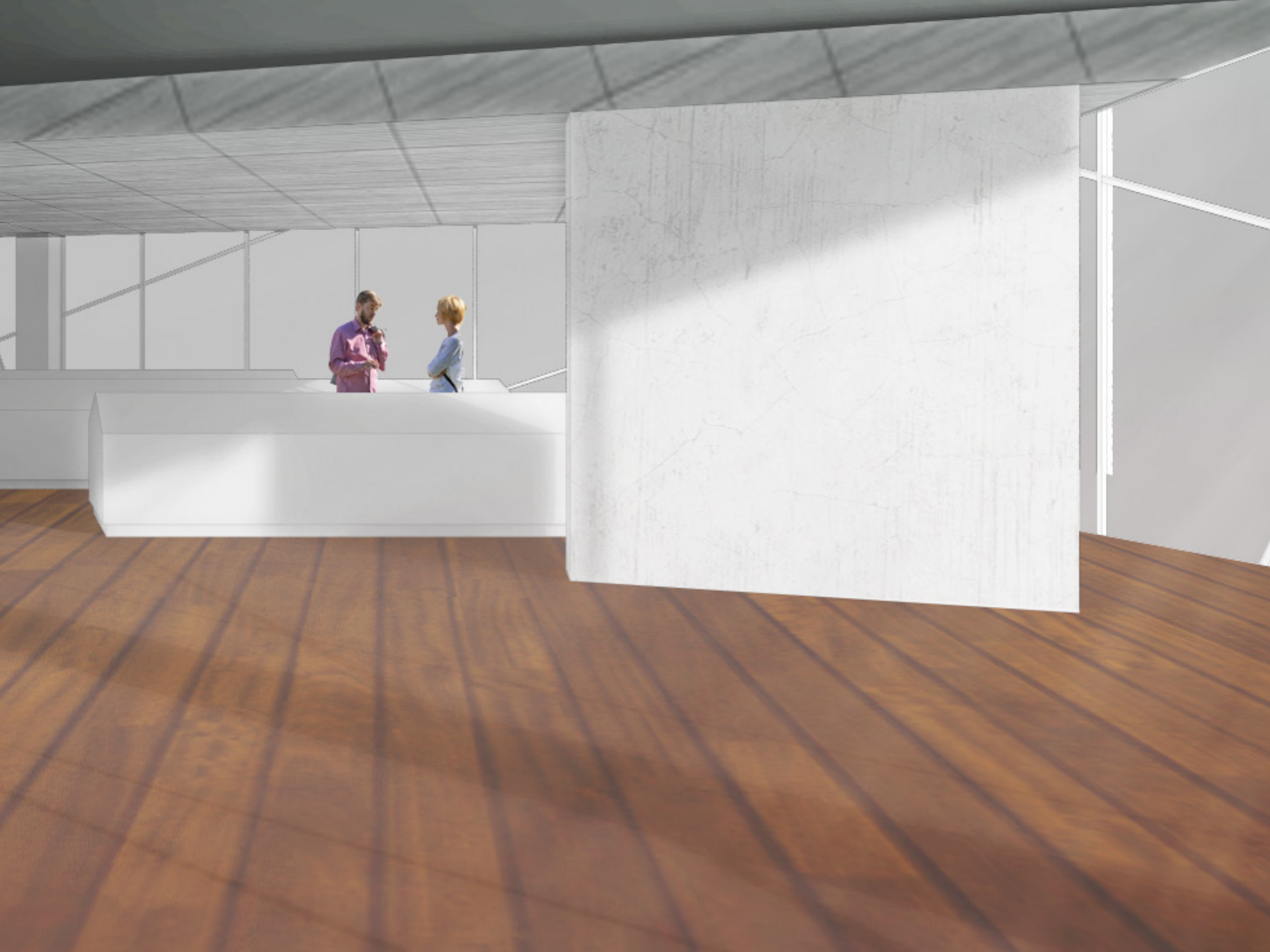

Figure 8.16: Immigration Gallery 


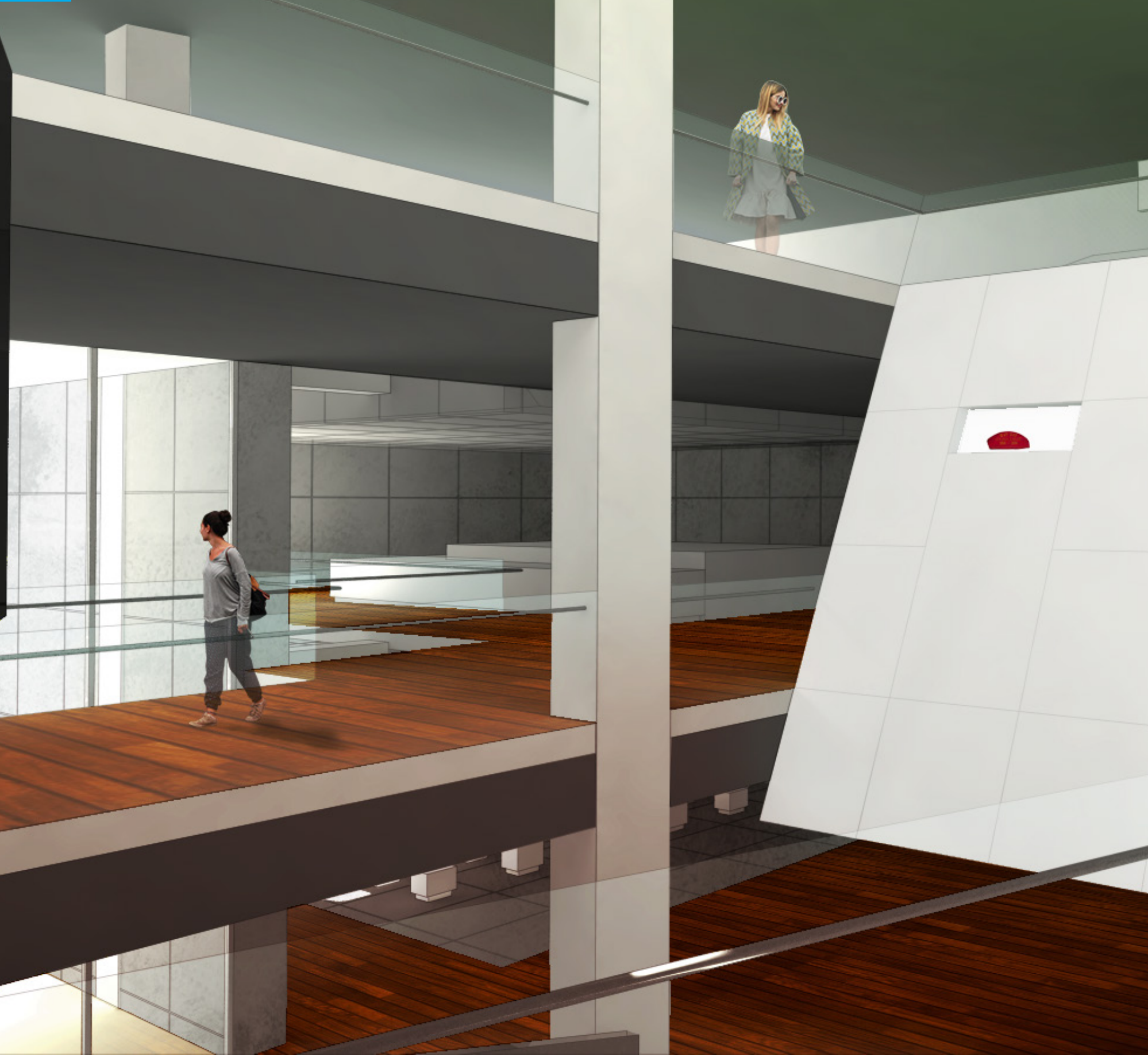




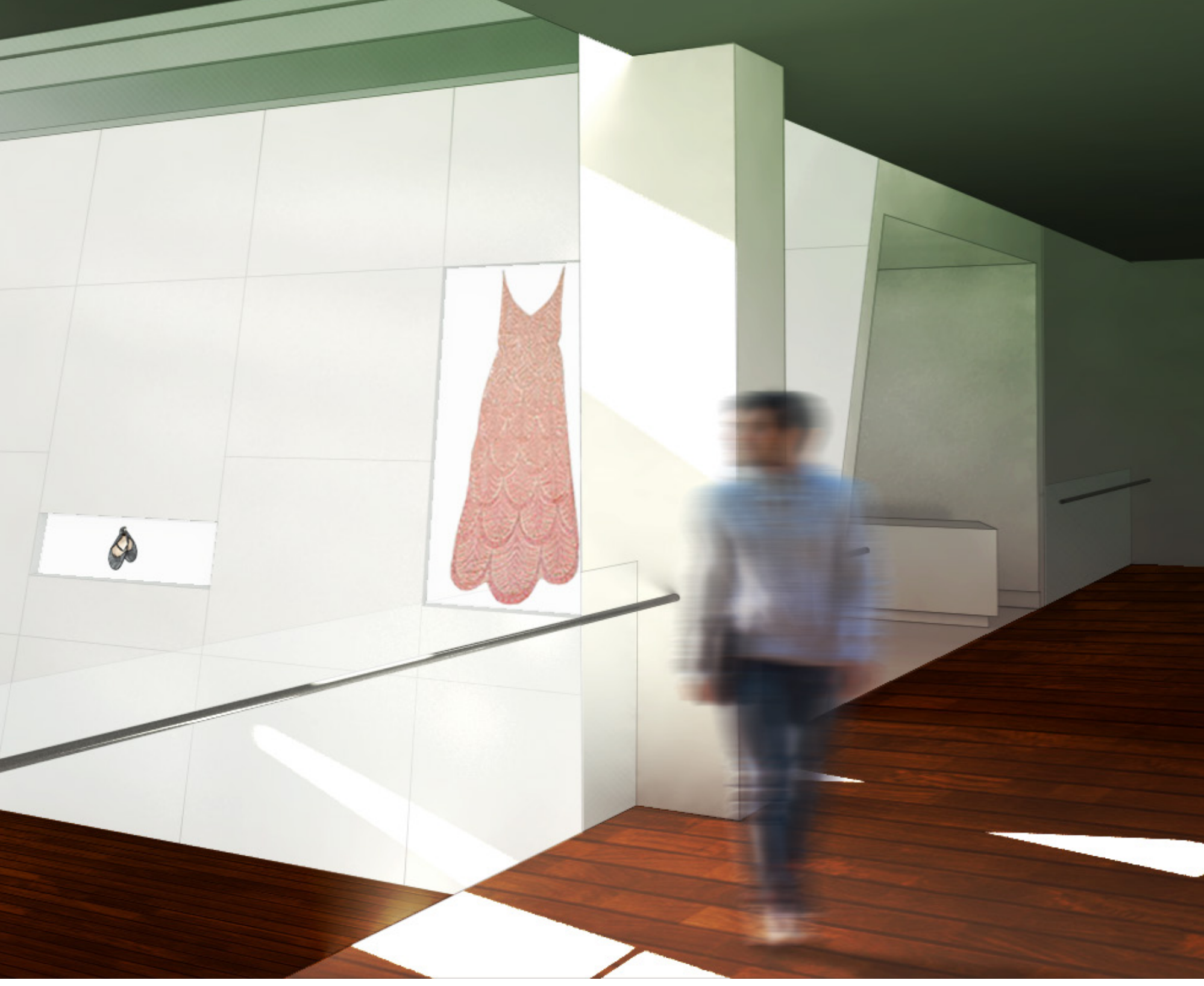

Figure 8.17: Women's History Gallery 


\subsection{6 education \& industry and transportation galleries}

As visitors are brought up to the fourth floor, they enter into the Education \& Industry Gallery and the Transportation gallery. The scale of gallery drastically increases, and is created by the shift in the tertiary vertical grid. This allows for the accomodation of larger transportation artefacts or the suspension of artefacts. The exhibitions are harmoniously arranged like a streetscape, derived from the museum's inherent order, to allow for a genuine experience of the galleries. The Transportation gallery artefacts are arranged along the centre of the gallery, with the industry and education artefacts along the perimeter, to mimic a typical street environment. The Aboriginal bark canoes will be suspended in the void between the southern end of the gallery and the north-western end, to create a sectional relationship with the cultural diversity gallery two floors below, while affording an authentic viewing experience for the artefact.

\subsection{7 architectural heritage gallery}

The Architectural Heritage gallery is situated on the top surface of the hovering gallery space on the north end of the museum. Various artefacts are exhibited in a way that they would have been authentically experienced. The gallery would also take advantage of the shift in scale, in which the gallery is nested within, to allow for larger architectural items to be exhibited on the northern wall. 
1 industry \& transportation gallery

2 education gallery

3 architectural heritage gallery

4 civic \& military gallery

\begin{tabular}{lll}
012 & 5 \\
\hline
\end{tabular}

5 'social city' space

6 artefact digitization space

7 washrooms

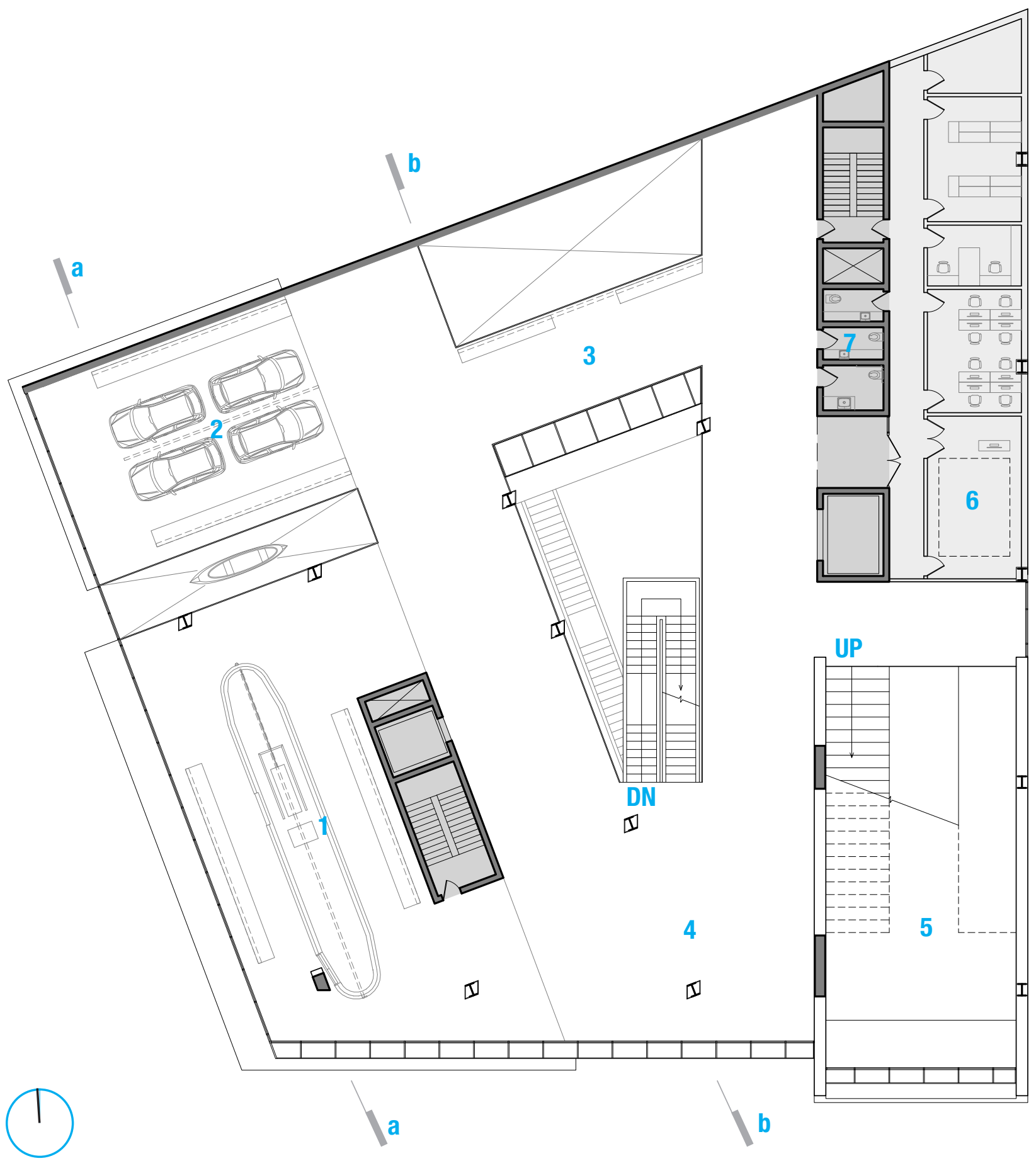

Figure 8.18: Fourth Floor 


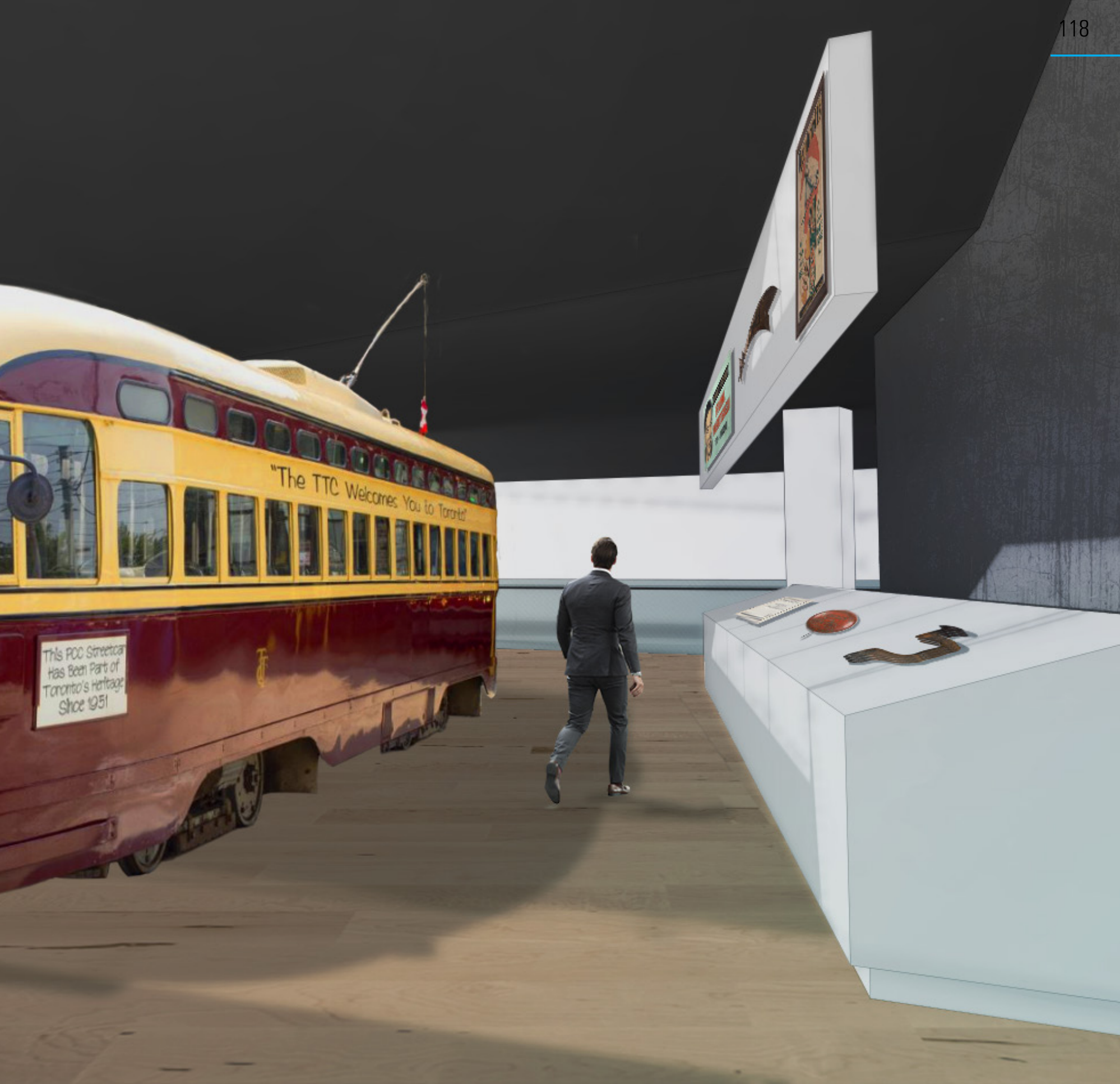

Figure 8.19: Industry and Transportation Gallery 


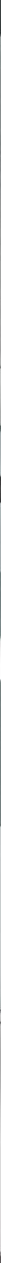

Figure 8.20: Architectural Heritage Gallery 


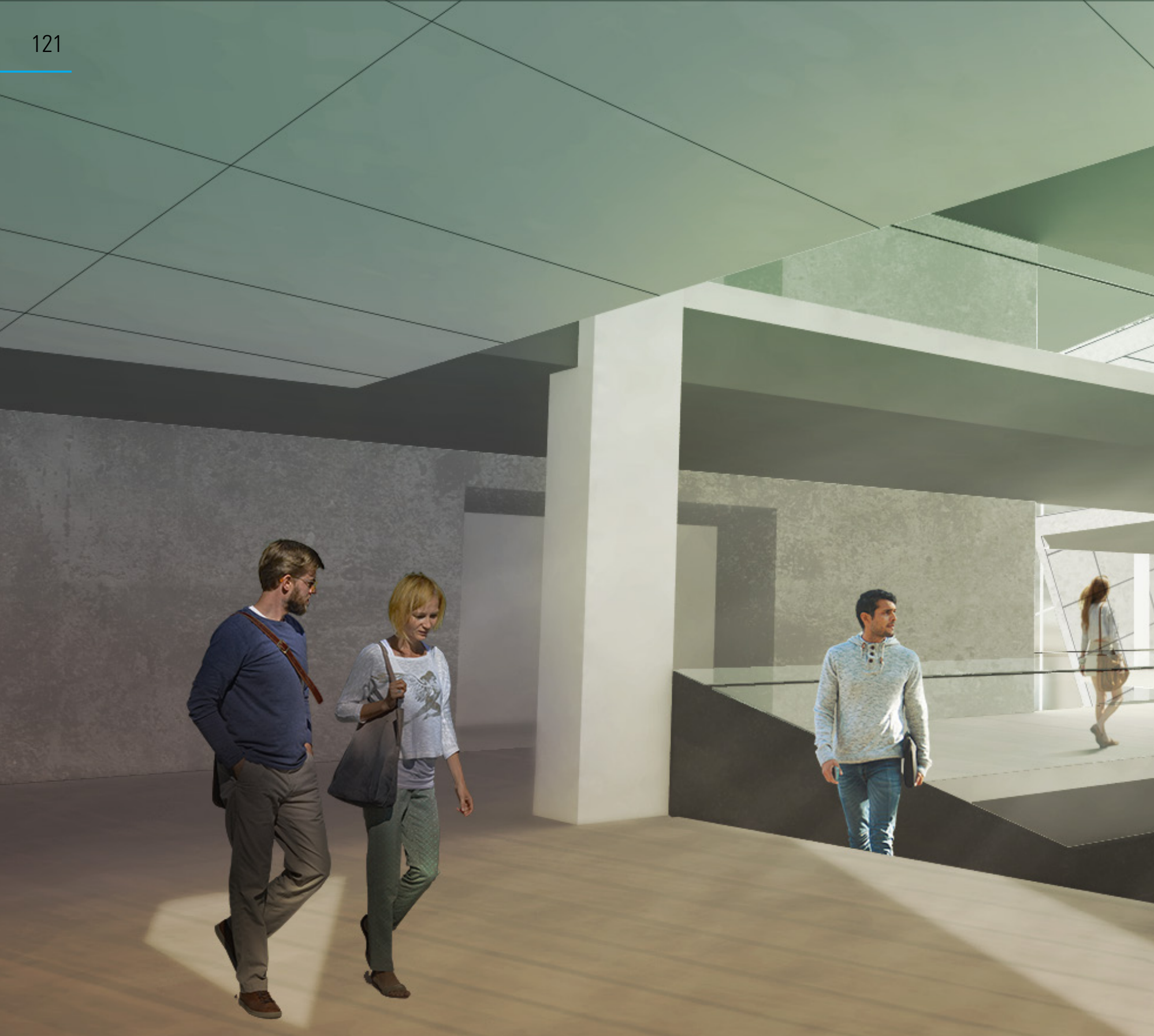




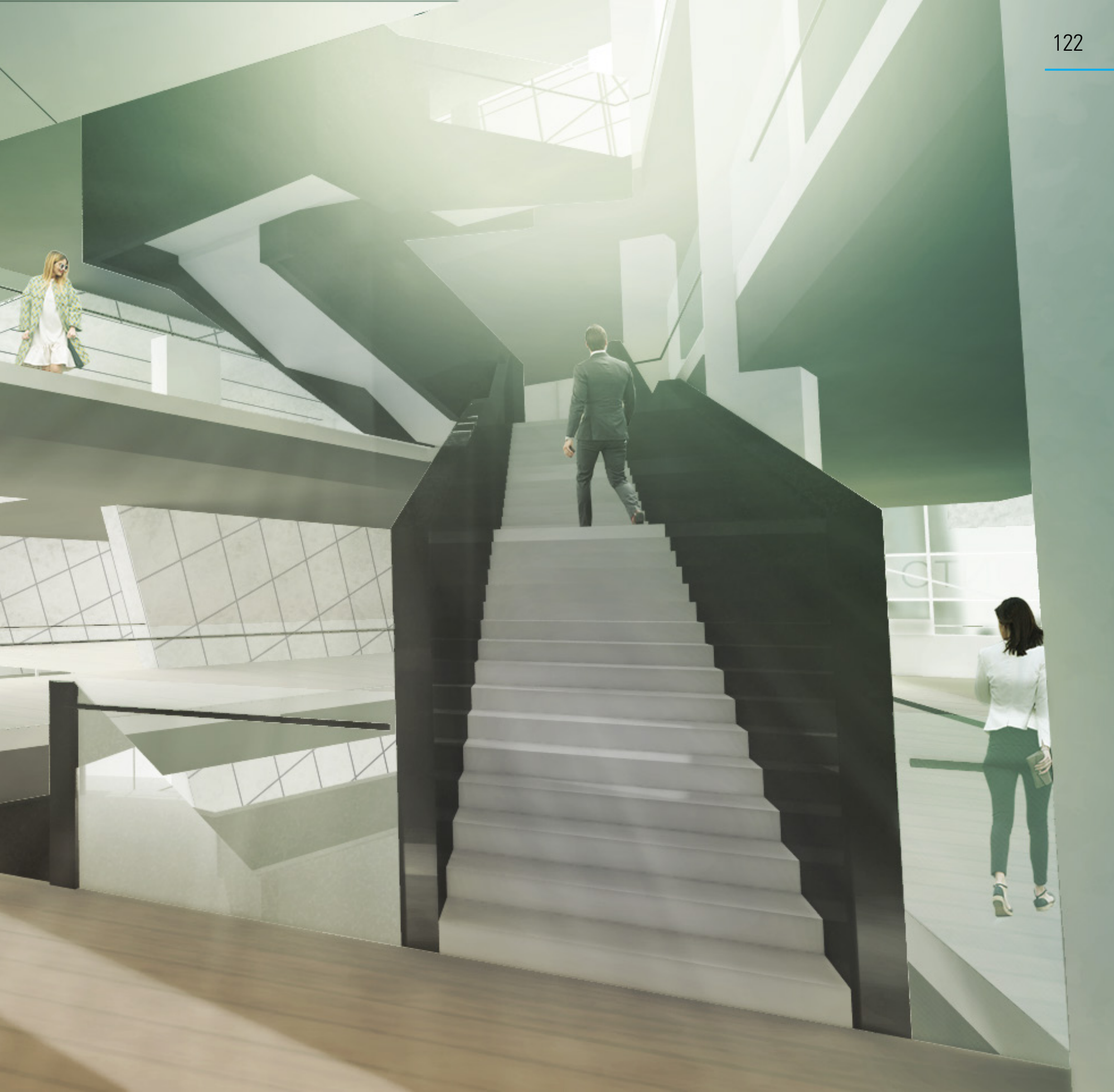

Figure 8.21: Atrium 

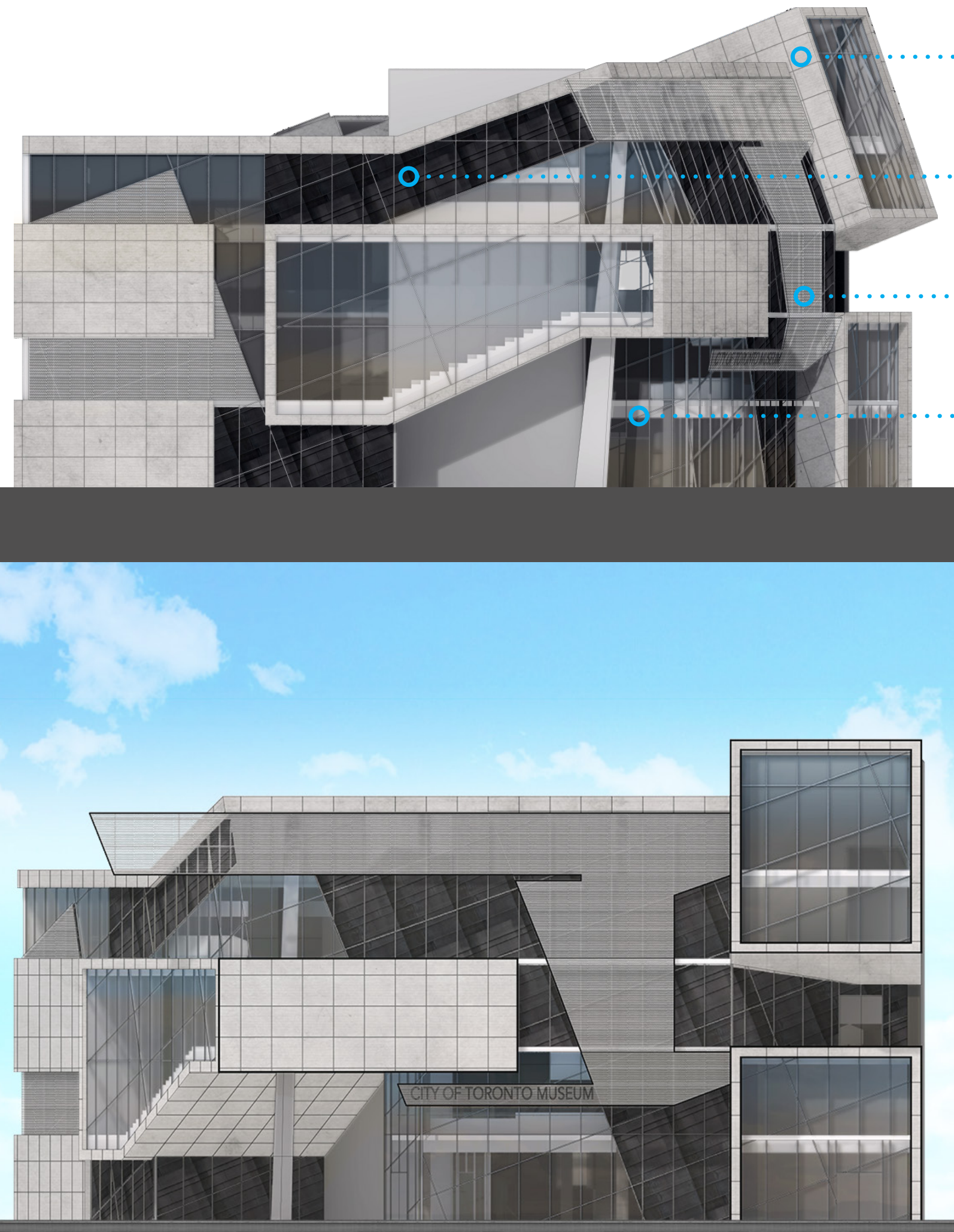
Figure 8.22: Western Material Elevation

Fire-finished Algonquin limestone

IGU zinc-filled

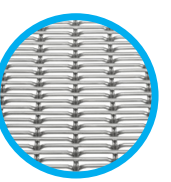

Steel mesh

Reinforced stainless steel mullion

Figure 8.23: Dundas Street West Elevation

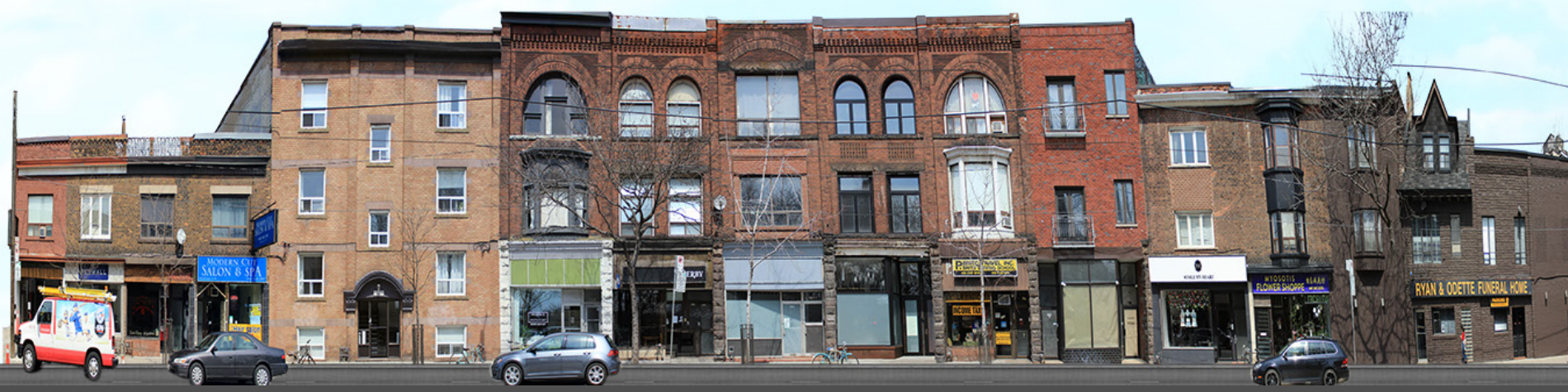




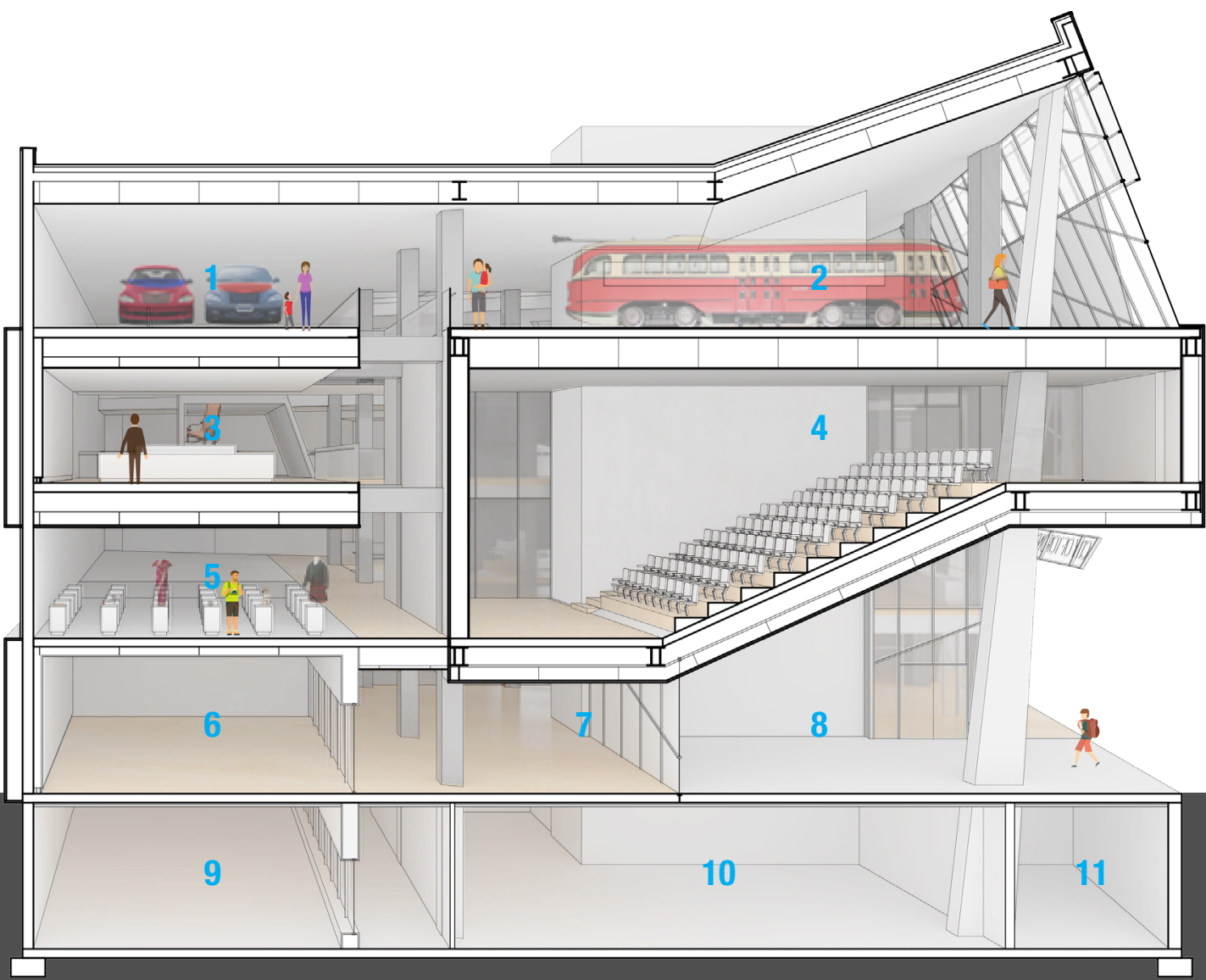

1 education gallery

2 industry \& transportation gallery

3 entertainment gallery

4 125-seat auditorium

5 cultural diversity gallery

6 offices

7 front desk \& coat check

8 entrance

9 archive room

10 mechanical

11 electrical 


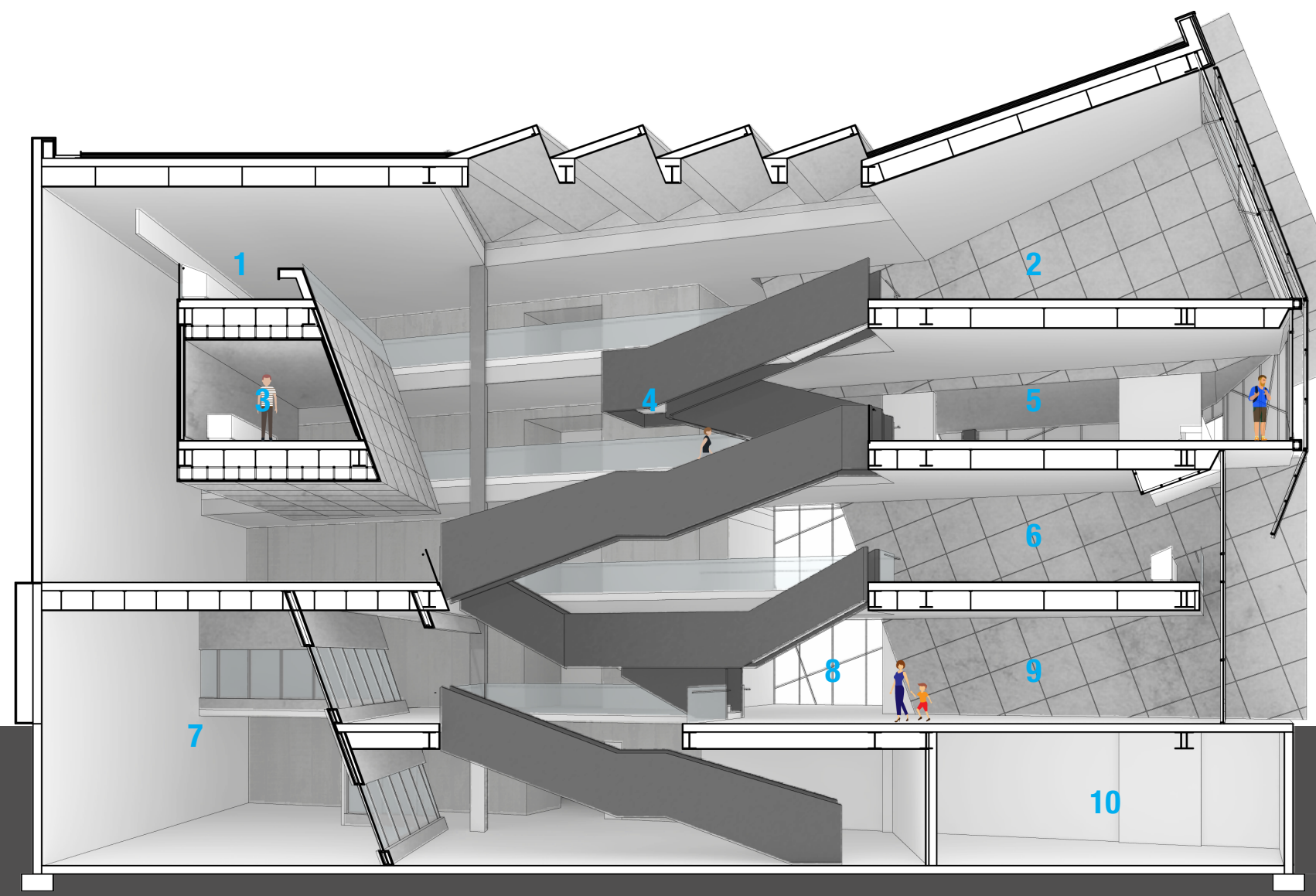

1 architectural heritage gallery

2 civic \& military history

3 women's history gallery

4 central atrium

5 immigration gallery

6 aboriginal heritage gallery

7 archive room

8 lobby

9 temporary exhibit space

10 workshop/prep room 
poured concrete cores

reinforced concrete columns

concrete load-bearing wall

vierendeel truss system

$\square$ steel wide flanges 
8.18 women's history gallery critical examination

Figure 8.27: Dynamic Exhibition Wall
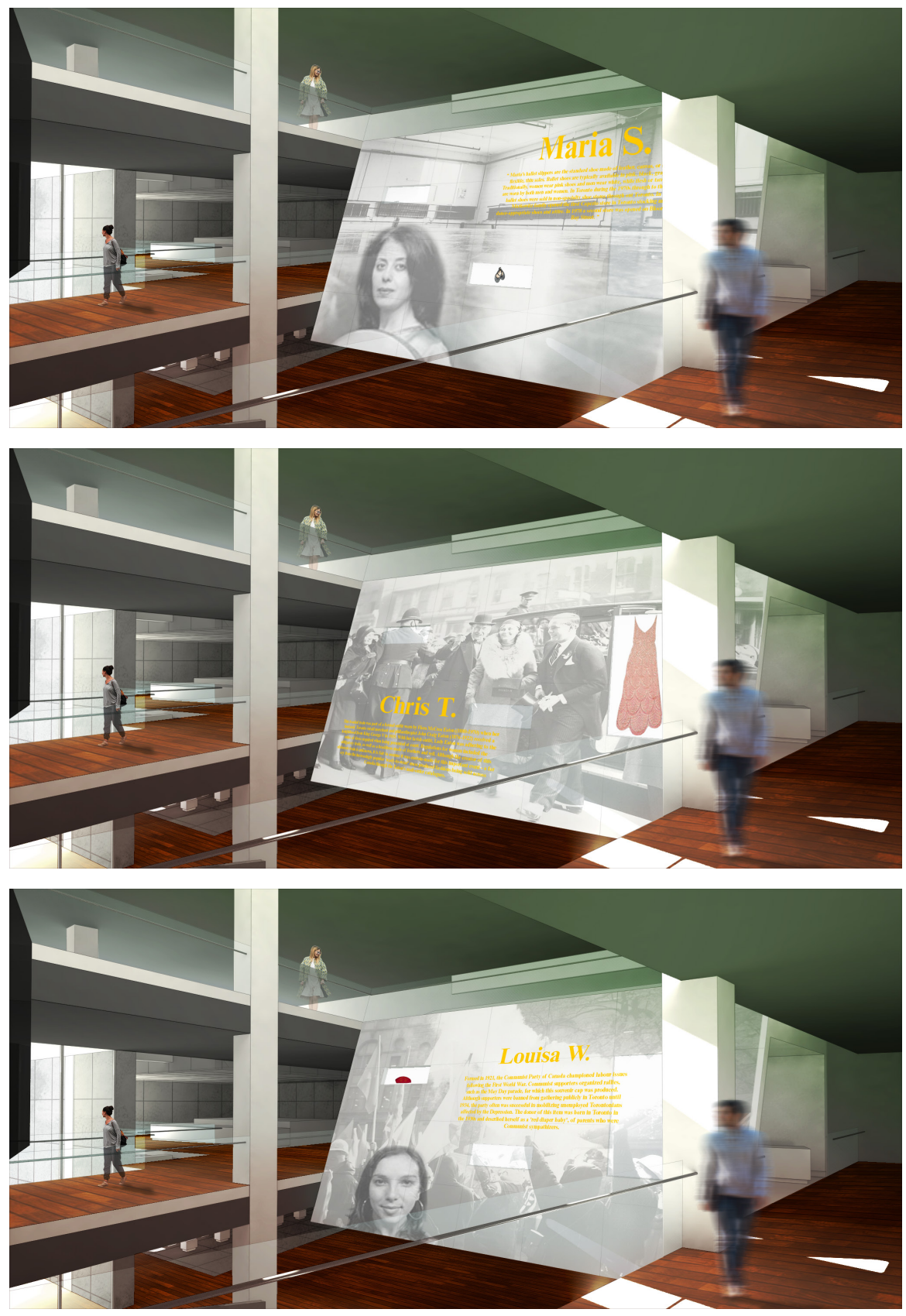


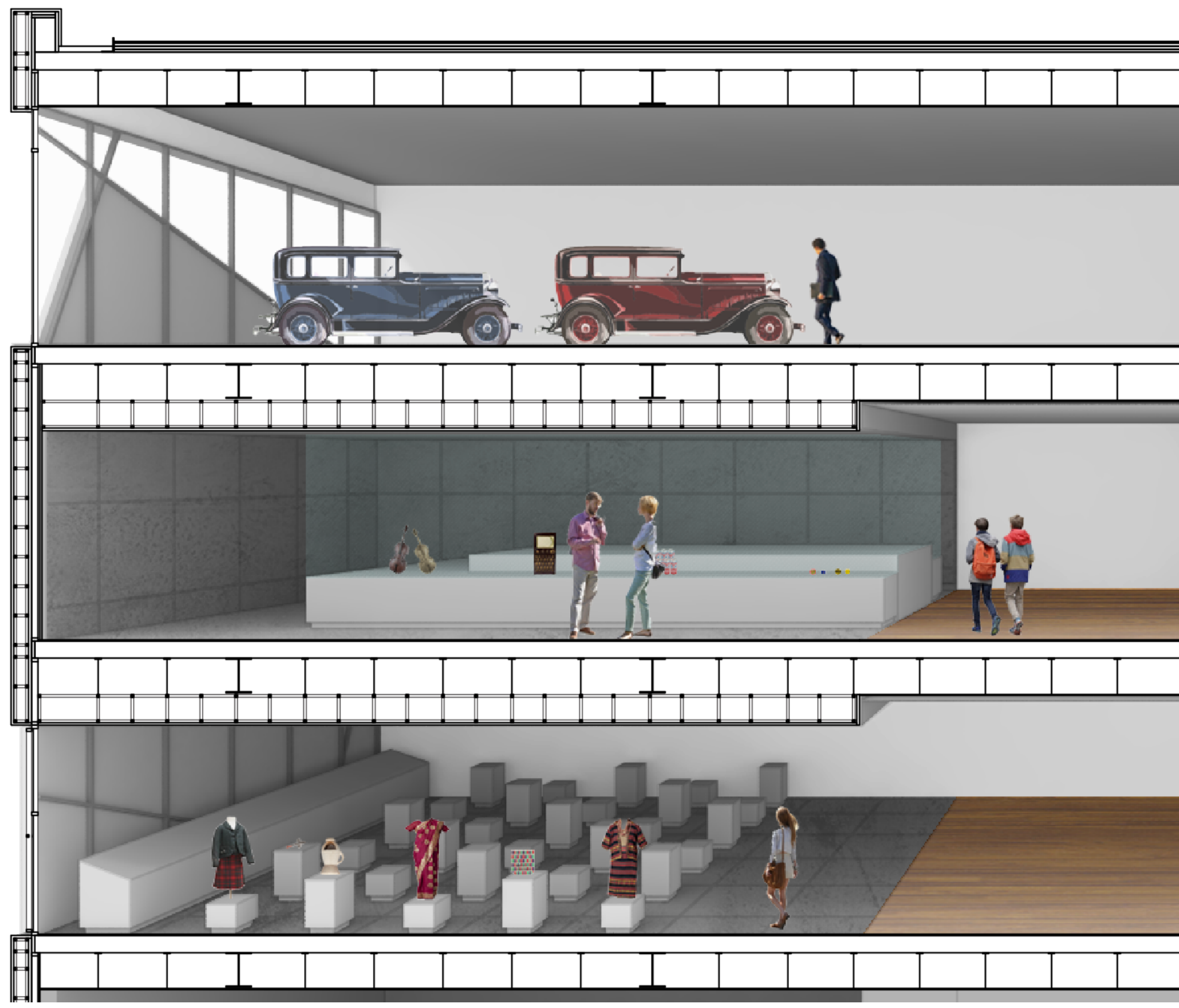

Figure 8.28: Northern Galleries Section 
\begin{tabular}{l|l|l|l|l|l|l|l|l|l|l|l|l|l|l|}
\hline &
\end{tabular}

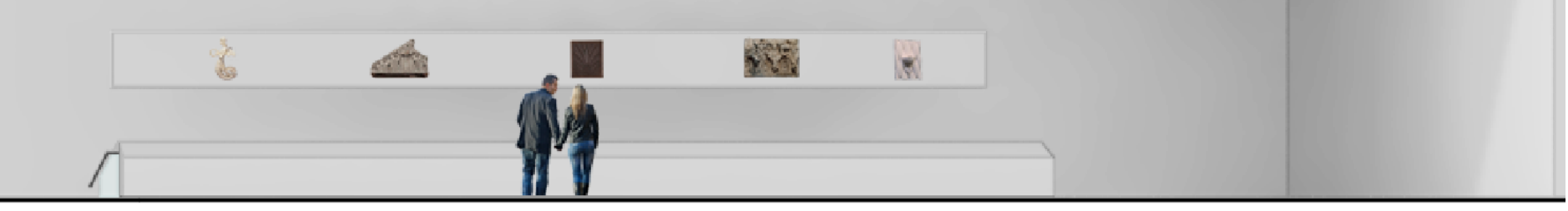

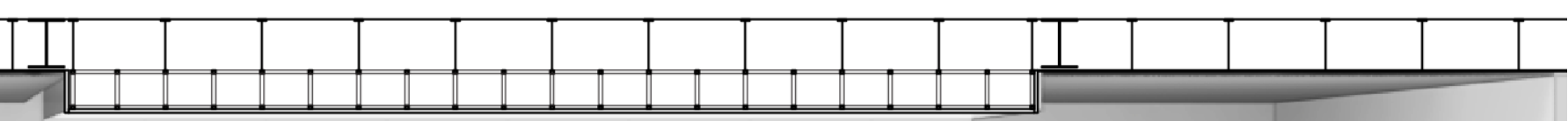

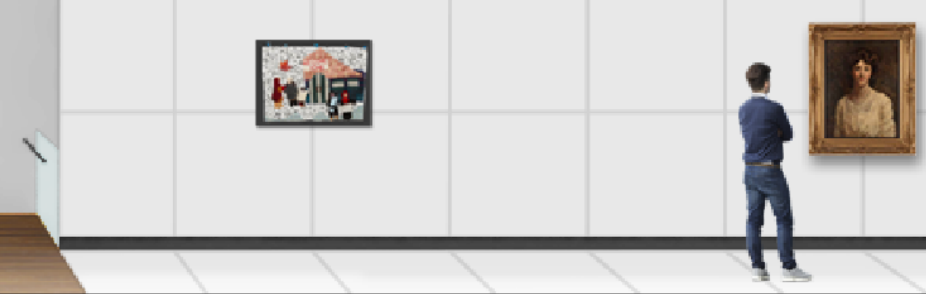

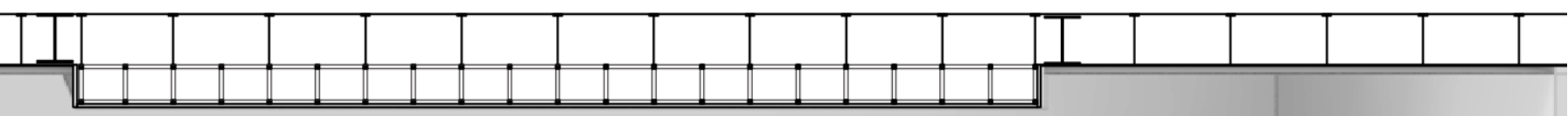

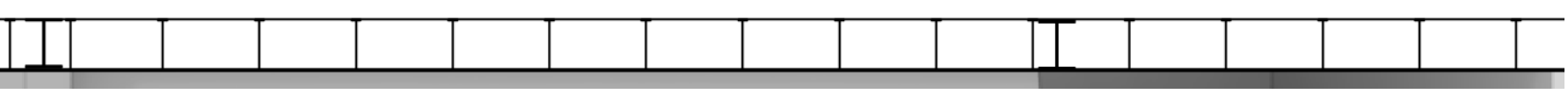

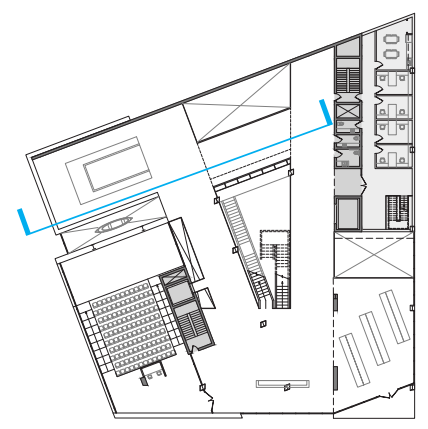




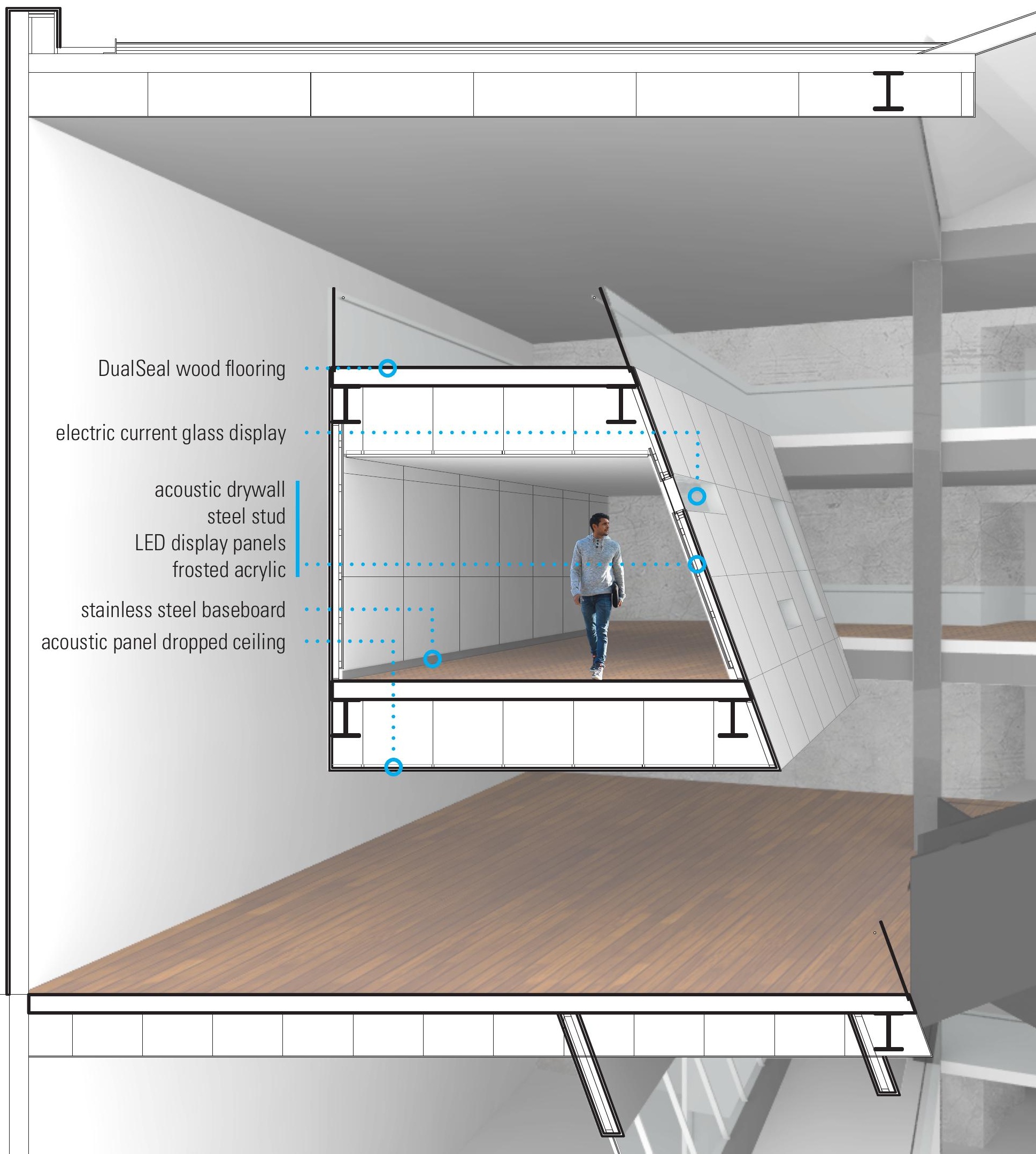


The Women's History gallery serves as a strong demonstration of all the design research and strategies that challenge notions of autonomy in contemporary architecture. It's simple design, in accordance with the multiple architectural grids, reinforces its spatial perceptibility throughout the entirety of the museum. By embedding its volume within the larger gallery space, an increased sense of programmatic awareness, cohesion and function is created in relation to many of the other spaces spread throughout the building.

While ideas of integration, continuity and connectivity to enhance the architectural experience of the museum can be found it its form, circulation, and sensorial experience, the Women's History serves as a programmatic represenation of these ideas. Architecturally, the gallery reinforces the presence of the tertiary order created by the rotated grid to challenge of the perception of autonomy and isolation. This idea is most easily recognized in section, as it has a clear relationship to the atrium, the central staircase, the surrounding gallery spaces, even the archive room beneath the museum.

To the museum's visitors, the Women's History gallery serves as a major point of reference. It allows the user to have a strong visual sense of spatial perceptibility as they circulate throughout the musuem. This idea of constant continuity and reconnectivity is foreign to contemporary design in large, multiuse buildings in Toronto.

As an exhibition space, the unique design of the gallery allows for a multiplicity of engagements. It can accomodate for a more traditional viewing experience of delicate artifacts on the interior, where lighting can be controlled and acoustics are isolated, and can communicate more nontraditional artifacts to the exterior along its angled wall. This canted surface functions as a dynamic display for the rotating items in the museum's collection (see Figure 8.27). 
9.0 CASE STUDIES 

9.2 très grand bibliothèque (1989) oma

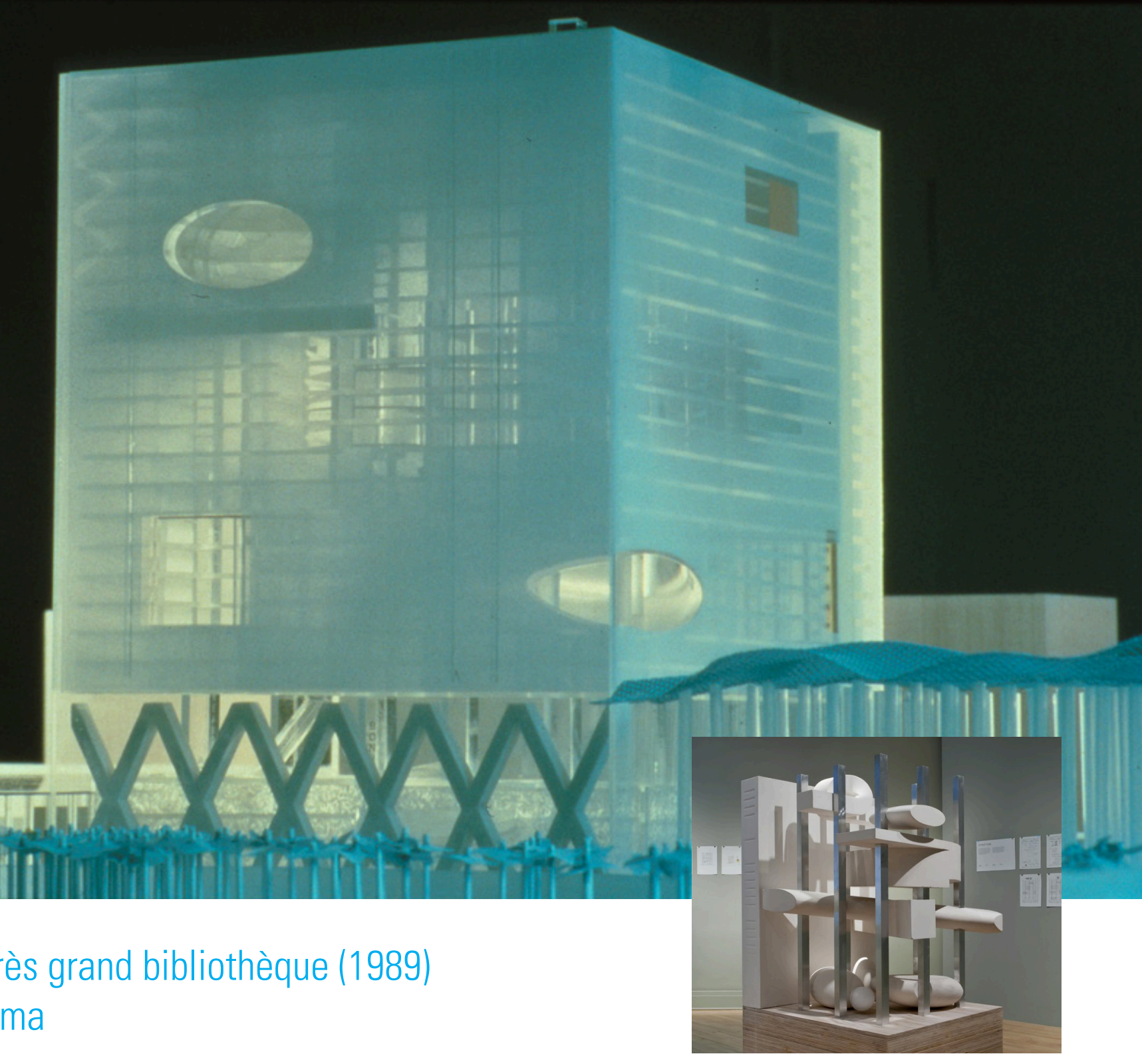

Rem Koolhaas' proposal for the Très Grand Bibliothèque in Paris stems directly from his critique of the New York Athletic Club. The competition outlined required program space for 5 libraries: reference, recent aquisitions, catalogues, moving images, and scientific research. OMA's proposal resulted in a large, dense conceptual volume of information in which all 5 libraries blended into each other. The volume was not bounded by a typical ordering system (although the design was supported by a 9 column grid for pragmatic purposes and not theoretically). This concept critiques the notion of contiguous programming. Interaction is no longer defined by flat-stacked floor plates, but is manifested as an ambiguous matrix of volumes. The building is further reinforced by a singular winding channel of public space that carves through the library block. This strategy inverts the typical solid-void relationship in which the library space is subordinate to the public spaces. Naturally, the singular public corridor enhances opportunity for social encounters of great intensity. 



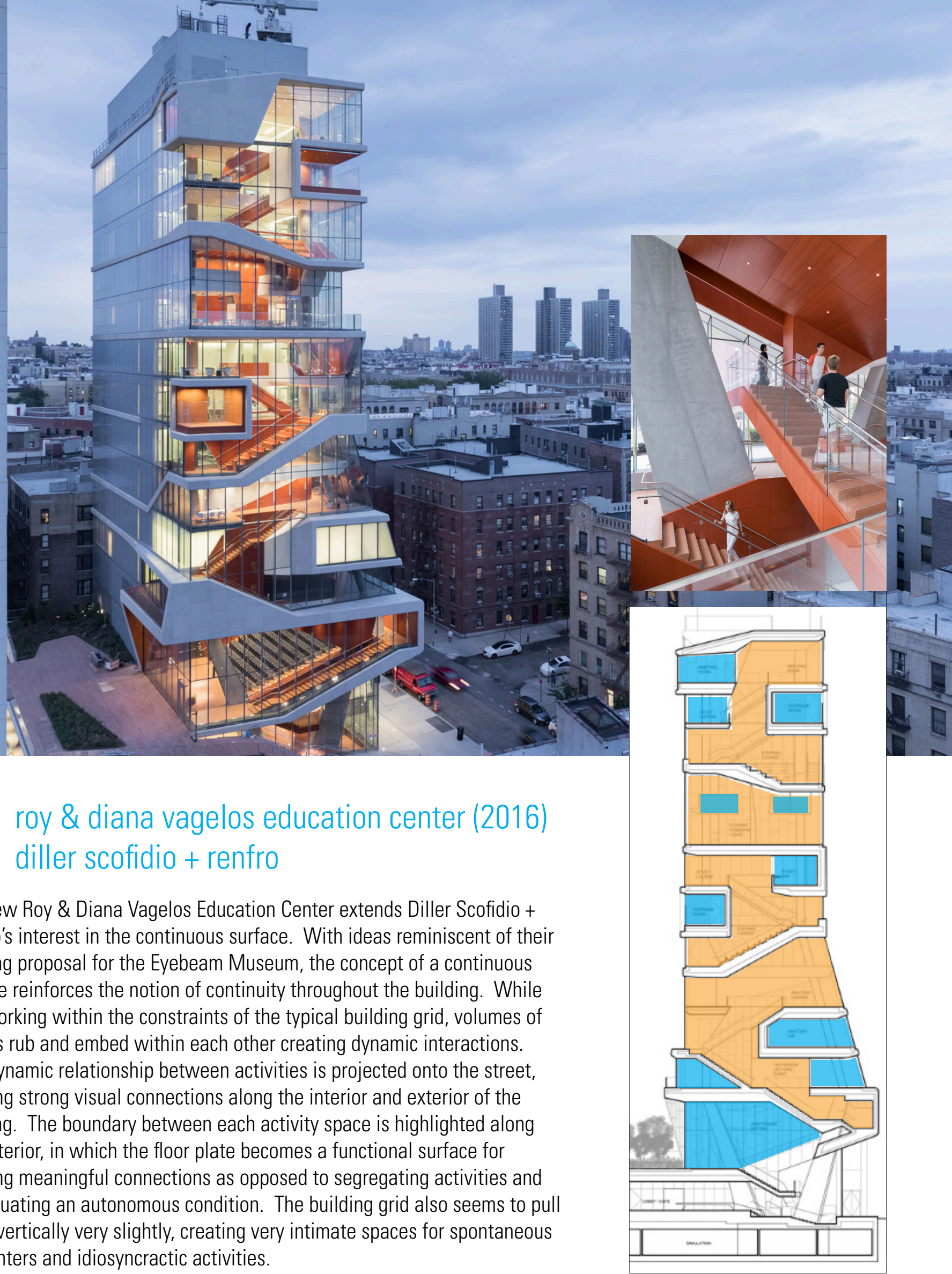




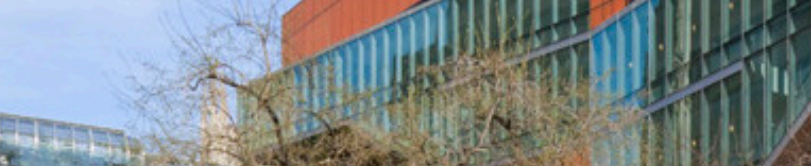

\section{6 the diana center at barnard college (2010) weiss/manfredi}

The Diana Center at Barnard College strategically orchestrates a bissecting centralized activity space throughout the educationational building, highlighting the social activitiy on campus. A variety of study spaces begins to melt into one large social hub, as various human activities can be observed throughout various levels of the building. Whether you are looking into the central space from the exterior, from one of the adjacent ancillary spaces, or from the parkette and street, varying degress of seehear contacts can be made. The central study spaces reinforce a continuity throughout the building, absolving any notion of autonomous activitiy that may exist in isolation. 



\subsection{APPENDIX}

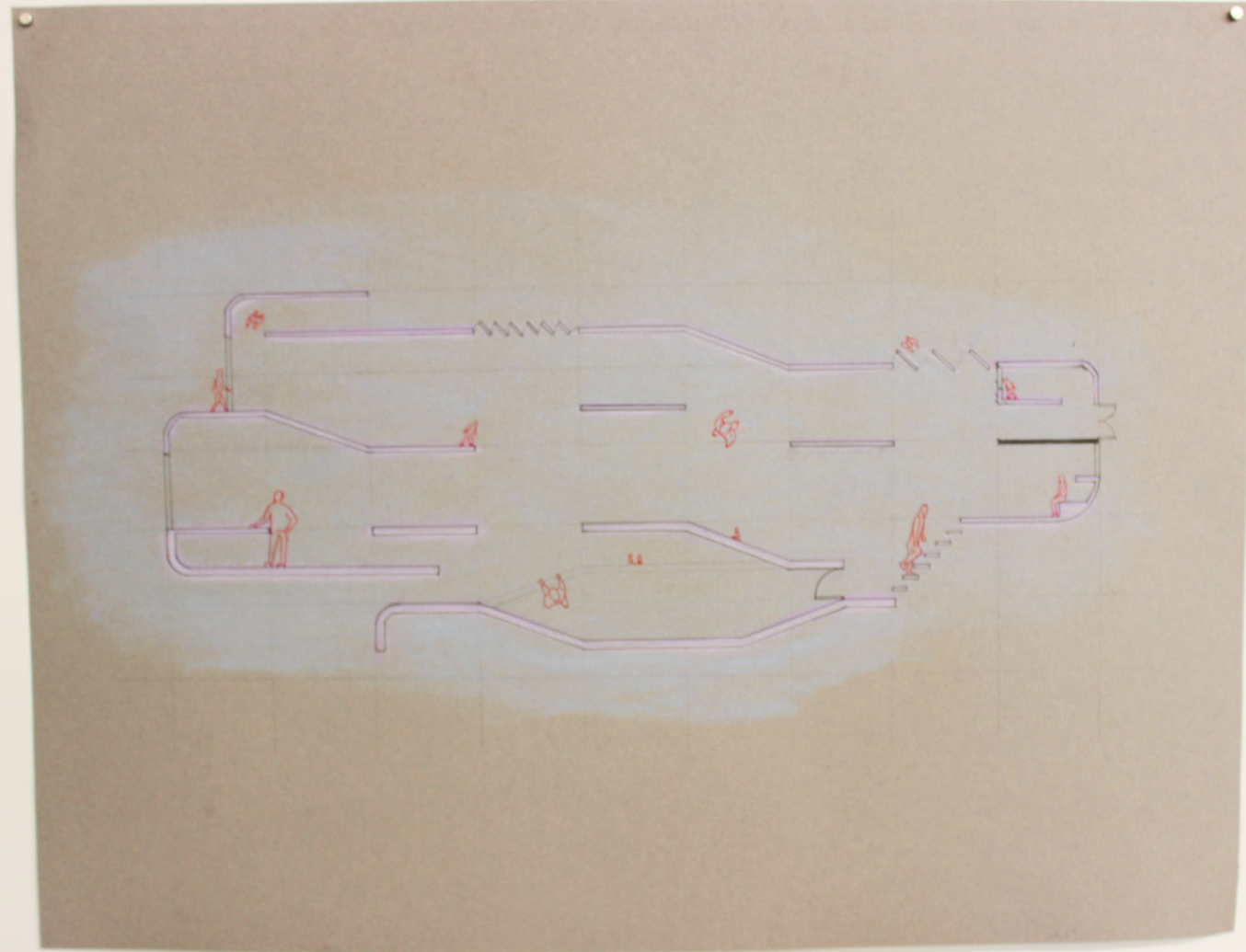

Figure A.1: Ambidextrous Reality 1 


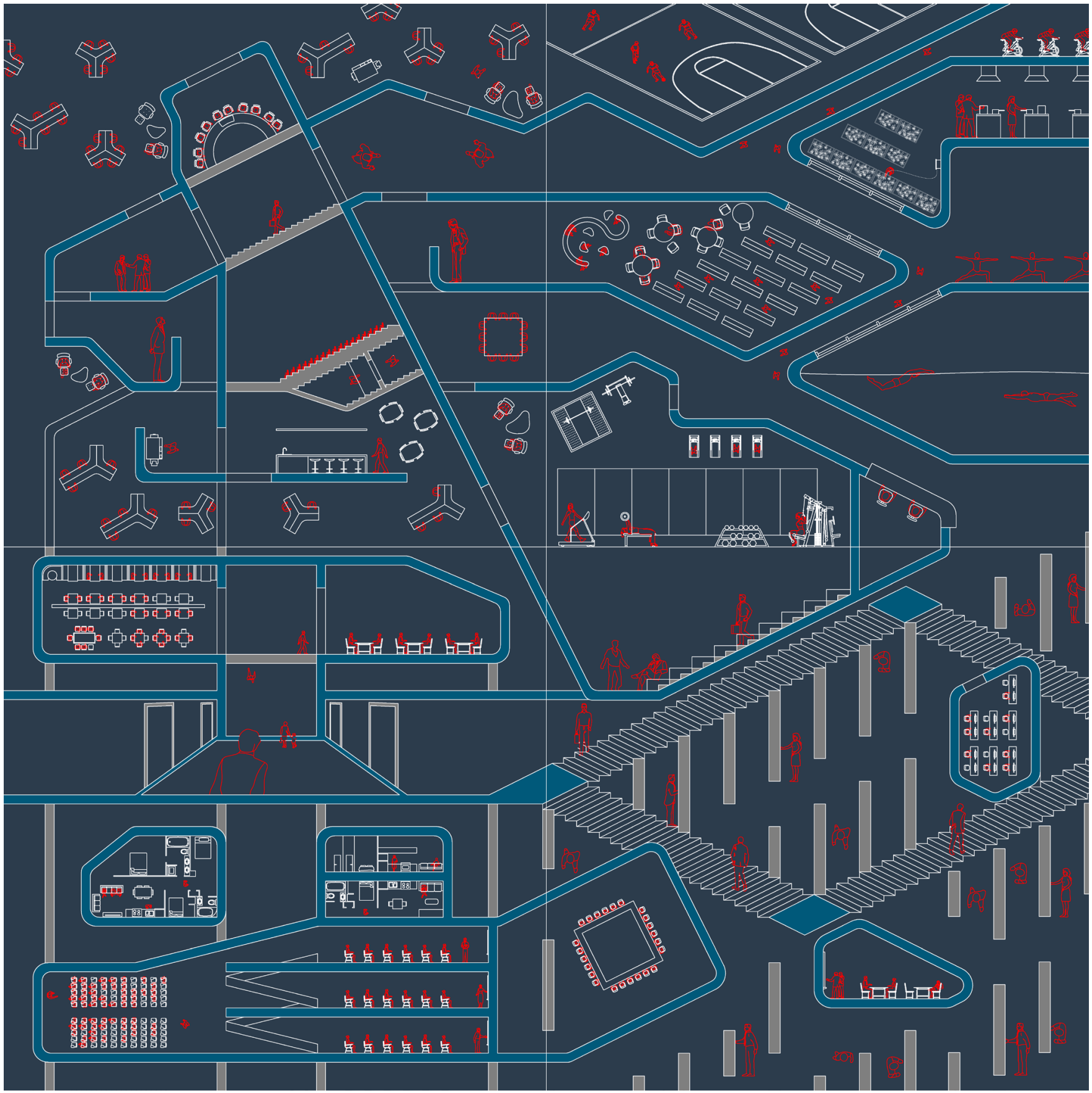

Figure A.2: Ambidextrous Reality 2 


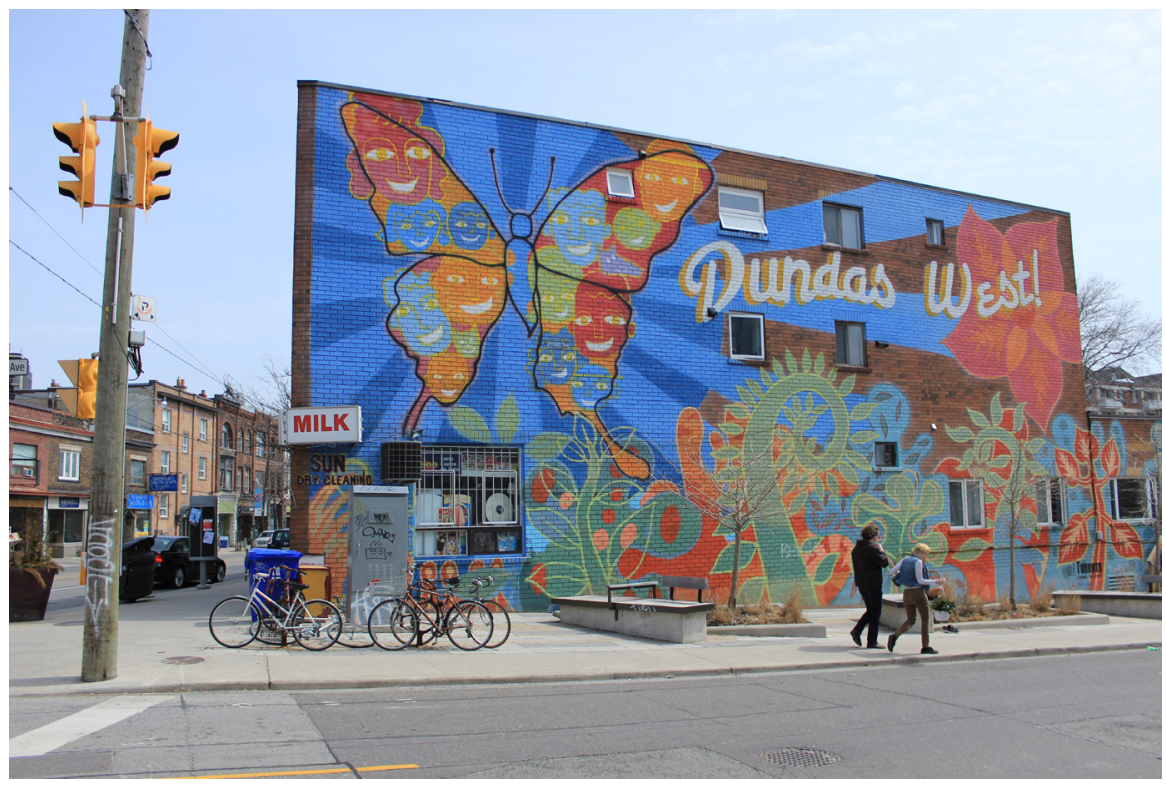

Figure A.3: Neighbourhood Mural 1

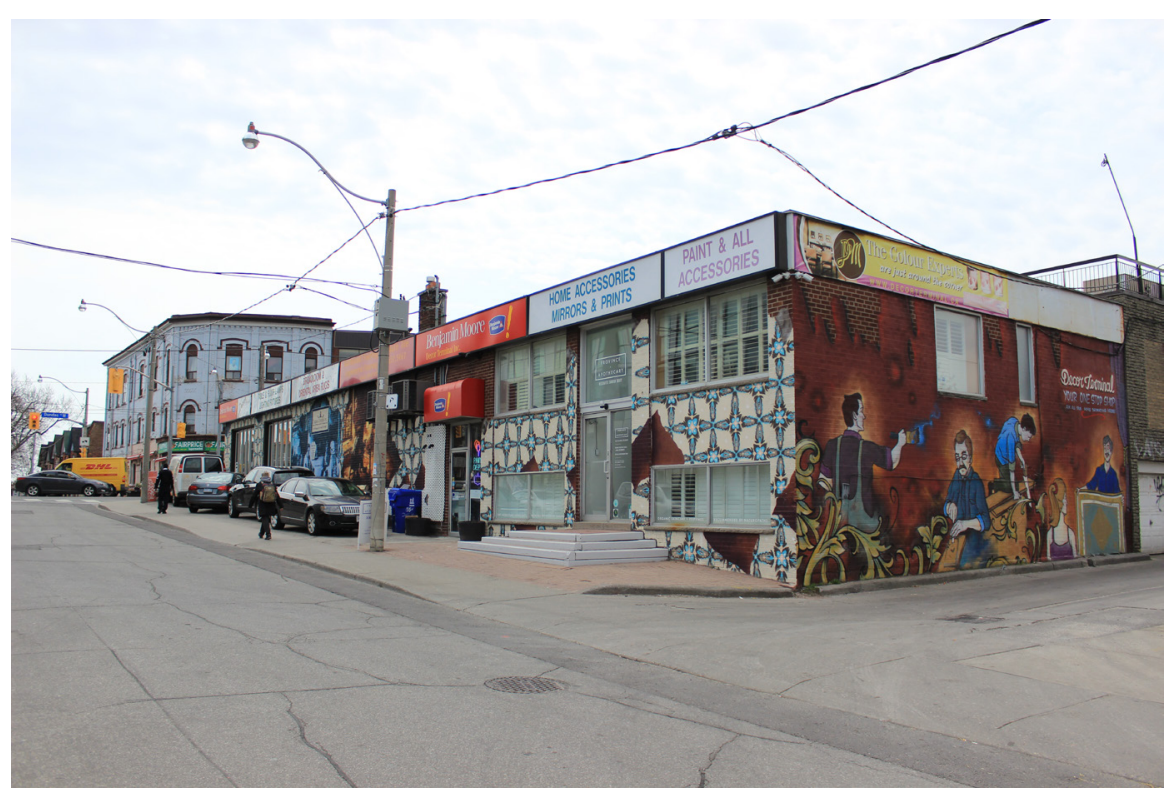

Figure A.4: Neighbourhood Mural 2 
Figure A.5: Lula Facade \& Alley

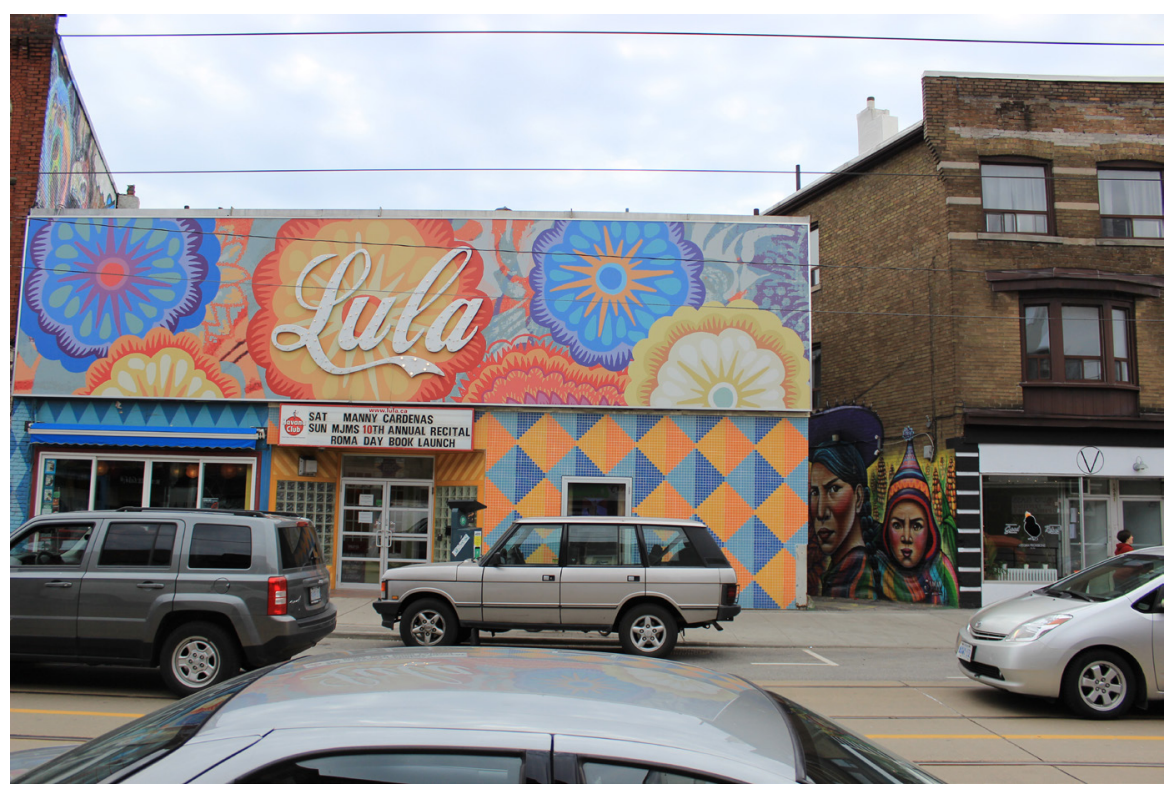

Figure A.6: Lula Alley Mural

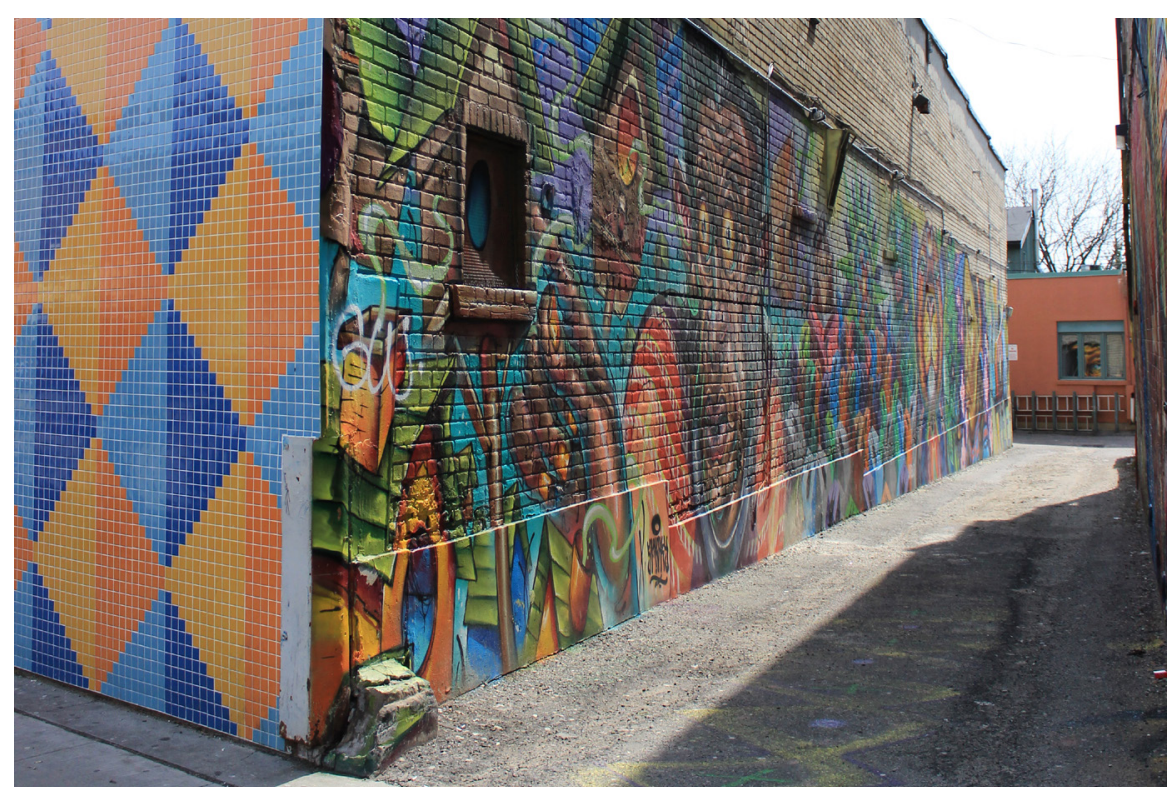




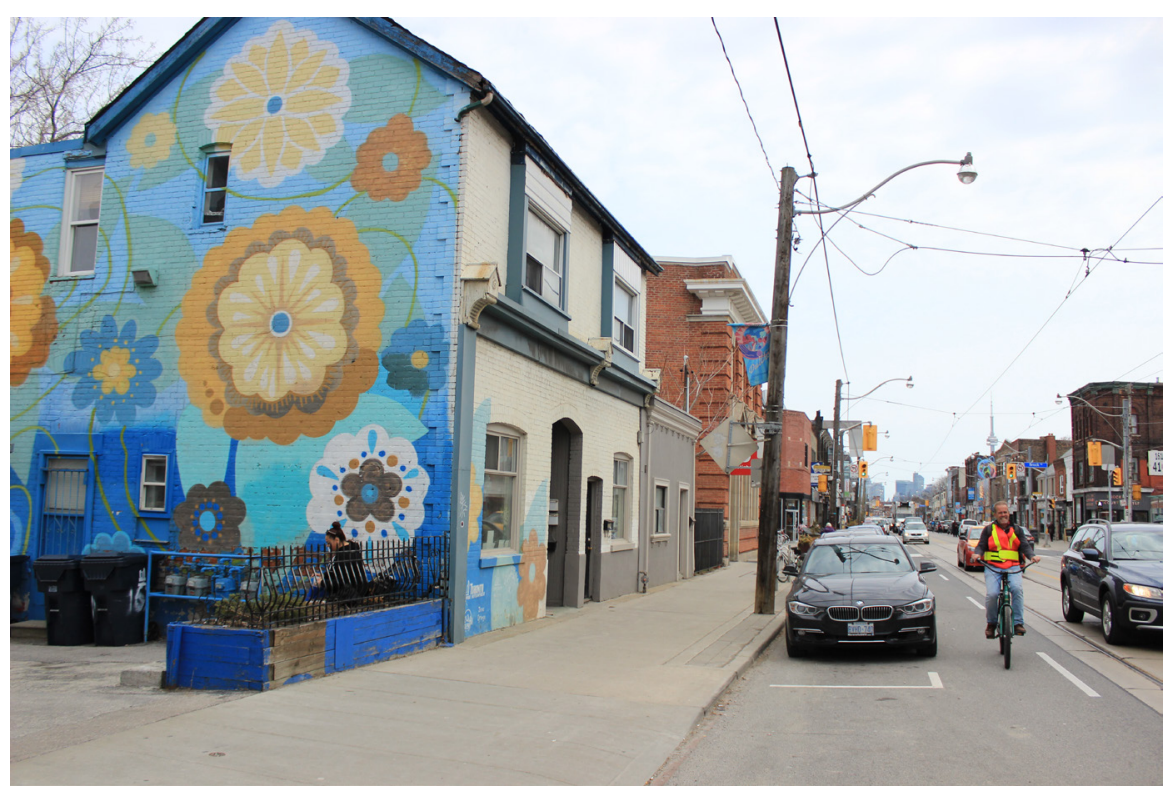

Figure A.7: Neighbourhood Mural 3

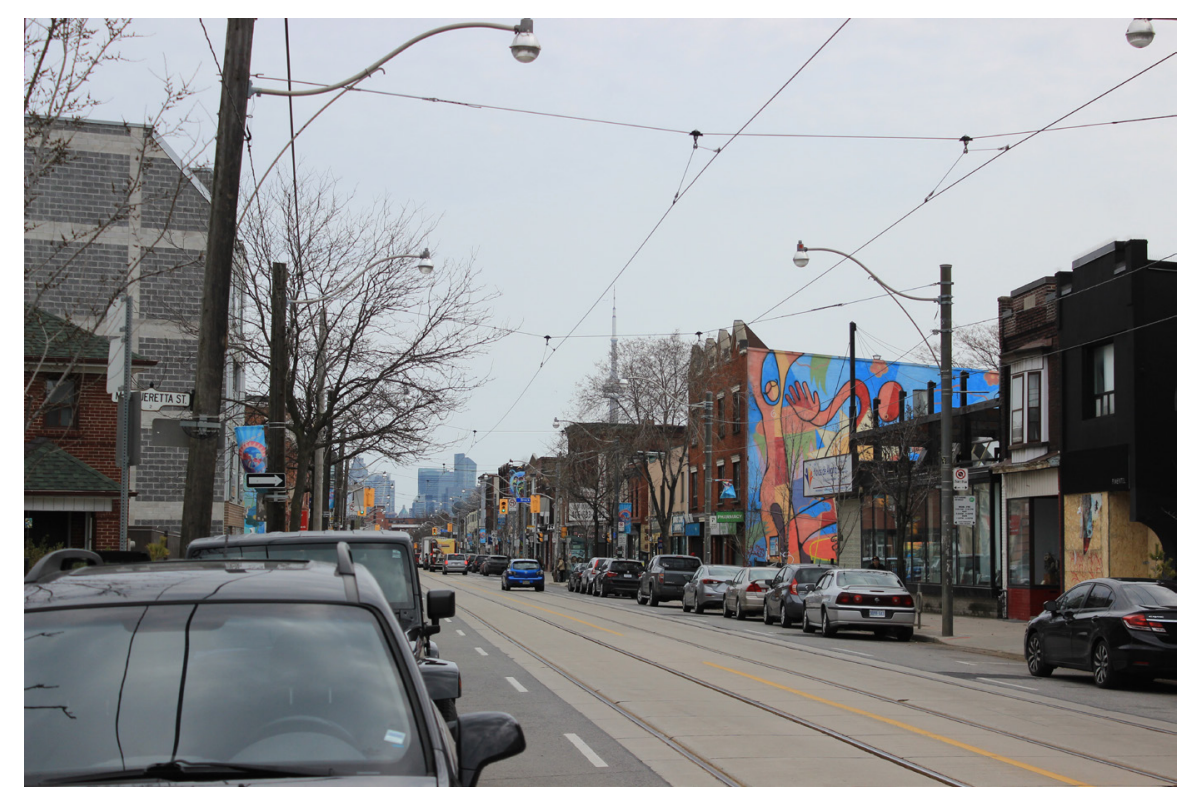

Figure A.8: Neighbourhood Mural 4 
Figure A.9: Building Grid Condition 1
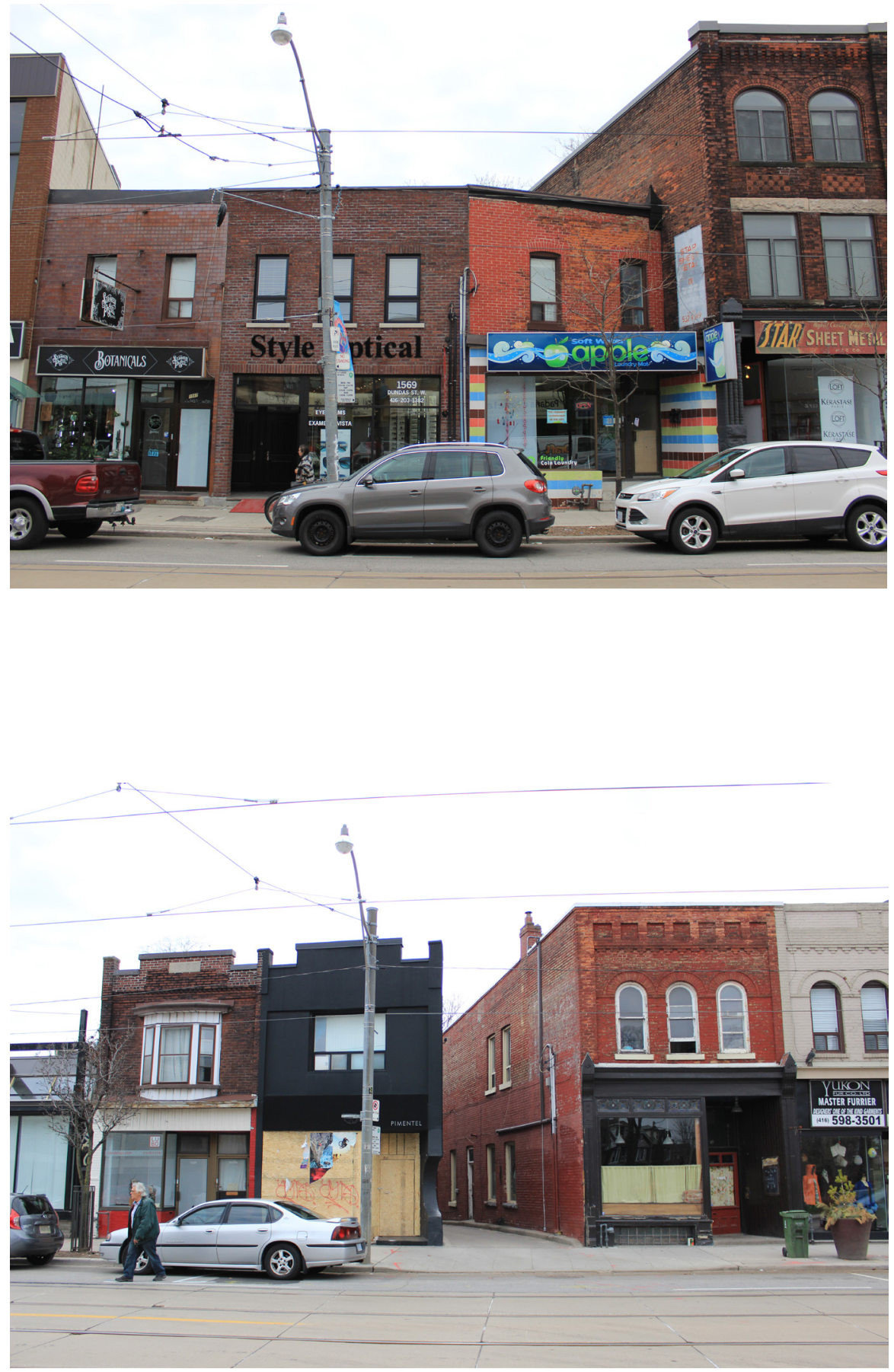

Figure A.10: Building Grid Condition 

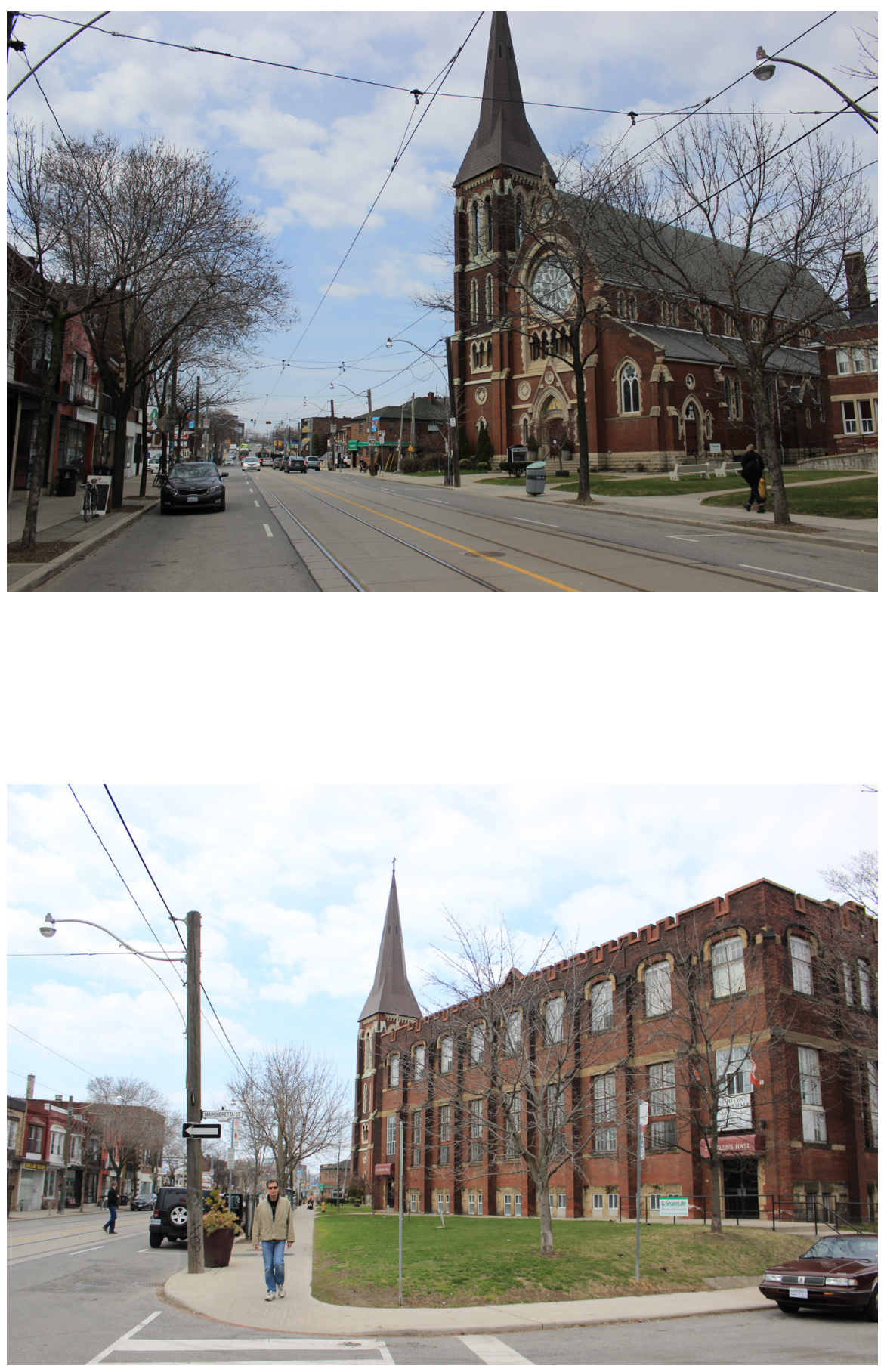

Figure A.11: Little Portugal Cultural Institution: St: Helen's Church 1

Figure A.12: Little Portugal Cultural Institution: St: Helen's Church 2 
Figure A.13: Current Site Condition 1

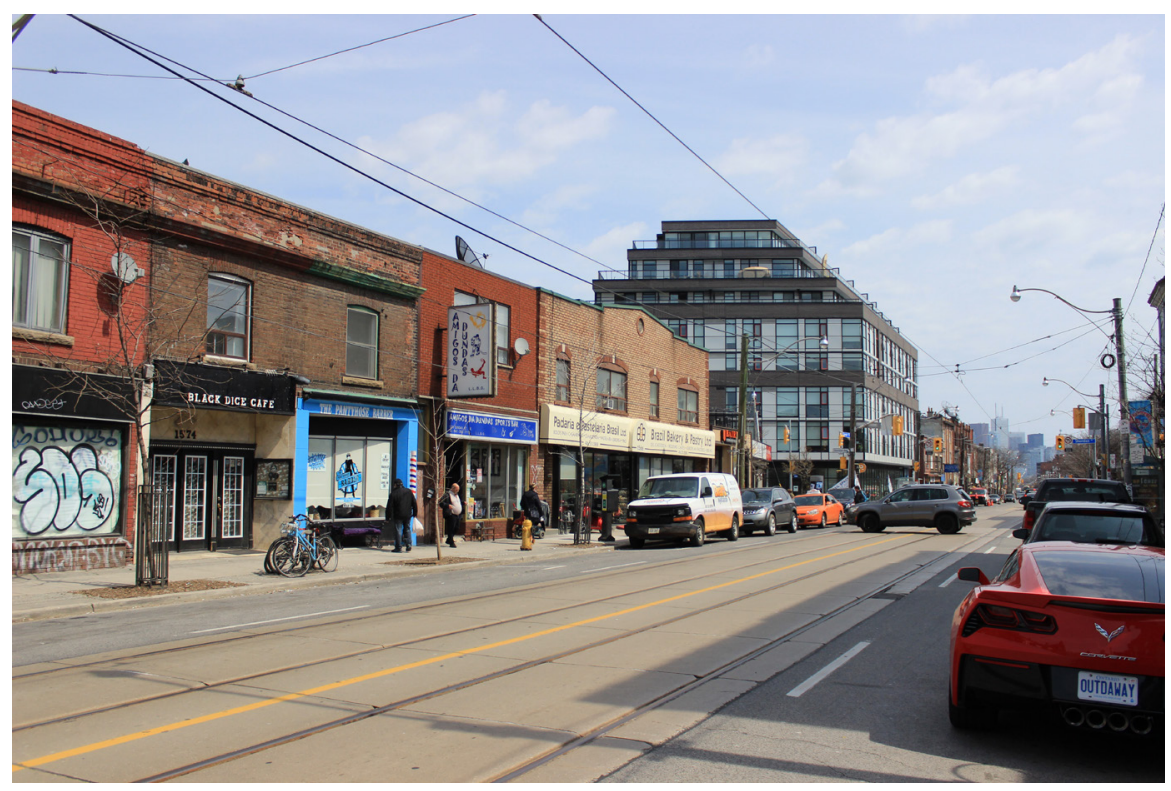

Figure A.14: Current Site Condition 2

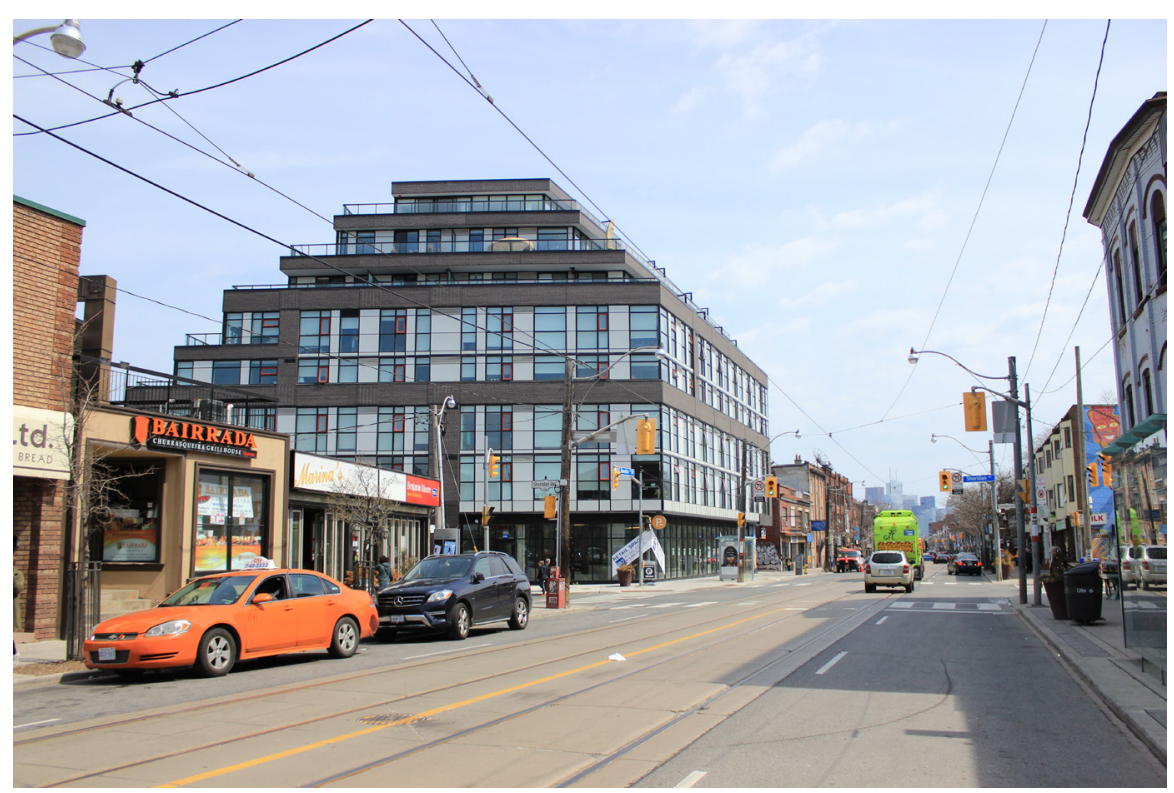




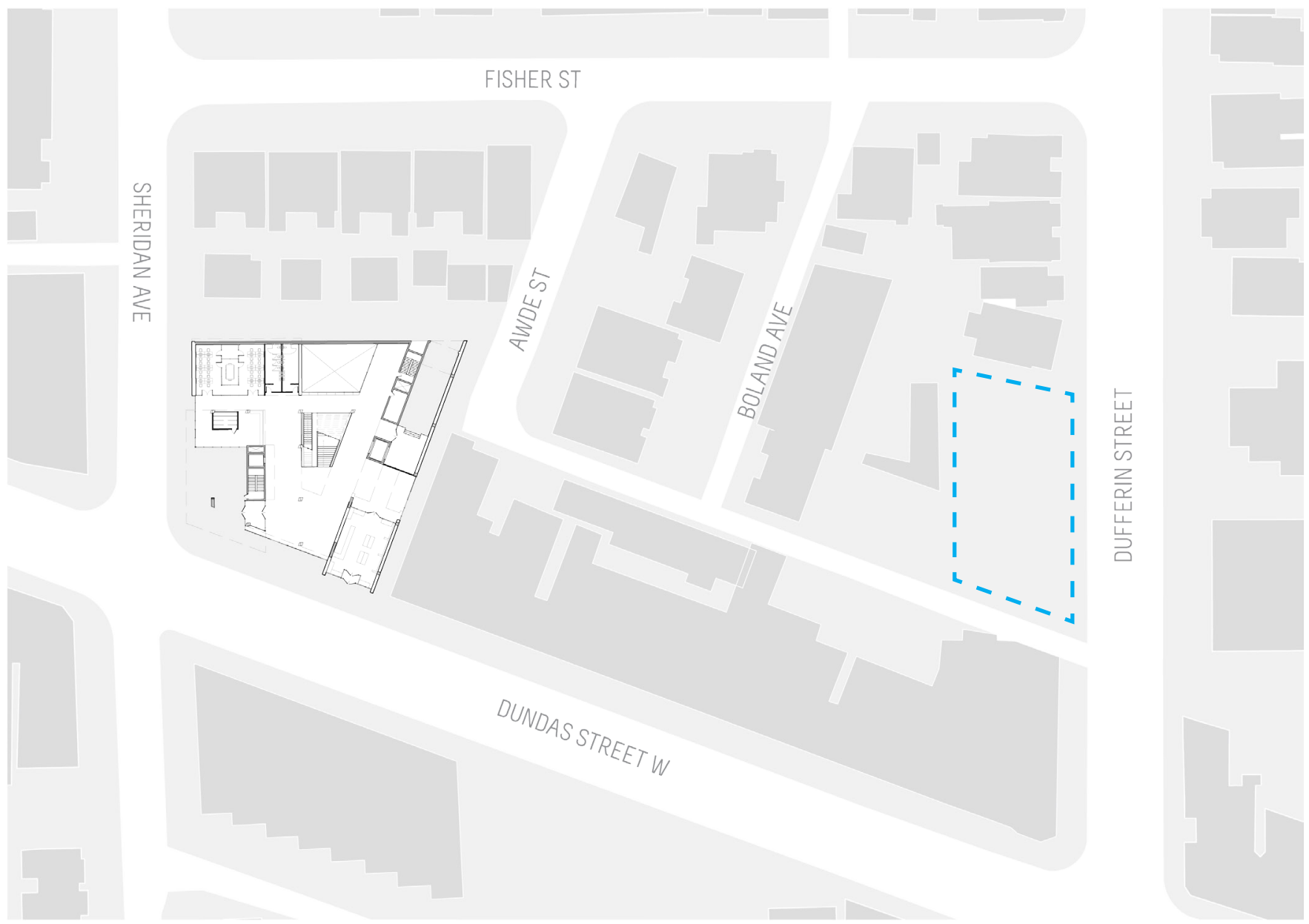

Figure A.14: Parking 


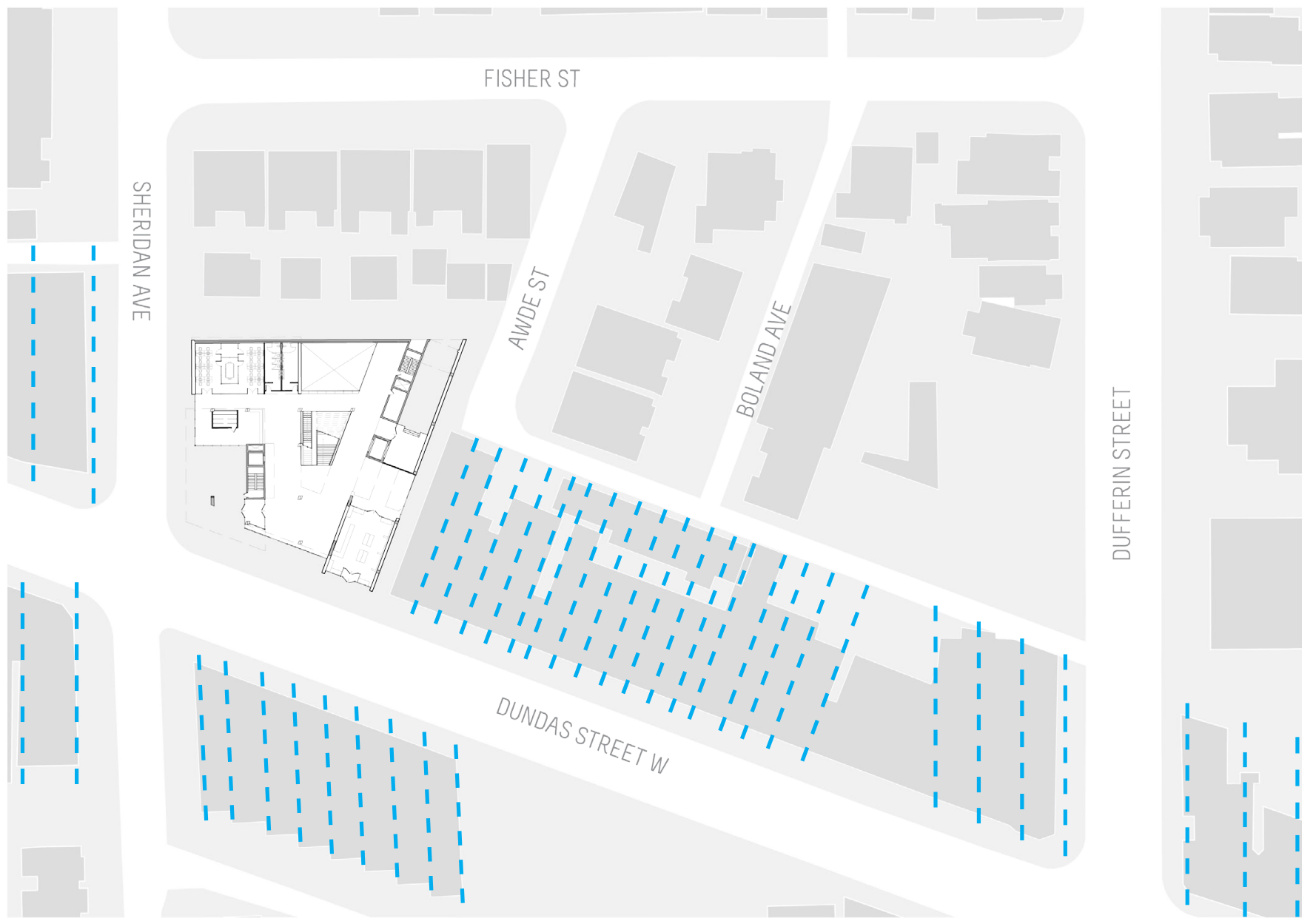

Figure A.16: Building Block Orientation 


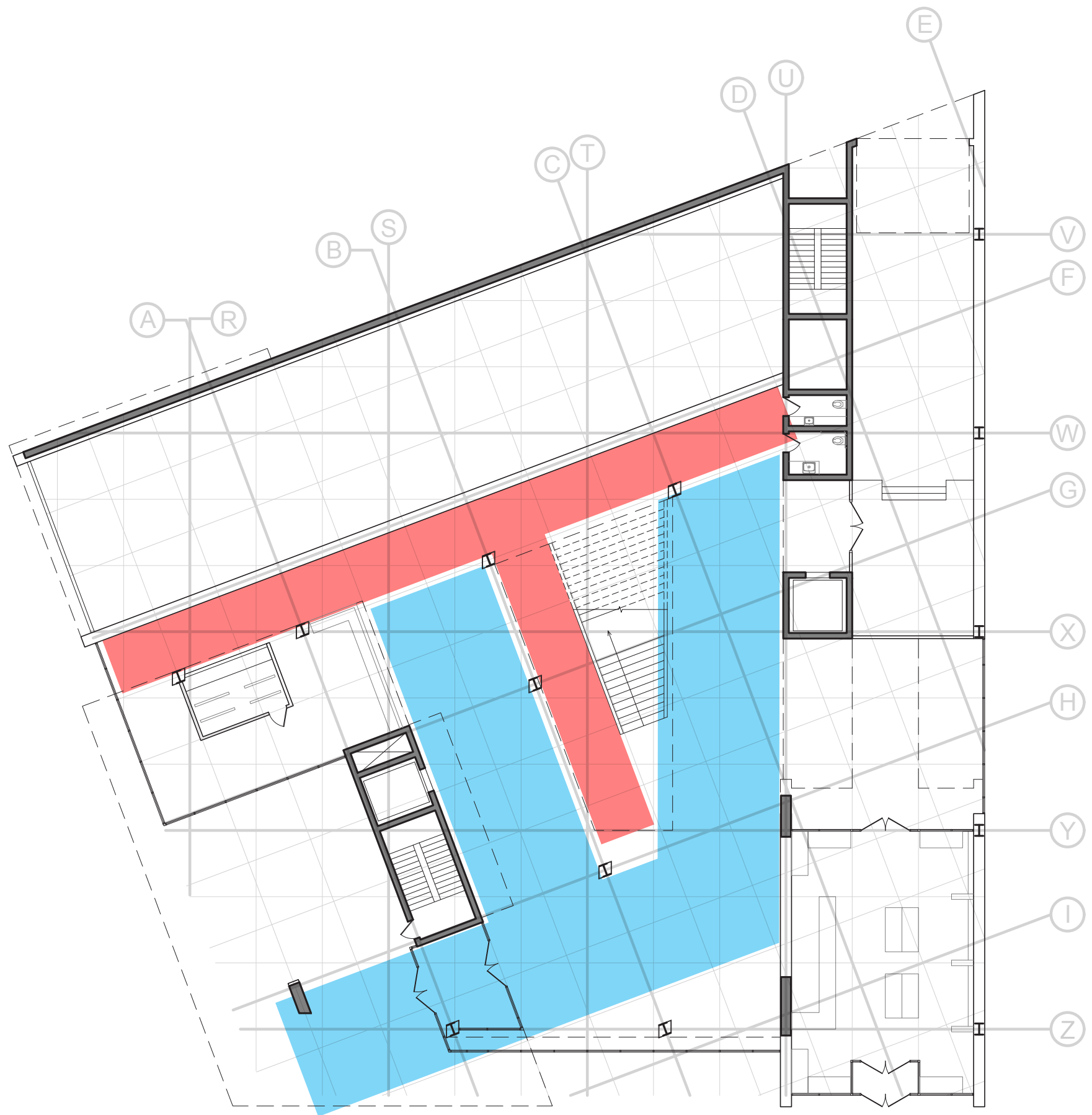

Figure A.17: Ground Floor Circulation Hierarchy 
(E)

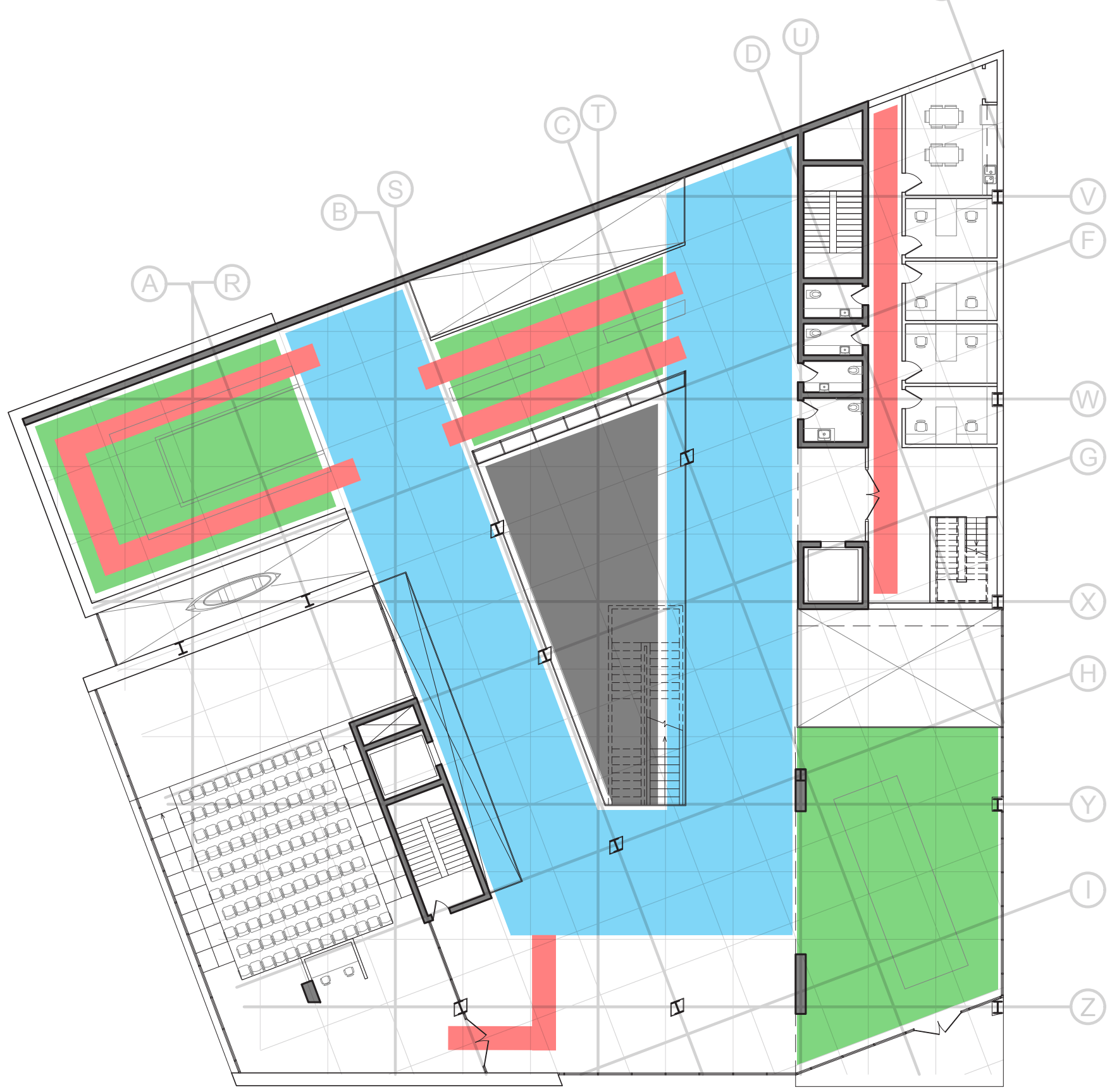

Figure A.18: Second Floor Circulation

Hierarchy 


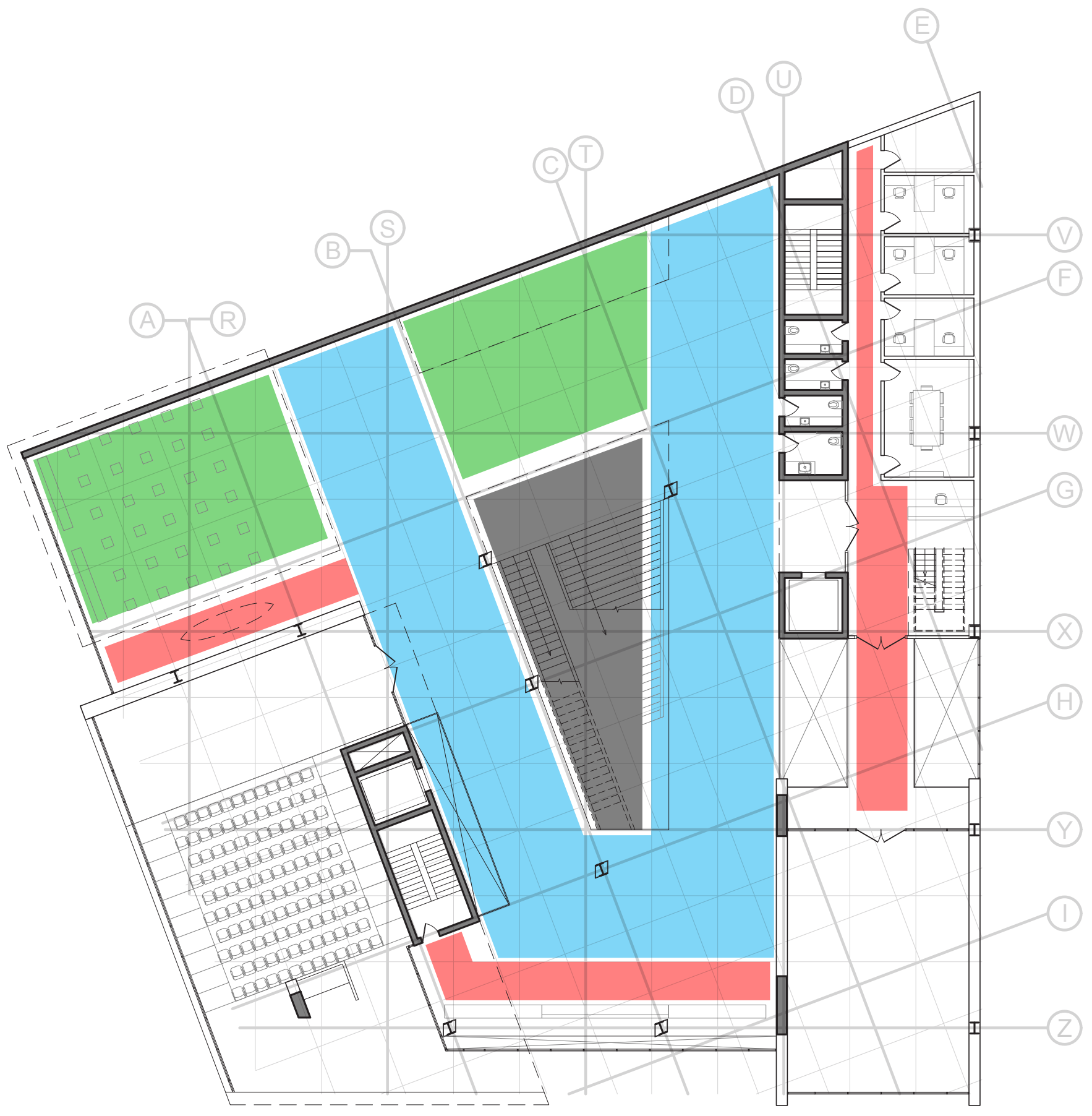

Figure A.19: Third Floor Circulation Hierarchy 
(E)

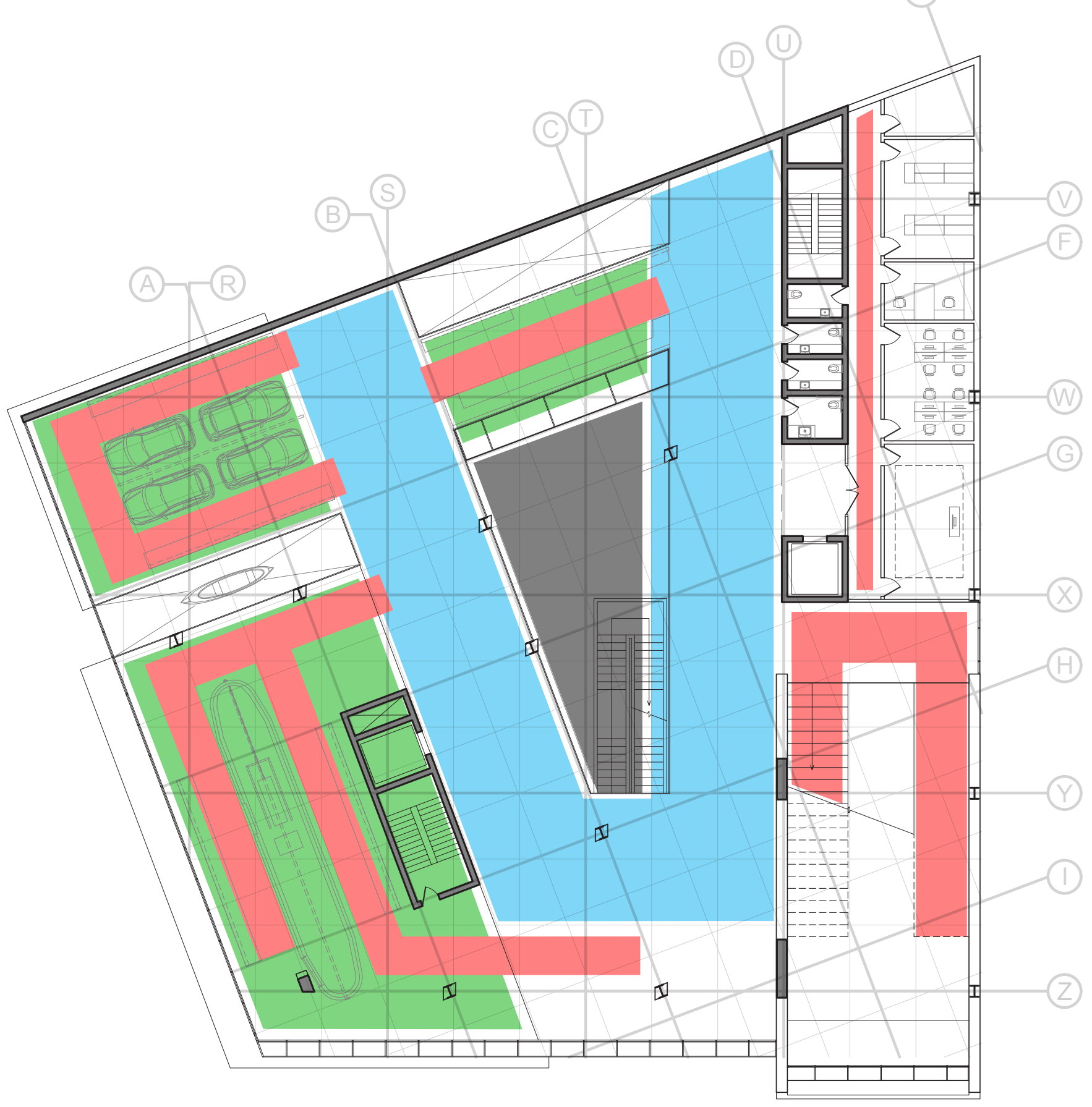

Figure A.20: Fourth Floor Circulation

Hierarchy 
Figure A.21: Concept Model 1
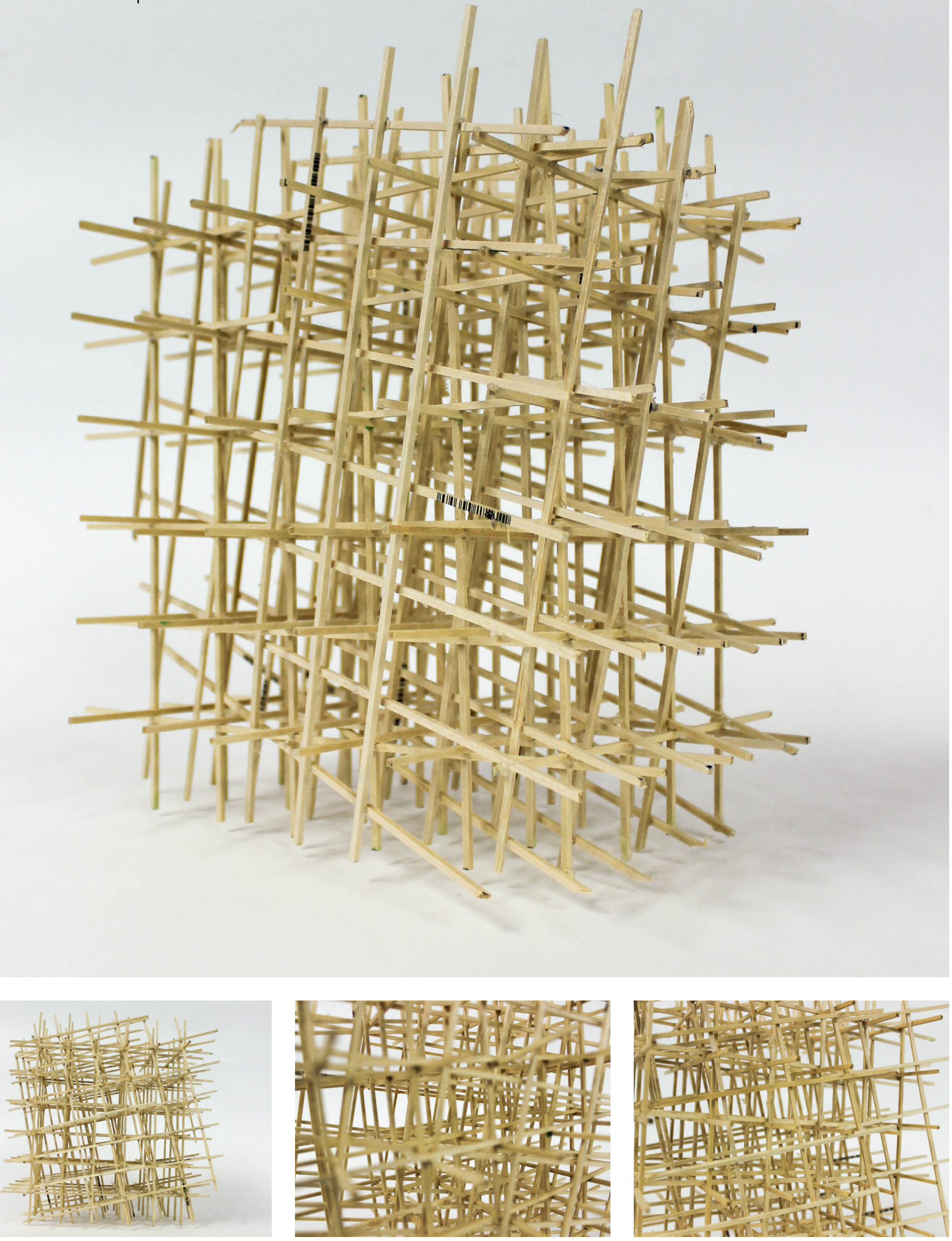
Figure A.22: Concept Model 2
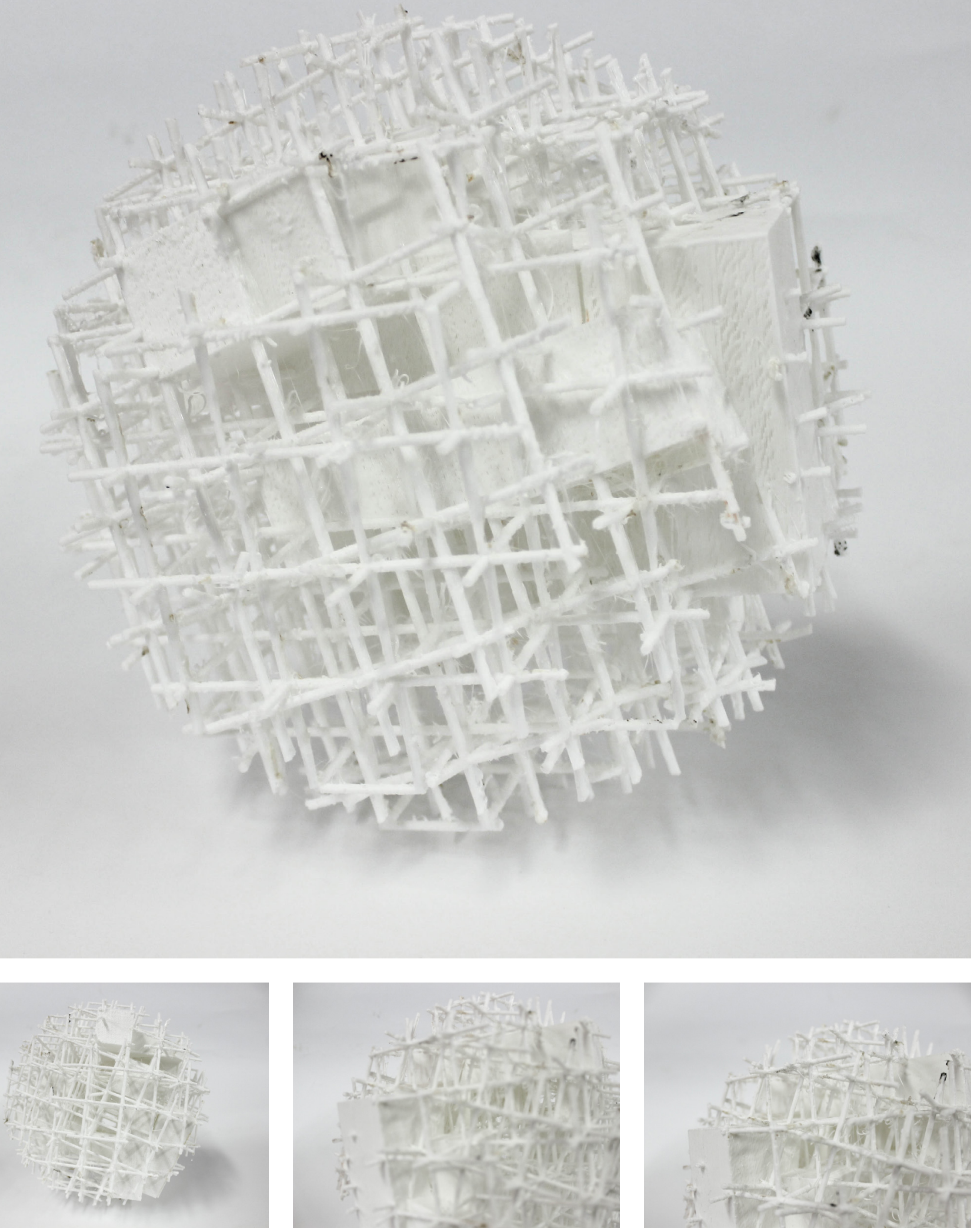
Figure A.23: Concept Model 3
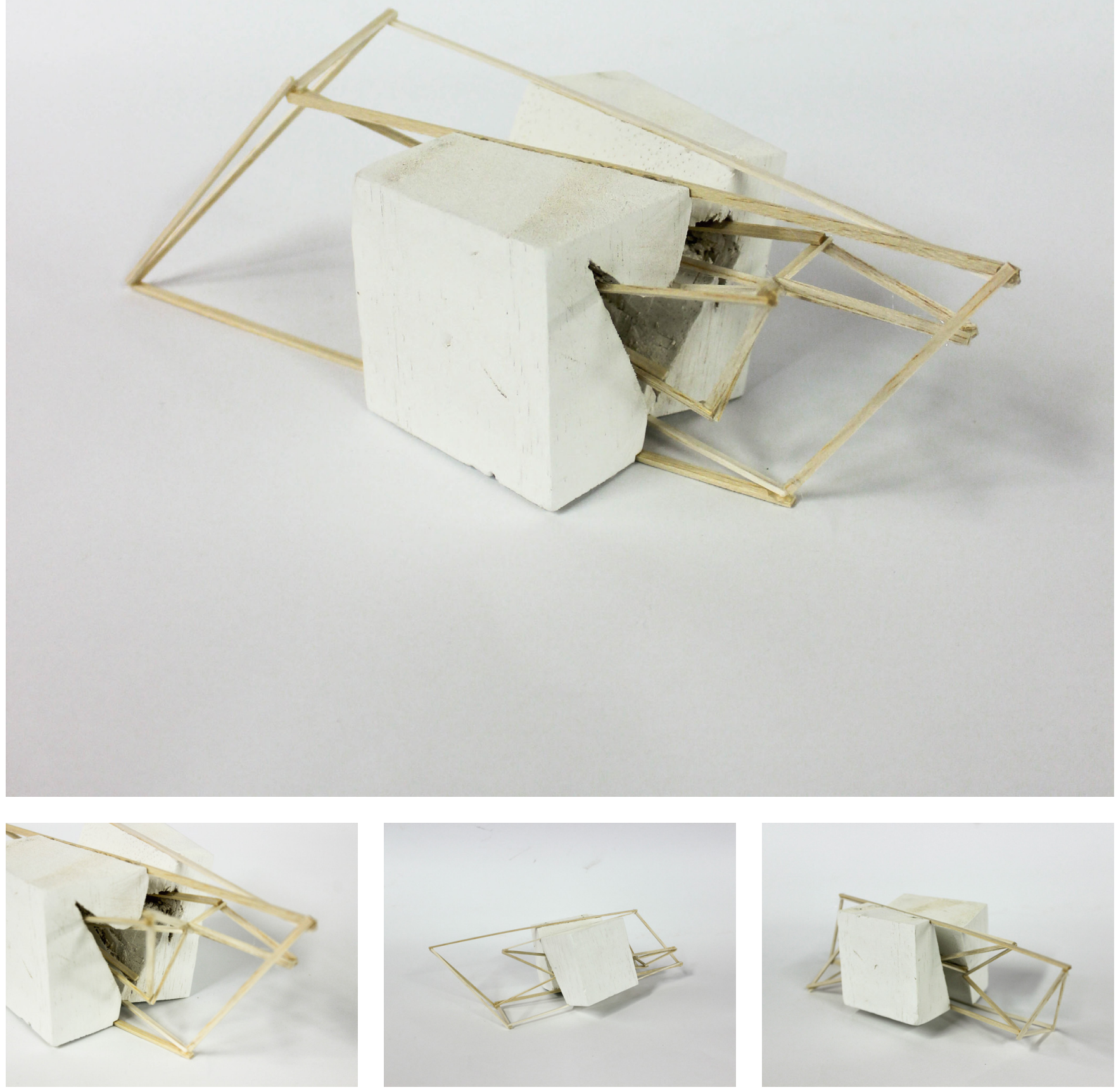
Figure A.24: Concept Model 4
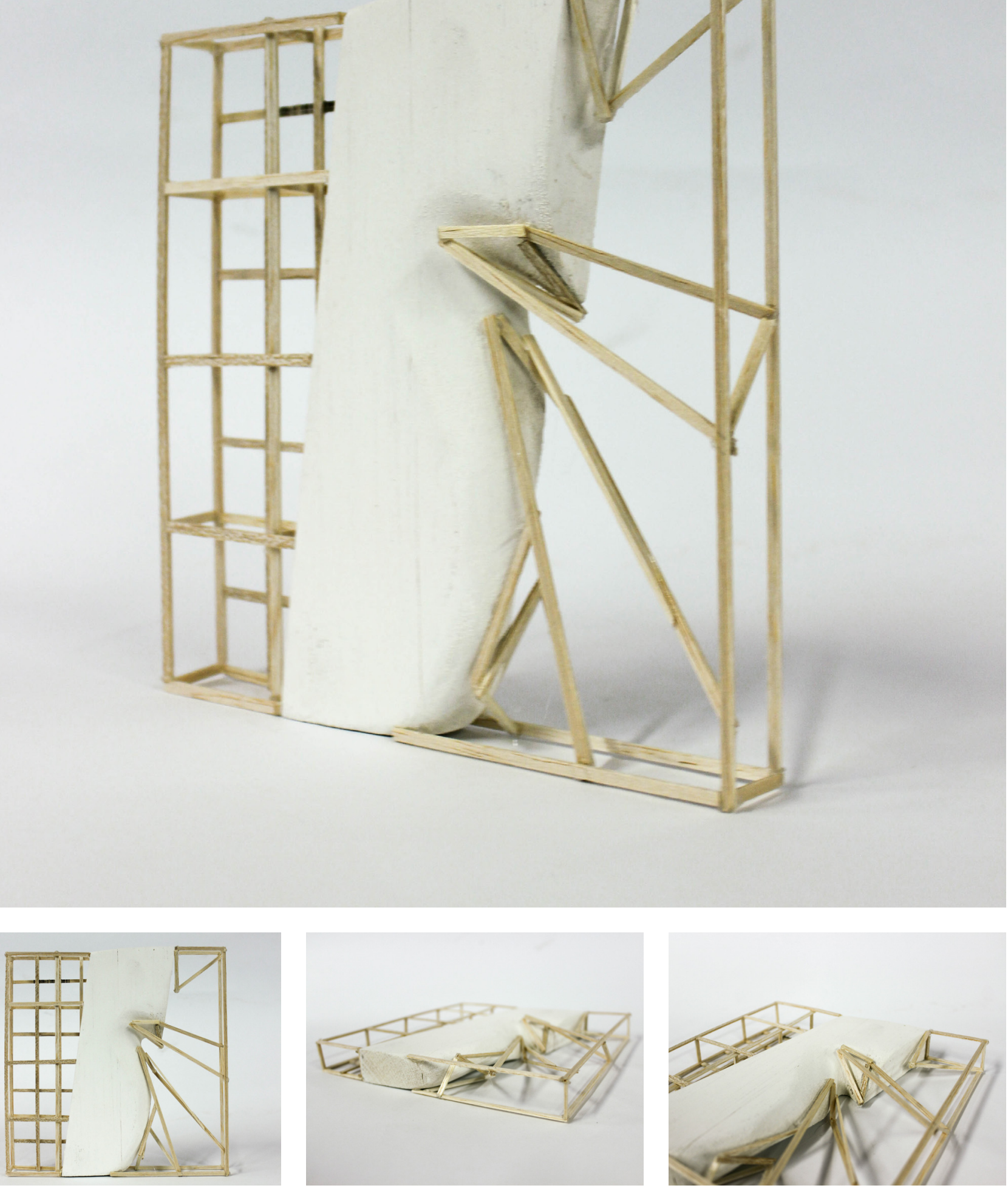
Figure A.25: Building Section Model

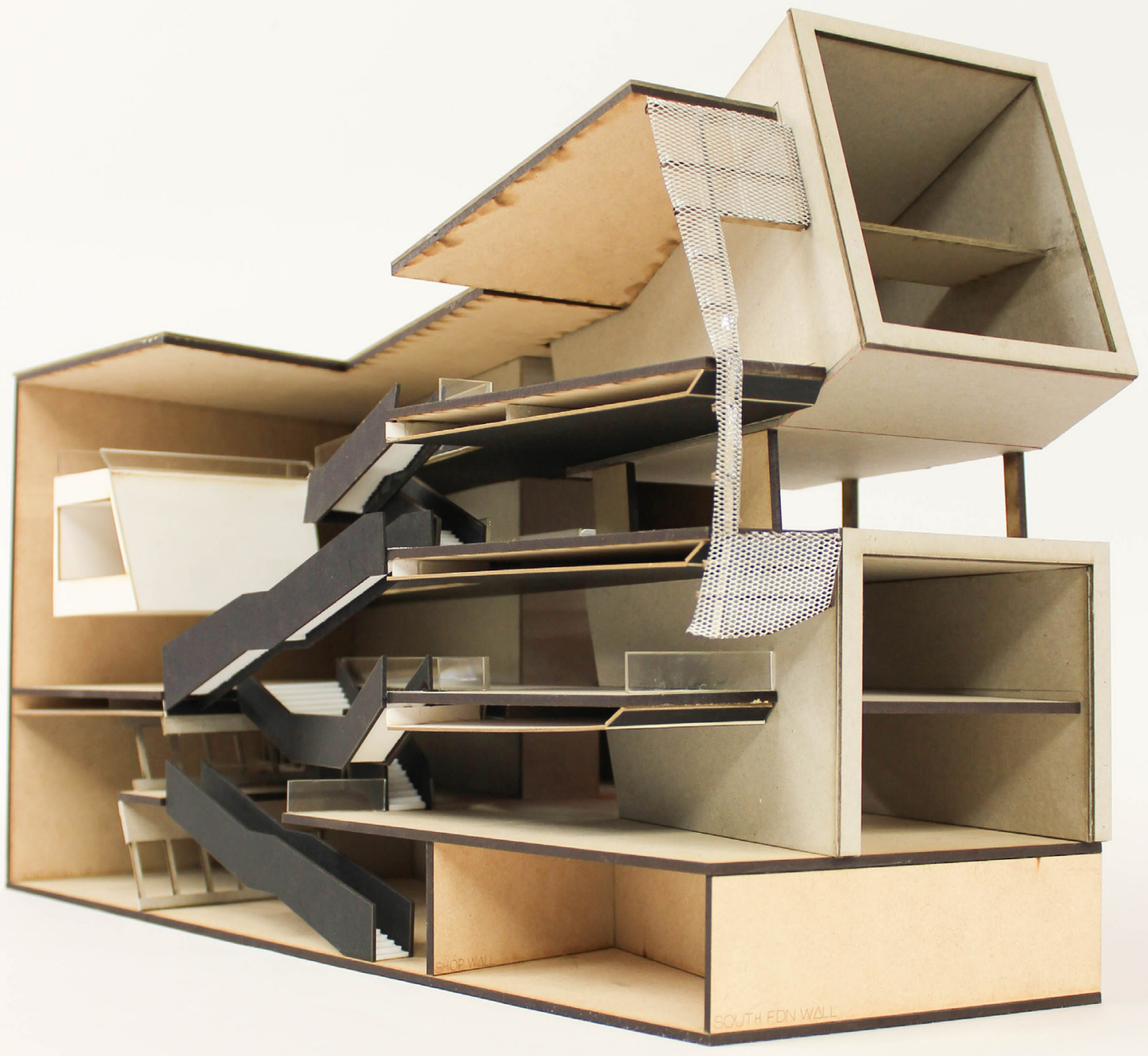



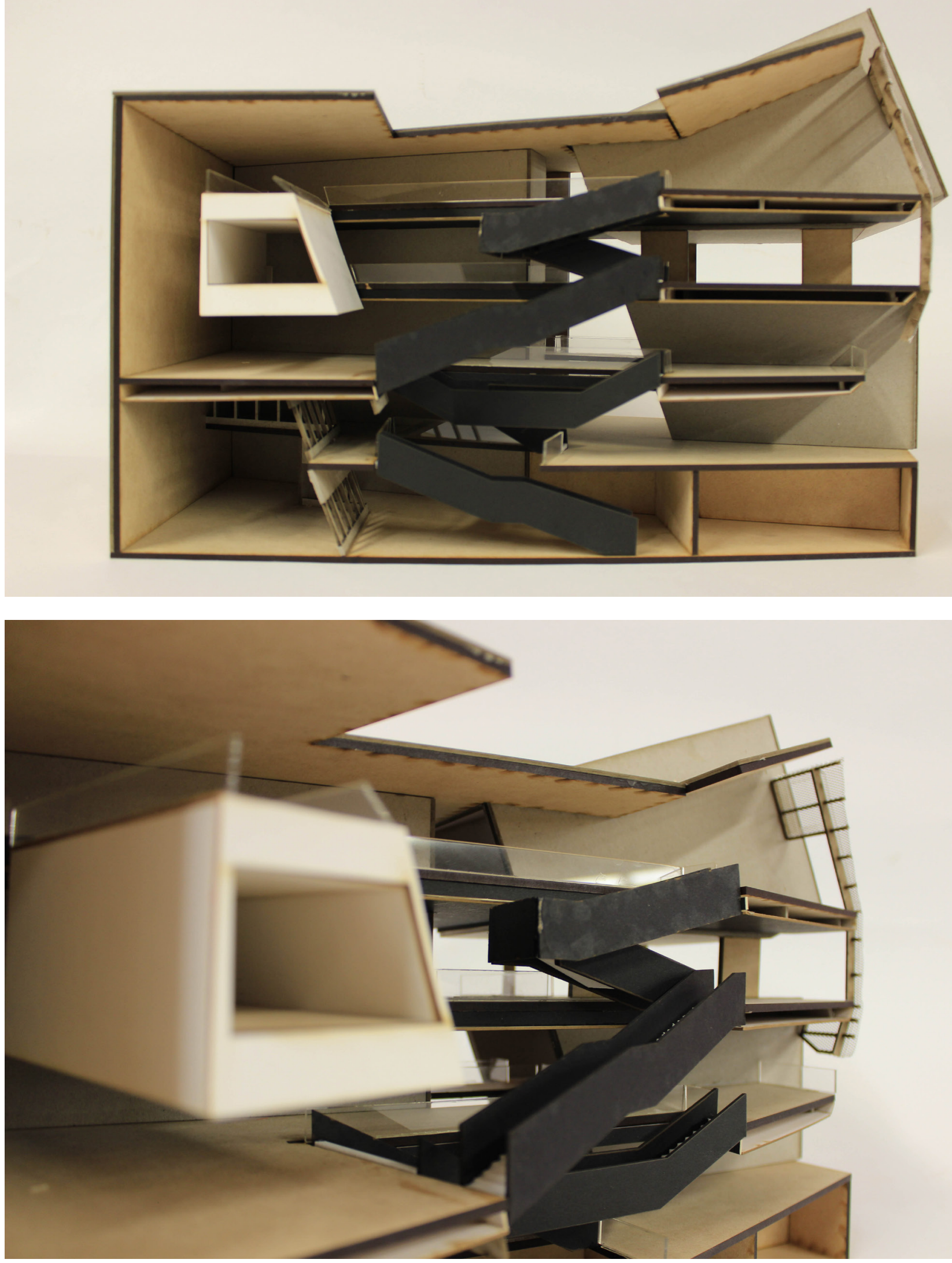

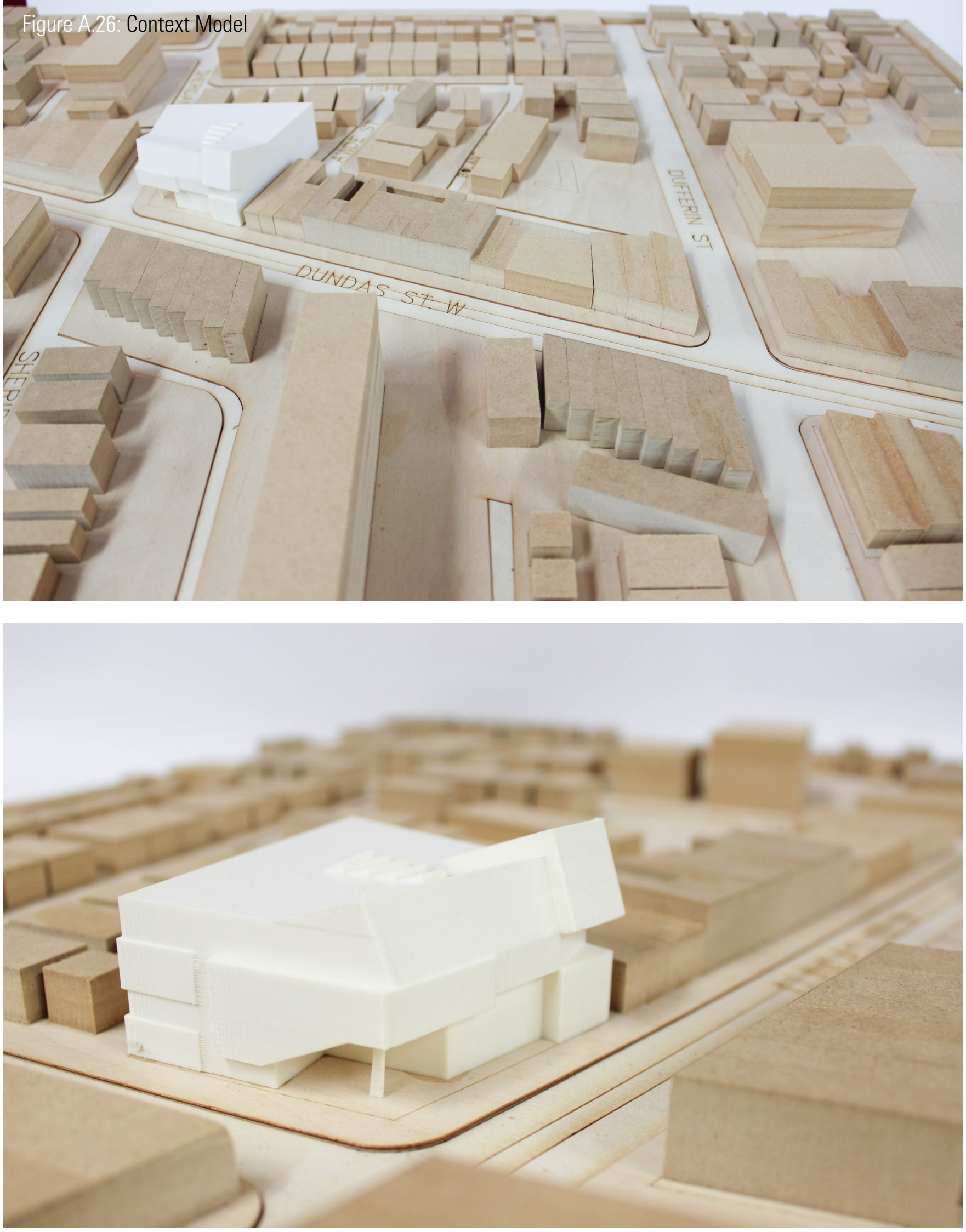


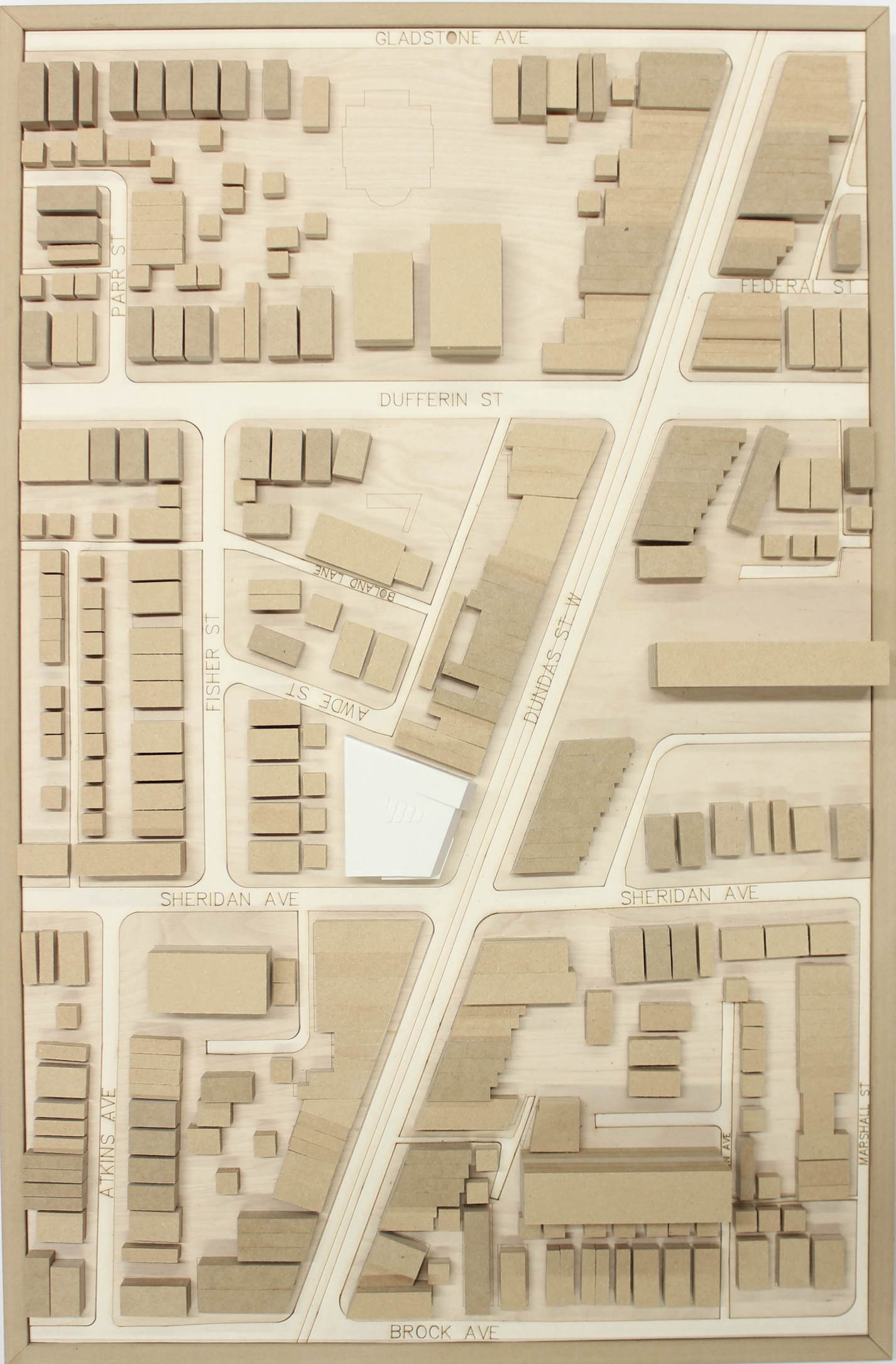




\subsection{REFERENCES}

Argan, Giulio Carlo. The Renaissance City. New York: G. Braziller, 1970.

Arthur, Eric Ross., and Stephen A. Otto. Toronto: No Mean City. Toronto: Buffalo, 1986.

Batty, Michael, and Paul Longley. Fractal Cities: A Geometry of Form and Function. London: Academic Press, 1994.

Benjamin, Andrew E. Blurred Zones: Investigations of the Interstitial Eisenman Architects, 1988-1998. New York: Monacelli Press, 2003.

Böck, Ingrid. Six Canonical Projects by Rem Koolhaas Essays on the History of Ideas. Berlin: Jovis Berlin, 2014.

Brenner, Neil, Peter Marcuse, and Margit Mayer. Cities for People, Not for Profit: Critical Urban Theory and the Right to the City. London: Routledge, 2012.

Brillembourg, Alfredo, Hubert Klumpner, and Lieven De Cautier. The Vertical Village: Individual, Informal, Intense. Edited by Winy Maas. Rotterdam: NAI Publishers, 2012.

Castagnoli, F. Orthogonal Town Planning in Antiquity. Cambridge, MA: MIT Press, 1971.

Cook, Peter, and George Rand. Morphosis: Buildings and Projects. New York: Rizzoli, 1989.

Eisenman, Peter. Eisenman Inside Out: Selected Writings, 1963-1988. New Haven, CT: Yale University Press, 2004.

Eisenman, Peter. Ten Canonical Buildings: 1950-2000. New York: Rizzoli, 2008. 
Eisenman, Peter, Rem Koolhaas, and Brett Steele. Supercritical. Vol. 1. Architecture Words. London: AA Publications, 2010.

Evers, Bernd, and Christof Thoenes. Architecture Theory: From the Renaissance to the Present: 89 Essays on 117 Treatises. Köln: Taschen, 2011.

Gehl, Jan. Life Between Buildings: Using Public Space. Copenhagen: Danish Architectural Press, 2006.

Gehl, Jan. Cities for People. Washington, DC: Island Press, 2010.

Hall, Edward T. The Hidden Dimension. Garden City, NY: Doubleday, 1966.

Hall, Thomas. Planning Europe's Capital Cities: Aspects of Nineteenth Century Urban Development. London: E \& FN Spon, 1997.

Holt, Michael, and Marissa Looby. "Beyond the Wall, the Floor." Australian Design Review. June 27, 2014. Accessed March 27, 2017. https://www. australiandesignreview.com/architecture/beyond-the-wall-the-floor/.

Jacobs, Jane. The Death and Life of Great American Cities. New York: Vintage Books, 1992.

Kandinsky, Wassily, and Hilla Rebay. Point and Line to Plane. New York: Dover Publications, 1979.

Koolhaas, Rem. Delirious New York: A Retroactive Manifesto for Manhattan. New York: Monacelli Press, 1994.

Koolhaas, Rem, Bruce Mau, and Jennifer Sigler. S, M, L, XL. New York: Monacelli Press, 1995.

Koolhaas, Rem, and Sanford Kwinter. Rem Koolhaas: Conversations with Students. Houston, TX: Rice University, School of Architecture, 1996. 
Koolhaas, Rem. Content. Köln: Taschen, 2004.

Kostof, Spiro. A History of Architecture: Settings and Rituals. New York: Oxford University Press, 1985.

Kostof, Spiro. The City Shaped: Urban Patterns and Meanings Through History. Boston: Little, Brown, 1991.

Kostof, Spiro. The City Assembled: The Elements of Urban Form Through History. Boston: Little, Brown, 1992.

Lewis, Paul, Marc Tsurumaki, and David J. Lewis. Manual of Section. New York: Princeton Architectural Press, 2016.

Lindner, Christoph. Imagining New York City: Literature, Urbanism, and the Visual Arts, 1890-1940. New York: Oxford University Press, 2015.

Lynch, Kevin. The Image of the City. Cambridge, MA: MIT Press, 1960.

Lynch, Kevin. Good City Form. Cambridge, MA: MIT Press, 1981.

Mayne, Thom. "Connected Isolation." In Theories and Manifestoes of Contemporary Architecture, edited by Charles Jencks and Karl Kropf, 30103. Chicester: Academy Editions, 1997.

Mayne, Thom. Morphosis: Buildings \&amp; Projects, 1999-2008. New York: Rizzoli International Publications, 2009.

Morris, David. The Sense of Space. Albany: State University of New York Press, 2004.

Per, Aurora F., Javier Mozas, and Javier Arpa. This Is Hybrid: An Analysis of Mixed-Use Buildings by A T. Vitoria-Gasteiz, Spain: T Architecture Publishers, 2011. 
Pirenne, Henri. Medieval Cities: Their Origins and the Revival of Trade. Rice, Gordon S., Tom Leung, Alex Temporale, Florian Freitag, Ariane Schwarz, and Scott A. Lukas. "Thresholds." OAA Perspectives 23, no. 4 (Winter 2015/2016).

Rowe, Colin, and Fred Koetter. Collage City. Cambridge, MA: MIT Press, 1978.

Saalman, Howard. Medieval Cities. New York: Braziller, 1968.

Simmel, Georg. The Philosophy of Money. London: Routledge \& Kegan Paul, 1978.

Tafuri, Manfredo. "Toward a Critique of Architectural Ideology." In Architecture Theory Since 1968, translated by Stephen Sartarelli, edited by K. M. Hays, 2-35. Cambridge, MA: MIT Press, 1998.

Teixeira, Carlos. Toronto's Little Portugal: A Neighbourhood in Transition. Publication no. 35. Centre for Urban \& Community Studies, University of Toronto. March 2007. Accessed November 2016. http://www. urbancentre. utoronto.ca/pdfs/researchbulletins/CUCSRB35Teixeira.pdf.

Teymur, Necdet, Thomas A. Markus, and Tom Woolley. Rehumanizing Housing. London: Butterworths, 1988.

Tschumi, Bernard. Architecture and Disjunction. Cambridge, MA: MIT Press, 1994.

Tschumi, Bernard, and Frédéric Migayrou. Bernard Tschumi - Architecture: Concept \&amp; Notation. Paris: Centre Pompidou, 2014.

Venturi, Robert. Complexity and Contradiction in Architecture. New York: Museum of Modern Art, 1992.

Wall, Alex. "Programming the Urban Surface." In Recovering Landscape: Essays in Contemporary Landscape Architecture, edited by James Corner. New York: Princeton Architectural Press, 1999. 
Ward-Perkins, John B. Cities of Ancient Greece and Italy: Planning in Classical Antiquity. New York: Braziller, 1975.

Wu, Jenny, and Dwayne Oyler. "Dwayne Oyler and Jenny Wu: "Lineworks"" YouTube. March 12, 2014. Accessed August 11, 2016. https://www.youtube. com/watch?v=MaF8YOsE_ZA.

Wycherley, R. E. How the Greeks Built Cities. London: Macmillan, 1962. 
